\title{
Visualização Volumétrica em Odontologia
}

\author{
Igor Prata Soares
}

Orientadora: Profa. Dra. Rosane Minghim

Dissertação apresentada ao Instituto de Ciências Matemáticas e de Computação - ICMC-USP, como parte dos requisitos para obtenção do título de Mestre em Ciências - Área: Ciências de Computação e Matemática Computacional.

USP - São Carlos

Maio de 2000 
Aos meus pais,

Flávio e Maria Teresa,

cujo amor me trouxe à luz do mundo

À Cynthia,

pela paciência e carinho

Ao Senhor Deus,

Pai, Filho e Espírito Santo,

pela inspiração e pelo amor que me conquistou 


\section{Agradecimentos}

Os agradecimentos eu gostaria de fazer na forma de abraços, como fez Gil, Gilberto Gil, aquele abraço.

Me recordo bem de um amigo e professor, Elton, me estimulando a começar o mestrado, aquele abraço.

Foi montada uma república para que eu, José Geraldo, Vangrei e Denilson vivêssemos as alegrias e o stress de cada dia. A eles fica registrado aquele abraço.

Aos amigos das churrascadas, videokês, war (me refiro ao jogo, claro!) e muitas risadas: Enzo, Walter, Cláudio, Gedson, Willian, Adenilso, Daniele, Janaina, Renato, Alexandre, Rômulo, Maxweel, Marcelo, Alex, Fernando, Bruno e muitos outros, aquele abraço.

Ao amigo da grande viagem ao Pantanal e Bonito, Magnus, aquele abraço.

À galera da $A B U$ (Aliança Bíblica Universitária), que me ajudou muito a perceber a voz do Senhor em várias ocasiões, aquele abraço.

Ao Chicão (Carlos Frederico, mais conhecido como Billy) e também ao Chicão (Luís) que me auxiliaram no trabalho, aquele abraço.

Aos professores Luís Gustavo, Castelo e Maria Cristina pela força no trabalho, aquele abraço. Gostaria ainda de destacar a ajuda do amigo José Geraldo que, principalmente por trabalhar com a mesma área da computação, me ajudou na elaboração do meu trabalho, aquele abraço.

Ao pessoal do tênis (artifício usado para aliviar a carga de final de mestrado) Rosane, Gustavo e Sandro, aquele abraço.

Em especial à amiga, professora e orientadora Rosane pela força, compreensão, paciência e orientação, aquele abraço.

E finalmente, também agradeço à FAPESP pelo apoio financeiro da bolsa e do projeto. 


\section{Índice}

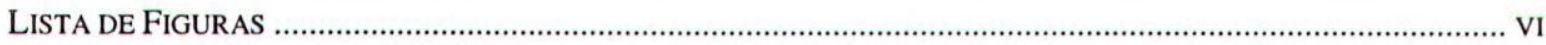

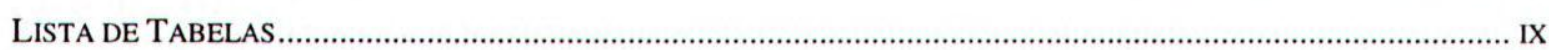

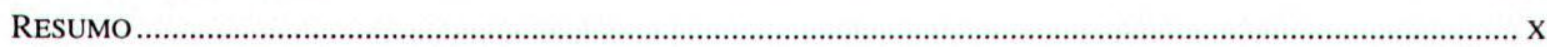

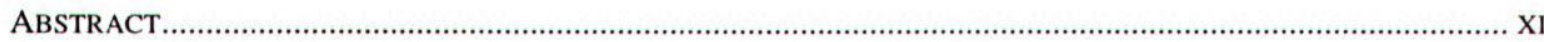

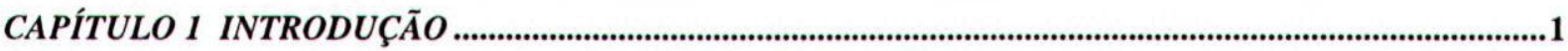

CAPÍTULO 2 VISUALIZAÇÃO CIENTÍFICA E INTERAÇÃO..............................................................

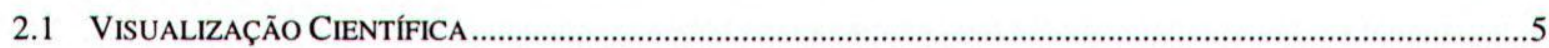

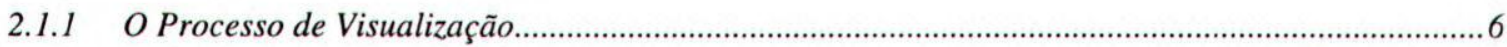

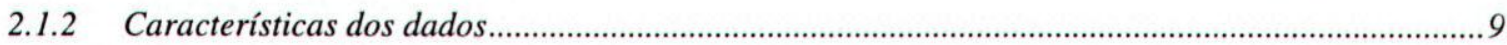

2.1.3 Organização do Volume de Dados ...................................................................................................... 10

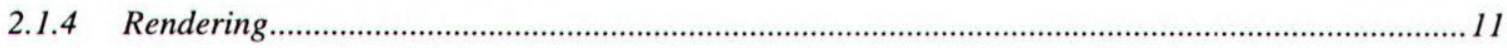

2.1.5 Métodos de Visualização Volumétrica ................................................................................................12

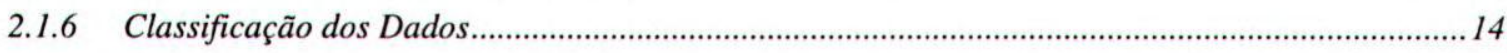

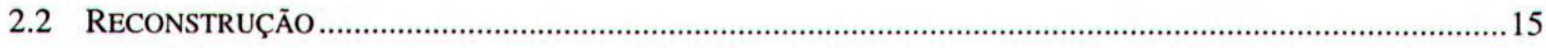

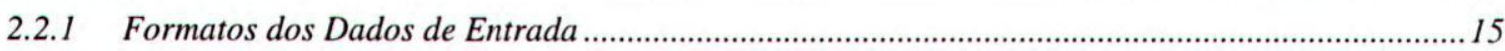

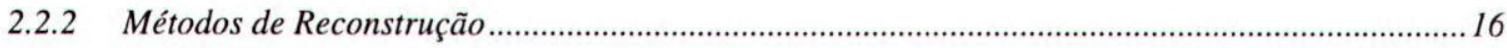

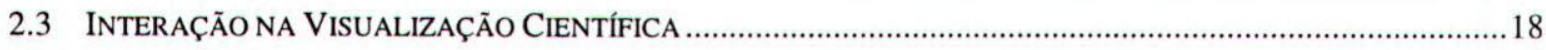

2.3.1 Análise Visual de Dados Científicos ..........................................................................................19

2.3.2 Classificação de Visualização Científica Imersiva ............................................................................21

CAPÍTULO 3 RENDERING VOLUMÉTRICO DIRETO COM MAPEAMENTO DE TEXTURA................25

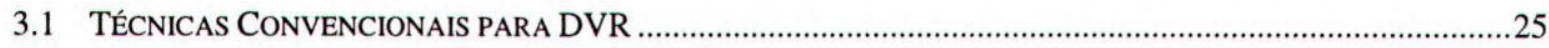

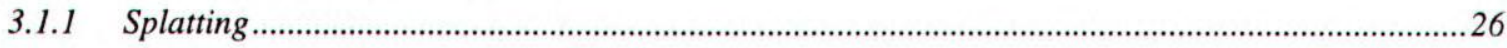

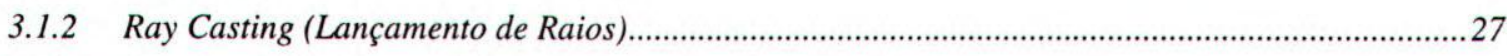

3.2 O RENDERING VOLUMÉTRICO DIRETO COM TEXTURAS (DVRT) ............................................................28

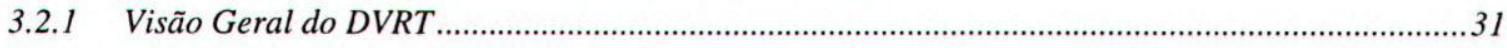

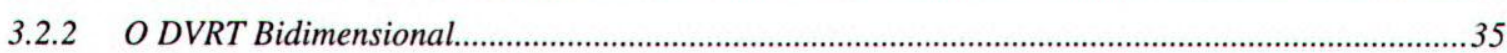

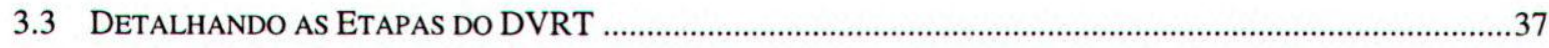

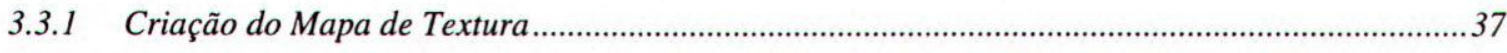

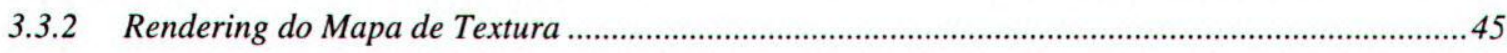

CAPÍTULO 4 IMPLEMENTAÇÃO DO DVRT COM TONALIZAÇÃO NO VTK........................................53

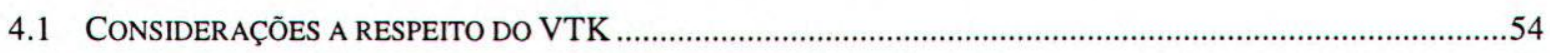

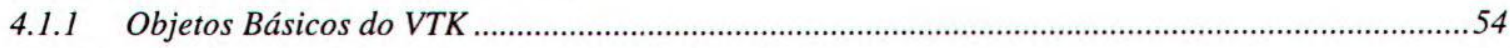

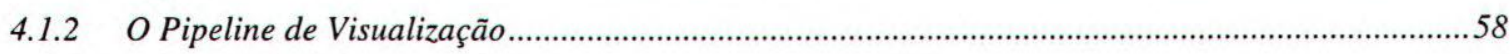

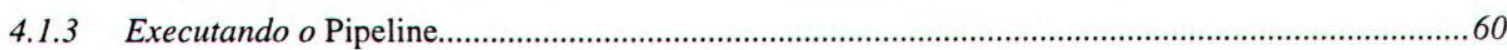




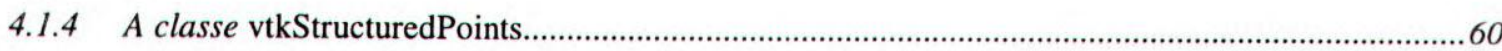

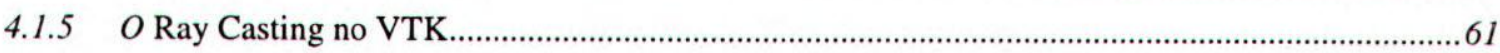

4.2 O RENDERING VOLUMÉTRICO COM TEXTURA (DVRT) NO VTK ……...................................................64

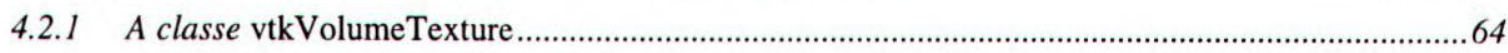

4.2.2 A classe vtkVolumeTextureMapper..........................................................................................

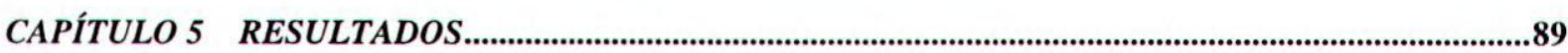

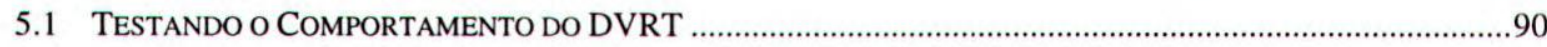

5.2 APLICANDO O DVRT AOS DADOS DENTÁRIOS........................................................................................95

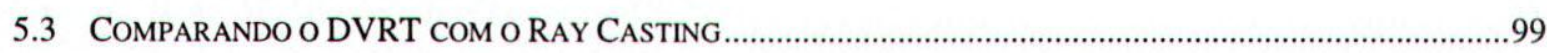

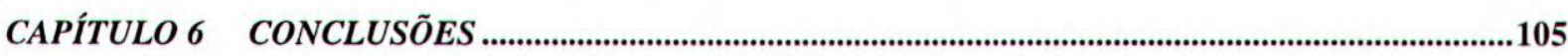

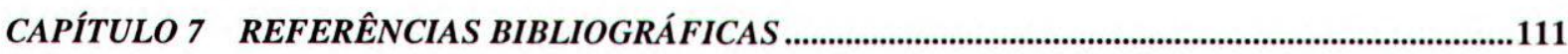

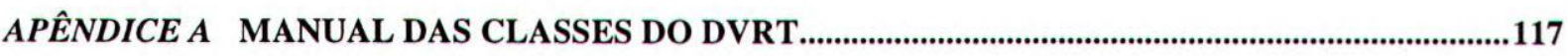

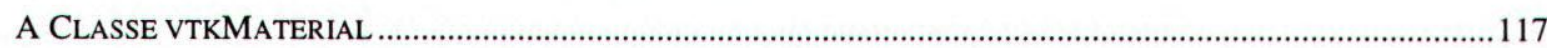

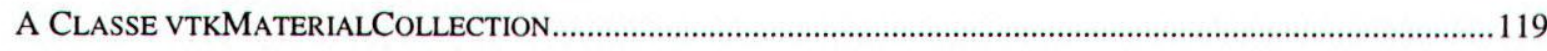

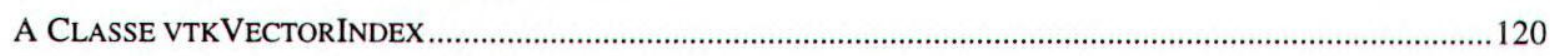

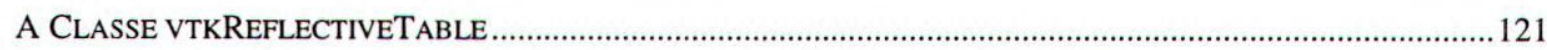

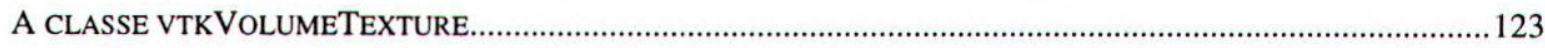

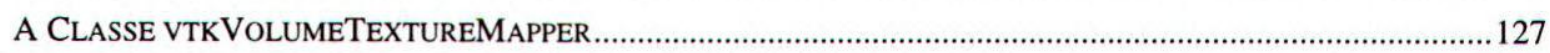

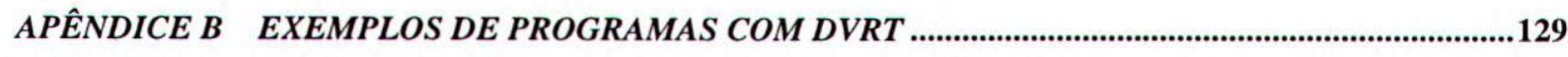

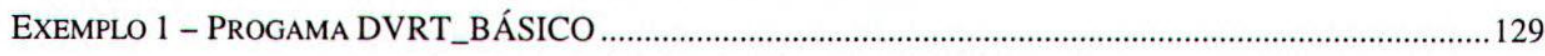

EXEMPLO 2 - PROGRAMA DVRT_TONALIZADO_.......................................................................................1 131 


\section{Lista de Figuras}

Figura 2.1 - Dados convertidos em gráfico 6

Figura 2.2 - Esquema do processo de visualização volumétrica 7

Figura 2.3 - Ilustração do processo de visualização 8

Figura 2.4 - Voxel, valores no centro dos hexaedros.__ 10

Figura 2.5 - Célula, valores nos vértices dos hexaedros. __ 10

Figura 2.6-Diferentes tipos de malhas_____ 10

Figura 2.7 - Imagens de um mesmo conjunto de dados, porDVR e SF___ 13

Figura 2.8 - Tipos dos dados de entrada __ 15

Figura 2.9-Ambigiiidade devido d̀s ramificą̧ões __ 17

Figura 2.10 - Extensão da sistema de visualização com algumas capacidades de ambientes virtuais___ 22

Figura 2.11 - Extensão do sistema de ambiente virtual com alguns recursos de visualização científica.___22

Figura $2.12-$ Escrevendo um novo sistema, usando alguns recursos de visl. científica $e$ de ambientes virtuais 22

Figura 2.13 - Objetos de visualizaçāo importados para ambientes virtuais __ 22

Figura 2.14 - Integração de ambiente virtual com sistema de visualização científica __ 22

Figura 3.l-Splatting__ 27

Figura 3.2 - Uma footprint para o algoritmo Splatting. Areas escuras indicam maior intensidade __ 27

Figura 3.3 - Disparo de raios para o volume __ 28

Figura 3.4 - Algoritmo básico de Ray Casting __ 28

Figura 3.5 - A amostragem no Ray Casting____________ 29

Figura 3.6 - Mapeamento de Textura 2D em um objeto geométrico. ___ 30

Figura 3.7 - Nuvem conseguida através de textura sólida com funçōes de efeito ___ 30

Figura 3.8 - Coordenada de textura nos vértices do objeto geométrico.___ $3 l$

Figura 3.9 - Plano de corte através da densidade da água envolvendo uma molécula de açúcar ___ 32

Figura 3.10 - Construção do mapa de textura a partir do volume de dados a ser visualizado ___ 33

Figura 3.11 - Exemplo de funçäo de transferência para as componentes de cor $R, G$ e $B$

Figura 3.12 - Planos de Amostragem interceptando um Mapa de Textura __ 33

Figura 3.13 - Construção do mapa de textura levando-se em consideração luz direcional ___ 35

Figura 3.14 - Planos de amostragem posicionados nas três possiveis configurações para DVRT 2D. __ 35

Figura 3.15 - $O$ refinamento de uma aresta da esfera. A aresta $A B$ é dividida em $A C$ e $C B$. _ 38

Figura 3.16 - O processo de refinamento em dois niveis de uma esfera ___ 39

Figura 3.17-Esquema de uma Tabela de Reflexão __ 40

Figura 3.18-Reflexäo Especular ___ 41

Figura 3.19 - Esquema do processo de criaçāo do mapa de textura. ___ 44

Figura 3.20-Bounding cube com 6 planos de amostragem.___ 45

Figura 3.21 - Correspondência entre o plano de amostragem e a tela (display). _ـ 46

Figura 3.22 - Um plano de amostragem com apresentação dos pontos de amostragem. __ 47

Figura 3.23 - Polígonos de textura referentes a um volume de dados. ___ 47 
Figura 3.24 - Volume decomposto em oito blocos, marcados em azul 49

Figura 3.25 - Ordem de visitação dos octantes para uma determinada direção de visão______ 50

Figura 3.26 - Ordem do processamento dos blocos no rendering._ 50

Figura 3.27 - Imagem obtida por mapeamento de textura ___ 52

Figura 3.28 - Imagens estéreo conseguidas com mapeamento de textura____ 52

Figura 4.I - Esquema do fluxo do DVRT com tonalização e sem esse recurso — 53

Figura $4.2 \rightarrow$ Diagrama ilustrativo dos objetos gráficos do VTK _ 55

Figura 4.3 - Atributos da câmera. _ـ_ 56

Figura 4.4 - Movimentos da camera centrados no ponto focal ___ 56

Figura 4.5 - Estrutura parcial de um programa típico utilizando o VTK.___ 58

Figura 4.6 - Conexão entre os objetos do pipeline ___________ 59

Figura 4.7 - Exemplo de conexão de objetos para criação do pipeline de visualização _ـ 59

Figura 4.8 - Esquema de um volume de dados do tipo vtkStructuredPoints.____ 61

Figura 4.9 - Estrutura de um programa em C++ para o Ray Casting ___ 62

Figura 4.10-A estrutura de um programa que usa DVRT no VTK __ 64

Figura 4.11 - Busca por um índice (i) para um dado vetor (v) no Indice de Gradientes____ 67

Figura 4.12 - Esquematização da visualização tonalizada de dois volumes de dados ___ 69

Figura 4.13 - Lógica do método MakeVolumeTexture da classe vtkVolumeTexture ___ 71

Figura 4.14 - A cadeia de invocaçăo do método render para o caso do DVRT _ 72

Figura 4.15 - Seqüência de obtenção dos pontos que definem o bounding cube __ 74

Figura 4.16 - Disposiçāo dos Planos de Amostragem no Bounding Cube ___ 75

Figura 4.17 - Destaque dos pontos que devem ser amostrados em um Plano de Amostragem___ 75

Figura 4.18 - A numeraçâo dos vértices do volume de dados e suas adjacências____ 76

Figura 4.19 - Obtenção dos pontos que definem os polígonos de textura ___ 77

Figura 4.20 - Logica de implementação para obtenf̧ão dos polígonos de textura ___ 79

Figura 4.21 - Utilização dos vetores limite para delimitar a regiäo de pixels coberta pelo poltgono de textura 80

Figura 4.22 - Uma janela de visualização do VTK com apresentação das direfentes regiöes ____ 81

Figura 4.23 - Lógica do algoritmo para amostrar um plano de amostragem ___ $82{ }^{-}$

Figura 4.24 - O processo de amostragem ___ 83

Figura 4.25 - Um texel do Mapa de Textura como os valores RGBA dispostos como voxel e célula___ 83

Figura 4.26 - Interseção de um polígono de amostragem com a regiäo de amostragem ______ 85

Figura 4.27 - A definição das regiões de amostragem no espaço e na tela ___ 86

Figura 4.28 - Organizaçäo logica do método Render do vtkVolumeTextureMapper ____ 87

Figura 4.29 - Hierarquia de Classes apresentando as classes implementadas para o DVRT_ 87

Figura 5.1 - DVRT utilizando diferentes espaçamento entre planos de amostragem __ 90

Figura 5.2 - DVRT com amostragem dos tipos texel-voxel e texel-célula ___ 91

Figura 5.3 - Duas apresentações por DVRT na mesma janela de visualização do VTK___ 92

Figura 5.4-DVRT tonalizado para diferentes coeficientes____ 93

Figura 5.5 - Verificą̧āo da regiäo tonalizada____ 93

Figura 5.6 - Esfera preta apresentada por DVRT tonalizado com duas luzes presentes na cena___ 93

Figura 5.7 - Inversäo do hemisfério tonalizado____ 93 
Figura 5.8-DVRT utilizando tabela de reflexão 94

Figura 5.9 - Fotografias de seções sequlenciais de um dente descalcificado e tingido 95

Figura 5.10 - Contornos do dente submetidos d̀ reconstruçäo 95

Figura 5.11 - Juntando as partes do dente em único volume 96

Figura 5.12 - DVRT tonalização do dente 97

Figura 5.13-DVRT mal tonalizado para o dente visto de cima ou de baixo 97

Figura 5.14 - Visualizações do dente obtidas com DVRT e Ray Casting 100

Figura 5.15 - Visualizações tonalizadas do dente obtidas com DVRT e Ray Casting 102

Figura 5.16 - Visualização tonalizada do dente onde a distribuição dos escalares nāo é boa 102

Figura 5.17 - Visualização tonalizada da parte externa do dente 103

Figura 6.I - Imagem rascunhada de um volume e refinada 108

Figura 6.2 - Problemas com o Z-Buffer 108

Figura BI -Imagem obtida pelo programa DVRT_BÁSICO 130

Figura B2 - Imagem obtida pelo programa DVRT_TONALIZADO 132 


\section{Lista de Tabelas}

Tabela 4.1 - Opções de interação do vtkRenderWindowinteractor. 57

Tabela 4.2 - A permutaçäo dos sinais das coordenadas dos vetores presentes no Indice de Gradientes 66

Tabela 5.1 - Relação de tempo consumido na construção do Indice de Gradientes e da Tabela de Reflexão $-94$

Tabela 5.2 - Contagem do tempo (em segundos) consumido nas várias etapas no DVRT 98 


\section{Resumo}

Neste trabalho de mestrado foi estudado um processo de geração de imagens a partir de dados volumétricos dentários. Para isso foi elaborado e implementado um método de Rendering Volumétrico Direto que faz uso de texturas volumétricas (DVRT - Direct Volume Rendering with Texture). Esse método funciona criando um mapa de textura tridimensional a partir do volume de dados e então amostrando-o com planos de cortes paralelos entre si e ao plano de visão, a imagem final é então obtida pela composição desses planos. Para facilitar a compreensão do volume submetido à visualização foi implementada a possibilidade de gerar imagens tonalizadas, obtidas a partir da interação do volume de dados com as luzes direcionais presentes na cena. O método DVRT foi implementado na forma de classes incorporadas à biblioteca de visualização orientada a objetos de propósito geral, o VTK (Visualization Toolkit), apresentando resultados satisfatórios. 


\section{Abstract}

This work reports on the implementation of a Direct Volumetric Rendering (DVR) and Visualization technique in the context of a general-purpose, low cost visualization software with available source code. The technique employs a texture mapping strategy to combine scalar values of volumetric data into threedimensional images. Relevant implementation issues of this technique are presented, and the results are discussed in the light of a target application, namely visualization in dentistry. The technique presented here, DVRT, has demonstrated to behave better than the ray casting DVR technique for the data sets of interest, and also to produce very good results under shading. 


\section{Capítulo 1}

\section{Introdução}

A crescente disponibilidade de recursos computacionais para o cálculo, simulação e aquisição de dados permite que cientistas e engenheiros produzam enormes conjuntos de dados, bi ou tridimensionais (2D ou 3D), em geral multivariados. A aplicação de técnicas de Computação Gráfica a dados científicos com o objetivo de ganhar compreensão desses dados, testar hipóteses e esclarecer fenômenos e efeitos em geral, compreende o objeto de estudo da área denominada Visualização Científica (ViSC - Visualization in Scientific Computing) [CG87][Min97a]. Ferramentas de visualização de dados estão, aos poucos, tornando-se acessíveis para instituições acadêmicas, empresas de pequeno porte e mesmo indivíduos, graças à rápida evolução da tecnologia computacional. A tendência é que tais ferramentas brevemente passem a exercer um impacto real na vida diária das pessoas, particularmente as que atuam em pesquisa científica, engenharia, medicina e educação. Atualmente, já é possível utilizar soluções de visualização de baixo custo como ponto de partida para sistemas mais populares e como base para pesquisas em visualização. A um custo reduzido, pode-se ter uma biblioteca como o VTK (Visualization ToolKit) [Sch98], que é extensível, inclui código fonte, e permite criar um sistema configurado para uma aplicação em particular.

$\mathrm{Na}$ área de medicina pode-se testemunhar um esforço concentrado na aplicação de técnicas de visualização 3D tanto em sistemas de apoio a diagnóstico como no apoio ao entendimento da anatomia e de doenças humanas [Udu91][Cos96][Tre96][Lor95][Rou94]. Em Odontologia, assim como em Medicina, dados podem ser gerados gerados por dispositivos de medição não invasivos, como Raios$X$, Tornografia e Ressonância Magnética. No entanto, essas medições são mais difíceis de serem empregadas em odontologia, uma vez que estruturas menores (como dentes) exigem equipamentos de alta precisão, o que via de regra não justifica pelo custo. Nesse caso, uma fonte de dados é a fotografia microscópica de fatias de dentes reais, extraídos de animais ou seres humanos. Os resultados dessas medições são representados por imagens $2 \mathrm{D}$ com resolução e clareza variáveis. Modelos $3 \mathrm{D}$ desses dados podem ser gerados por um processo denominado 'reconstrução' [Lor87][Lor95][Mat94] [Mon94][Alg96][Tre96], possibilitando uma visão mais global e real dos órgãos e de suas partes apresentadas nos exames, e também um melhor entendimento da estrutura interna dos órgãos. 
Existem, basicamente, duas abordagens para a geração de visualizações 3D a partir de dados de cortes 2D justapostos em um volume. A primeira, denominada Surface Fitting (SF), ou Extração de Superfícies, consiste em gerar uma representação geométrica intermediária (uma ou mais superfícies) através do processo de reconstrução mencionado acima. É possível também reconstruir volumes para definir o interior de objetos.

A outra abordagem, denominada Direct Volume Rendering (DVR), ou Rendering Volumétrico Direto [Kau93], consiste em calcular parâmetros de iluminação diretamente a partir das propriedades das unidades do volume de dados chamados voxels (os correspondentes $3 \mathrm{D}$ dos pixels $2 \mathrm{D}$ ). $\mathrm{O}$ rendering volumétrico direto produz resultados visuais muito efetivos e precisos, mas a um custo computacional alto. Já o rendering por superfícies permite o acesso direto a superfícies, que podem ser manipuladas individualmente, mas está sujeito a mais erros de geração decorrentes de exceções no processo de:

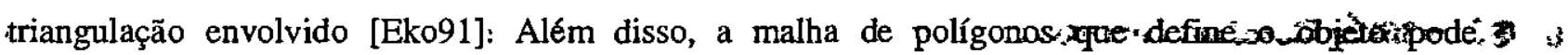
apresentar uma estrutura de difícil manuseio.

Várias dificuldades estão associadas à utilização de modelos e imagens 3D em aplicações médicas. Do ponto de vista tecnológico, a criação de modelos precisos ainda representa um problema. Existe resistência dos profissionais da área à utilização de novos recursos visuais (o uso de cores, por exemplo, é questionado), a qual é reforçada pela dificuldade de garantir a confiabilidade dos modelos elaborados 'artificialmente'. Adicionalmente, existem problemas inerentes à perda de informações na redução de dimensão necessária para a apresentação dos modelos $3 \mathrm{D}$ em dispositivos $2 \mathrm{D}$ (como a tela do computador) [Ke193][Wo193]. Finalmente, pode-se mencionar que a capacidade de geração de imagens complexas em tempo real ainda deixa a desejar.

Apesar das dificuldades, a constante evolução dos equipamentos de detecção e medição tem permitido 'avanços nas técnicas visuais de representação. Em odontologia, essa evolução tem atraído atenção inclusive em nível nacional [Fer96]. Pode-se apontar semelhanças e diferenças no desenvolvimento de visualizações para aplicações médicas e odontológicas. A maioria das visualizações na área médica são voltadas ao apoio a diagnósticos, uma aplicação ainda limitada em odontologia. Entretanto, aplicações relacionadas ao estudo, educação, planejamento e treinamento de procedimentos são extremamente promissoras. A reconstrução de modelos dentários segue as mesmas linhas das reconstruções médicas, ainda que com requisitos diferentes de precisão e eficiência.

Os benefícios da representação 3D de dentes e de outras partes da boca e face são consideráveis. $\mathrm{O}$ primeiro deles é educacional, pois permite utilizar modelos computacionais para explicar estruturas e funções dentárias tanto em nível escolar como de estudo universitário não-intervencionista (educação do futuro dentista anterior à sua aproximação com seres humanos). Com o uso de técnicas e periféricos de realidade virtual, também pretende-se utilizar modelos dentários no treinamento de procedimentos vários, inclusive de cirurgias, como a cirurgia de canal, que apresenta problemas no 
treinamento [Goe98] atualmente. Um outro sub-produto educacional é a possibilidade de apresentação ao paciente, em consultórios e clínicas, dos procedimentos clínicos a serem realizados. Outros benefícios incluem a possibilidade de utilização de um modelo virtual, criado a partir de dados reais de dentes, para apoiar o planejamento de procedimentos clínicos e para o estudo e simulação da evolução de doenças.

Como parte de uma colaboração entre o Grupo de Computação Gráfica e Processamento de Imagens (CG \& PD) do ICMC, a School of Information Systems - University of East Anglia - Inglaterra, e a Faculdade de Odontologia de Araraquara - UNESP, foi gerado um conjunto de "dentes virtuais" [Shi98a,b,c] a partir de dados obtidos de fatias de um dente. Um modelo 3D foi criado pela reconstrução das superfícies que definem as estruturas de interesse no dente a partir de contomos planares identificados em cada fatia. Superfícies externas e internas do dente foram reconstruídas usando a abordagem de funções de campo [Jon94]. A implementação do algoritmo foi feita como uma extensão à biblioteca VTK, foi criada uma classe adicional denominada vtkSamplingFromContoursFilter [Sch98]. Além disso, outro algoritmo de reconstrução, desenvolvido em [Non98], foi aplicado aos mesmos dados com resultados mais animadores [Non99][Non00a].

Assim como o trabalho mencionado acima, o produto deste mestrado é parte da elaboração de um projeto para treinamento e implementação de visualização tridimensional de informações odontológicas. Isso inclui estudo de algoritmos apropriados para reconstrução de estruturas presentes na boca e arcada dentária, técnicas gráficas e sonoras de exploração de tais estruturas e interfaces multimídia adequadas para análise, treinamento e apresentação de informações dentárias anatômicas, cirúrgicas e patológicas. A tal projeto tem sido dado o nome de 'Odontologia Virtual'.

O objetivo deste trabalho foi estudar e testar a viabilidade e aplicação do rendering volumétrico direto no contexto do sistema de odontologia virtual. Para isso, foi decidido implementar, no contexto do VTK, um método de rendering volumétrico direto baseado no mapeamento de texturas, uma vez que, sendo uma técnica recente na época do início desse mestrado, se mostrava (como foi confirmado) adequada para o que o projeto propõe. Esse método foi então aplicado aos volumes de dados dentários a fim de constatar a sua utilidade, e complementar, juntamente com as reconstruções mencionadas acima, um conjunto de ferramentas básicas para a visualização dentária.

A estrutura dos capítulos desta dissertação é a seguinte: No próximo capítulo são apresentados alguns conceitos básicos relativos à Visualização Científica, área da computação gráfica onde este trabalho se enquadra. $O$ capítulo 3 e 4 estão intimamente relacionados, sendo que no capítulo 3 são apresentados os conceitos concernentes à técnica de rendering volumétrico direto com mapeamento de texturas volumétricas. A implementação desses conceitos no contexto do VTK é descrita no capítulo 4. Para a compreensão da etapa de implementação do trabalho é estritamente necessária a leitura do capítulo 3. 
No capítulo 5 são apresentados os resultados obtidos aplicando o método implementado. Finalmente no capítulo 6 sāo descritas as conclusões do trabalho e suas ramificações. 


\section{Capítulo 2}

\section{Visualização Científica e Interação}

Este capítulo tem por objetivo apresentar os conceitos fundamentais necessários para o desenvolvimento do presente trabalho de mestrado, bem como refletir seu atual estágio de desenvolvimento dentro do campo de visualização. Este capítulo é dividido em três seções. A primeira diz respeito à modalidade da computação gráfica conhecida como visualização de dados, sendo a visualização científica mais abordada. A segunda seção apresenta a reconstrução de modelos tridimensionais, apresentando técnicas para efetuá-la. A última seção apresenta conceitos de interação em visualização. Muito embora esses conceitos não estejam diretamente relacionados às implementações realizadas no trabalho, eles são necessários para contextualizar o desenvolvimento apresentado em seguida, e também para familiarizar o leitor menos habituado no tema te visualização científica e suas aplicações.

\subsection{Visualização Científica}

Cientistas, engenheiros, médicos e analistas de negócios, dentre outros profissionais, freqüientemente precisam analisar grandes quantidades de informação ou estudar o comportamento de centenas processos. Simulaçōes numéricas em supercomputadores geralmente produzem arquivos de dados contendo milhares de dados. Similarmente, câmeras de satélites e outras fontes de medição estão acumulando grandes arquivos de dados mais rapidamente do que eles podem ser interpretados. Varrer esses grandes conjuntos de números para determinar tendências e relações é um processo tedioso e não muito efetivo. Mas se os dados são convertidos para um formato visual, as tendências e padrōes são quase sempre identificados imediatamente. A figura 2.1 apresenta um exemplo de um grande conjunto de dados que foi convertido para um gráfico de alturas relativas sobre um plano de chăo. Uma vez que os valores de densidade, do exemplo, são exibidos dessa maneira, pode-se perceber facilmente padrões de comportamento dos dados [Hea97]. 
É importante ressaltar que o objetivo da visualização não é entender os dados por si só, mas o fenômeno que os gerou. Uma técnica de visualização envolve vários passos: a construção de um modelo empírico a partir dos dados; a seleção de algum mecanismo de mapeamento do modelo em um objeto de visualização abstrato, como uma imagem ou um mapa de contornos; e o rendering da imagem no dispositivo de exibição gráfico. A visualização computacional envolve, portanto, a transformação e mapeamento de dados em objetos gráficos, além da sua exploração por meios computacionais [Min97a].

O uso desses recursos gráficos para aplicações que possuam informações geométricas associadas é geralmente chamado de visualização científica. Ainda não se tem ao certo uma data para o surgimento da visualização computacional científica. Em [Ear94], Brian M. Collins refere-se ao trabalho de McCormick et. al, [McC87], Visualization in Scientific Computing, apresentada no ACM SIGGRAPH em 1987, como sendo o marco inicial para o surgimento de workshops, conferências, livros e jornais especializados nesse ramo da computação gráfica. Nesse trabalho, McCormick et. al recomendavam que deveriam ser investidos fundos na produção e pesquisa de ferramentas de visualização, e que estas deveriam tornar-se disponíveis em larga escala para cientistas e engenheiros das diversas áreas.

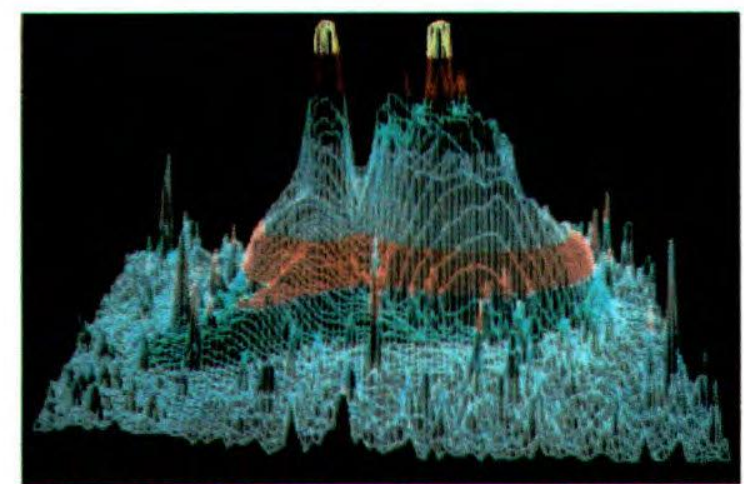

Figura 2.1 - Dados convertidos em gráfico [Hea97].

Entretanto, o campo da visualização científica não teve início repentino em 1987. De fato, há dois períodos distintos na história da visualização: o primeiro durou aproximadamente da metade do século XVII ao início do século XX. Os mais brilhantes cientistas da Europa (Watt, Descartes, Lambert, Playfair, entre outros) desenvolveram técnicas de visualização de dados; o segundo período começou no início da década de 1960, logo após a introdução dos primeiros computadores. Nesse período, métodos para representação computacional dos dados desenvolvidos durante o primeiro período foram utilizados em diferentes ramos da ciência: cristalografia, biologia, medicina, entre outros [Ear94].

\subsubsection{O Processo de Visualização}

O subcampo mais ativo da visualização científica é a visualização volumétrica. Visualização Volumétrica é o processo de projetar um conjunto de dados multidimensional em um plano de imagem bidimensional com o propósito de obter entendimento da estrutura dentro do volume de 
dados. Quase sempre, o conjunto de dados é definido como uma malha tridimensional com um ou mais valores escalares e possivelmente um ou mais valores vetoriais, associados a cada ponto da massas de dados [Elv92].

Para uma melhor usabilidade, as técnicas de visualização volumétrica devem oferecer representações de dados de fácil entendimento, rápidas de serem manipuladas e razoavelmente rápidas de serem renderizadas ${ }^{1}$. Os usuários cientistas devem ser capazes de alterar os parâmetros da visualização e perceberem a imagem resultante instantaneamente. Visualização volumétrica é largamente usada em medicina, geociência, astronomia, química, microscopia, engenharia, testes não destrutivos e em muitas outras áreas da ciência [Elv92].

O processo de visualização volumétrica pode ser visto, de uma maneira geral, como o esquema apresentado em [Kau93], e reproduzido na figura 2.2, no qual é proposta uma nomenclatura para as etapas envolvidas no processo de visualização de um volume de dados.

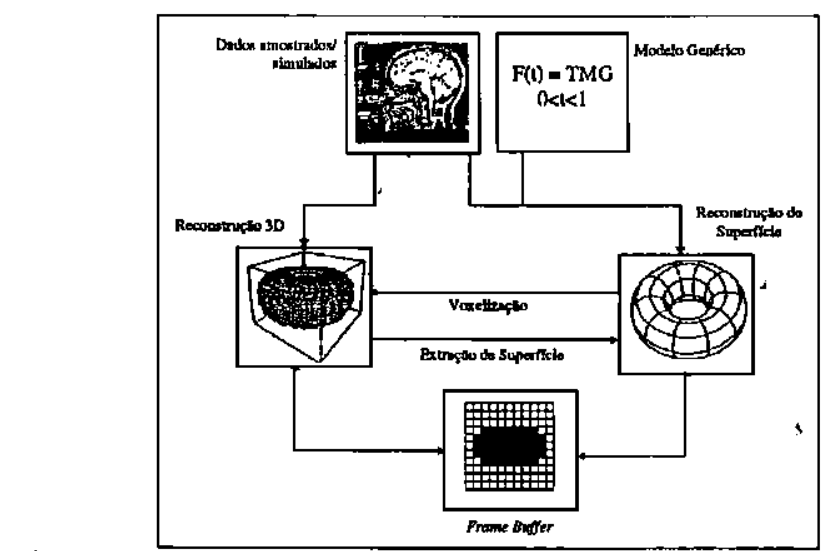

Figura 2.2 - Esquema do processo de visualização volumétrica [Kau93].

Os dados são gerados por dispositivos de amostragem ou por modelos computacionais, sendo produzida uma amostra dos pontos de um objeto real ou simulado computacionalmente, geralmente por uma seqüência de varredura de seções ou ainda por um conjunto de pontos desestruturados. Esse conjunto de dados pode ser processado e filtrado por técnicas de processamento de imagens e, então, ser reconstruído na forma de um volume de dados pelo empilhamento das seções e uma interpolação entre elas. Um objeto volumétrico é representado, tipicamente, por uma grade tridimensional de voxels (unidades de volume) com um ou mais valores numéricos associados a cada voxel. Uma fonte de dados alternativa é a conversão de um modelo geométrico contínuo em uma malha volumétrica. Esse processo de conversão é denominado voxelização. $O$ passo inverso, gerar um modelo de superfície a partir de uma matriz de voxels, também é possível, por um processo de extração de superfície. A

\footnotetext{
' Renderizar é o verbo ulilizado para indicar o processo de rendering
} 
visualização pode ser feita seguindo-se as duas abordagens básicas: Rendering Volumétrico Direto e Rendering por Extração de Superfície, apresentado na seção 2.1.5.

Os campos de Computação Gráfica, Processamento de Imagens e Visualização se sobrepõem. A saída resultante da computação gráfica é uma imagem, enquanto que a saída resultante da visualização é freqüentemente conseguida através da computação gráfica. As áreas de processamento de imagens e computação gráfica estão tipicamente combinadas em algumas aplicações. Por exemplo, na reconstrução de imagens médicas, as seções de corte de um órgão são processadas usando processamento de imagem. As fatias são vistas e manipuladas usando métodos, de visualização, que são renderizadas por meio de métodos de computação gráfica. [Hea97].

Em resumo pode-se dizer que a visualização é uma atividade que engloba o processo de exploração e entendimento dos dados. Isso inclui processamento de imagens, computação gráfica, processamento e filtragem de dados, metodologias de interface com o usuário, técnicas computacionais e projeto de software. A figura 2.3 ilustra essa perspectiva.

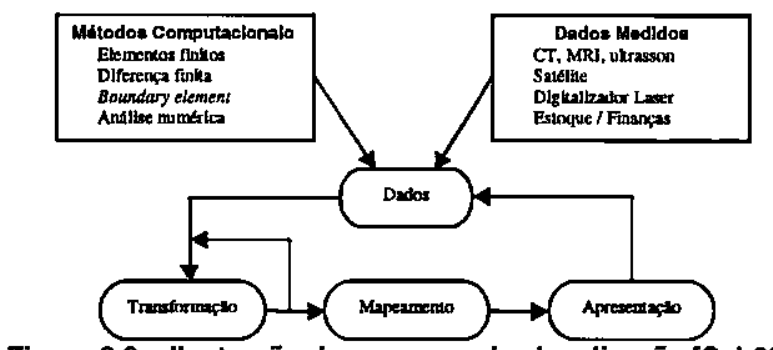

Figura 2.3 - llustração do processo de vlsualizaçāo [Sch98].

Na figura 2.3, pode-se perceber que a visualização focaliza os dados. No primeiro passo, os dados são adquiridos de alguma fónte. A seguir, os dados são transformados por vários métodos e então mapeados para um formato apropriado para ser apresentado ao usuário. Finalmente os modelos são renderizados, completando o processo. $O$ processo pode repetir para que os dados sejam melhor entendidos ou para o desenvolvimento de outros modelos do fenômeno que gerou os dados.

Os dados em Visualização científica podem estar definidos sobre domínios bidimensionais (2D), tridimensionais (3D) e, genericamente, multidimensionais. Em geral, eles estão organizados em uma malha (regular ou irregular), mas podem se constituir de um conjunto de pontos esparsos. As informaçōes associadas a cada ponto podem ser um ou mais valores escalares, vetoriais ou tensoriais, e os dados podem ser estáticos ou variantes no tempo. Uma grande variedade de técnicas de visualização está disponível atualmente (vide, por exemplo, [Fri91][Kel93][Ros94][Sch98]), mas ainda não existe uma classificação abrangente que englobe todas as técnicas situando-as em um arcabouço bem definido. Embora algumas tentativas de situar as principais técnicas em um arcabouço genérico foram executadas [Bro92][Ber89][Ga194]. 
No presente trabalho as técnịcas em questão tratam da visualização de campos escalares em volumes. Existem técnicas de visualização específicas para entidades escalares, vetoriais e tensoriais. A dimensão do domínio também é particularmente importante na definição de métodos de visualização apropriados [Min97a].

\subsubsection{Características dos dados}

Cientistas usam visualização volumétrica para comparar resultados numéricos derivados de experimentos empíricos com resultados derivados de simulaçōes de eventos empíricòs. Programas de análise de elementos finitos ou de dinâmica de fluidos computacional são freqüentemente usados para simular eventos da natureza. Se um é demasiado grande, pequeno, rápido ou lento para ser visto na natureza então apenas o volume de dados do evento simulado pode ser estudado.

A origem dos dados em visualização cientifica é bastante variada. Dispositivos de aquisição de dados particulares, tais como scanners CT e MRI, são alternativas para amostrar uma característica específica de uma substância. Essa característica é usualmente diferente para cada tipo de dispositivo usado. Pode-se criar imagens que mostram as características mais importantes de dois conjuntos de dados referentes a uma mesma substância em duas etapas: registrando (alinhando espacialmente) as duas massas de dados, em seguida escolhendo um algoritmo que se refere aos valores mais apropriados dos dois conjuntos de dados, aplicando-o a todos os pontos dos conjuntos de dados. Isso pode ser feito durante o rendering ou em um passo de composição pós-processamento [Elv92].

Volumes de dados são usualmente tratados como um array de voxels (elementos de volume), ou um array de células. A abordagem por voxels determina que cada célula do volume de dados tenha o mesmo valor. Um voxel é, portanto, uma área hexaedral de valor não variante em tomo de um ponto central da malha de dados (ver figura 2.4). Em alguns algoritmos a contribuição dos voxel para a imagem diminui de acordo com a distância do centro da região de influência. Em outros algoritmos o voxel tem contribuição constante em toda a região de influência. A abordagem por células vê o volume como uma coleção de hexaedros cujos vértices são pontos da malha e cujos valores variam entre os pontos da malha (ver figura 2.4). Esta apresentação permite estimar valores dentro da célula através de interpolação entre os valores nos vértices da célula. A funções de interpolação maỉs comumente usadas são as trilineares e tricúbicas. A vantagem de se usar voxel é que nenhuma suposição é feita sobre o comportamento dos dados entre os pontos da malha, ou seja, apenas dados conhecidos são utilizados para gerar uma imagem. As imagens geradas por malhas compostas por células têm aparência mais suave que aquelas provindas de malhas compostas por voxels. Devido à sua natureza, a validade de imagens baseadas em células não pode ser verificada formalmente [EIv92]. 


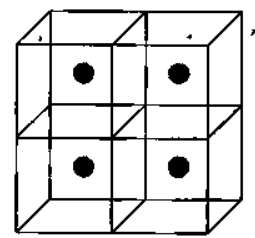

Figura 2.4 - Voxel, valores no centro dos hexaedros.

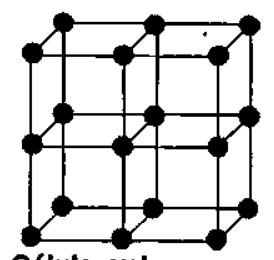

Figura 2.5 - Céluta, valores nos vértices dos hexsedros.

\subsubsection{Organização do Volume de Dados}

O volume de dados representa o trecho do espaço $3 \mathrm{D}$ onde se localiza o objeto, dado ou cena a ser renderizado. Uma malha faz referência à organização do volume de dados. Existem diferentes tipos de malhas. Em uma malha cartesiana todos os elementos são quadrados (no caso $2 \mathrm{D}$ ) ou cubos idênticos (no caso 3D), alinhados aos eixos principais. A figura 2.6(a) ilustra uma malha cartesiana para o caso 2D. Uma malha regular tem todos os seus elementos idênticos e alinhados aos eixos, mas esses elementos são retângulos (ou paralelepípedos) regulares, ao invés de quadrados ou cubos (ver figura 2.6(b)). Elementos de uma malha retilínea são quadriláteros ou hexaedros alinhados aos eixos, mas não necessariamente idênticos, como ilustrado na figura 2.6(c). Elementos em uma malha estruturada são quadriláteros ou hexaedros não alinhados aos eixos principais, como os que aparecem em grades esféricas ou curvilíneas (ver figura 2.6(d)). Uma malha estruturada em blocos é um conjunto de malhas estruturadas agrupadas. Uma malha desestruturada (ver figura 2.6(e)), contém polígonos ou poliedros sem qualquer padrão explícito de conectividade. No caso $3 \mathrm{D}$, as células podem ser tetraedros, hexaedros, pirâmides, etc. Uma malha híbrida é uma combinação de quaisquer dos tipos anteriores [Own96].

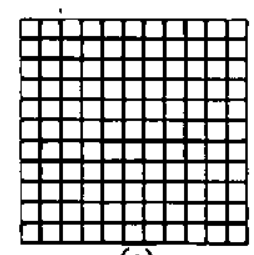

(a)

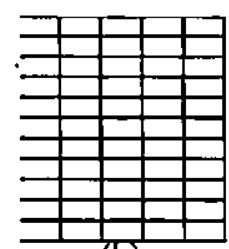

(b)

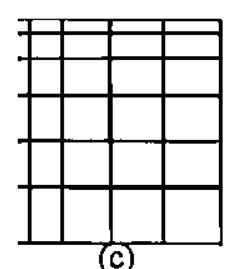

(c)

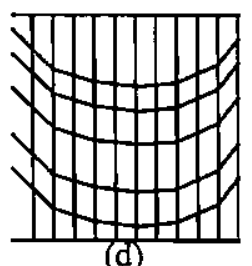

(d)

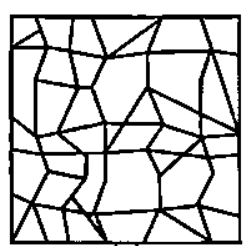

(e)

Figura 2.6 - Diferentes tlpos de malhas [Own96].

Em resumo, a principal distinção entre malhas vem do fato de que conjuntos de dados podem ser regulares (estruturados), ou irregulares (desestruturados). Conjuntos regulares apresentam um relacionamento determinado (implícito ou explícito) entre os pontos aos quais estão associados os dados. Com isso, não é necessário armazenar explicitamente as posições de todos os pontos. No caso de uma malha cartesiana, por exemplo, basta manter a posição inicial, o espaçamento entre os pontos e o número total de pontos, o que permite uma representação computacional compacta. Esse não é o caso dos conjuntos irregulares que, por outro lado, têm a vantagem de serem mais flexíveis e de 
permitir representações adaptativas (com mais células nas regiōes nas quais a informação é mais densa) [Min97a].

O presente trabalho diz respeito ao desenvolvimento de técnicas aplicáveis a malhas regulares.

\subsubsection{Rendering}

O rendering é o processo de geração de uma imagem em uma tela a partir de uma descrição computacional [Min97a]. Esse processo varia enormemente, envolvendo desde a geração de desenhos em duas dimensões (2D) até técnicas sofisticadas de geração de imagens tridimensionais (3D). A maioria das técnicas 3D, nas quais é baseada a "quase" totalidade dos algoritmos em visualização científica, gera a imagem de um objeto através da simulação de sua iluminação ambiente. Em outras palavras, algoritmos de rendering consideram que os objetos em uma cena são atingidos por raios provenientes de fontes de luz. As técnicas de rendering baseadas nesse conceito variam consideravelmente: as mais simples desconsideram as reflexões entre objetos e a atenuação da luz nò ambiente, enquanto que as técnicas mais complexas, como o Ray-tracing [Wat89][Hea97], que produzem imagens bastante realísticas, simulam a interação dos raios de luz com todos os objetos da cena, a um alto custo computacional.

Em visualização científica, boa parte das estratégias de rendering é baseada em modelos simples de iluminação, pois espera-se das imagens que sejam mais significativas do que realísticas. Os processos de rendering podem ser subdivididos em duas categorias: Métodos baseados no espaço da imagem (ou ordem da imagem) e métodos baseados no espaço do objeto (ou ordem do objeto). Nos primeiros, a cena a ser visualizada é renderizada a partir dos pontos de tela (pixels), verificando-se quais elementos no espaço contribuem para a cor de cada pixel da área visível em tela. A segunda classe de métodos trabalha renderizando individualmente cada objeto da cena.

Métodos de rendering em visualização científica podem ser também classificados como de frente-para-trás ou de trás-para-frente, dependendo da forma como o espaço é percorrido, ou seja, primeiro os objetos mais próximos ou primeiro os objetos mais distantes do observador são considerados, respectivamente. Além disso, existem técnicas de rendering por superfícies e volumétricas [Min97a], conforme discussão.

Pelo fato do ambiente de apresentação de dados ser 3D na maioria das vezes, as apresentações gráficas associadas a esse volume usualmente levam o nome de visualização volumétrica. As principais técnicas de visualização volumétrica são apresentadas a seguir. 


\section{2:1.5 Métodos de Visualização Volumétrica}

Os algoritmos fundamentais para visualização volumétrica podem ser classificados em duas categorias: DVR ou. Direct Volume Rendering (Rendering Volumétrico Direto), e SF ou SurfaceFitting (Extração de Superfícies).

A abordagem DVR inclui métodos tais como Ray Casting, métodos de interpolação, Splating e rendering $V$-buffer. Os dois últimos métodos são comumente chamados métodos de projeção [Wi191a][Wil91b]. Os métodos DVR são caracterizados pelo mapeamento direto dos elementos do volume de dados na tela, sem o uso de primitivas geométricas como uma representação intermediária. DVR é especialmente apropriado para criação de imagens de conjuntos de dados contendo características amorfas como nuvens, fluidos e gases. Uma desvantagem no uso do DVR é que o conjunto de dados deve ser percorrido inteiramente toda vez que uma imagem é renderizada. Uma amostragem de baixa resolução ou aleatória pode ser usada no volume de dados a fim de prover uma imagem rápida de baixa qualidade para checagem de parâmetros. $O$ processo de aumentar gradativamente a resolução e qualidade de uma imagem DVR é conhecido como refinamento progressivo. Maiores detalhes sobre métodos DVR são fornecidos no capítulo 3.

Os algoritmos SF tipicamente ajustam primitivas de superfícies (usualmente planares), como malhas poligonais, em superfícies de contorno de valores constantes de um conjunto de dados volumétricos. $O$ usuário começa pela escolha de um valor de interesse, e então primitivas geométricas são automaticamente ajustadas nas superfícies definidas pelo valor escolhido. As células em que todos valores dos vértices estão acima (célula dentro) ou abaixo (célula fora) do valor escolhido são descartadas e, portanto, não afetam a imagem final. Deve-se considerar que número de primitivas geométricas geradas para visualizar a superfície é, geralmente, bastante elevado para um conjunto de dados extenso. A figura 2.7 apresenta duas figuras obtidas a partir do mesmo conjunto de dados pelos métodos DVR (figura 2.7(a)) e SF (figura 2.7(b)).

A abordagem SF inclui métodos como contour-connecting, marching cubes, marching tetrahedra, e dividing cubes dentre outros [Min97a][Elv92]. Os métodos SF são tipicamente mais rápidos que os DVR, uma vez que o SF percorre o volume de dados apenas uma vez para extrair a superfície. Depois de extraída a superfície, as primitivas geométricas podem ser renderizadas rapidamente por hardware ou métodos de rendering convencionais. $O$ rendering acontece toda vez que o usuário muda a posição ou direção de visão, ou ainda quando algum parâmetro de iluminação é modificado. A mudança do valor que define uma superfície é custosa, pois necessita que todo o volume de dados seja visitado novamente para que um novo conjunto de primitivas de superfície seja extraído. Os métodos SF sofrem de vários problemas, tais como pedaços de superfície com valores positivos ou negativos falsos e a incorreta manipulação de pequenas características ou ramificações nos dados. Note que tais 
artefatos podem ser incorretamente interpretados pelos usuários como características nos dados [Elv92].

Em [Sha96] é feita uma discussão a respeito do emprego da visualização volumétrica direta ou visualização de superfícies no que tange à sua utilização em imagens médicas. Veja as duas afirmações abaixo:

"O rendering volumétrico é ainda relativamente lento, até para as workstations topo de linha. Como o advento do hardware para rendering volumétrico especializado, o rendering volumétrico se tornará, em um futuro próximo, o principal mecanismo para visualizar dados médicos”, Arie Kaufman [Sha96].

"O rendering volumétrico pode produzir imagens de superficies. Portanto, deve-se concluir que em um futuro não muito distante, quando o rendering volumétrico de um conjunto de dados médicos for inexpressivo e suficientemente rápido, o rendering por superficies já não será mais utilizado”, Sandy Napel [Sha96].

Kaufman [Kau93] apresenta uma discussão mais completa dessa futura migração para técnicas de rendering volumétrico.
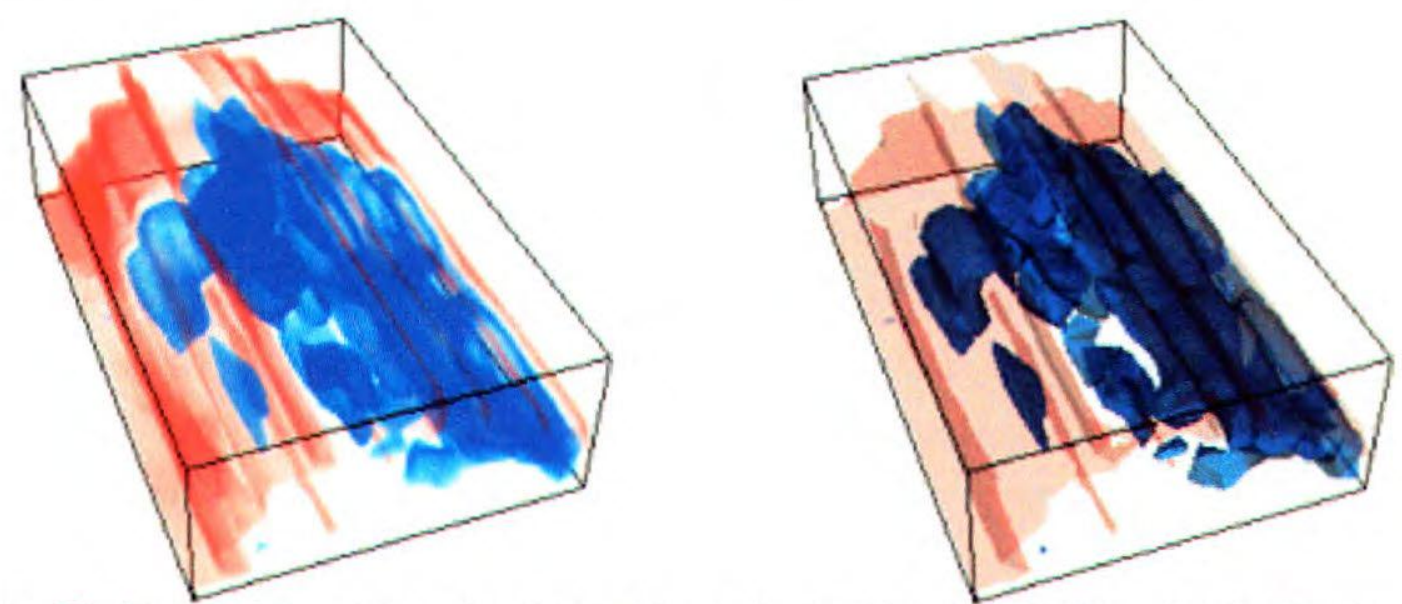

Figura 2.7 - Imagens de um mesmo conjunto de dados. Em (a) por Rendering Volumétrico Direto (DVR) e em (b) por Extração de Superficies (SF). 


\subsubsection{Classificação dos Dados}

A classificação dos dados é a tarefa mais difícil que um usuário da visualização volumétrica deve realizar. Ela implica na escolha de um valor limite, se um algoritmo SF estiver sendo usado, ou na escolha de valores de cor e opacidade para serem associados com intervalos de valores de dados se um método DVR estiver sendo usado. Uma tabela de cores do DVR serve para mapear os valores dos dados em cores significativas. Uma tabela de opacidades do DVR é utilizada para expor as partes do volume mais interessantes ao usuário e para dar transparência total às partes que não são de interesse, ou transparência parcial às superfícies intermediárias.

No DVR, cada elemento em um volume contribui com cor para a imagem final. A quantidade de cor a ser contribuída por um elemento é determinada pela cor e opacidade do elemento corrente e as cores e opacidades de todos os elementos entre o elemento corrente e o plano de imagem. Para conseguir uma imagem razoável o usuário dever escolher com cuidado as tabelas de cor e opacidade. Os programadores da visualização são responsáveis por assegurar que valores interpolados não sejam mapeados, através das funções de transferência da tabela de cores, em materiais não existentes ou cores incorretas.

Outro fator que influencia a classificação dos dados é o conhecimento do material pelo usuário. Se o usuário estiver familiarizado com o material sendo classificado, a especificação da tabela é facilitada. No entanto, se o usuário não estiver familiarizado com o material, a classificação pode requerer extensiva exploração dos dados ou até mesmo consulta a uma pessoa que possua conhecimento das características do material [Elv92]. Existem várias abordagens para apoiar o usuário na escolha de tabelas de cores adequadas a um conjunto de dados [Oli98].

Como apresentado nesta seção, a visualização científica volumétrica tem por objetivo oferecer ao cientista maneịras para visualizar dados volumétricos. Os dados são gerados por dispositivos de amostragem ou por modelos computacionais, sendo produzida uma amostra dos pontos de um objeto real ou simulado computacionalmente. Esse conjunto de dados pode ser reconstruído na forma de um volume de dados. Esse processo de reconstrução é o assunto da seção seguinte. 


\subsection{Reconstrução}

Esta seção apresenta uma visão geral do processo de reconstrução de modelos $3 \mathrm{D}$ a partir de informaçōes $2 \mathrm{D}$ ou 1D, mostrando também os possíveis formatos dos dados de entrada e como eles podem ser adquiridos. Conforme o formato desses dados, existem diferentes soluções para a reconstrução.

\subsubsection{Formatos dos Dados de Entrada}

Os dados de entrada contêm informações sobre a geometria e, às vezes, também sobre a topologia_de. alguns pontos que pertencẹm, ou _estäo próximos, àsuperfície que se deseja reconstruir. Os dados dẹ entrada podem ser um conjunto de fatias paralelas do volume em estudo, em _que cada seção_contém um certo número de contornos da superfície [Mey92][Non98], como mostra a figura 2.8(a). Em geral, a aquisição das fatias gera um elemento fotográfico, onde os pixels_contém informação de densidade, intensidade ou cor. Dessa foto, os contornos sạa extraídos de forma manual ou automática. Outro formato possível é um conjunto de pontos desestruturados [Alg96][Blo98] como mostra a figura 2.8(b).

Uma_possível divisão dos métodos de reconstrucãa pode ser: métodos que trabalham com fatias e métodos que trabalham com pontos desestruturados.

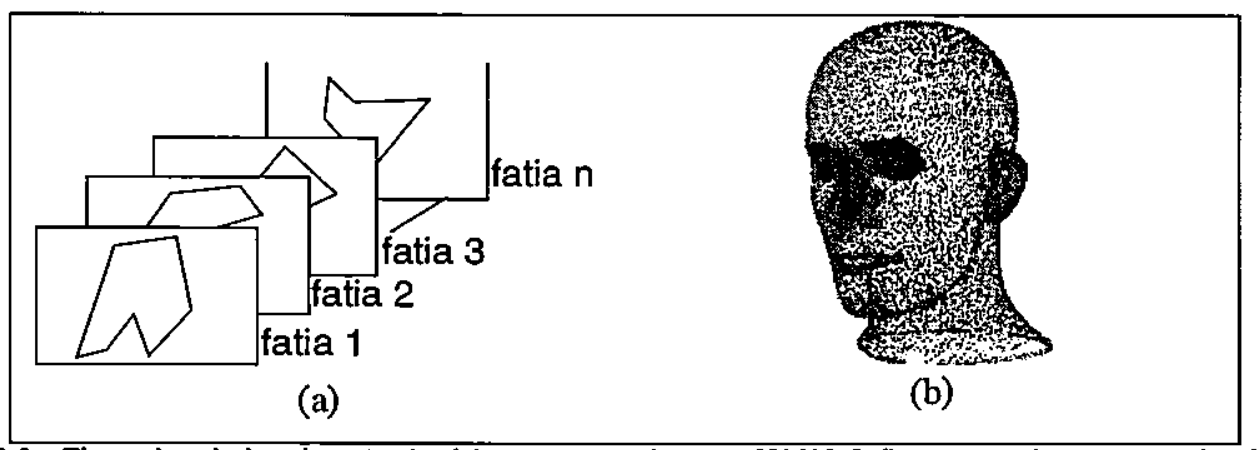

Flgura 2.8 - Tipos dos dados de entrada: (a) contornos planares [Shi98a]; (b) pontos desestruturados [8lo98].

Algumas das formas de aquisição de dados são: microscopia, tomografia computadorizada, ressonância magnética e ultra-som. A Microscopia é utilizada para obter imagens_de lâminas preyiamente preparadas a parțir de um objeto que se deseja estudar. Na Tomografia Computadorizada, a densidade de um voxel (ou pixel) representa a atenuação dos raios $\mathrm{x}$ conforme os tecidos_contidos nesse voxel (ou pixel). Na Ressonância Magnética, a densidade representa um agregado.de. propriedades magnéticas das_moléculas contidas no.voxel. A resolução do dispositivo de aquisição de dados pode afetar o processo de reconstrução. Quanto maior a resolução, os dados são amostrados em 
um nível maior de detalhes e mais artefatas_são-acrescentades-des-dades,-difieultande-o processo de reconstruçāo [Bio98].

Uma altemativa à aquisição por dispositivos provém des processos de_simulaçãa. Neles, fenômenos sãa definidos e simulados por métodos numéricos. A saída desses processos pode ser dada por conjuntos de pixels ou voxels, da mesma forma que nos processos deaquisiçãa.

\subsubsection{Métodos de Reconstrução}

Segundo Meyers et al. [Mey92] a reconstrução a partir de fatias possui duas abordagens diferentes: a baseada em volume (voxels), e a baseada em tecelagem de contornos. Existem ainda abordagens para reconstrução de superfícies à partir de pontos desestruturados no espaço.

Nos métodos baseados em volume as fatias são utilizadas para construir uma malha tridimensional da qual a sùperfície é extraída. Essa abordagem funciona bem quando o espaçamento entre as fatias é tão bom quanto à resolução dessas fatias. Caso contrário, um espaçamento grande entre fatias adjacentes provocará falta de correspondência entre contornos.

Os métodos baseados em tecelagem de contornos normalmente tratarn o problema da reconstrução corno quatro sub-problemas, a saber: correspondência, tecelagem, ramificação e adaptação da superfície [Mey92].

O problema da correspondência surge quando existem múltiplos contornos em uma fatia, de rnodo que eles precisem ser organizados em grupos representando diferentes objetos a serem reconstruídos. Uma solução automatizada para este problema é muito difícil. Em geral, são feitas suposiçōes sobre a forma dos objetos para se obter uma solução razoável. Um fator determinante na resolução do problema de correspondência é o espaçamento entre as fatias. Para espaçamentos pequenos a correspondência pode, na maioria das vezes, ser resolvida sem ambigüidade.

Resolvido o problema da correspondência sabe-se quais contornos representam a mesma superfície. $O$ problema de tecelagern ${ }^{2}$ procura determinar qual a melhor maneira de associar os pontos de contornos adjacentes.

Dados dois contornos quaisquer, pode-se ligar os seus pontos de várias maneiras. Para definir a maneira "correta", assume-se que a superfície definida entre os contornos tenha uma característica em particular, como, por exemplo, volume máximo ou área mínima. 
O problema da ramificação ocorre quando existem $m$ contornos em uma fatia e $\mathbf{n}$ contornos em uma fatia adjacente $\left(m \neq n\right.$ e $\left.m_{3} n>0\right)$. Isso provoca ambigüidade, como mostra a figura 2.9. Alguns métodos necessitam da intervenção do usuário para a resolução desse problema [Shi98a]. As soluções para este problema se baseiam na composição de contornos, unindo vértices adjacentes ou fabricando vértices entre contornos, mas algumas vezes é necessário definir a triangulação entre os vértices. Após a composição, é feita a tecelagem entre os contomos.

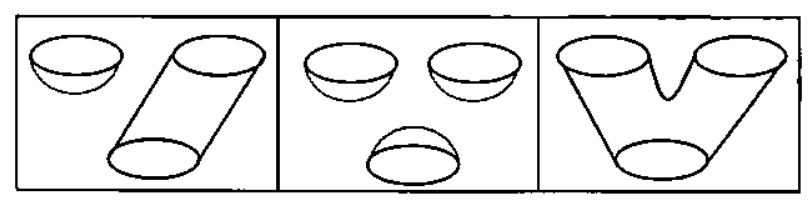

Figura 2.9 - Ambigüidade devldo às ramiflcaçōes [Shi98a].

As soluções dos problemas de correspondência, tecelagem e ramificação resultam em uma triangulação no espaço do objeto. A partir dessa triangulação, pode-se obter uma superfície suave que aproxima ou interpola a superfície em estudo. A escolha entre interpolação e aproximação depende da natureza dos dados de entrada. Caso esses dados sejam imprecisos, pode-se utilizar aproximação; caso contrário, deve-se utilizar a interpolação. Muitas vezes a própria malha pode ser utilizada coṃ̣ superfície resultante [Shi98a], sendo que a suavidade é obtida pelo método de iluminação.

Como visto nesta seção, pode-se reconstruir um volume, ou um conjunto de superfícies, a partir doṣ dados obtidos por equipamentos de amostragem ou por simulação computacional. Esse volume , reconstruído pode então ser apresentado por alguma técnica de visualização. No processo de jvisualização é interessante que o usuário tenha uma boa interatividade com a apresentação dos dados, ẹsse é o assunto da próxima seção.

${ }^{2} \mathrm{O}$ termo em inglês correspondente a tecelagem é tiling. Esse problema consiste em tecer uma malha de triângulos entre os contornos. 


\subsection{Interação na Visualização Científica}

Segundo [Bry94], tradicionalmente, a visualização científica é usada para duas funções: exploração e apresentação. No início da visualização científica com uso de computadores, era bastante difícil para o pesquisador produzir visualizações além dos gráficos tradicionais e plots. Era necessário uma familiaridade com programação em computação gráfica, uma necessidade que estava resolvida com a criação de "lojas de visualização", onde uma visualização era produzida "sob encomenda". Um pesquisador provia dados para um programador de visualização que então produzia uma imagem ou animação de alta qualidade. Assim existia um investimento significativo envolvido na produção de visualizações. Isso serviu ao propósito da visualização como meio de apresentação, o que escondeu o uso da visualização como meio de exploração.

Nos dias de hoje, os sistemas de visualização facilitam a visualização para exploração. No entanto, os sistemas convencionais dificultam esse tipo de visualização principalmente devido: o tempo requerido para renderizar a visualização a partir de uma entrada do usuário, a falta de facilidade de uso da interface que controla a visualização, e a falta de intuitividade das próprias técnicas.

A questão do tempo é devida principalmente: à velocidade do hardware do sistema de visualização, a complexidade dos algoritmos usados para realizar a visualização, e o tamanho e complexidade dos dados que estão sendo visualizados. A redução significava do tempo de rendering de uma visualização realça o manuseio da visualização no processo de exploração e descoberta. Ou seja, é necessário buscar a interação de tempo real.

Quanto à interface, o problema se dá principalmente na dificuldade de se mapear os dispositivos tradicionais de interação, que são $2 \mathrm{D}$, em açōes de uma cena 3D. Nesse processo ocorre uma grande limitaçạao na interação com a visualização. Uma alternativa interessante é utilizar dispositivos empregados em realidade virtual, que são de natureza 3D. Assim, a questão se resume em conseguir uma interface 3D que seja natural ao homem, aproveitando sua experiência de manipulação de objetos 3D no ambiente em que vivem. Com o auxílio de dispositivos de interação apropriados, as atividades de interação em mundos virtuais 3D se tornam mais próximas do natural, o que é mais difícil quando se faz uso de dispositivos $2 \mathrm{D}$.

Existem dois aspectos importantes quanto à interação de tempo real para visualização: resposta interativa e taxa de animação. A resposta interativa diz respeito a quão rápido o usuário vê o resultado de sua ação. Se a resposta for lenta, o usuário terá dificuldades em utilizar ferramentas de visualização de posicionamento preciso. A taxa de animação está relacionada com a rapidez que as imagens são apresentadas ao usuário. Essa taxa é particularmente relevante no que diz respeito ao 
controle de visão e a visualização de conjuntos de dados variantes no tempo. Se a taxa de animação for baixa as imagens serão percebidas como uma série de cenas e năo como uma evolução contínua ou movimento.

Experiências mostram que para uma animação e interação viável, o seguinte critério dever ser satisfeito: o sistema deve prover retomo à ação do usuário em menos de 0.1 segundos e uma animação deve rodar com aproximadamente 10 quadros por segundo [Bry94].

De acordo com [Haa97], as técnicas de realidade virtual oferecem novas possibilidades para representar e investigar dados multidimensionais. Os ambientes virtuais são caracterizados por simularem um ambiente que comporta como se fosse real, dando ao usuário a impressão de estar imerso em objetos virtuais. A exploração imersiva de dados científicos é naturalmente o próximo passo depois que a visualização for interativa e em tempo real [Vin98].

\subsubsection{Análise Visual de Dados Científicos}

Projetar um ambiente virtual egocêntrico para analisar dados científicos demanda um bom conhecimento da natureza do problema. Um "problema" de visualização pode ser caracterizado pela natureza dos dados, pelas representações particulares que são usadas para descrever os dados, e pelo objetivo de análise dos dados. Todos estes aspectos devem ser considerados no projeto do ambiente dè exploração dos dados científicos [Bak95].

\subsubsection{Características dos Dados}

A caracterização dos dados científicos pode ajudar a especificar um ambiente virtual apropriado. Uma classificação sugerida [Dar93], caracteriza mundos virtuais em termos de tamanho, densidade e atividade. Quanto à atividade, os mundos como estáticos ou dinâmicos, onde as mudanças devem ser determinísticas e previsíveis ou então aleatórias. Em temos de densidade, o mundo pode ser esparso, denso ou compacto (cluttered). Quanto ao tamanho, um mundo pequeno é aquele que pode ser apresentado por inteiro com detalhamento suficiente, o mundo infinito é aquele que não tem limites. Cada uma dessas características pode guiar o projeto do mundo virtual. Por exemplo, se a escala física dos dados é pequena, deve ser razoável representar e renderizar o conjunto de dados tal qué ele esteja visível por completo a todo o momento. A imersão pode até não ser necessária em algumas situações, evitando problemas como desorientação. Esse não é o caso de mundo de dados extensos onde é impossível analisar os dados de apenas um ponto de visão e a sua exploração requer apresentação de sub-regiōes. Uma visão egocêntrica (visão típica de ambientes virtuais, onde a visão é construída de acordo com a posição do usuário) pode não ser efetiva se o conjunto de dados for muito denso, ou seja, os objetos estão muito próximos uns dos outros. 


\subsubsection{Tarefa de Análise dos dados}

Um pesquisador típico adota um número de objetivos de análise durante o curso da exploração visual de um conjunto de dados científicos. Esses objetivos podem ser de pesquisa (identificar, localizar, distinguir, etc) ou de cómputação (comparar, associar, etc) [Bak95]. Dentro do campo da visualização científica, as atividades de análise de dados têm sido categorizadas como:

- Global: envolvendo o conjunto de dados inteiramente;

- Grupo: envolvendo um conjunto de pontos não adjacentes;

- Local: envolvendo somente algumas regiões do conjunto de dados e

- Ponto: restringe os dados a uma localização particular no espaço de dados.

\subsubsection{Percepção e Múltiplos parâmetros de Display}

Como apresentado no início deste capítulo, o objetivo da visualização é possibilitar ao usuário entender os dados. Um bom conhecimento da forma de como o cérebro e o sistema visual percebem a informação pode ajudar a melhorar o processo e os resultados da visualização.

A percepção é um processo ativo: "é mais que o processo passivo de aceitação e processamento das entradas de nossos sentidos pelo sistema nervoso. Existem mais algumas características relacionadas ao nosso sistema sensorial, por exemplo, o intervalo de ondas que nós podemos ver e ouvir, as cores e tons que nós podemos distinguir, a percepção de um aparente movimento suave quando as figuras são seqüenciadas rapidamente"[Hib95].

Vale lembrar que o sistema visual humano não está imune de confusões e deve-se levar isso em consideração quando se está projetando uma visualização. Abaixo são listados alguns dos fatores que provocam ilusões ao sistema visual [Rhe95]:

- A percepção de tamanho de um objeto pode ser afetada por sua cor.

- A percepção de matiz de uma cor pode ser influenciada por sua saturação.

- A percepção de saturação de uma cor pode ser influenciada por seu matiz.

- A percepção de profundidade de um objeto pode ser influenciada por sua cor.

- A percepção de cor de um objeto pode ser influenciada pela cor dos objetos que o envolvem.

Sempre que possível, as condições que promovem estas ilusões devem ser evitadas.

A visualização baseada na percepção visa fazer a apresentação dos dados tão eficiente e efetiva quanto possível. Ou seja, procura maximizar a quantidade de informação que o usuário pode perceber na visualização [Rhe95]. 
As visualizaçōes que representam os valores de dados usando múltiplos parâmetros de display podem retratar os dados mais efetivamente que nas visualizaçōes que mapeiam cada dado em apenas um parâmetro de display. Esta afirmação pode ser confirmada como se segue [Rhe95]:

- Parâmetros de display diferentes comunicam diferentes tipos de informação mais eficientemente. Por exemplo, brilho comunica o formato do objeto mais eficientemente que matiz, mas matiz permite distinguir melhor os níveis dos dados que brilho.

- Parâmetros de display múltiplos podem contomar deficiências visuais. Se um parâmetro de display é ambíguo ou ineficiente por causa da deficiência visual do usuário, um outro parâmetro de display pode compensar isso.

- Parâmetros de display múltiplos reforçam uns aos outros. Nesta forma, áreas com diferentes valores têm maiores diferenças visuais umas das outras.

Portanto, ter atenção nos princípios da percepção é essencial para a construção de visualizações efetivas e de qualidade.

\subsubsection{Classificação de Visualização Científica Imersiva}

Similar à visualização científica convencional, a visualização imersiva pode ser feita em diferentes níveis de interação e dinâmica. Alguns tipos possíveis de cenas nesse contexto são [Haa97]: cena estática sem interação, cena estática com interação, cena dinâmica sem interação e cena dinâmica com interação.

A cena dinâmica com interação é a mais promissora dessas altemativas, mas muitos dos problemas precisam ser resolvidos para sua realização, principalmente a precisão de interação em ambientes virtuais e a velocidade de visualização. 
Analisando os sistemas existentes para visualização e aqueles para ambientes virtuais, [Bak95] sugere as seguintes possibilidades de realizar visualização imersiva:

1. Extensão do sistema de visualização existente com algumas capacidades de ambientes virtuais adicionadas (ver figura 2.10 ).

2. Extensão do sistema de ambiente virtual existente com alguns recursos de visualização científica adicionados (ver figura 2.11 ).

3. Escrita de um novo sistema às pressas, usando alguns recursos de visualização científica e de ambientes virtuais (ver figura 2.12).

4. Utilização de um sistema de ambientes virtuais existente para investigar objetos pré-computados por algum sistema de visualização científica (ver figura 2.13).

5. Integração de ambiente virtual complexo com sistema de visualização científica (ver figura 2.14).

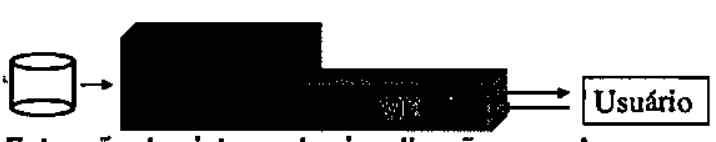

Figura 2.10 Extensăo do sistema de visuallzação com algumas capacldades de ambientes virtuals [Bak95].

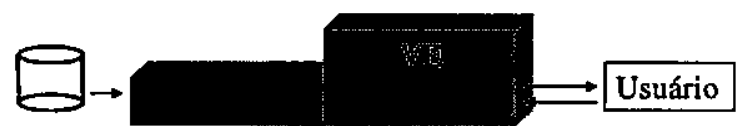

Figura 2.11 - Extensāo do sistema de amblente virtual com alguns recursos de vlsualização clentffica [Bak95].

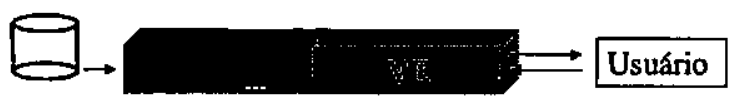

Flgura 2.12 - Escrevendo um novo slstema, usando alguns recursos de visuailzaçäo clentiffce e de ambientes virtuais [Bak95].

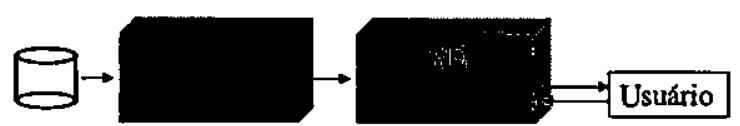

Flgura 2.13 - Objetos de visual lzaçäo Importados para amblentes virtuais [Bak95].

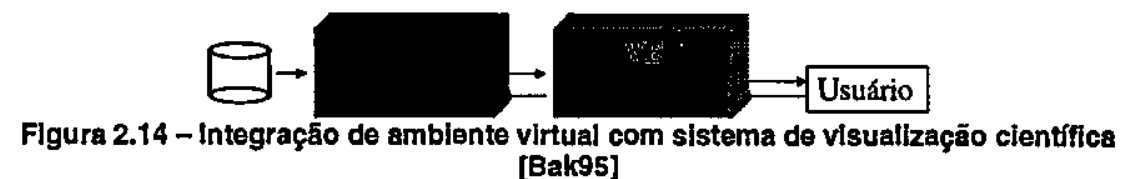

A extensāo de sistemas de visualizaçăo existentes tem inconvenientes como, por exemplo, a interface com o usuário não ser viável para o ambiente virtual. Além disso, ferramentas de ambientes virtuais devem ser reimplementadas.

A possibilidade 2 é o caminho mais simples, e suficiente para algumas aplicaçōes. Cenas estáticas e cenas dinâmicas pré-computadas podem ser investigadas. Técnicas como data probing ou particle 
tracing podem ser aplicadas, com um número de restrições, desde que todas as situações possíveis tenham sido pré-computadas para a apresentação em ambientes virtuais.

Para usar todos os benefícios dos ambientes virtuais e da visualização científica, a possibilidade 5 é necessária, isto é, integração completa dos dois sistemas. Neste caso, a comunicação entre os sistemas é um ponto que merece atenção. Por exemplo, em data probing ou em particle tracing, a quantidade de dados a ser transmitida entre os dois sistemas é pequena. Mas em outros casos, por exemplo, um novo valor determinante para uma isosuperfície ou uma nova função de mapeamento para a cor da superfície, uma grande quantidade de dados dever ser transmitida. Assim, faz sentido caracterizar a comunicação entre um ambiente virtual e um sistema de visualização científica pela largura de banda disponível.

Como visto, a realidade virtual oferece novas oportunidades para construção de ambientes interativos. Bons ambientes são difíceis de serem projetados. Usando estes ambientes para a análise de dados científicos é particularmente difícil por causa da natureza dos dados e necessidade de flexibilidade e interatividade na interface.

Neste capítulo foram apresentados conceitos básicos de visualização científica que são importantes para o desenvolvimento do presente trabalho de mestrado. A visualização científica foi apresentada como a área geral desta monografia, a qual trata da aplicação de técnicas de mapeamento visual para apresentação de dados em odontologia. A reconstrução de superfícies, uma das técnicas mais convencionais da visualização, foi discutida. Esse tema é importante, uma vez que os resultados deste trabalho são comparados com aqueles anteriormente produzidos por reconstrução de superfícies [Min00]. A interação no contexto da visualização também foi apresentada, em virtude da sua importância para as tendências atuais em visualização.

Pela análise dos temas apresentados, percebe-se que a visualização caminha no sentido tanto da utilização de múltiplas técnicas de mapeamento gráficos a partir de dados (com destaque às técnicas volumétricas diretas de rendering), quanto ao acesso remoto a dados e gráficos via internet e de forma interativa (com destaque à tecnologia de realidade virtual). O rendering volumétrico direto é visto, por muitos autores, como uma técnica necessária em aplicações volumétricas, principalmente aquelas relacionadas a área médica, e sua aplicação ao projeto em que se insere esse trabalho de mestrado representa o tema central deste texto e é discutido em detalhe no próximo capítulo. 


\section{Capítulo 3}

\section{Rendering Volumétrico Direto com Mapeamento de Textura}

Como visto na seção 2.1.5, existem várias abordagens para visualização de dados volumétricos. Entre elas, a maioria das técnicas dedicadas a dados escalares podem ser divididas em duas classes principais: Visualização Volumétrica por Extração de Superfícies (Surface Fitting - SF) e Visualização por Rendering Volumétrico Direto (Direct Volume Rendering - DVR). Na primeira classe, são utilizadas técnicas de detecção para gerar superfícies, definidas por um conjunto de valores de interesse dentro do volume, para então renderizar a geometria resultante de forma convencional. Na Segunda classe, a imagem é gerada diretamente a partir do volume de dados sem a necessidade de uma estrutura intermediária. O presente trabalho se encaixa na forma DVR de geração de imagens a partir de volumes de dados, portanto essa classe de técnicas é o objetivo deste capítulo. A seção 3.1 apresenta as técnicas mais comumente utilizadas para obter DVR. A seção 3.2 apresenta o mapeamento de textura, que é uma técnica recente para promover DVR.

\subsection{Técnicas Convencionais para DVR}

O rendering volumétrico direto tem por base a geração de imagens a partir de malhas volumétricas de dados escalares, onde a esses valores são associadas cores e opacidades. A combinação dessas cores através de alguma estratégia de projeção fomece a imagem final sem a utilização de formas geométricas intermediárias.

As técnicas mais comuns para DVR são o Splating e o Ray Casting, apresentados nas seçōes 3.1.1 e 3.1 .2 respectivamente. 


\subsubsection{Splatting}

O Splatting [Min97a][Elv92][Wat89] é um algoritmo de DVR que opera na ordem dos objetos, isto é, os voxels são projetados diretamente no plano de imagem (ver figura 3.1). O algoritmo percorre os voxels em um percurso de frente-para-trás ${ }^{3}$, sendo que a contribuição de cada voxel é calculada e combinada com as contribuições dos outros voxels que projetam no mesmo pixel.

A contribuição de um voxel é maior perto do centro de sua projeção, diminuindo em direção à periferia. Em um primeiro passo, a face do volume (fatia) mais próxima do plano da imagem é determinada. Os voxels dessa fatia serão projetados primeiro. A cada voxel é atribuída uma cor e uma opacidade, de acordo com as tabelas de mapeamento (classificação dos dados, ver seção 2.1.6) definidas pelo usuário. Esses valores são atenuados conforme o gradiente no voxel. A seguir, o voxel é projetado no plano da imagem.

Para calcular a contribuição de um voxel em particular, e depois compor as contribuições dos voxels, um núcleo (kernel) de reconstrução é usado. Para uma projeção ortográfica, o núcleo mais comum é um Gaussiano esférico, ilustrado na figura 3.2. A projeção desse núcleo no espaço da imagem (denominada sua "pegada", "footprint") é calculada. O tamanho é ajustado de acordo com os tamanhos relativos do volume e do plano de imagem, de forma que o volume preencha a imagem. $O$ centro do núcleo é colocado no centro da projeção do voxel no plano da imagem (que não necessariamente coincide com o centro do pixel). A seguir, a tonalidade e opacidade do pixel são determinadas pela soma das contribuições de todos os voxels para esse pixel, ponderadas segundo o núcleo (kernel). Um aspecto importante é que a footprint de cada voxel permanece constante na projeção ortográfica e, portanto, precisa ser calculada uma única vez. No caso de uma visualização perspectiva, a footprint varia ao longo do volume, e como o seu cálculo é caro, a visualização perspectiva é muito mais lenta do que a ortográfica.

A ordem do percurso também poderia ser alterada. O percurso frente-para-trás apresenta vantagens em alguns casos. Por exemplo, o processo de composição para um pixel pode ser interrompido assim que a sua opacidade acumulada atinge o valor 1. Em um percurso trás-para-frente o valor de um pixel pode mudar significativamente durante o rendering. Por outro lado, esse tipo de percurso pode ser útil para o usuário ir visualizando as imagens progressivamente, vendo as estruturas que serão posteriormente ocultas por outras.

\footnotetext{
${ }^{3}$ ordem frente-para-trás primeiro são processados os voxels à frente seguindo até aos que estão atrás, a "frente" do volume é a parte que está mais próxima ao observador.
} 


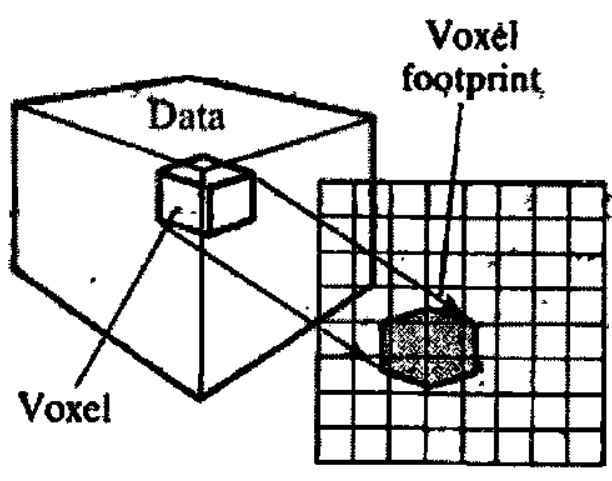

Figura 3.1 - SplattIng [Wat89].

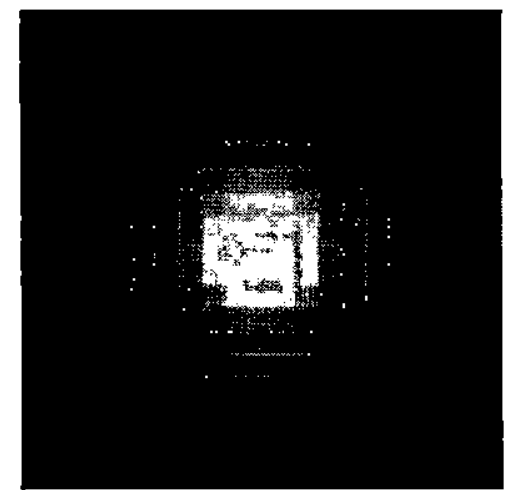

Figura 3.2 - Uma tootprint para o algorltmo Splatting. Areas escuras indicam maior intensidade [Sch98]

\subsubsection{Ray Casting (Lançamento de Raios)}

Técnicas que operam no espaço da imagem determinam como as amostras de dados afetam cada pixel da imagem usando uma variação da técnica de rendering tradicional conhecida como 'ray tracing [Min97a][Elv92][Wat89]. No ray tracing tradicional, os raios interagem apenas com a superfície dos objetos, e um raio pode gerar vários outros quando atinge uma superfície., No Ray Casting volumétrico, um raio continua o seu caminho pelo interior do volume em linha reta, até que a opacidade acumulada no caminho do raio atinja o máximo (valor 1), sendo que não são geradas sombras ou reflexões no processo. Esse é o algoritmo mais usado para a geração de imagens volumétricas de alta qualidade.

No processo básico do Ray Casting, um raio é disparado a partir da câmera, passando por um determinado pixel no plano da imagem e penetrando no volume, como ilustrado na figura 3.3. O raio é amostrado em pontos discretos, separados por uma distância fixa $d$. O valor associado a um ponto no interior de uma célula é calculado por interpolação constante (o valor do voxel é tomado como sendo o valor do dado no ponto) ou por interpolação linear a partir dos valores nos vértices. A interpolação linear produz resultados melhores, mas é computacionalmente mais cara. Em seguida, as̉ tabelas de mapeamento são usadas para determinar a cor e a opacidade associadas a esse valor do dado. A opacidade é atenuada de acordo com a magnitude do gradiente, que dá uma boa indicação da quantidade de um material dentro de uma célula. Os valores de cor e opacidade são adicionados ao valor do pixel usando uma fórmula ponderada (em geral, voxels mais à frente recebem um peso maior), e o raio prossegue para o próximo ponto de re-amostragem. A figura 3.4 descreve os principais passos do algoritmo. Para cada voxel interceptado pelo raio são acumuladas a cor e a opacidade associadas, até a opacidade atingir o valor 1 , ou até que o raio deixe o volume. Se a opacidade não atingiu 1 quando o raio deixa o volume, a cor acumulada é multiplicada pela opacidade parcial. $O$ processo é repetido para cada pixel no plano da imagem. 


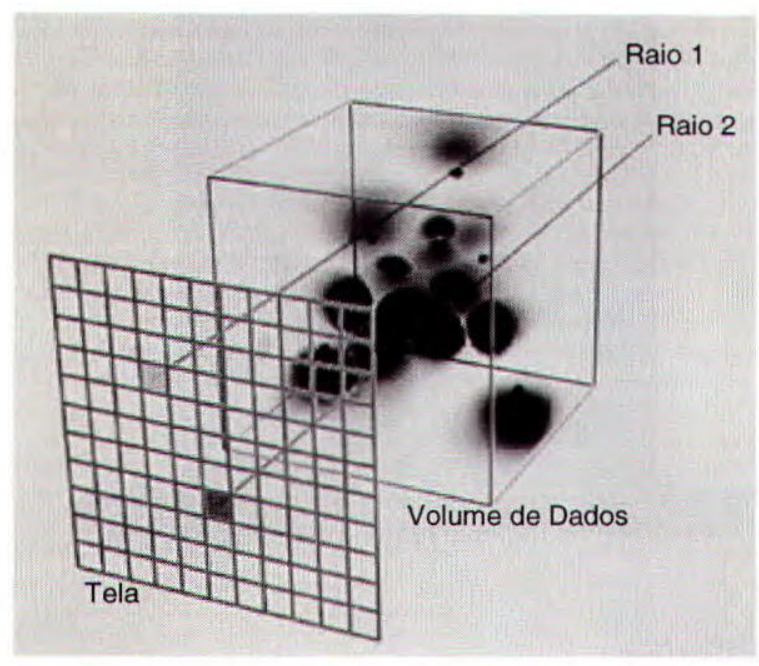

Figura 3.3 - Disparo de raios para o volume [Sch98].
Para cada Pixel

Para cada $\mathrm{f}(\mathrm{i}, \mathrm{j}, \mathrm{k})$ ao longo do raio iniciado em Pixel

Verifique $f(i, j, k)$ nas tabelas de classificação

Se novo material

Obtenha normal à superfície/calcule a cor pondere a cor segundo a opacidade acumule contribuição da cor e opacidade

Pixel recebe cor acumulada.

Figura 3.4 - Algoritmo básico de Ray Casting [Min97a].

Uma vantagem dessa técnica é que objetos pequenos ou pouco definidos são mostrados. Além disso, o processo não envolve uma classificação binária do tipo "dentro ou fora", como nos algoritmos de extração de superfícies (ver seção 2.1.5 do capítulo 2). As imagens mostram o conteúdo do volume todo, e não apenas de uma superfície em particular. Adicionalmente, o traçado de um raio é independente dos demais, o que torna o algoritmo facilmente "paralelizável". Uma desvantagem do Ray Casting é o alto custo computacional, que é $\mathrm{O}\left(\mathrm{n}^{3}\right)$, onde $\mathrm{n}$ é a dimensão do volume, sendo que não existem métodos para rendering em hardware.

Uma outra alternativa para se fazer o rendering volumétrico direto é através da utilização de texturas em uma abordagem conhecida como rendering volumétrico com mapeamento de textura. Esse é o assunto principal do presente trabalho e é tratado no restante do capítulo.

\subsection{O Rendering Volumétrico Direto com Texturas (DVRT)}

O Rendering Volumétrico Direto (DVR) é tradicionalmente realizado pela técnica de lançamento de raios (Ray Casting), vista acima. Convencionalmente, a iteração principal do processamento opera na ordem do raio, isto é, um raio é lançado e são realizadas amostragens, separadas por distâncias fixas, até que tenha atravessado todo o volume de dados. Apenas quando um raio é processado por inteiro que o próximo é iniciado.

É importante notar que resultados idênticos podem ser obtidos se todos os raios forem processados simultaneamente, isto é, a cada ponto de amostragem, acumulam-se opacidades e cores para todos os raios, o que eqüivale dizer que cada ponto posiciona um plano de amostragem. O Ray Casting com projeção ortogonal é equivalente a tomar uma série de cortes paralelos ao plano de visão e compô-los adequadamente. Similarmente, o Ray Casting com projeção perspectiva é equivalente a fazer 
amostragens nas partes interceptadas por esferas concêntricas centradas no ponto de visão (ver figura 3.5). Nas abordagens usando planos paralelos e esferas concêntricas, o processamento segue a ordem das superfícies de amostragem, ou seja, uma superfície de cada vez [Grz98]. O mapeamento de textura para $D V R$ sempre é baseado na ordem das superfícies de amostragem, como é apresentado no restante deste capítulo.
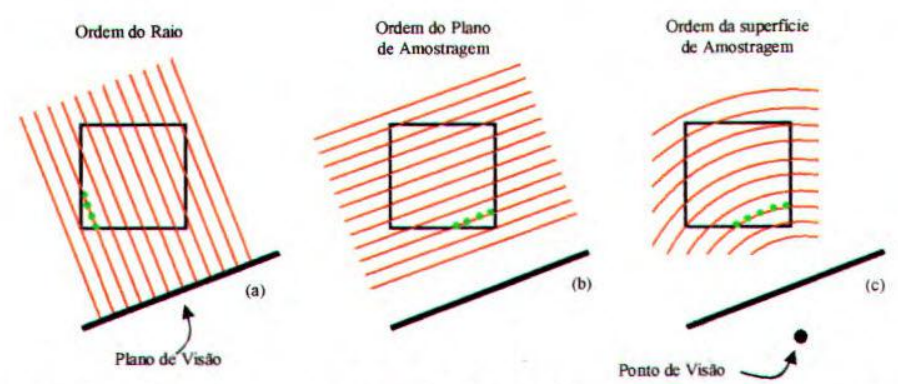

Figura 3.5 - A amostragem no Ray Casting pode ser realizada seguindo a ordem dos raios (a), em planos paralelos (b) ou em esferas concêntricas (c) [Grz98].

$\mathrm{Na}$ teoria, o rendering volumétrico com mapeamento de textura e o Ray Casting têm a mesma complexidade, $\mathrm{O}\left(\mathrm{n}^{3}\right)$ (n é a resolução do volume de dados), e produzem imagens com a mesma qualidade. As duas técnicas amostram o volume inteiro usando interpolação pelo vizinho mais próximo ou trilinear, e combinam as amostragens para formar um valor para o pixel utilizando uma função de blending. Portanto, pode-se ver o rendering volumétrico por mapeamento de textura 3D e por Ray Casting padrão como funcionalmente equivalentes. A principal vantagem de se usar mapeamento de textura é a capacidade de utilização de hardware gráfico para realizar a amostragem e as operações de blending. Além disso, diferenças na imagem resultante para algumas configurações fazem do DVRT uma alternativa útil para analisar no volume aspectos adicionais aqueles apresentados por Ray Casting. Existem vários inconvenientes no uso de hardware gráfico para DVR, pois eles produzem mais artefatos e apenas um número pequeno de raios são permitidos, por problemas de memória. Além disso, técnicas avançadas como tonalização são mais difíceis de serem realizadas. Essas limitações tendem a desaparecer com a evolução do hardware para mapeamento de textura [Sch98].

O mapeamento de textura foi originalmente desenvolvido para imprimir a aparência de materiais do mundo real às superfícies de um objeto geométrico. O mapeamento de textura pode ser visto, simplificadamente, como uma imagem bidimensional (2D) sendo mapeada para a superfície do objeto (ver figura 3.6). O uso de mapeamento de textura requer duas informações básicas: o mapa de textura e as coordenadas de textura. O mapa de textura é a figura a ser mapeada no objeto e as coordenadas de textura especificam a localização, no objeto, onde a figura é mapeada [McR98]. Uma boa referência para entendimento do mapeamento de textura na sua forma convencional é [Ebe98]. 


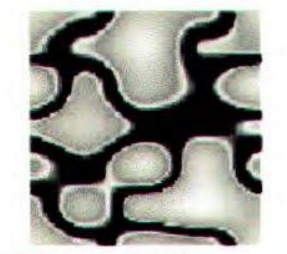

Mapa de Textura
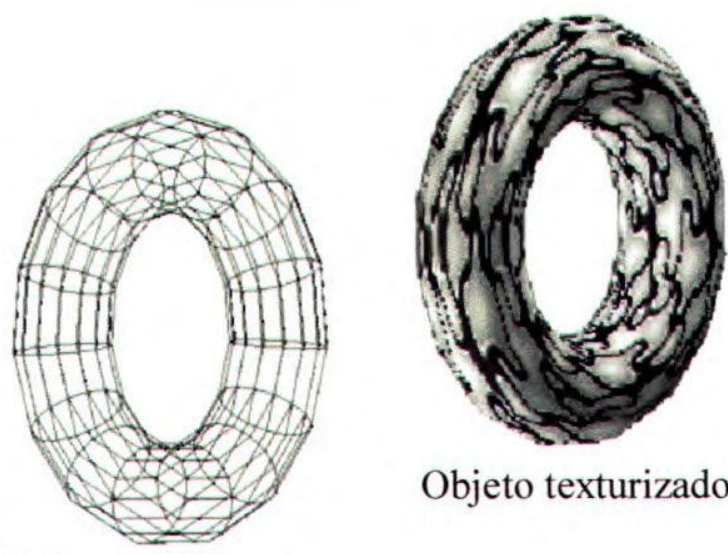

Objeto texturizado

Objeto geométrico

Figura 3.6 - Mapeamento de Textura 2D em um objeto geométrico.

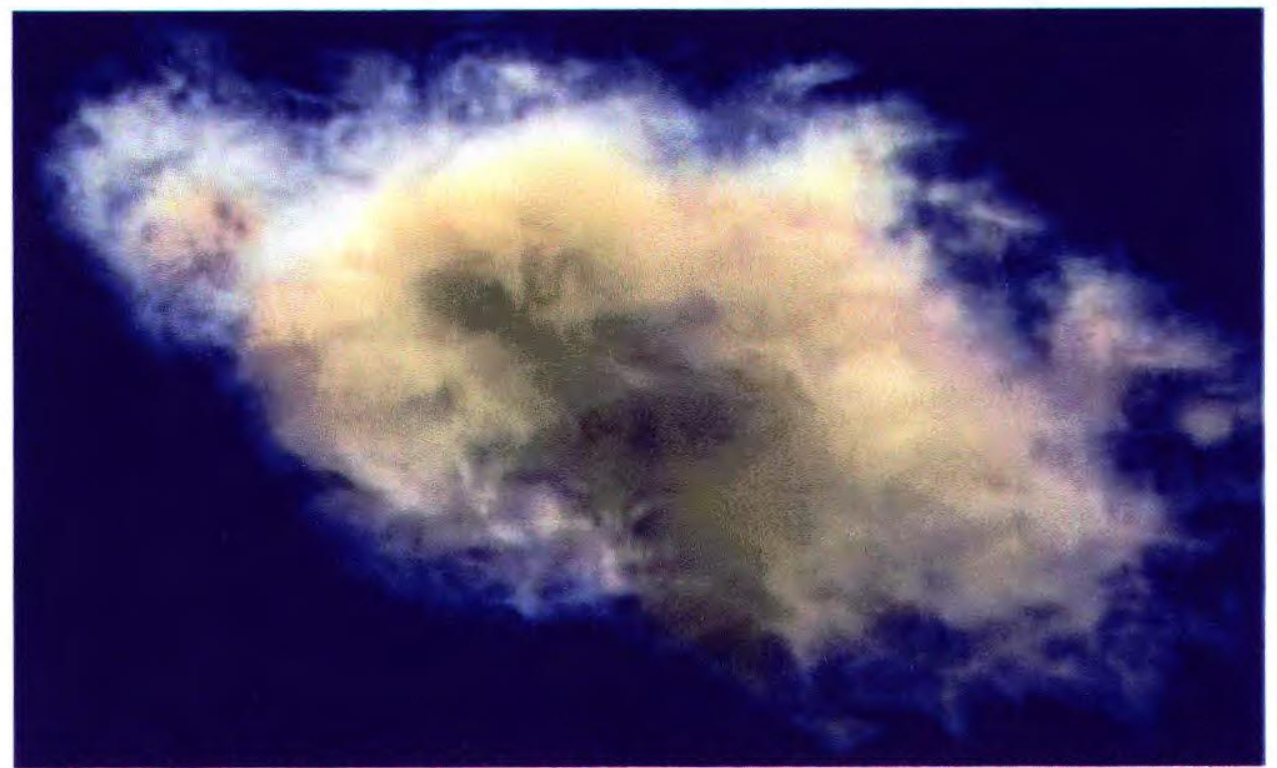

Figura 3.7 - Nuvem conseguida através de textura sólida com funções de efeito [Ebe98].

A textura sólida é uma abordagem tridimensional (3D) para mapeamento de textura. Ela pode ser vista como um espaço 3D de cores que envolve o objeto. Quando a textura sólida é aplicada no objeto, é como se o espaço definido estivesse sendo esculpido no material representado pela textura. Um bom exemplo disso é o uso da textura sólida para criação de objetos feitos de mármore ou madeira. $\mathrm{O}$ espaço da textura sólida define um volume 3D de madeira ou mármore, no qual o objeto é colocado. Funções de ruído e turbulência podem ser empregadas nesse tipo de textura a fim de conseguir efeitos de gazes, e possibilitando a criação de outros objetos dispersos, como nuvens (ver figura 3.7).

Um passo fundamental no processo de mapeamento de textura é determinar como mapear a textura na geometria. Para fazer isso, cada vértice do objeto tem associada uma coordenada de textura. Essa coordenada mapeia o vértice no mapa de textura como pode ser visto na figura 3.8. O sistema de coordenadas de textura usa os parâmetros $(\mathrm{r}, \mathrm{s})$ para especificar valores de textura $2 \mathrm{D}$ e os parâmetros $(\mathrm{r}, \mathrm{s}, \mathrm{t})$ para textura $3 \mathrm{D}$, se for o caso. Pontos entre os vértices são linearmente interpolados para determinar valores do mapa de textura correspondente [Sch98]. 


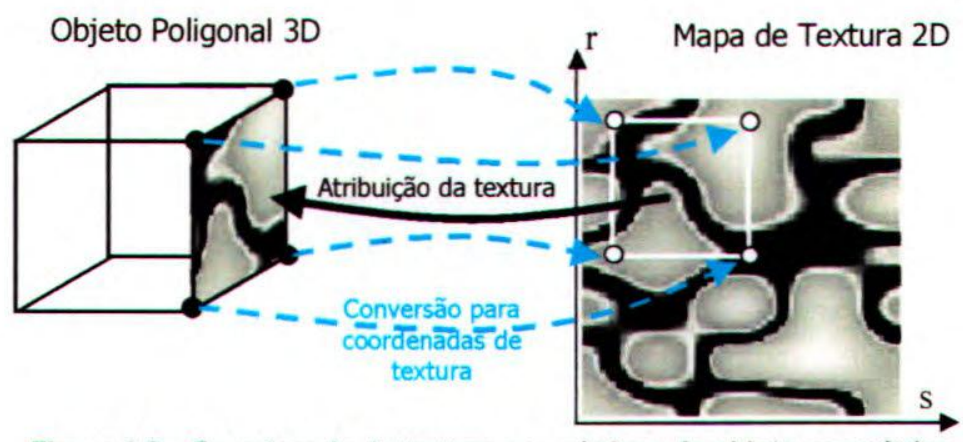

Figura 3.8 - Coordenada de textura nos vértices do objeto geométrico.

Com o amadurecimento desses métodos, o mapeamento de textura encontrou lugar no hardware gráfico, chamando a atenção dos pesquisadores para o seu uso de textura em visualização, e principalmente, no DVR [Cab94].

Nas próximas seções é apresentada uma visão geral do DVRT como também uma descrição detalhada de suas etapas.

\subsubsection{Visão Geral do DVRT}

É comum associar a técnica de DVR com Mapeamento de Textura Volumétrica (Direct Volume Rendering with Texture - DVRT) com o sentido convencional do mapeamento de textura que é o de mapear uma imagem na superfície de objetos, como descrito acima. No entanto, é importante notar que esse conceito não apresenta forte semelhança com a abordagem DVRT. No DVRT uma textura sólida (volumétrica) é construída, a textura volumétrica é então aplicada a vários planos que combinados produzem a imagem final do volume. O nome (DVRT) foi dado porque existe de fato o uso de mapeamento de texturas, mas não no sentido tradicional (2D). Portanto, para que se possa compreender a técnica apresentada a seguir com maior facilidade, é recomendado que não se faça associação direta com o mapeamento de textura 2D tradicional.

A aplicação mais simples de texturas 3D é de um plano de corte. Este plano pode cortar o mapa de textura 3D, correspondente ao volume de dados, em qualquer orientação arbitrária. O polígono planar usado para efetuar o corte apresenta a imagem da fatia do volume, como se uma faca separasse uma parte do volume naquele local. A figura 3.9 apresenta um plano de corte em um volume de dados que contém a densidade da água envolvendo uma molécula de açúcar. O plano de corte corresponde apenas à parte que representa água [Tes95]. A molécula de açúcar foi renderizada por um outro método. 


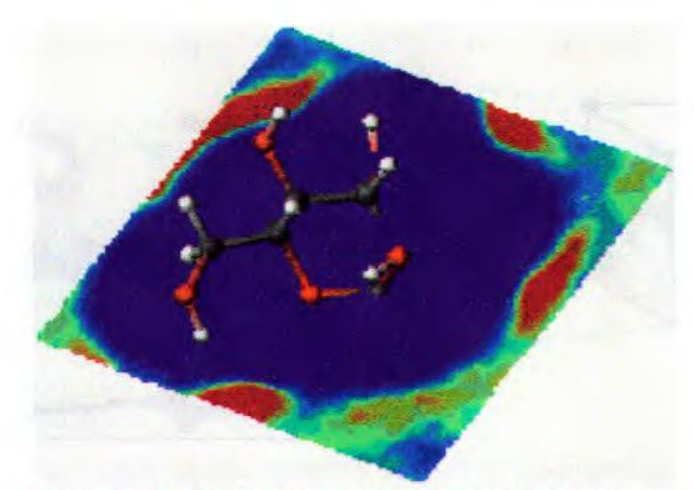

Figura 3.9 - Plano de corte através da densidade da água envolvendo uma molécula de açúcar [Tes95].

O conceito de plano de corte pode ser estendido para objetos de formas variadas. A idéia consiste em sondar uma propriedade volumétrica e apresentá-la nos lugares em que as primitivas geométricas cortem o volume. As primitivas geométricas podem assumir formas variadas como, por exemplo, uma esfera coletando informação sobre a propriedade a uma certa distância de um ponto específico, ou pode ser estendido para descrever uma superfície de um objeto arbitrário. Vários planos de corte podem ser apresentados simultaneamente a fim de promover a visualização do volume de dados inteiro [Tes95].

O algoritmo para Rendering Volumétrico Direto com Mapeamento de Texturas 3D (DVRT) pode ser dividido em 2 etapas: a criação do mapa de textura e de rendering do volume de textura. Uma breve introdução em cada uma dessas partes é apresentada a seguir.

Antes do algoritmo DVRT ser iniciado, o usuário deve fazer a classificação dos dados. A classificação consiste em restringir intervalos de escalares de interesse. Esses intervalos de escalares representam diferentes materiais. Aos materiais são atribuídas cores e opacidades.

O algoritmo inicia com a criação de um mapa de textura 3D, ou volume de textura, que pode ser definido como um volume composto de unidades, análogo ao volume de dados. Cada unidade recebe o nome de texel e armazena valores de intensidade de cor e opacidade (RGBA). O termo cor será usado no decorrer dessa discussão como a união das intensidades de cor (RGB) e da opacidade (A). O mapa de textura é construído a partir do volume de dados a ser visualizado. Um texel do mapa de textura contém a cor corresponde ao escalar presente em um voxel do volume de dados. A conversão de escalares em cores é feita através de funções de transferência (figura 3.10). 


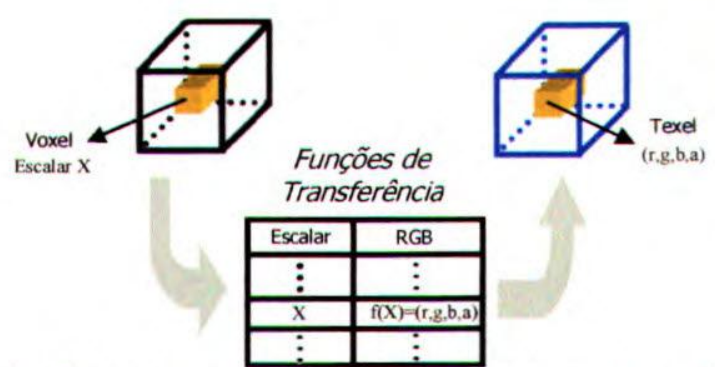

Figura 3.10 - Construção do mapa de textura a partir do volume de dados a ser visualizado.

A função de transferência é uma forma mais geral de LookupTable. Uma função de transferência é qualquer expressão que mapeia valores escalares em especificações de cores. Por exemplo, a figura 3.11 mapeia valores escalares em valores de intensidades separadas para as componentes de cor $\mathrm{R}, \mathrm{G} \mathrm{e}$ B. Pode-se também usar funções de transferência para mapear dados escalares em outras informações, tal como transparência local [Sch98].

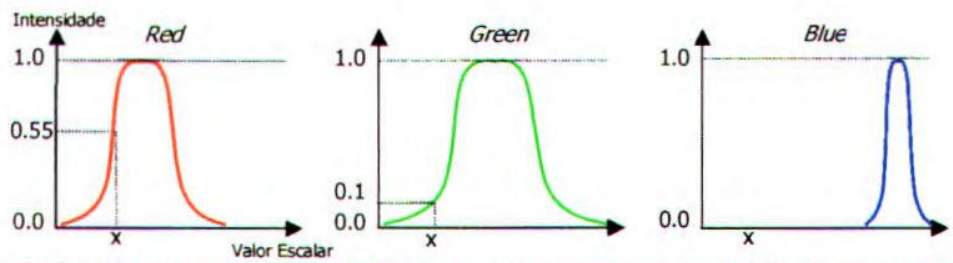

Figura 3.11 - Exemplo de função de transferência para as componentes de cor $R$, $G$ e $B$. As intensidades retornadas para o escalar x são: red $=0.55$, green $=0.1$ e blue $=0.0$.
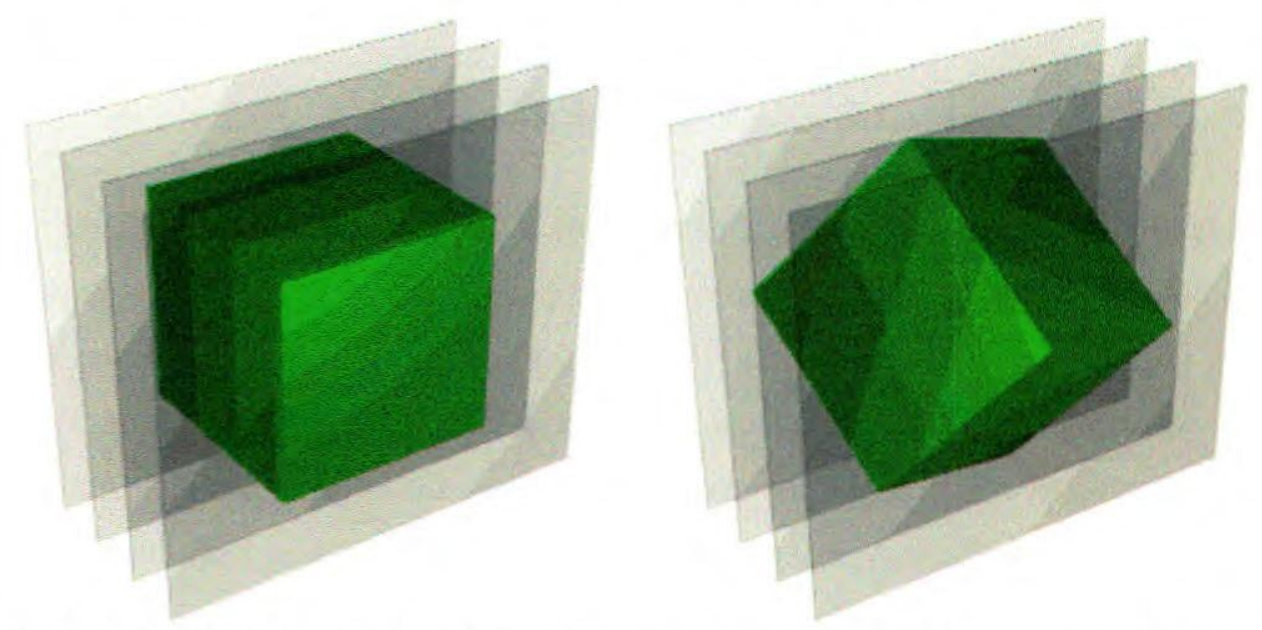

Figura 3.12 - Planos de Amostragem interceptando um Mapa de Textura (em verde) [Gel96].

Uma vez criado o mapa de textura, inicia-se a sua amostragem por meio de planos de amostragem (figura 3.12). Eles são dispostos paralelamente entre si e perpendiculares à direção de visão. Cada plano de amostragem tem por finalidade colher informações de cor no mapa de textura. Após o processo de amostragem, cada plano possui a imagem (textura) relativa à posição do corte no mapa de textura. A região do plano de amostragem que intercepta o mapa de textura recebe o nome de polígono de textura.

Após a texturização dos planos de amostragem, suas imagens devem ser combinadas a fim de gerar a imagem do volume presente no mapa de textura, num processo denominado blending. A combinação 
das imagens dos planos é feita atrãués de um operador de blending. A imagem final resultante da combinação de todos os planos de amostragem corresponde à imagem $3 \mathrm{D}$ do volume em análise, encerrando assim o processo de DVRT.

O algoritmo acima pode ser modificado para que se possa gerar imagens levando em consideração luz direcional, apresentando assim efeitos de reflexão. Essa alteração acontece na etapa de criação do mapa de textura. A etapa de rendering permanece inalterada.

Na construção do mapa de textura levando-se em consideração a interação com luz direcional, a cor de um texel pode sofrer influência das luzes presentes na cena. Para que aconteça a construção do mapa de textura é necessário ter, para cada voxel, o escalar, o gradiente e a classificação do voxel (ambiente ou refletor). Os escalares já estão presentes no próprio volume de dados. Os gradientes, que são vetores que aproximam a normal à superfície, podem ser obtidos através da análise da vizinhança dos voxels. Um vetor gradiente $\partial$ para um voxel de posição $(x, y, z)$ pode ser obtido por:

$$
\begin{aligned}
& \partial x=d(x+1, y, z)-d(x-1, y, z) / 2 \Delta x \\
& \partial y=d(x, y+1, z)-d(x, y-1, z) / 2 \Delta y \\
& \partial z=d(x, y, z+1)-d(x, y, z-1) / 2 \Delta z
\end{aligned}
$$

onde $d(x, y, z)$ é o escalar do voxel de posição $(x, y, z)$ e $\Delta$ o espaçamento entre voxels.

A classificação dos voxels consiste em determinar se ele é refletor ou ambiente. Um voxel é classificado como refletor quando ele deve sofrer influência das luzes direcionais presentes na cena. São esses os voxels que pertencem à região de fronteira dos materiais no volume sendo visualizados. Um voxel é classificado como ambiente quando ele não deve interagir com as luzes direcionais, ou seja, são aqueles presentes no interior dos materiais sendo visualizados. Dessa forma, faz-se necessário que o volume de dados sofra um pré-processamento para obtenção dos gradientes quantizados e da classificação de cada voxel como refletor ou ambiente.

Quando o voxel já possui as três informações necessárias (escalar, gradiente e classificação), o mapa de textura pode ser criado. Se um voxel for classificado como ambiente, o seu texel correspondente recebe a cor (rgba) retornada pelas funções de transferência. Isso ocorre porque os voxels ambientes não interagem com as luzes direcionais. Quando o voxel for classificado como refletor, seu texel correspondente recebe a cor das funções de transferência (RGBA) somada às componentes de reflexão difusa e especular. Os cálculos dessas componentes de reflexão podem sér tabelados para agilizar a criação do mapa de textura. A figura 3.13 apresenta a construção do mapa de textura levando-se em consideração luz direcional. 


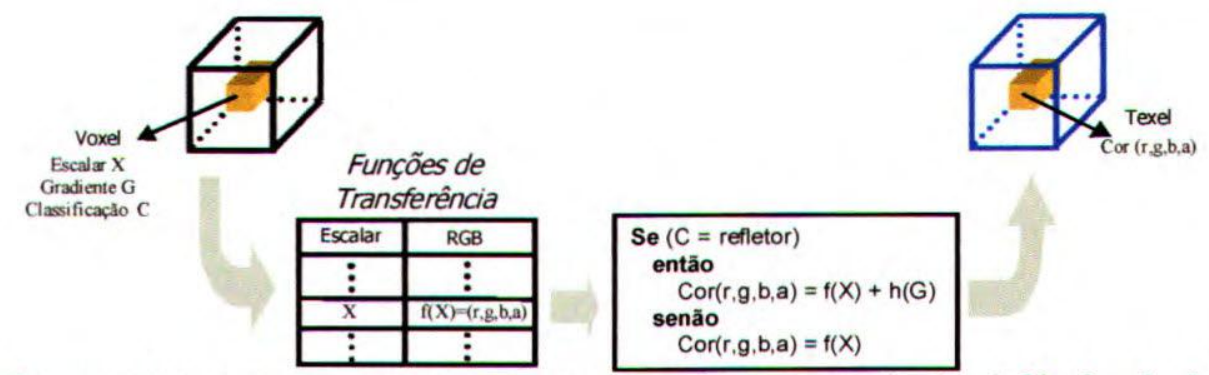

Figura 3.13 - Construção do mapa de textura levando-se em consideração luz direcional, $f$ é a função de transferência e $h$ a função que retorna as componentes de reflexão para um dado gradiente.

A criação do mapa de textura tem várias partes, as quais são ativadas por diferentes eventos. A classificação de voxels acontece quando a função de transferência ou os parâmetros dos gradientes mudam. A tabela de reflexão é recalculada quando os parâmetros de iluminação mudam ou quando a direção de visão muda. $\mathrm{O}$ mapa de textura é preenchido sempre que qualquer um dos eventos citados acima acontece. Isso faz com que o algoritmo com luz direcional fique consideravelmente mais caro se comparado com o sem tonalização.

\subsubsection{O DVRT Bidimensional}

Se o volume de dados for visto como uma pilha de fatias, um conjunto de texturas 2D pode substituir diretamente as imagens do volume. Ou seja, uma textura correspondendo a uma camada de voxels. Para cada volume de dados são gerados três conjuntos de mapas de texturas $2 \mathrm{D}$, cada conjunto sendo perpendicular a um dos 3 eixos que definem o mapa de textura. $O$ conjunto de texturas escolhido para o rendering deve ser sempre o que mais se aproxima perpendicularmente à direção de visão escolhida. No pior caso, as fatias de dados estão inclinadas $45^{\circ}$ em relação a direção de visão. A figura 3.14 apresenta as configurações possíveis dos planos de amostragem para o DVRT 2D.
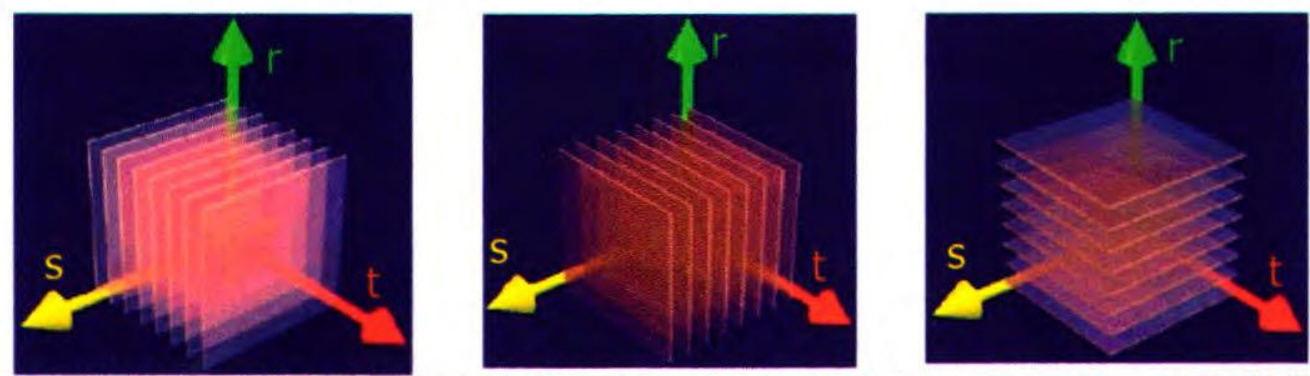

Figura 3.14 - Planos de amostragem posicionados nas três possiveis configurações para DVRT 2D.

Quando um conjunto de texturas é escolhido, ele deve ser renderizado seguindo a ordem de trás para frente (do mais distante ao mais próximo ao observador). Alternativamente, os planos de amostragem que estiverem entre os pontos centrais dos voxels podem ser texturizados por um procedimento de duas passagens, isto é, o plano é renderizado duas vezes. A cada passagem, faz-se a texturização de uma das duas camadas de voxels mais próximas e sua filtragem com um fator apropriado de pesagem linear. Desse modo, os frames podem ser obtidos mesmo se as estações gráficas não suportarem interpolação em terceira dimensão [Tes95]. 
O DVRT 2D produz imagens com menor qualidade visual que o DVRT 3D. Como pode ser observado na discussão acima, na versāo $3 \mathrm{D}$ os planos de amostragem devem estar sempre perpendiculares à direção de visão. O problema com o DVRT 2D é que os planos de amostrăgem do mapa de textura não podem estar sempre perpendiculares à direção de visão.

Os passos para a apresentação de um volume usando texturas $2 \mathrm{D}$ podem ser resumidos da seguinte forma [McR98]:

1. Gerar os três conjuntos de texturas $2 \mathrm{D}$ do conjunto de dados. Cada conjunto é perpendicular a um dos principais eixos do volume de dados.

2. Escolher o número de fatias para amostragem.

3. Encontrar o ponto de visão e a direção de visão desejados.

4. Encontrar o conjunto de texturas 2D que estiver mais perpendicular à direção de visão. Gerar os polígonos de dados de forma a estarem paralelos ao conjunto de texturas 2D escolhido. Usar as coordenadas de textura para texturizar os polígonos adequadamente.

5. Usar a matriz de transformação de textura para estabelecer a orientação desejada das imagens texturizadas nas fatias.

6. Renderizar cada fatia como um polígono texturizado, de trás para frente. O operador de blending é executado em cada fatia; o tipo de blending depende do efeito desejado.

7. Quando o ponto de visão ou a direção de visão muda, deve-se re-computar as posições das fatias de dados e atualizar a matriz de transformaçăo de textura conforme necessário.

O algoritmo DVRT implementado neste trabalho de mestrado é o DVRT 3D e suas etapas são apresentadas com maiores detalhes na próxima seção. 


\subsection{Detalhando as Etapas do DVRT}

As etapas de construção do mapa de textura e de rendering do mapa de textura para o DVRT incorporando luz direcional são detalhadas, respectivamente, nas próximas subseções[Gel96].

\subsubsection{Criação do Mapa de Textura}

Tanto o volume de dados quanto o mapa de textura são malhas volumétricas. Cada voxel presente no volume de dados possui um texel correspondente no mapa de textura. As cores (rgba) presentes nos texels correspondem à soma das componentes de luz refletida e ambiente. A componente de luz ambiente é baseada no modelo tradicional "gás luminoso", usado no DVR [Gel96]. A componente de luz refletida representa uma superfície respondendo à luz direcional e só se aplica aos voxels pertencentes às fronteiras dos materiais do volume sendo visualizados.

\subsubsection{A componente de Luz Ambiente}

Imaginando-se que entre cada dois planos de amostragem consecutivos passasse um fatiador, o mapa de tex tura poderia ser visto como um conjunto de fatias, sendo que no centro de cada fatia se encontra um plano de amostragem. Isto significa que cada plano deve contribuir com intensidade de cor e opacidade adequados para tal fatia. A espessura de toda fatia, $\Delta$, é justamente a distância do primeiro ao último plano de amostragem dividida pelo número de planos. Seja $E(r g b)$ a emissão de cor por unidade de distância e $A_{1}$ a opacidade por unidade de distância. Esses valores são computados para cada voxel do volume de dados que deve ser visualizado. A cor $C(p)$ e opacidade $A$ que devem ser atribuídas aos texels do mapa de textura como componentes de luz ambiente são computados pelas fórmulas [Gel96]:

$$
\begin{gathered}
\alpha=\ln \left(\frac{1}{1-A_{1}}\right) \\
C(p)=E(p)\left(\frac{1-e^{-\alpha \Delta}}{\alpha . \Delta}\right) \\
A=1-\alpha^{-\alpha \Delta}
\end{gathered}
$$


Essas equações expressam a integração de cor e opacidade através da espessura da fatia, sem considerar o modelo de tonalização, e é aplicada tanto aos voxels classificados como ambientes quanto ao refletores.

Quando um voxèl 'é classificado como ambiente isso implica que o seu texel correspondente receberá a cor da componente de luz ambiente. Essa componente é calculada pela multiplicação da cor obtida da função de transferência pelo coeficiente de luz ambiente no material. Quando o voxel é classificado como refletor a cor do texel será a soma das componentes de luz ambiente e refletida.

O vetor gradiente de densidades, além do uso na etapa de classificação, é fundamental na estimativa da normal à isosuperfície que passa em determinado voxel onde a luz refletida deve ser considerada. Esses vetores são utilizados na versão do DVRT com de iluminação volumétrica direcional e podem ser indexados através de um Índice de Gradientes. O Índice de Gradientes é apresentado a seguir.

\subsubsection{O Índice de Gradientes}

Os gradientes calculaḍos para cada voxel do volume de dados podem ser aproximados (quantizados) e tabelados por um Índice de Gradientes. Sua utilidade é evitar que a tonalização seja calculada apenas uma vez para gradientes considerados próximos, como será visto no decorrer do capítulo. Esse Índice de Gradientes consiste em uma tabela contendo um número finito de gradientes unitários. A tabela é construída a partir do refinamento recursivo de uma esfera de raio unitário. Os vetores são tomados a partir do centro na direção dos pontos da superfície da esfera.

O processo de refinamento inicia-se a partir de um icosaedro (12 pontos formando 20 triângulos equiláteros). Um passo de refinamento gera quatro novos triângulos para cada triângulo presente na esfera (ver figura 3.15). Para isso cada aresta (por exemplo $A B$ ) deve ser dividida em duas (por exemplo $\mathrm{AC}$ e $\mathrm{BC}$ ), gerando assim um novo ponto (C). Esse novo ponto corresponde ao vetor (OC, sendo $O$ é o centro da esfera) obtido pela soma dos vetores relativos aos pontos da extremidade da aresta e sua normalização $(\mathrm{OC}=|\mathrm{OA}+\mathrm{OB}|)$. $\mathrm{O}$ processo de refinamento pode ser observado na figura 3.16.

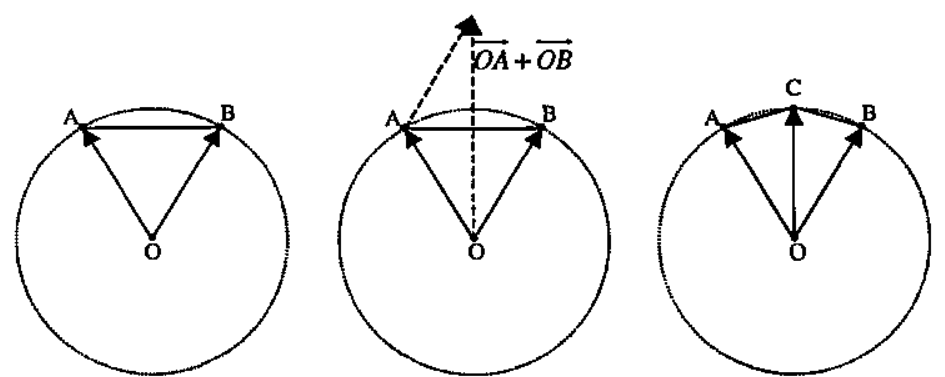

Figura 3.15 - O refinamento de uma aresta da esfera. $A$ aresta $A B$ é dividida em $A C$ e $C B$. 


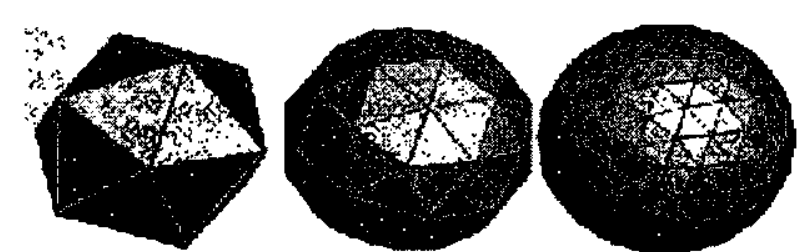

Figura 3.16 - O processo de refinamento em dois nivels de uma esfera (icosaedro) para geração do lndice de Gradientes [Woo97].

Seja $k$ o nível de refinamento da esfera. O número $(G)$ de gradientes unitários presentes no índice (ou seja, o número de pontos na superfície da esfera ) é dado pela seguinte função:

$$
G=10 * 4^{k}+2
$$

Cada vetor do Índice de Gradientes é utilizado para calcular uma componente de luz refletida. Essa componente é armazenada em uma Tabela de Reflexão.

\subsubsection{A Componente de Luz Refletida e a Tabela de Reflexão}

Para se obter a componente de luz refletida, é necessário obter o vetor gradiente de cada voxeI, como também os vetores direcionais das luzes presentes na cena com suas respectivas cores e o vetor de direção de visão.

Os cálculos da tonalização são baseados na discretização dos gradientes do volume de dados pelo Índice de Gradientes, visto na seção anterior. Para que seja obtida a componente da luz refletida para um voxel classificado como refletor, o vetor gradiente desse voxel recebe um índice $(g)$. Esse índice referencia a entrada do Índice de Gradientes que contém o vetor unitário cuja direção mais se aproxima à do gradiente em questão. $O$ índice $(g)$ com um material $(m)$ são utilizados para obter a componente de luz refletida presente em uma tabela denominada Tabela de Reflexão. Essa tabèlà armazena a cor (rgb) relativa à interação das luzes direcionais presentes na cena com cadá gradiente do Índice de Gradientes, combinado com um material. Dessa maneira, a quantidade de entrádas da Tabela de Reflexão é justamente o número de gradientes do Índice de Gradientes multiplícado pela quantidade de materiais especificados pelo usuário (ver figura 3.17). A utilização do Índice de Gradientes e da Tabela de Reflexão é feita com o intuito de economizar computação no momento de construção do mapa de textura, evitando que seja necessário fazer os cálculos da componente de luz refletida para cada voxel refletor. 


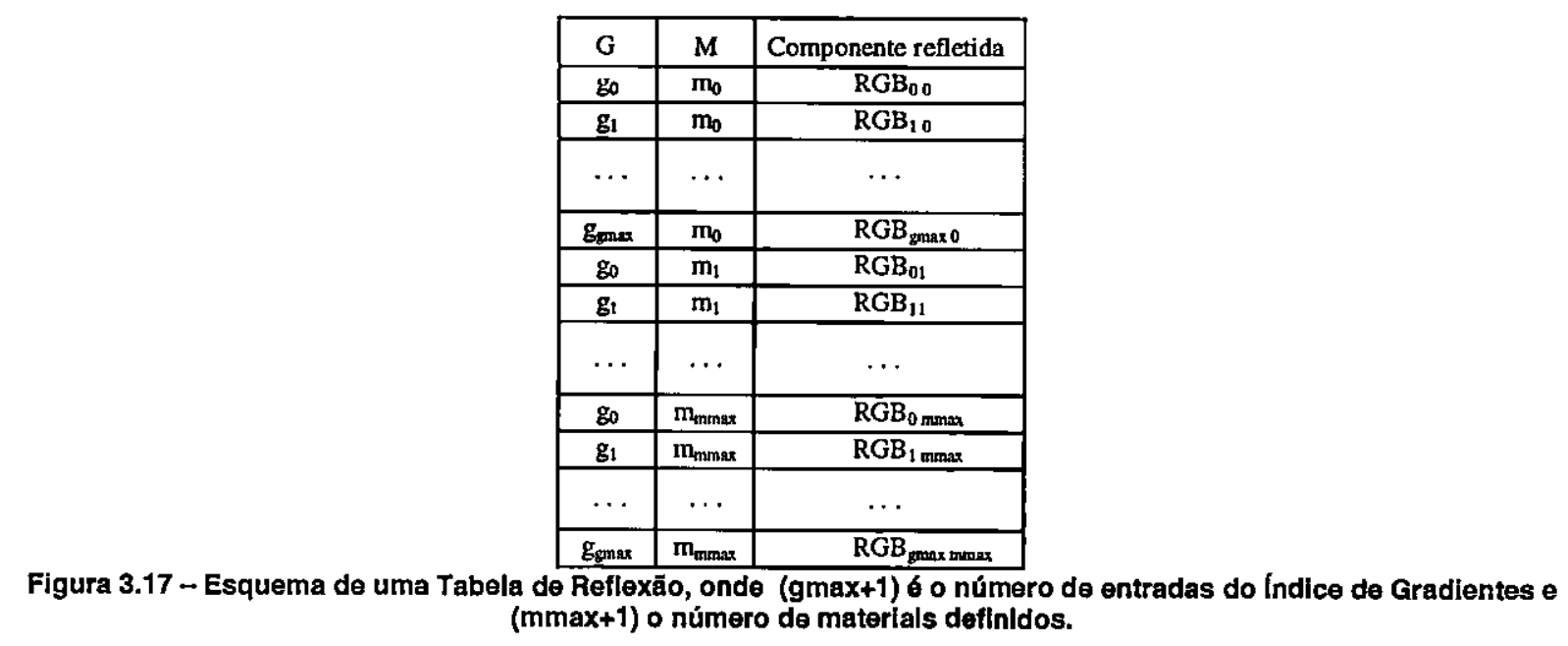

A componente de luz refletida é formada pela composição de dois tipos de reflexão a difusa e a especular [CG 98].

A lei dos co-senos de Lambert governa a reflexão de uma luz proveniente da fonte de luz por uma superfície idealmente difusa. Essa lei determina que a intensidade da luz refletida por uma superfície idealmente difusa é proporcional ao coseno do ângulo entre a direção da luz incidente e a normal à superfície. Especificamente,

$$
\mathrm{I}=\mathrm{I}_{1} \mathrm{k}_{\mathrm{d}} \cos \theta \quad 0 \leq \theta \leq \pi / 2 \quad \text { (equação 3.1) }
$$

onde $I$ é a intensidade da luz refletida, $I_{l}$ é a intensidade da luz emitida pela fonte e incidente à superfície, $K_{d}\left(0 \leq K_{d} \leq 1\right)$ é a constante de difusão da superfície e $\theta$ é o ângulo entre a direção da luz incidente $\mathbf{L}$ e a normal à superfície $\mathbf{N}$ (figura 3.18). $\mathrm{O}$ coeficiente $K_{d}$ depende do material e do comprimento de onda da luz incidente. Entretanto, para modelos de iluminação simples, pode ser assumido como sendo constante. O termo $\cos \theta$ pode ser substituído pelo produto escalar $\mathbf{N}$. L.

A equação que governa a reflexão especular é a equação de Fresnel, que afirma que a reflexão especular da luz é direcional. Para uma superfície idealmente especular, o ângulo de reflexão será igual ao ângulo de incidệncia e toda energia refletida será na direção do raio refletido (R). Isso implica que o vetor de visão $\mathbf{S}$ é coincidente com o vetor de reflexão $\mathbf{R}$; isto é, o ângulo $\alpha$ é zero. Porém, para superfícies em geral a luz é refletida em todas as direções de um modo não uniforme e aleatório, com intensidade dependendo do ângulo do raio incidente (figura 3.18). 


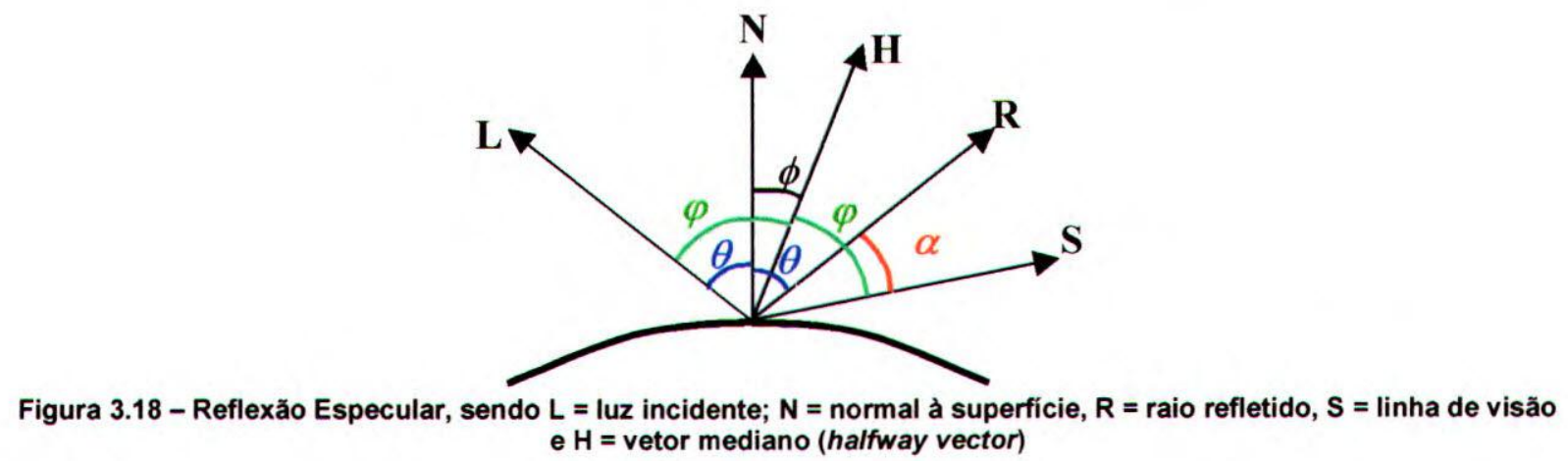

A reflexão especular é direcional, isto é, depende do ângulo com que a luz incidente atinge a superfície e é dada pela seguinte equação:

$$
\mathrm{I}_{\mathrm{S}}=\mathrm{I}_{1} \cdot \mathrm{k}_{\mathrm{s}} \cos ^{\mathrm{n}} \alpha \quad 0 \leq \alpha \leq \pi / 2 \quad \text { (equação 3.2) }
$$

onde $\mathrm{K}_{\mathrm{s}}\left(0 \leq \mathrm{K}_{\mathrm{s}} \leq 1\right)$ é o coeficiente especular da superfície e $n$ é o parâmetro de reflexão especular que é responsável pelo brilho da superfície sendo apresentada. Quanto maior o valor de $n$ mais intenso é o brilho da superfície.

Como $\mathbf{S}$ e $\mathbf{R}$ são vetores unitários, $\cos \alpha$ pode ser substituído pelo produto escalar R.S. O vetor $\mathbf{R}$ pode ser obtido pela equação: $\mathbf{R}=(2 \mathbf{N}$. L $) \mathbf{N}-\mathbf{L}$. Um modelo um tanto simplificado pode ser obtido através do uso do vetor mediano (halfway vector) $\mathbf{H}$ entre os vetores $\mathbf{L}$ e $\mathbf{R}$. A simplificação se dá na substituição do $\cos \alpha$ por N.H, ou seja do $\cos \alpha$ pelo $\cos \phi$. Dessa forma a equação 2 fica da seguinte forma:

$$
\mathrm{I}_{\mathrm{s}}=\mathrm{I}_{1}, \mathrm{k}_{\mathrm{s}}(\mathbf{N} \cdot \mathbf{H})^{\mathrm{n}} \quad \text { (equação 3.3) }
$$

Combinando os resultados obtidos anteriormente pelas equações 1 e 3 , tem-se um modelo de iluminação dado pela equação:

$$
I_{s}=I_{l}\left(k_{d}(\mathbf{N} . \mathbf{L})+k_{s}(\mathbf{N} \cdot \mathbf{H})^{n}\right) \quad \text { (equação 3.4) }
$$

Se múltiplas fontes de luz estiverem presentes, os efeitos são linearmente adicionados e o modelo de iluminação torna-se:

$$
I_{s}=\sum_{j=1}^{m} I_{l_{j}}\left(K_{d}(N . L)_{j}+K_{s}(N . H)_{j}^{n}\right) \quad(\text { equação 3.5) }
$$

Os valores de cor (rgb) obtidos pela equação acima são armazenados na Tabela de Reflexão. A equação 3.5 é aplicada a cada componente R, G e B da cor. Observe que a equação 5 é dependente da direção de visão ( $\mathbf{R}$, necessária para calcular $\mathbf{H}$ ), da normal à superfície ( $\mathbf{N}$, no caso, um gradiente) e da classificação do material $\left(\mathbf{K}_{\mathbf{d}}, \mathbf{K}_{\mathbf{s}}\right.$ e $\left.\mathbf{n}\right)$. Por isso a Tabela de Reflexão deve ser calculada para cada 
direção de visão e indexada por um gradiente e um material. Os valores presentes nessa tabela só são aplicados aos voxels que forem classificados como refletores.

\subsubsection{Classificação dos Voxels Refletores}

Um voxel é classificado como refletor quando ele está na fronteira de um material sendo visualizado. A classificação se dá levando em conta o valor do escalar, o gradiente do voxel, e o intervalo de escalares que formam o material onde o voxel está presente.

Seja $d$ o valor escalar presente no voxel sendo analisado e $b$ o valor inferior da extensão de escalares do mesmo material de $d$. Seja $\Delta$ o espaçamento inter-voxels. Um dos 26 voxels vizinhos possui escalar menor que $b$ se e somente se $(d-b)<S$, onde

$$
S=\Delta_{x}\left|\gamma_{x}\right|+\Delta_{y}\left|\gamma_{y}\right|+\Delta_{z}\left|\gamma_{z}\right|
$$

o valor $S$ é chamado de deslocamento do escalar na diagonal da célula. Um teste similar pode ser realizado para o limite superior $a$ do mesmo material de $d$, usando $(a-d)<S$.

Quando $S$ está próximo do valor de $(d-b)$ ou $(a-d)$ pode-se determinar a probabilidade de estar na fronteira do material, ao invés de se fazer uma decisão binária. Quando $S \leq 0.5(d-b)$, a probabilidade é zero e aumenta linearmente- para 1 quando $S \geq 1.5(d-b)$. É possível fazer um ajuste fino na classificação dos voxels através dos fatores de escala (0.5 e 1.5), causando o aumento ou diminuição da camada de voxels que são considerados de fronteira.

Quando um voxel é de fronteira, o seu texel correspondente deve receber cor (rgba) levando-se em consideração a luz direcional. Para isso, o índice do gradiente, previamente relacionado ao voxel, deve ser obtido para que a cor presente na tabela de reflexão seja conseguida. Essa cor deve ser combinada com a componente de luz ambiente do voxel para então ser atribuída ao texel. 
Antes da criação do mapa de textura utilizando tabela de reflexão é necessário algum préprocessamento, onde:

- Índice de Gradientes é gerado dado um nível de refinamento.

- A tabela de reflexão é calculada dada uma configuração da cena, um Índice de Gradiente e as definições de materiais.

- Os vetores gradientes do volume de dados são calculados por diferenças centrais.

- Os vetores gradientes do volume de dados são indexados de acordo com o Índice de Gradientes, o que evita que o gradiente de um voxel seja aproximado pelo Índice de Gradientes mais de uma vez.

Realizado o pré-processamento, a figura 3.19 apresenta um esquema representativo da criação do mapa de textura onde cada voxel do volume de dados deve ser processado. O escalar presente em um voxel é analisado para determinar se o voxel deve ou não ser visualizado. Essa análise consiste em verificar se o escalar pertence a algum material especificado pelo usuário. Se o escalar não pertencer a qualquer material, o texel correspondente ao voxel em processamento recebe uma cor transparente. Caso o escalar seja visível, o voxel deve ser visualizado e portando a componente de luz ambiente já pode ser obtida por meio da função de transferência. Essa componente ainda não pode ser atribuída ao texel porque o voxel ainda pode ser classificado como refletor. Essa classificação do voxel em refletor ou ambiente se dá levando-se em conta o escalar presente no voxel e o seu gradiente. Se o voxel for classificado como ambiente, a componente de luz ambiente, já calculada, pode ser atribuída ao texel. Caso o voxel seja refletor, a componente de luz refletida deve ser obtida e somada à ambiente. A componente de luz refletida é dependente do gradiente do voxel, por isso, o índice desse gradiente, já calculado, é obtido. Esse índice e o material do voxel em questão compõem a componente de luz refletida da tabela de reflexão. Nesse ponto as componentes de luz refletida e ambiente (já calculadas) podem ser somadas e a cor resultante atribuída ao texel no mapa de textura. Quando todos os voxel tiverem sido classificados e seus texels correspondentes possuidores de cor, o mapa de textura está pronto para ser renderizado. 


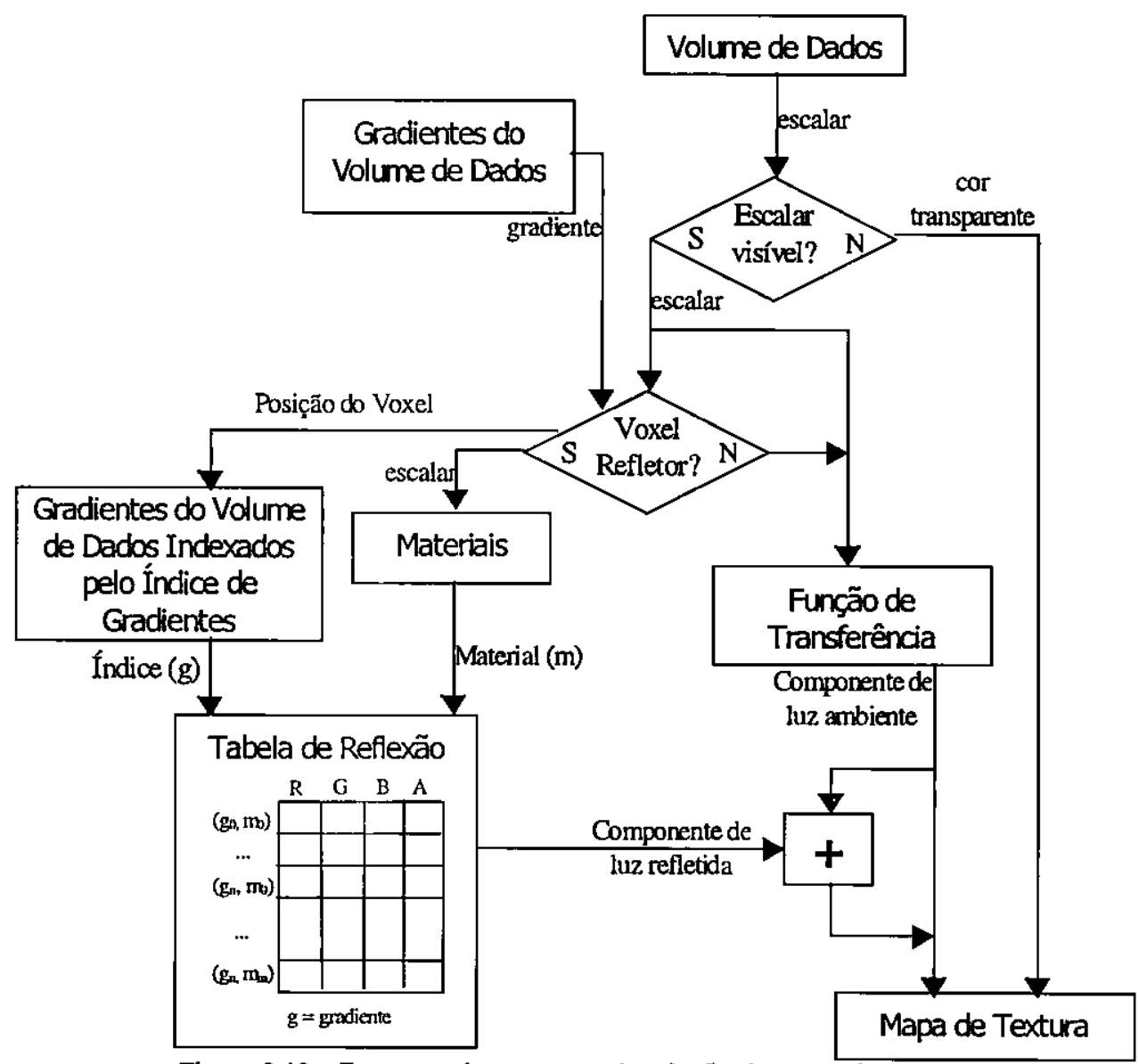

Figura 3.19 - Esquema do processo de criação do mapa de textura. 


\subsubsection{Rendering do Mapa de Textura}

Uma vez criado o mapa de textura, ele deve ser amostrado para que então ocorra o rendering. A amostragem consiste em aplicar a textura presente no mapa de textura a um conjunto de planos de amostragem paralelos entre si e perpendiculares à direção de visão.

Os planos de amostragem são limitados por um bounding cube tal que possa conter inteiramente o mapa de textura em qualquer rotação. Por esse motivo o comprimento da aresta do bounding cube deve ser igual ao da diagonal do volume de textura. Os planos de amostragem são definidos dentro do bounding cube e são paralelos à sua face frontal (figura 3.20).

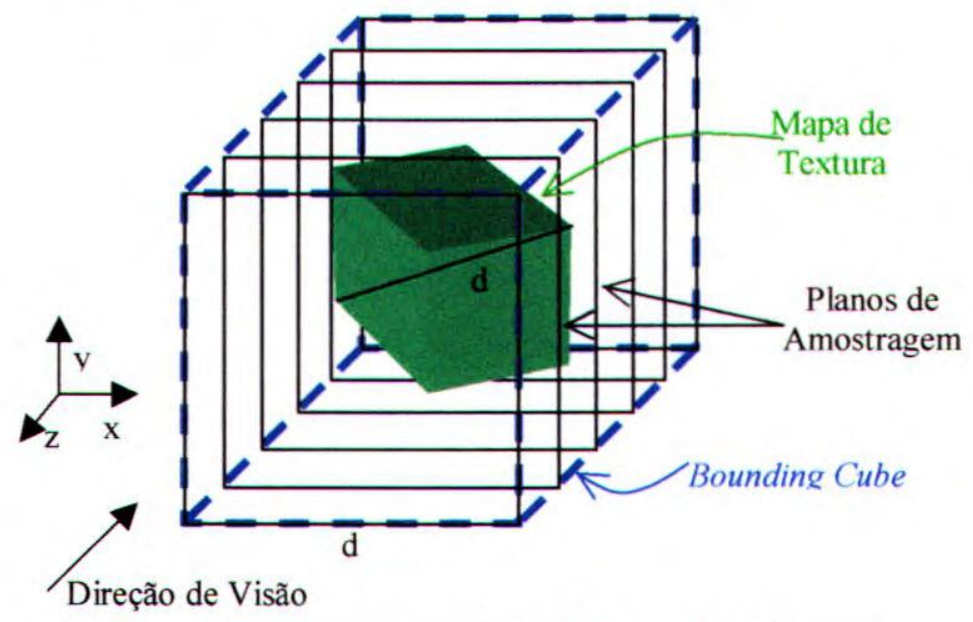

Figura 3.20 - Bounding cube com 6 planos de amostragem.

Sempre que ocorre algum deslocamento ou rotação da câmera o bounding cube deve ser reposicionado para que sua face frontal permaneça perpendicular à direção de visão, o que garante que os planos de amostragem também permaneçam.

Como os planos de amostragem são perpendiculares à direção de visão, eles delimitam uma região quadrada da tela (display). Amostrar, ou texturizar, os planos, significa obter do mapa de textura informações de cor e opacidade para cada pixel da região coberta na tela. Assim, os planos de amostragem podem ser vistos como uma grade, onde cada nó corresponde a um pixel da tela (figura $3.21)$.

Quanto maior o número de amostragens no mapa de textura por pixel melhor a qualidade da imagem e maior é o custo computacional. Deve-se, portanto, chegar a um acordo quanto ao número de amostragens que devem ser feitas para cada "pixel" do plano de amostragem. Em geral, uma amostragem por pixel é suficiente. 


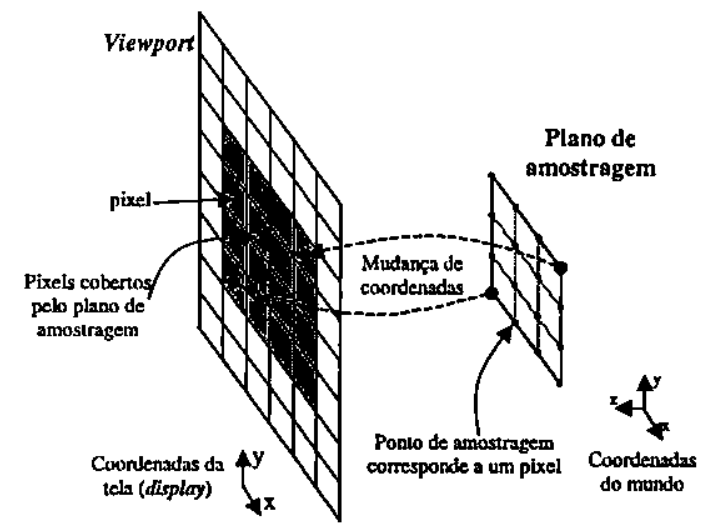

Figura 3.21 - Correspondência entre o plano de amostragem e a tela (display).

O bounding cube e os planos de amostragem são definidos no sistema de coordenadas do mundo, ou seja, no sistema de coordenadas onde estão posicionados a câmera, as luzes e o mapa de textura. No mapa de textura existe o sistema de cọordenadas de textura, e é nesse sistema que estão dispostas as informações rgba. Os pixel da tela estão dispostos segundo o sistema de coordenadas da tela (display). Sendo assim, no processo de texturização dos planos de amostragem, existem 3 sistemas de coordenadas distintos em evidência, pois um pixel da tela (coordenada" da tela) deve ser pintado por uma cor presente no mapa de textura (coordenada de textura) por meio de um plano de amostragem (coordenada do mundo).

Para definir quantos pixels são cobertos por um plano de amostragem, é necessário transformar, do sistema de coordenadas do mundo para as da tela, as duas coordenadas da diagonal da face frontal do bounding cube. A diferença na coordenada $\mathrm{x}$ fomece o número de pixels na horizontal $\mathrm{n}_{\mathrm{x}} \mathrm{e}$ na coordenada y os pixels na vertical $n_{y}$.

Com os pontos que definem cada plano de amostragem deve-se calcular os vetores de incremento, $\Delta x$ e $\Delta y$ (ver figura 3.22). Esses vetores são utilizados na obtenção dos pontos de amostragem no plano. Eșses vetores são obtidos da seguinte forma:

$$
\begin{aligned}
& \Delta \mathrm{x}=(\mathrm{C}-\mathrm{B}) /\left(\mathrm{n}_{\mathrm{x}}-1\right) \\
& \Delta \mathrm{y}=(\mathrm{B}-\mathrm{A}) /\left(\mathrm{n}_{\mathrm{y}}-1\right)
\end{aligned}
$$

onde $\mathrm{A}$ (ponto superior/esquerdo), B (ponto inferior/esquerdo) e C (ponto inferior/direito) são pontos que definem o plano de amostragem e $n_{x}$ e $n_{y}$ o número de amostragens na direção horizontal e vertical do plano respectivamente. $O$ ponto inicial das amostragens $\left(P_{\text {inicial }}\right)$ é o inferior esquerdo (B). Qualquer outro ponto de amostragem do plano pode ser obtido pela soma de vetores $\Delta \mathrm{x}$ e $\Delta \mathrm{y}$ às coordenadas do ponto $P_{\text {inicial. }}$ 


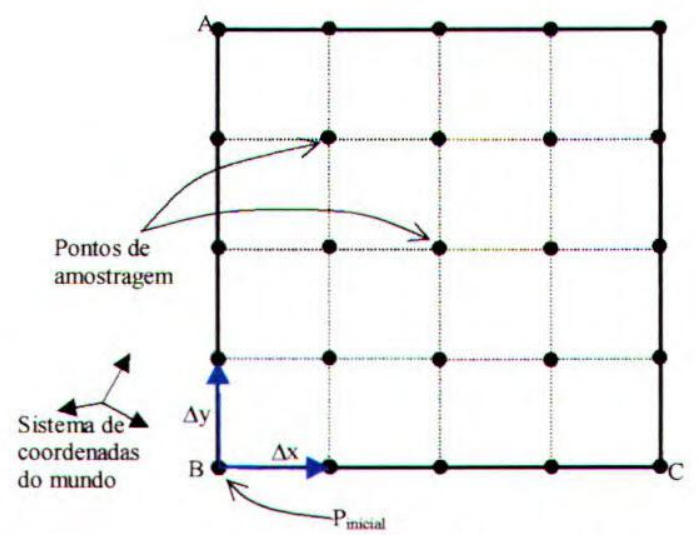

Figura 3.22 - Um plano de amostragem com apresentação dos pontos de amostragem.

Conceitualmente, a parte de um plano de amostragem que intercepta o volume de textura recebe o nome de polígono de textura. Para cada plano de amostragem, os pontos que definem o polígono de textura são obtidos através da interseção do plano de amostragem com o volume de textura. Os polígonos de textura são importantes para se restringir a região do plano onde se deve fazer amostragens. As regiões dos planos que não pertencem aos polígonos recebem cores completamente transparentes. A figura 3.23 apresenta um conjunto de polígonos, já texturizados, referentes a um volume de dados.

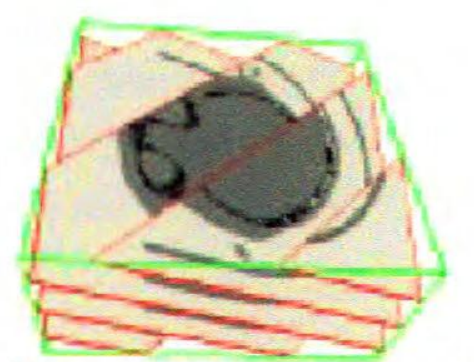

Figura 3.23 - Polígonos de textura (em vermelho) referentes a um volume de dados (em verde) [Grz98].

Quando todos os planos de amostragem estão texturizados, dá-se início ao processo de rendering. As texturas dos planos são combinadas através de um operador de blending, sendo que, primeiramente, acontece o blending da cor de fundo com o plano mais distante do observador. A partir daí a combinação dos planos acontece seguindo a ordem de trás para frente, terminando com o plano mais próximo ao observador. A imagem desejada do volume de dados é apresenta quando todos os planos tiverem sido processados. 


\subsubsection{Operadoreș de Blending}

Os operadores de blending são funções que fazem a composição da imagem a partir dos dados encontrados nas fatias. Existem várias funções de blending, algumas das quais são citadas abaixo [McR98]:

Over: o operador over é o mais comum. Ele aproxima o fluxo de luz através de um material translúcido colorido. A transparência de cada ponto no material é determinada pelo valor $\alpha$ do texel. Os texels com valores $\alpha$ (quantidade de opacidade) altos tendem a obscurecer os texels que estão atrás deles.

Under: as fatias renderizadas de frente-para-trás com o operador under produzem o mesmo resultado que o operador over no rendering de trás para frente.

Attenuate: este operador simula raio- $x$ no material. Os valores $\alpha$ dos texels são os responsáveis pelo controle da atenuação do brilho da luz através do material ao longo da direção de visão e em direção ao ponto de visão. Sendo ássim o valor $\alpha$ controla a densidade do material. O brilho final de cada pixel é atenuado pelo total da densidade do texel ao longo da direção de visão.

MIP (Maximum Intensity Projection): é usado em imagens médicas para visualizar o fluxo de sangue. MIP encontra $0 \alpha$ do texel mais brilhante de todas as fatias de textura para cada localização do pixel. MIP é um operador de realce de contraste. Estruturas com valores $\alpha$ mais altos tendem a se sobressair aos dados que o envolvem.

Diferentes valores $\alpha$ no dado volumétrico freqüentemente correspondem a diferentes materiais no volume sendo renderizado. Para ajudar a analisar o volume de dados, uma classificação pode ser aplicada aos texels, destacando classes particulares dos dados do volume que sejam de interesse do analisador.

O operador de blending utilizado neste trabalho é o over e tem a seguinte equação:

$$
\operatorname{Cor}_{i}(r g b)=\left(1-\alpha_{i}\right) \cdot \operatorname{Cor}_{i-1}(r g b)+\alpha_{i} \cdot \operatorname{Cor}_{i}(r g b)
$$

onde $\operatorname{Cor}_{0}(r g b)=$ cor de fundo e $\alpha_{0}=1$. 


\subsubsection{2 'Virtualizando' a Memória de Textura}

Devido ao fato do volume de textura ser quase sempre bem maior que a memória de textura, ele precisa ser dividido em subvolumes menores, chamados blocos de textura, que podem ser carregados inteiramente na memória de textura. A figura 3.24 apresenta um volume decomposto em oito blocos. Cada bloco pode ser considerado como um mapa de textura separado que pode ser acessado através das coordenadas de textura dos pontos no espaço do objeto. Quando um bloco de textura é acessado pela primeira vez, é necessário um operador de binding de textura para definir o bloco como o mapa de textura corrente. Os acessos subsequentes ao bloco usarão o mesmo mapa de textura até que outro bloco seja encontrado. O binding não é caro se o bloco já estiver na memória de textura; caso o bloco não esteja na memória, ele deve ser carregado. Se a memória já estiver cheia é necessário fazer um swapping da memória inteira. O carregamento e o swapping são muito caros e quase sempre é o custo dominante nos algoritmos baseados no mapeamento de textura [Fan96].

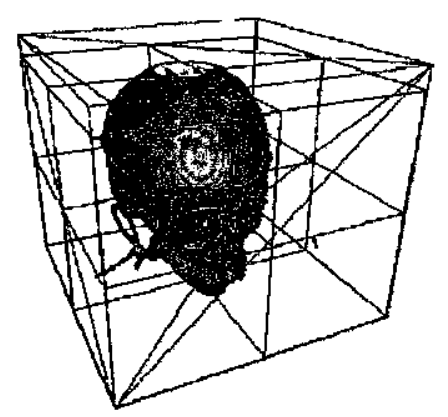

Figura 3.24 - Volume decomposto em oito blocos, marcados em azul [Grz98].

Uma estrutura de dados hierárquica como a $O c t r e e^{4}$ pode ser usada para a subdivisão do volume de textura em blocos. Em [Fan96] pode-se encontrar uma implementação utilizando subdivisões uniformes, isto é, os blocos de textura possuem o mesmo tamanho dos octantes do volume de textura. A octree pode ser útil no processo de busca de um determinado bloco.

Ao invés de tomar um plano e computar suas interseções com todos os blocos de textura, pode-se tomar os blocos um a um e computar todos os polígonos. Para assegurar que os polígonos sejam computados na ordem correta, os blocos devem ser ordenados primeiro. Como os blocos já estão organizados em uma octree, o processo de ordenação para uma dada direção de visão é simples. Assumindo que a direção de visão seja dada pelas coordenadas $(x, y, z)$ relativas ao sistema ortogonal de coordenadas da octree, os sinais das coordenadas determinam a ordem na qual os oito filhos de cada nó são visitados. A figura 3.25 apresenta a ordem dos octantes para uma determinada direção de

${ }^{4}$ Octree é uma estrutura hierárquica em árvore usada para representar um espaço 3D. Cada nó da árvore corresponde a um octante (região do espaço) e pode possuir 8 nós filhos se for necessário subdividir o octante. 
visão. A figura 3.26 apresenta o processamento do rendering para os blocos correspondentes à figura 3.24 .

\begin{tabular}{|ccc|c|}
\hline \multicolumn{3}{|c|}{ Direção de Visão } & Orḍem dos Blocos \\
\hline $\mathrm{X}$ & $\mathrm{Y}$ & $\mathrm{Z}$ & \\
\hline$\geq 0$ & $\geq 0$ & $\geq 0$ & $7,6,5,3,4,2,1,0$ \\
\hline$<0$ & $\geq 0$ & $\geq 0$ & $6,7,4,2,5,3,0,1$ \\
\hline$\geq 0$ & $<0$ & $\geq 0$ & $5,4,7,1,6,0,3,2$ \\
\hline$<0$ & $<0$ & $\geq 0$ & $4,5,6,0,7,1,2,3$ \\
\hline$\geq 0$ & $\geq 0$ & $<0$ & $3,2,1,7,0,6,5,4$ \\
\hline$<0$ & $\geq 0$ & $<0$ & $2,3,0,6,1,7,4,5$ \\
\hline$\geq 0$ & $<0$ & $<0$ & $1,0,3,5,2,4,7,6$ \\
\hline$<0$ & $<0$ & $<0$ & $0,1,2,4,3,5,6,7$ \\
\hline
\end{tabular}

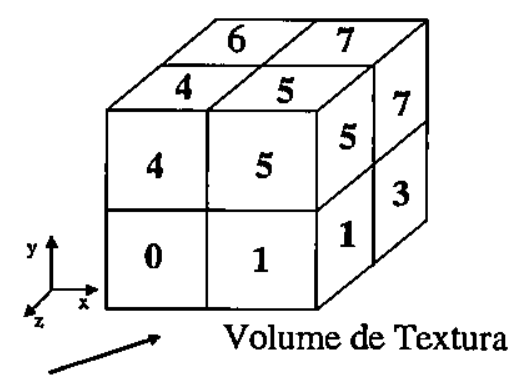

Direção de Visão $(x, y, z)$

Flgura 3.25 - Ordem de visitação dos octantes para uma determinada direção de visão [Fan96].

Como podem existir milhares de blocos de textura, computar a interseção dos planos de cada um dos blocos pode ser computacionalmente muito caro. Uma alternativa para aliviar o processamento consiste em gravar a configuração dos polígonos de alguns blocos e aplicá-la a outros blocos que aceitem a mesma configuração.
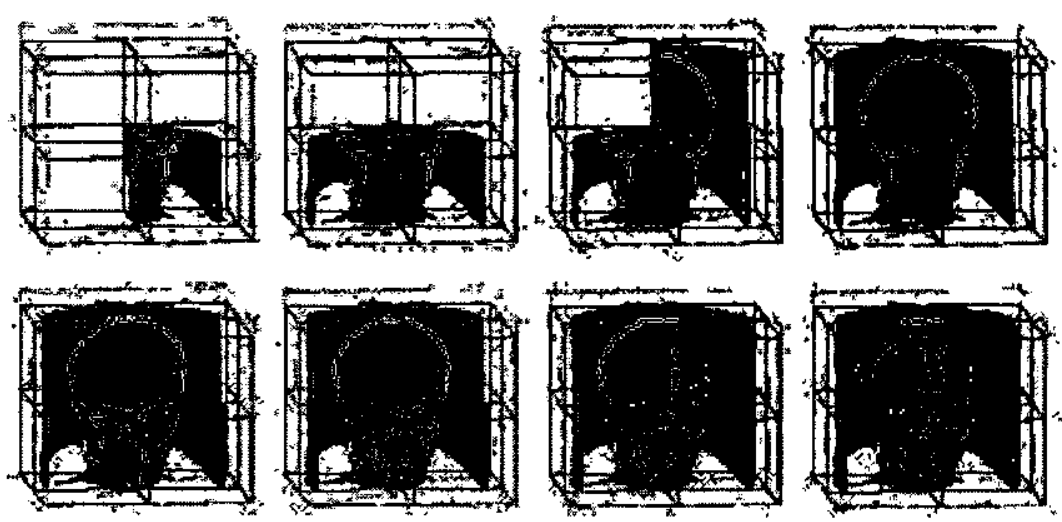

Figura 3.26 - Ordem do processamento dos biocos no rendering. [Grz98] 


\subsubsection{Misturando Objetos Volumétricos e Geométricos}

Em algumas aplicações pode ser útil apresentar conjuntos volumétricos juntamente com primitivas geométricas em uma mesma cena. Por exemplo, dados médicos podem ser renderizados de forma volumétrica com próteses poligonais inseridas na apresentação. A geometria embutida pode ser opaca ou transparente.

No DVR com mapeamento de textura, os objetos geométricos opacos são renderizados juntamente com os polígonos das fatias dos dados volumétricos usando depth buffering para ambos. Com depth buffering, os pixels dos planos que estão atrás do objeto não são renderizados, enquanto que os dos planos na frente do objeto são renderizados com blending. O blending dos planos na frente do objeto obscurece gradualmente o objeto, fazendo com que ele pareça imerso no volume.

Se o objeto deve ser transparente, apenas uma fatia de cada vez deve ser renderizada. $O$ objeto é cortado em fatias grossas usando os planos de corte. A grossura das fatias corresponde ao espaçamento entre as fatias de dados do volume. Cada fatia do objeto é correspondente a uma das fatias de dados. Cada fatia do objeto é renderizada com blending juntamente com o polígono da fatia de dados correspondente, na ordem de trás para frente [McR98].

Como apresentado neste capítulo, a utilização de mapeamento de textura para DVR possibilita tanto projeção ortogonal como perspectiva com alta qualidade e velocidade maior que as técnicas DVR convencionais. É possível também obter projeção estéreo ortogonal ou perspectiva da cena. Além disso, um modelo de iluminação pode ser aplicado na visualização dos dados. Na criação do mapa de textura, erros de arredondamento se tomam problemas significativos quando a quantidade de bits por texel é pequena. Por exemplo, a utilização de 8 bits para os texels provoca erros consideráveis, ao passo que o uso de 12 bits reduz consideravelmente a quantidade de erros. Para que a técnica tenha um bom desempenho é necessário que se tenha hardware que a suporte. As malhas a serem renderizadas utilizando mapas de textura 3D não precisam ser necessariamente cúbicas regulares; em [Grz98] é apresentada uma abordagem para malhas tetraédricas. A figura 3.27 apresenta uma imagem obtida através da utilização de mapeamento de textura. A figura 3.28 apresenta dois exemplos de imagens -estéreo obtidos por mapeamento de textura, e é possível perceber o efeito 3D mesmo sem a utilização

${ }^{5}$ Depth Buffering é a memória que contém a profundidade (ao longo da normal ao plano de visão) de um elemento correspondente no frame buffer (memória onde a definição da imagem fica armazenada). 
de aparelhos apropriados. Para isso basta colocar o papel a uma distância dos olhos (aproximadamente $30 \mathrm{~cm}$ ) que possibilite, através de um jogo de visão, ver três quadros álinhados hórizontalmente ao invés de dois.

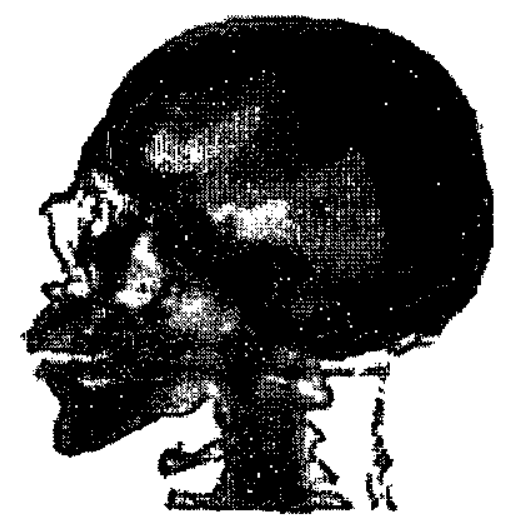

Figura 3.27 - Imagem obtida por mapeamento de textura [Gel96].
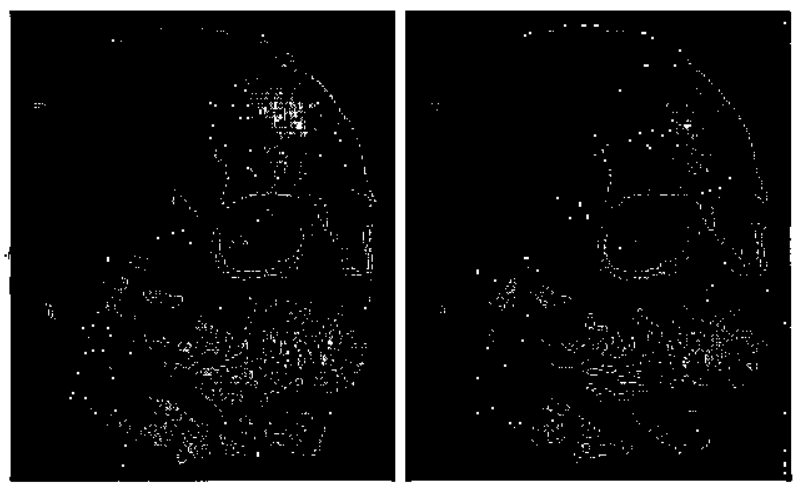

Figura 3.28 - Imagens estéreo consegujdas com mapeamento de textura [Gel96].

No contexto deste trabalho, a técnica DVRT foi implementada no contexto do VTK, o software de visualização de fonte aberto apresentado mencionado anteriormente. Exçeto pela virtualização da memória e pelo uso do hardware, o DVRT foi implementado, passo a passo, nos moldes apresentados neste capítulo. Essa implementação é apresentada no próximo capítulo, e assim existe uma associação direta entre os temas daqui com as seções do capítulo 4, e referências cruzadas são utilizadas para indicar esse fato e orientar o leitor, do rendering volumétrico direto com mapeamento de textura incorporando luz direcional. 


\section{Capítulo 4}

\section{Implementação do DVRT com Tonalização no VTK}

Este capítulo destina-se a apresentar como o DVRT foi implementado no contexto do VTK. O presente capítulo está fortemente ligado ao capítulo 3, uma vez que apresenta a implementação de alguns tópicos lá apresentados. Portanto, é necessário para compreender a implementação descrita neste capítulo se ter em mente os conceitos apresentados no capítulo anterior, e referências cruzadas são utilizadas para evidenciar esse fato.

Como visto no capítulo 3, o DVRT pode ser dividido em duas etapas: a construção do mapa de textura e o rendering. A primeira etapa foi implementada na classe vtkVolumeTexture e a segunda na classe vtkVolumeTextureMapper, como será visto no decorrer deste capítulo. A figura 4.1 apresenta esquematicamente o processo do DVRT utilizando tonalização tabelada (linha pontilhadas) e sem tonalização (linhas contínuas)..

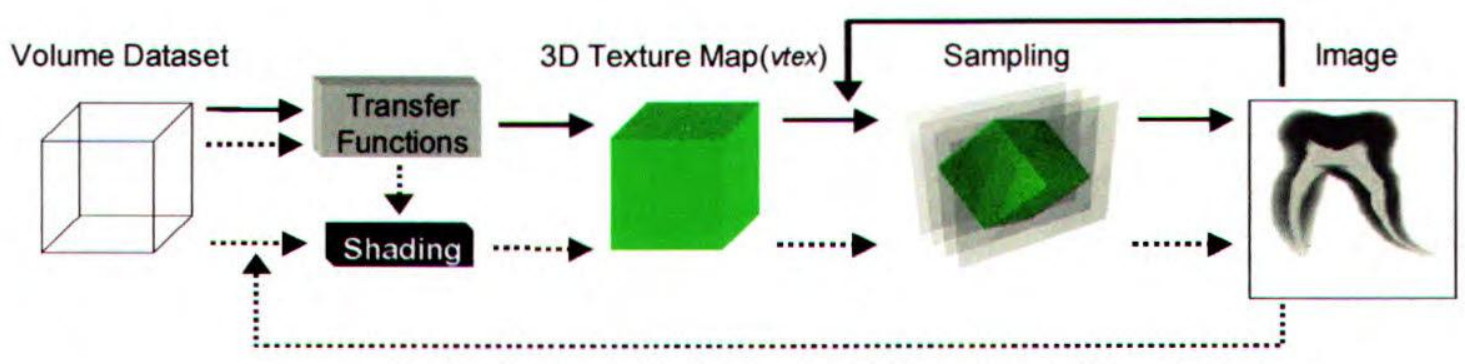

Figura 4.1 - Esquema do fluxo do DVRT com tonalizaçăo (linhas tracejadas) e sem esse recurso (linhas contínuas).

Inicialmente, na seção 4.1, são apresentadas algumas considerações relevantes sobre o VTK (Visualization Toolkit), biblioteca de visualização onde o DVRT foi incorporado, seguidas da implementação propriamente dita do DVRT (vtkVolumeTexture e vtkVolumeTextureMapper), no contexto do VTK, na seção 4.2 . 


\subsection{Considerações a respeito do VTK}

A técnica de visualização desenvolvida foi implementada como uma extensão à biblioteca de visualização VTK (Visualization Toolkit) [Sch98]. Essa biblioteca é bastante flexível, uma vez que o seu código fonte está disponível, e é desenvolvida utilizando a tecnologia de orientação a objetos, o que facilita a expansão do código. Com essa possibilidade, pode-se configurar o sistema para uma aplicação, alterar o código fonte para resolver problemas específicos, criar interfaces adequadas para um tipo de aplicação, de usuário, ou de tarefa, bem como implementar novas idéias e algoritmos. $\mathrm{O}$ VTK pode ser programado utilizando Tcl/Tk, C++ ou Java. Os demais módulos já implementados dos projetos de Odontologia Virtual e do PowerVis também são extensões do VTK, o que facilitará a integração deste trabalho com os demais já desenvolvidos e em andamento.

\subsubsection{Objetos Básicos do VTK}

No VTK, existem sete objetos que são usados para renderizar uma cena. Existem muitos outros objetos envolvidos em uma cena, mas esses sete são os mais comumente utilizados. Segue uma breve explicação de suas classes, as quais são apresentadas na figura 4.2.

vtkRenderWindow: gerencia uma janela no dispositivo de apresentação. As instâncias dessa classe são independentes do dispositivo, o que significa que não é necessário se preocupar com qual hardware ou 'software gráfico é utilizado. O software se adapta automaticamente a esses elementos do computador em uso na instanciação do vtkRenderWindow. Adicionalmente, os objetos dessa classe são usados para gerenciar renderizadores e armazenar as características gráficas específicas, tais como tamanho, posição, título da janela, profundidade da janela (window dept $h^{6}$ ) e o flag de double buffering ${ }^{7}$.

${ }^{6}$ Window depth indica quantos bits são alocados por pixel.

${ }^{7}$ Double buffering é uma técnica onde uma janela é logicamente dividida em dois buffers. Em um dado momento um buffer esta visível ao usuário, enquanto que o segundo buffer pode ser usado para desenhar a próxima imagem a ser apresentada. 


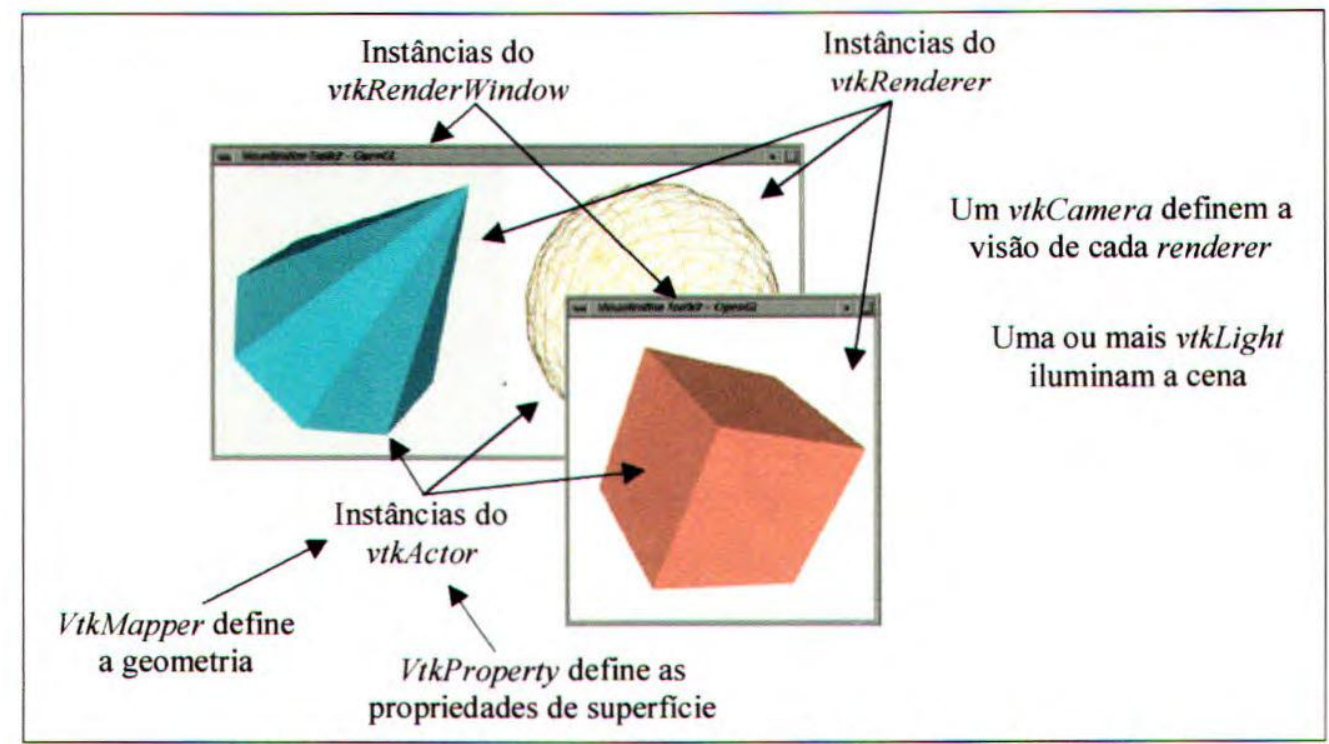

Figura 4.2 - Diagrama ilustrativo dos objetos gráficos do VTK [Sch98].

vtkRenderer: coordena o processo de rendering envolvendo luzes, câmeras e atores. Uma ou mais instâncias do vtkRenderer podem desenhar em uma instância do vtkRenderWindow. Cada instância mantém uma lista de atores, luzes, e uma câmera ativa para uma determinada cena. Pelo menos um ator deve ser definido pelo usuário, mas se as luzes e a câmera não forem especificadas, elas serão definidas com valores padrão pelo renderer. Em uma dada cena, os atores são posicionados no centro da imagem e a direção de visão padrão da câmera segue o sentido negativo do eixo z. O vtkRenderer fornece métodos para especificar a cor de fundo e a cor da iluminação ambiente. Também estão disponíveis métodos para conversão entre os sistemas de coordenadas do mundo, de visão e de apresentação (display). O lugar na renderwindow onde o renderer desenha é chamado viewport. Quando mais de um renderer é associado a um mesmo renderwindow, é necessário definir uma viewport para cada renderer.

vtkLight: representa uma fonte de luz para iluminar a cena. Normalmente uma luz está acesa para iluminar a cena. Se nenhuma luz está definida e acesa, o renderer adiciona uma luz automaticamente. As luzes podem ser posicionais ou infinitas. Luzes posicionais têm um ângulo cônico e fatores de atenuação associados. Luzes infinitas projetam raios de luz paralelos entre si.

vtkCamera: tem como principais parâmetros: posição de visão, ponto focal, localização dos planos de corte da frente e de trás, vetor view up (orientação da câmera) e campo de visão (ver figura 4.3). Existem também alguns métodos para facilitar a manipulação, tais como azimuth, zoom, roll e elevation (ver figura 4.4). Se nenhuma câmera for definida pelo usuário, o renderer instancia uma automaticamente, e a define como ativa. 


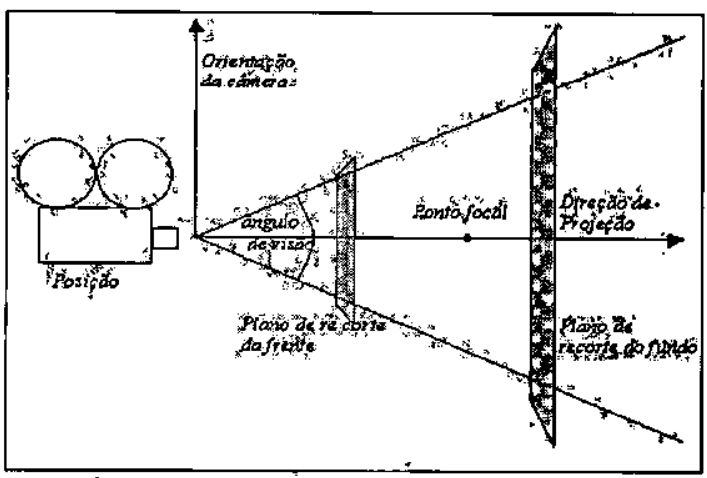

Figura 4.3 - Atributos da câmera [Sch98].

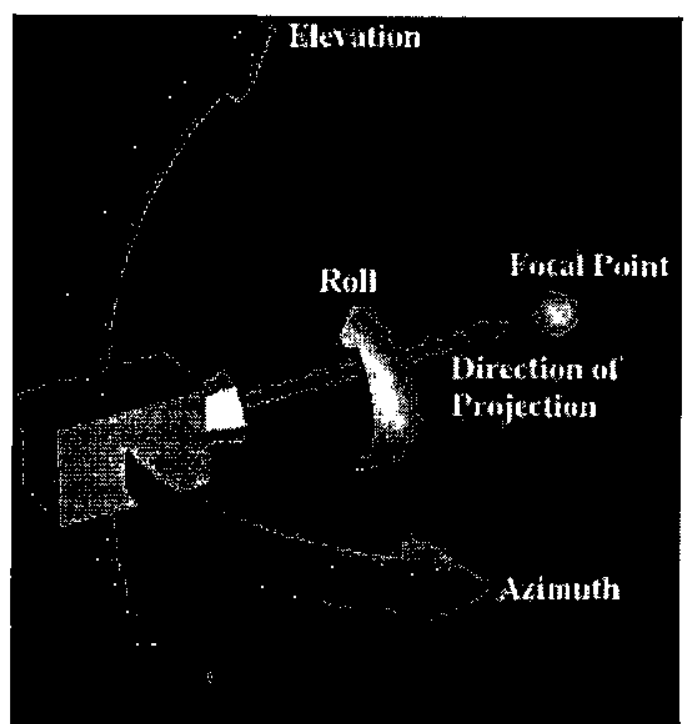

Figura 4.4- Movimentos da câmera centrados no ponto focal [Sch98].

vtkActor: representa um objeto renderizado na cena. $O$ ator combina propriedades de objeto (por exemplo: cor e tipo de tonalização), definições geométricas, e orientação no sistema de coordenadas do mundo. Isso é implementado através da utilização de variáveis de instância que referenciam a objetos das classes vtkProperty, vtkMapper e vtkTransform. Normalmente não é necessário criar objetos para propriedades e transformações, uma vez que essas são criadas e manipuladas por métodos dos atores, mas é necessário criar uma instância do vtkMapper.

vtkProperty: afeta a aparência renderizada de um ator, definindo cor, transparência e outras propriedades de iluminação, bem como propriedades de representação em fio de arame (wireframe) ou em superfície iluminada. Quando um ator é criado, uma instância do vtkProperty é automaticamente criada para ele. É possível criar uma instância dessa classe e associá-la a mais de um ator. Desse modo, vários atores podem compartilhar propriedades comuns.

vtkMapper: define a geometria do objeto e, opcionalmente, cores de vértices. Mais de um ator pode referenciar a mesma instância dessa classe. O mapper formata o resultado do pipeline de visualização para dispositivos gráficos, como pode ser visto na seção a seguir. 
Existe um outro objeto importante, uma instância do $v t k$ RenderWindowInteractor, que captura eventos de interação para um renderer em uma renderwindow. Depois de capturar esses eventos, ele executa certas operações como dolly ${ }^{8}$, rotação da câmera, escolha de ator, ativação e desativação do modo estéreo, e outras mais. A tabela 4.1 apresenta uma relação das opções de interação presentes nessa classe. Para que o vtkRenderWindowInteractor possa capturar os eventos, é necessário que ele esteja associado a alguma instância do vtkRenderWindow.

\begin{tabular}{|c|c|}
\hline Eventos & Descrição da ação \\
\hline botão esquerdo do mouse & Faz a rotação da câmera \\
\hline botão central do mouse & Faz o pan da câmera \\
\hline botão direito do mouse & Faz o dolly da câmera \\
\hline tecla "W" & Desenha os atores no modo fio de arame \\
\hline tecla "S" & Desenha os atores no modo de superfícies \\
\hline tecla "3" & Faz o chaveamento entre exibir ou não a cena no modo 3D estéreo. \\
\hline Tecla "R" & Retorna à posição inicial de visão da câmera \\
\hline tecla "E" & Sai da aplicação \\
\hline tecla "U" & Executa uma função definida pelo usuário \\
\hline tecla "O" & Seleciona o ator apontado pelo mouse \\
\hline
\end{tabular}

Em um programa para visualização que faça uso do VTK é necessário instanciar e fazer a conexão dos objetos citados acima. Na Figura 4.5 é apresentado um esquema de como isso é feito em um programa C++.

${ }^{8}$ Dolly é uma operação que move a posiçāo da câmera em direçăo ao seu ponto fical (dolly in) ou afastase dele (dolly out) 


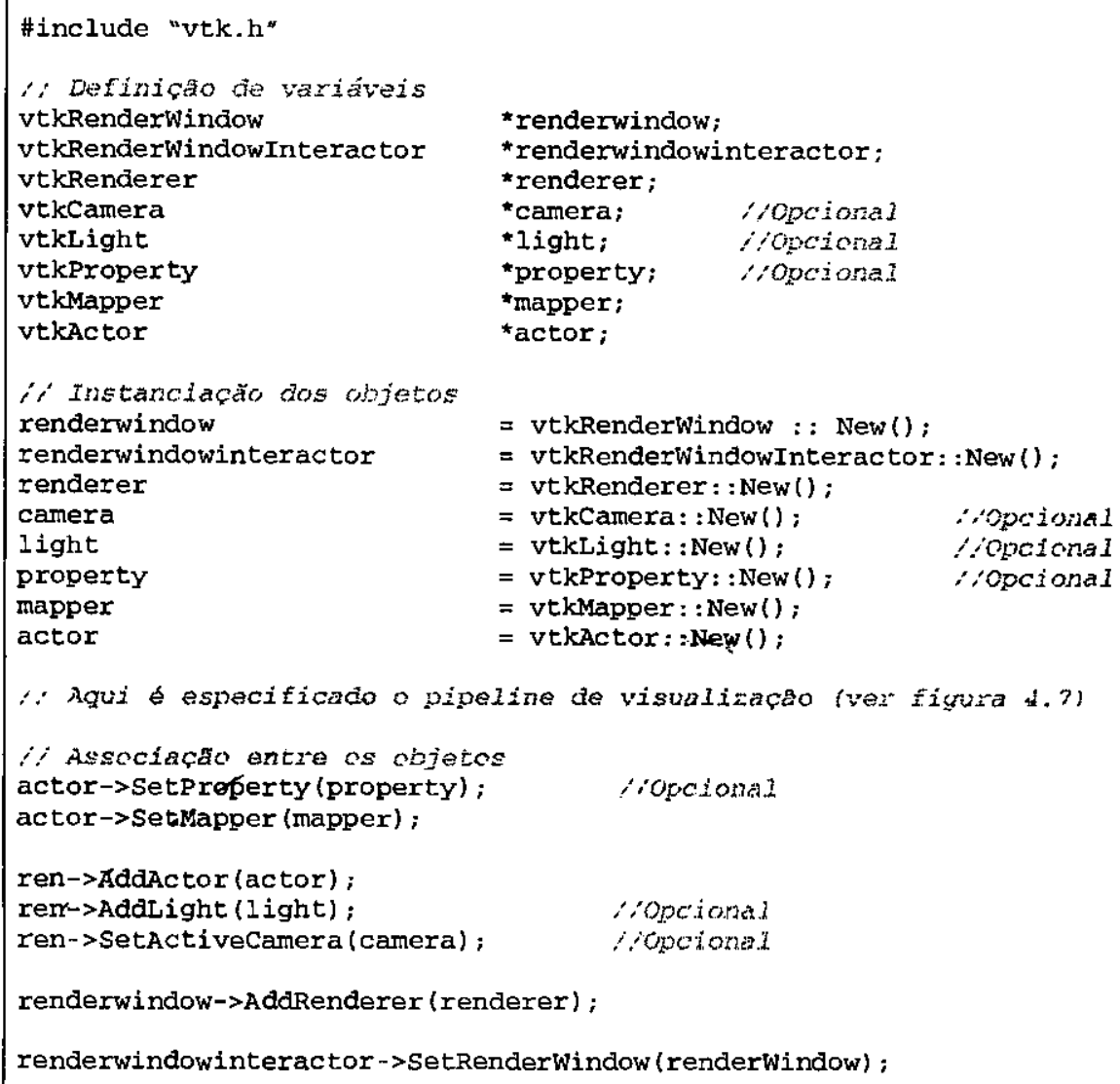

Figura 4.5 - Estrutura parcial de um programa típico utilizando o VTK.

A próxima seção apresenta um importante conceito presente no VTK, o pipeline de visualização.

\subsubsection{O Pipeline de Visualização}

No VTK, um pipeline consiste da ligação de objetos para representar dados (objetos de dados), objetos 'para operar nos dados (objetos de processamento) e uma indicação de direção do fluxo de dados (representada graficamente por uma seta conectando os objetos).

Os objetos de dados representam informações. Esses objetos também provêem métodos para criação, acesso e remoção dessas informaçōes. Objetos de dados representam modelos, malhas, quantidades físicas, medições, etc.

Os objetos de processamento operam em dados de entrada e produzem dados de saída. Esses objetos derivam novos dados a partir dos dados de entrada ou transformam os dados de entrada em uma nova forma. A entrada pode receber um ou mais objetos de dados, como também parâmetros para controlar sua operação. Os parâmetros locais incluem variáveis de instância ou associações, como também referências para outros objetos. Os objetos de processamento são caracterizados como objetos fonte 
(source objects), objetos de filtro (filter objects) ou objetos de mapeamento (mapper objects). Essa caracterização é baseada na função desses objetos no pipeline de visualização, isto é, se eles iniciam, mantém ou terminam o fluxo de dados no pipeline, respectivamente.

Os objetos fonte fazem interface com fontes de dados externas, e nesse caso são chamados objetos leitores (reader objects), ou geram dados a partir de parâmetros locais, e nesse caso são chamados objetos procedimentais (procedural objects).

Os objetos filtro requerem um ou mais objetos de dados como entrada e geram um ou mais objetos de dados como saída. Parâmetros locais são responsáveis por controlar a operação do objeto de processo. Algumas técnicas de visualização são implementadas por objetos desse tipo.

Os objetos de mapeamento requerem um ou mais objetos de dados como entrada e terminam o fluxo dos dados do pipeline de visualização. Esses objetos são tipicamente usados para converter dados em primitivas gráficas. Entretanto, eles também podem escrever os dados em um arquivo de saída ou fazer interface com outros dispositivos ou sistemas. Os objetos de mapeamento que escrevem os dados em arquivo são chamados de objetos de escrita (ou writers).

Os objetos do pipeline são conectados através dos métodos SetInput e GetOutput. O método SetInput associa um objeto de processo de dados à entrada do objeto de processo que dele necessita. $\mathrm{O}$ método GetOutput, retorna o objeto de dados presente na saída do objeto de processo que o gerou. É importante fazer a verificação dos tipos de dados que estão sendo passados da saída de um objeto para a entrada do outro, como pode ser visto no esquema da figura 4.6 .

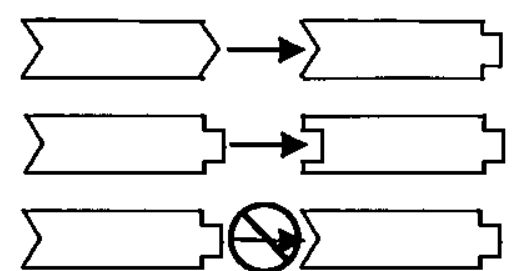

Figura 4.6 - Conexāo entre os objetos do pipellne. O tipo do objeto de dados deve ser observado [Sch98].

A figura 4.7 apresenta um exemplo genérico que ilustra a conexão de objetos em pipeline na linguagem de programação C++. Nesse exemplo, como em qualquer pipeline de um programa válido, como da figura 4.9 da seção 4.1.4, a conexão sempre se faz por meio dos métodos SetInput e GetOutput.

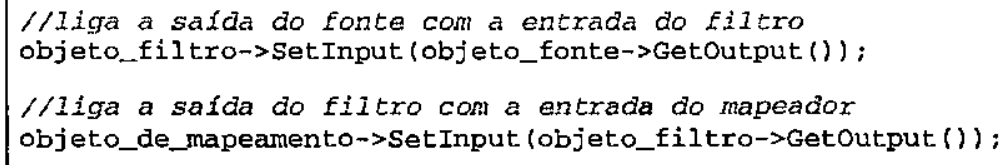

Flgura 4.7 - Exemplo de conexāo de objetos fonte, filtro e de mapeamento para criação do plpellne de visualizaçāo. 


\subsubsection{Executando o Pipeline}

O pipeline de visualização deve processar dados para gerar um resultado desejado. A execução do pipeline de visualização faz com que todos os objetos de processo pertencentes ao pipeline sejam executados, operando modificações nos dados à medida que o pipeline é percorrido.

Freqüentemente o pipeline de visualização é executado mais de uma vez. Após mudanças nos objetos de processamento ou em suas entradas, deve-se executar o pipeline novamente para que se consiga atualização dos resultados. Para um melhor desempenho, os objetos de processamento do pipeline são executados somente se mudanças ocorrerem nas entradas dos objetos.

Um objeto de dados de particular importância para este trabalho é o implementado na classe vtkStructuredPoints, pois o volume de dados submetido à visualização dever ser desse tipo. A seguir é apreșentada uma descrição da estrutura desses dados.

\subsubsection{A classe vtkStructuredPoints}

O volume de dados do tipo vtkStructuredPoints é uma coleção de pontos e células arranjadas regularmente no espaço. As figura 4.8 apresenta esquematicamente um volume desse tipo. Suas linhas, colunas e planos são paralelos ao sistema de coordenadas $x-y-z$. Seus pontos e células podem ser representados implicitamente pela especificação das dimensões, do espaçamento dos dados e da origem. As dimensões definem a topologia do conjunto de dados, enquanto que a origem e o espaçamento definem a geometria. A natureza regular da topologia e geometria sugere um sistema de coordenadas natural $i-j-k$. Tanto células quanto pontos são numerados de acordo com o crescimento nos eixos $x-y-z$. O número total de pontos nesse conjunto de dados é dado por $n_{x} \cdot n_{y} \cdot n_{z}$ enquanto que o número total de células é dado por $\left(n_{x}-1\right) \cdot\left(n_{y}-1\right) \cdot\left(n_{z}-1\right)$, sendo $n$ a dimensão do volume de dados em cada uma das direções $x-y-z$. Um ponto ou célula particular pode ser selecionado pela especificação dos três índices $i-j-k$. Cada ponto e célula particular possui um identificador, $p_{i d}$ e cell $l_{i d}$ respectivamente. $O$ identificador é um número inteiro que referencia uma posição em uma estrutura de dados. Para obter um identificador de um ponto, $p_{i d}$, ou de uma célula, cell $l_{i d}$, dados os índices $(i, j, k) \mathrm{e}$ as dimensões $\left(n_{x}, n_{y}, n_{z}\right)$, deve-se fazer uso das seguinte fórmulas:

$$
\begin{array}{ll}
p_{i d}=i+j \cdot n_{x}+k \cdot n_{x} \cdot n_{y}, & \text { onde } 0 \leq i \leq n_{x} \quad 0 \leq j \leq n_{y} \quad \text { e } \quad 0 \leq k \leq n_{z} \\
c e l l_{i d}=i+j \cdot\left(n_{x}-1\right)+k \cdot\left(n_{x}-1\right) \cdot\left(n_{y}-1\right), & \text { onde } 0 \leq i \leq n_{x}-1, \quad 0 \leq j \leq n_{y}-1 \text { e } \quad 0 \leq k \leq n_{z}-1
\end{array}
$$

Essas equações assumem que os identificadores percorrem mais rapidamente no eixo $x$, em seguida no eixo $y$ e por fim no eixo $z$. 


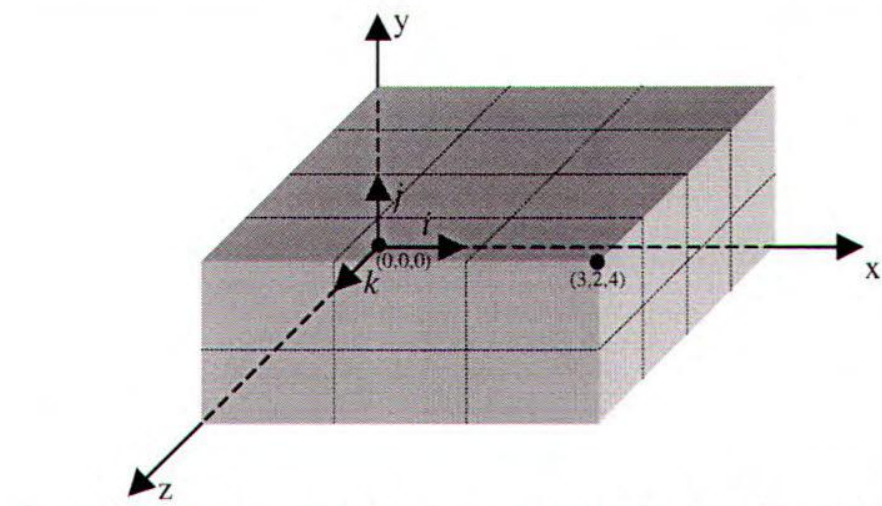

Figura 4.8 - Esquema de um volume de dados do tipo vtkStructuredPoints.

O vtkStructuredPoints trata apenas da estrutura de uma malha regular. Os atributos de dados são dados que estão associados à malha. Um modelo para volume de dados, como o vtkStructuredPoints, é constituído por pontos e células, e é muito natural pensar em associar atributos de dados aos seus pontos ou suas células. O VTK optou por fornecer maneiras diretas de se fazer associação de atributos de dados aos pontos (nós) de uma malha, e não apresenta uma maneira explícita de associar dados aos voxels (interior de células) de uma malha. Os atributos de dados podem ser escalares, vetores, tensores ou definidos pelo usuário. Existe uma correspondência de um para um entre pontos do conjunto de dados e atributos de dados. Os atributos de dados são acessados por meio dos identificadores de pontos.

O VTK fornece as classes vtkScalars, vtkVectors, vtkNormals, vtkTCoords e vtkTensors para organizar os atributos de dados. No caso deste trabalho de mestrado os dados do volume de interesse são escalares, portanto a classe utilizada é a vtkScalars.

A próxima seção apresenta uma técnica de visualização do VTK a qual é de particular interesse para esse trabalho de mestrado.

\subsubsection{O Ray Casting no VTK}

O Ray casting é uma técnica de rendering volumétrico direto que compõe a imagem de um volume de dados através da emição de raios partindo dos pixels da tela em direção ao volume de dados, como apresentado na seção 3.1.2 do capítulo 3. O VTK fornece classes que implementam essa técnica. A estrutura de um programa em C++ que faz uso do VTK para realizar o Ray Casting é apresentado na figura 4.9 . 
O método Ray Casting implementado no VTK exige que o volume de dados a ser visualizado seja do tipo vtkStructuredPoints. Uma malha de dados desse tipo é caracterizada por ser regular, isto é, tanto sua topologia ${ }^{9}$ quanto sua geometria ${ }^{10}$ são constantes.

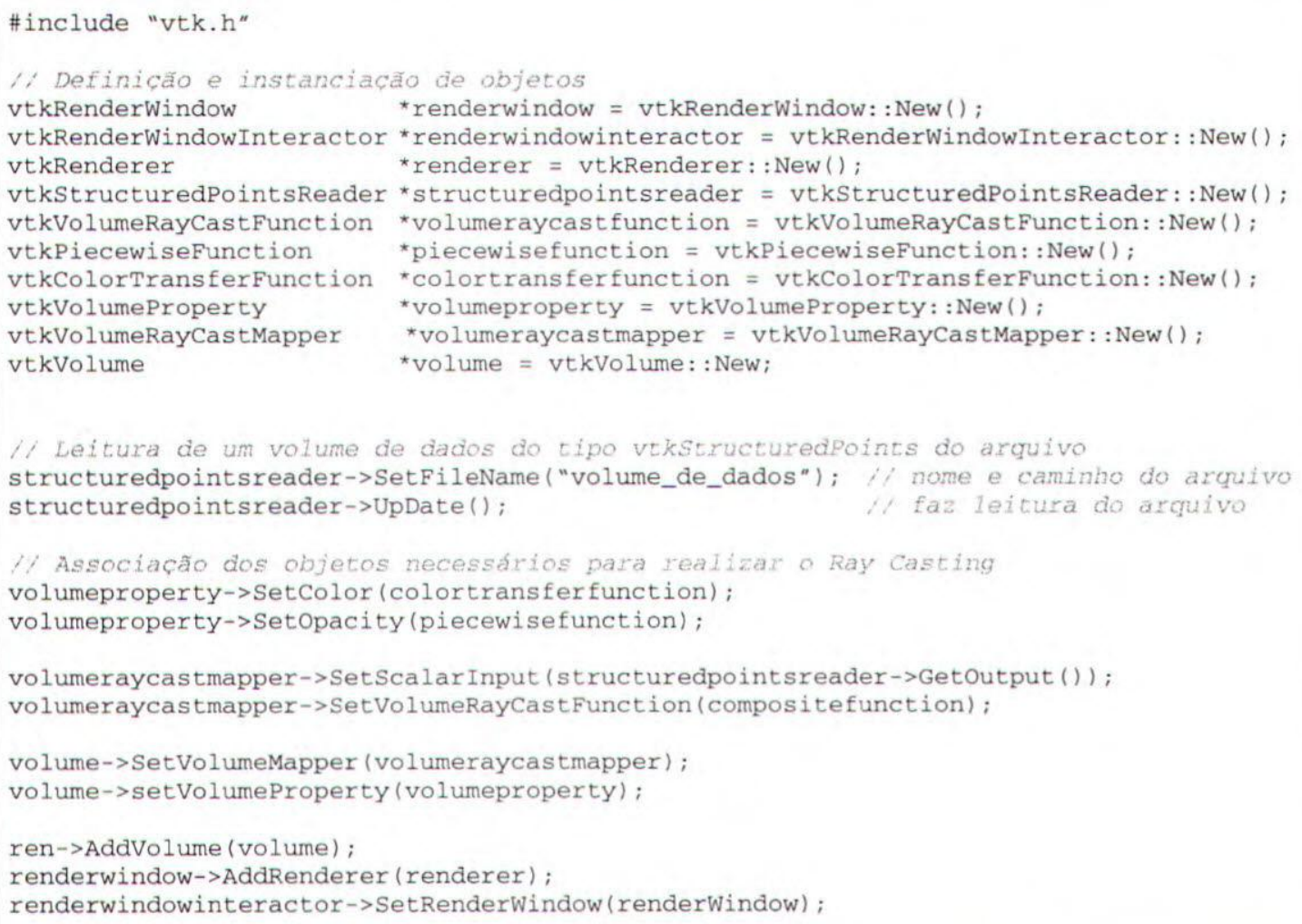

Figura 4.9 - Estrutura de um programa em C++ para o Ray Casting.

A classificação dos dados para o Ray Casting é feita através das classes vtkColorTransferFuncti vtkPiecewiseFunction. A primeira faz o mapeamento de valores escalares para intensidades de RGB e a segunda faz o mapeamento de escalares para valores de opacidade. Os objetos dessas c classes são associados ao vtkVolumeProperty.

Como a técnica funciona lançando raios, é necessário criar uma função de raio. Isso é feito atravé classe abstrata vtkVolumeRayCastFunction. Por se tratar de uma classe abstrata, a implementaçãc da função se encontra em outros objetos que herdam as propriedades dessa classe. O VTK forne seguintes funções para os rais enviados:

${ }^{9}$ Topologia: é um conjunto de propriedades invariantes sob certas transformações geométricas cı translação, rotação e escala. Exemplo, dizer que três pontos formam um triângulo [Sch98].

${ }^{10}$ Geometria: é a instanciação da topologia, a especificação de posição no espaço 3D. Exemplo, dizer qual as coordenadas dos pontos que formam o triângulo[Sch98]. 
- vtkVolumeRayCastCompositeFunction

- vtkVolumeRayCastMIPFunction

- vtkVolumeRayCastIsosurfaceFunction

A primeira função faz a composição ao longo do raio usando as propriedades presentes no vtkVolumeProperty. A segunda função realiza a projeção de intensidade máxima. A terceira função produz uma imagem de superfície, onde um isovalor deve ser fornecido para definir a isosuperfície. A função de raio é associada ao vtkVolumeRayCastMapper.

O ray casting faz uso de um objeto de mapeamento especial instanciado a partir da classe vtkVolumeRayCastMapper. Essa classe herda as propriedades de uma classe abstrata vtkVolumeMapper. O objeto da classe vtkVolume corresponde ao ator da cena. Como se trata de rendering volumétrico direto, é necessário adicionar um volume de dados ao renderer. Isso é feito pelo método AddVolume, ao invés do convencional AddActor presente na figura 4.9.

A implementação do método Ray Casting no VTK foi estudada para que a implementação do método DVRT no contexto do VTK obedecesse a mesma estrutura de conexão entre objetos. A próxima seção apresenta a implementação da abordagem DVRT no VTK realizada neste trabalho de mestrado. 


\subsection{O Rendering Volumétrico com Textura (DVRT) no VTK}

Um programa, escrito em $\mathrm{C}++$, que utilize o biblioteca VTK para utilizar o DVRT em um volume de dados terá a estrutura apresentada na figura 4.10. No apêndice B são apresentados exemplos de programas comentados que fazem uso do DVRT.

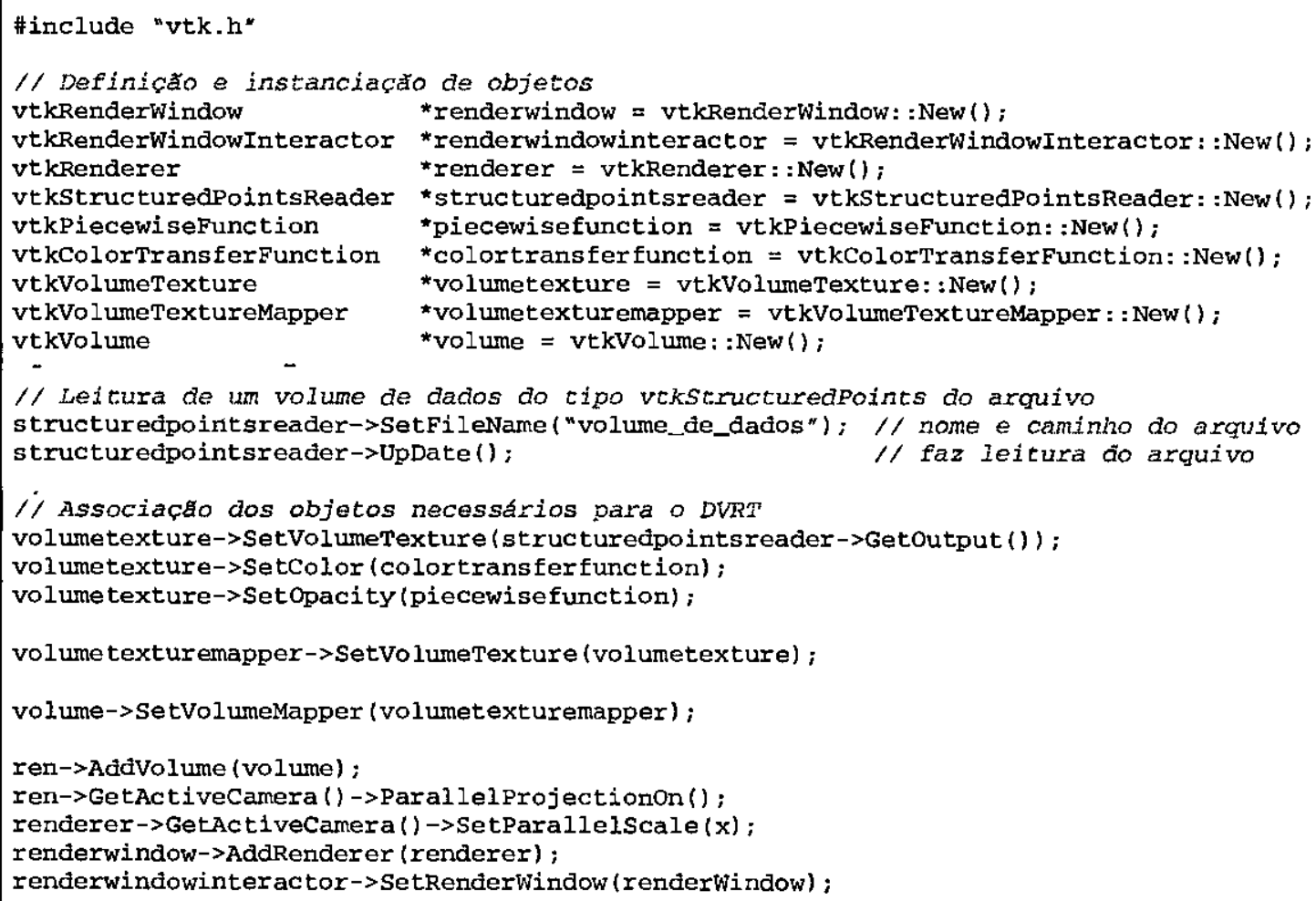

Figura 4.10 - A estrutura de um programa que usa DVRT no VTK.

Como pode ser observado através da comparação com o Ray Casting, para que seja implementado o método DVRT no VTK, basta criar as duas novas classes vtkVolumeTexture e 'vtkVolumeTextureMapper. As outras classes presentes na estrutura da figura 4.10 não necessitam ser modificadas. As próximas seções referem-se à implementação das duas novas classes.

\subsubsection{A classe vtkVolumeTexture}

A classe $v t k$ VolumeTexture tem por finalidade criar o mapa de textura a partir do volume de dados a ser visualizado. Conceitualmente, o mapa de textura é uma estrutura de dados equivalente ao volume de dados. A diferença está nos atributos de dados. O mapa de textura armazena valores RGBA (cor e opacidade) enquanto que o volume de dados armazena escalares.

Para que o vtkVolumeTexture possa fazer a conversão de escalares em intensidades de cor e opacidades é necessário que ele receba informações sobre a classificação de dados. Essa classificação 
é realizada por meio de definições de materiais e funções de transferência. Os materiais separam intervalos de escalares que devem ser visualizados, como também os atributos de iluminaçāo de cada um deles. Os escalares que não pertencem aos materiais definidos não precisam ser visualizados. Portanto, eles são associados a cores totalmente transparentes. Os escalares que pertencem a algum material recebem cores e opacidades por meio de funções de transferência.

Foram implementadas duas classes para tratar materiais: vtkMaterialCollection e vtkMaterial. A primeira classe manipula uma lista de objetos da segunda. Cada material é definido em uma instância da classe vtkMaterial, guardando as informaçōes concementes ao material. Essas informações são: o intervalo de escalares do material e os coeficientes de reflexão (ka, ks, kd e sp, ver seção 3.3) para o caso do rendering ser tonalizado. A manipulação dessas classes pode ser realizada intemamente na classe vtkVolumeTexture ficando, assim, transparente ao usuário, ou serem manipuladas externamente e adicionadas ao vtkVolumeTexture, através do método SetMaterials.

A definição de um material é realizada através do método AddMaterial que recebe como parâmetros de entrada os limites inferior e superior dos escalares e os coeficientes de iluminação ambiente, difuso, especular e de potência especular, respectivamente. Esse método funciona instanciando um objeto vtkMaterial e atribuindo a ele os valores recebidos. Caso o usuário queira trabalhar com as classes vtkMaterialCollection e vtkMaterial extemamente, ele deve fazer uso dos métodos:

- AddMaterial recebe como entrada os parâmetros do material diretamente ou um objeto da classe vtkMaterial pré definido.

- SetMaterials recebe um ponteiro para uma instância da classe vtkMaterialCollection.

- GetMaterials retoma um ponteiro para uma instância da classe vtkMaterialCollection.

As funções de transferência são definidas por classes presentes no VTK. A classe $v t k$ ColorTransferFunction é capaz de armazenar as informaçōes correspondentes a intensidades de cor RGB enquanto que a classe vtkPiecewiseFuction armazena as opacidades. Como pôde ser observado na figura 4.10, os objetos dessas classes são conectados ao vtkVolumeTexture pelos métodos SetColor e SetOpacity.

Conforme apresentado na seção 3.3, o mapa de textura é construído a partir do volume de dados. Na implementação do VTK, esses dois conjuntos de dados são do tipo vtkStructuredPoints, fomecido pelo VTK e apresentado na seção 4.1.4.

Os dados associados ao volume de textura podem sofrer influências das fontes de luz presentes na cena, se isso for de interesse do usuário. Esse é o assunto abordado na próxima seção. 


\section{2:1.1 Incorporando luz direcional}

A classe vtkVolumeTexture deve possibilitar a construção do mapa de textura levando em consideração luz direcional, ou seja, possibilitando uma visualização tonalizada, como apresentado no capítulo anterior. Uma alternativa de se promover essa tonalização é utilizar tabelas pré-calculadas para agilizar o cálculo. Para isso ela faz uso de duas classes, a vtkVectorIndex e a vtkReflectionTable, que auxiliam na construção do mapa de textura.

\section{A Classe vtkVectorIndex}

De acordo com a seção 3.3.1.2, o Índice de Gradientes tem como finalidade-fornecer aproximações para os gradientes dos voxels do volume de dados. Esse índice se encontra implementado na classe vtkVectorIndex.

A classe $v t k V e c t o r I n d e x$ é, portanto, responsável por criar e manipular uma tabela de vetores unitários. Ela é criada através da utilização de uma esfera de raio unitário e de centro posicionado na origem do sistema de coordenadas. Os vetores são dados pelo ponto central e pelos pontos distribuídos na superfície da esfera.

A quantidade de entradas na tabela aumenta em função do nível de refinamento da esfera, como pode ser visto na figura 3.16 da seção 3.3.1.2. Com o intuito de acelerar a manipulação do índice de vetores, apenas os vetores presentes no $1^{\circ}$ octante são tabelados. Os vetores nos demais octantes são adquiridos por permutação de sinais. O Índice de Gradientes é visto externamente como oito intervalos que são diferenciados apenas pelos sinais das coordenadas dos vetores. A permutação dos sinais nesses intervalos pode ser vista na tabela 4.2. Após a geração desses vetores, eles são ordenados em relação às suas coordenadas $x$ para facilitar o processo de busca por um índice.

\begin{tabular}{|ccc|c|c|c|}
\hline \multicolumn{3}{|c|}{ Indices } & \multicolumn{3}{c|}{ Gradientes } \\
\hline 0 & $\mathrm{a}$ & ng-1 & $+\mathrm{x}$ & $+\mathrm{y}$ & $+\mathrm{z}$ \\
\hline $\mathrm{ng}$ & $\mathrm{a}$ & $2 . \mathrm{ng}-1$ & $+\mathrm{x}$ & $+\mathrm{y}$ & $-\mathrm{z}$ \\
\hline 2.ng & $\mathrm{a}$ & $3 . \mathrm{ng}-1$ & $+\mathrm{x}$ & $-\mathrm{y}$ & $+\mathrm{z}$ \\
\hline 3.ng & $\mathrm{a}$ & $4 . \mathrm{ng}-1$ & $+\mathrm{x}$ & $-\mathrm{y}$ & $-\mathrm{z}$ \\
\hline 4.ng & $\mathrm{a}$ & $5 . \mathrm{ng}-1$ & $-\mathrm{x}$ & $+\mathrm{y}$ & $+\mathrm{z}$ \\
\hline 5.ng & $\mathrm{a}$ & $6 . \mathrm{ng}-1$ & $-\mathrm{x}$ & $+\mathrm{y}$ & $-\mathrm{z}$ \\
\hline 6.ng & a & $7 . n \mathrm{ng}-1$ & $-\mathrm{x}$ & $-\mathrm{y}$ & $+\mathrm{z}$ \\
\hline 7.ng & a & 8.ng-1 & $-\mathrm{x}$ & $-\mathrm{y}$ & $-\mathrm{z}$ \\
\hline
\end{tabular}

Tabela 4.2 - A permutaçäo dos sinais das coordenadas dos vetores presentes no Indice de Gradlentes. Onde ng é o número de gradlentes no $1 "$ octante.

A figura 4.11 apresentada esquematicamente um exemplo da obtenção de um índice (i) vetor aproximado para um vetor particular. A busca por um índice $(i)$ de um vetor aproximado a partir de um vetor qualquer ( $v)$ é realizada da seguinte maneira: 
- O correspondente $v^{\prime}$ de $v$ no $1^{\circ}$ octante é obtido pela simples conversão dos sinais negativos em positivos. Esse passo é necessário porque apenas os vetores do $1^{\circ}$ octante estão tabelados.

- Um índice ( $\left.i^{\prime}\right)$ correspondente a $v^{\prime}$ é obtido. A busca por $i^{\prime}$ inicia-se pela obtenção de um intervalo $(i$ min e $i$ 'max) na tabela de vetores através de busca binária [Yed96] pela coordenada $x$ de $v$ '. $\mathrm{O}$ limite inferior do intervalo, $i_{-}^{\prime} \min$, é obtido truncando-se a coordenada $x$ de $v$ na segunda casa decimal e o limite superior, $i_{-}^{\prime} \max$, é conseguido acrescentando-se 0.03 a $i$ ' min. Observe que esse intervalo delimita vetores que possuem coordenadas $x$ com no máximo 0.02 de diferença. A busca prossegue no intervalo $i_{-}^{\prime} \min$ e $i_{-}^{\prime}$ max através de busca seqüencial pela coordenada $y$ que mais se aproxime ao $y$ de $v^{\prime}$ retornando assim o índice esperado $i$ '.

- O índice desejado $i$ para $v$ deve corresponder ao intervalo do Índice de Gradientes para isso é utilizada a seguinte fórmula:

$i=i^{\prime}+\left(4^{*}\right.$ número de vetores do $l^{\circ}$ octante, se a coordenada $x$ de $v$ for $\left.<0\right)+$

$(2 *$ número de vetores do li octante, se a coordenada y de $v$ for $<0)+$

( número de vetores do $I^{\circ}$ octante, se a coordenada $z$ de $v$ for $<0$ ).

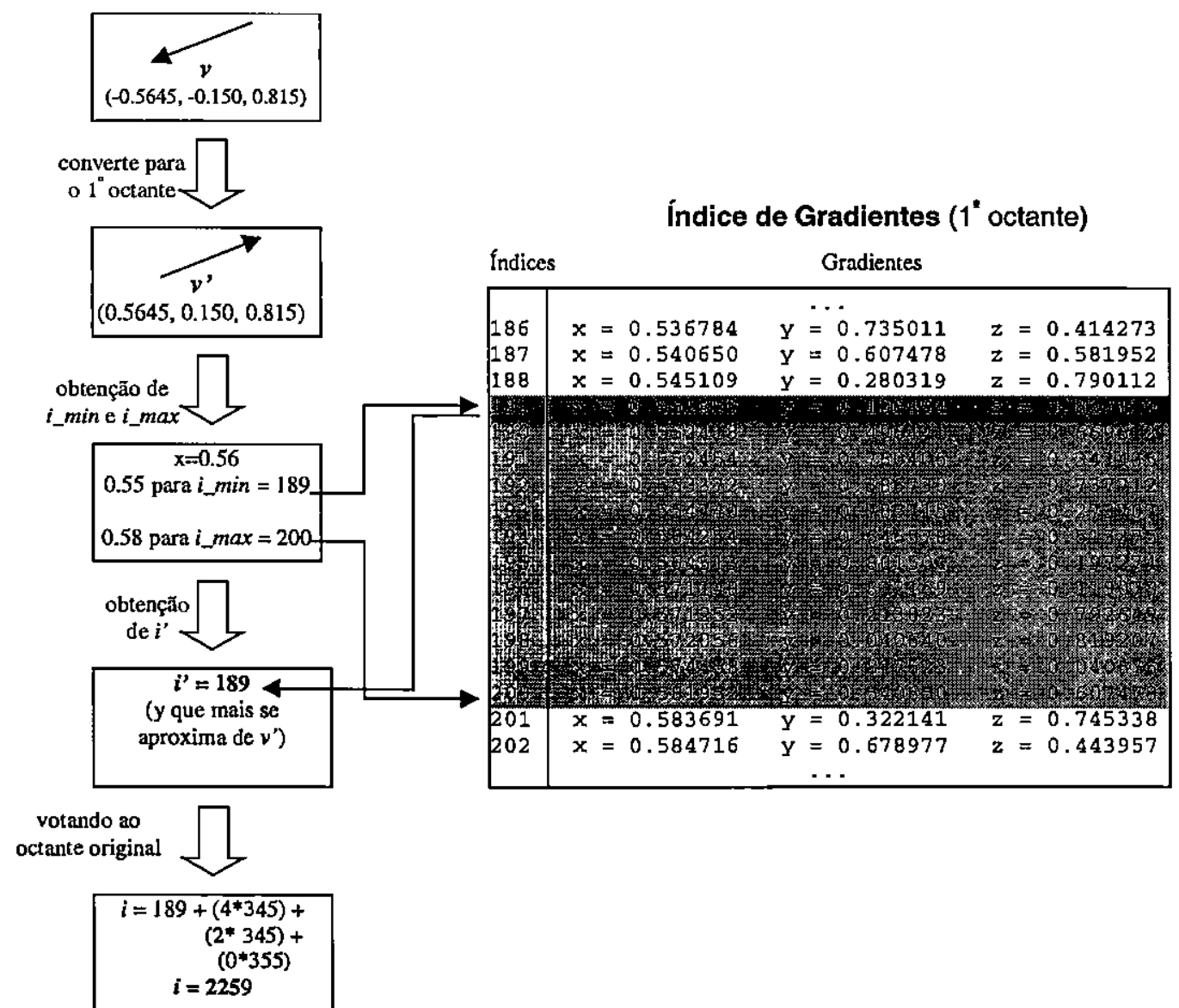

Figura 4.11 - Busca por um índlce (l) para um dado vetor ( $v$ ) no Índice de Gradientes. 
O Índice de Gradientes é utilizado na construção da Tabela de Reflexão implementada na classe vtkReflectionTable apresentada a seguir.

\section{A Classe vtkReflectionTable}

A classe vtkReflectionTable é responsável por criar a Tabela de Reflexão utilizada no processo de criação do mapa de textura considerando luz direcional. Quando um voxel deve ser visualizado e tonalizado, seu texel correspondente deve receber uma cor formada pela composição de luz ambiente $\mathrm{e}$ refletida. A Tabela de Reflexão mantém armazenadas as componentes de luz refletida para cada combinação entre os gradientes do Índice de Gradientes e os materiais definidos pelo usuário. Os cálculos de cada entrada da tabela são efetuados através das equações de Fresnel e da Lei de Lambert, apresentadas na seção 3.3.1.3.

As equações da componente de luz refletida levam em consideração os vetores direcionais das luzes presentes na cena, o vetor de direção de visão e um vetor normal à superfície que pode ser aproximado pelo gradiente naquele ponto. Os vetores normais são gerados no volume de dados e aproximados por vetores presentes no Índice de Gradientes. Os vetores normais pertencem ao sistema de coordenadas do volume de dados. Os vetores de direção das luzes e de visão pertencem ao sistema de coordenadas do mundo. Portanto, para que os cálculos sejam realizados, os vetores direcionais devem ser convertidos para o sistema de coordenadas do volume de dados.

A criação da Tabela de Reflexão inicia-se com a conversão dos vetores direcionais do sistema de coordenadas do mundo para as do volume de dados. Então, para cada material $(m)$ definido pelo usuário, cada um dos gradientes do Índice de Gradientes é obtido para que a componente de reflexão seja calculada e armazenada em uma entrada da tabela. Sendo assim, a Tabela de Reflexão é indexada pela tupla formada pelo material $(m)$ e um índice de gradiente $(g)$ fornecido pelo Índice de Gradientes.

A criação do mapa de textura não necessariamente precisa utilizar uma Tabela de Reflexão. A próxima seção diz respeito à construção do mapa de textura de acordo com as especificações do usuário.

\subsubsection{Construindo o Mapa de Textura}

A construção do mápa de textura consiste em ler os escalares no volume de dados e atribuir uma cor (RGBA) ao texel correspondente no mapa de textura de acordo com as configurações estabelecidas pelo usuário. Esses ajustes sāo efetuados através de métodos presentes na interface da classe vtkVolumeTexture (ver apêndice A).

No caso do uso de tonalização tabelada, os objetos responsáveis pelo Índice de Gradientes e pela Tabela de Reflexão ficam transparentes ao usuário do DVRT. Por isso, a interação com esses objetos é realizada de maneira indireta por meio de métodos presentes no vtkVolumeTexture. No entanto, 
existem métodos para realizar a manutenção direta de objetos vtkVectorIndex (Índice de Gradientes) e $v t k$ ReflectionTable (Tabela de Reflexão), caso seja conveniente.

Um problema que pode acontecer com freqüência é a tonalização do volume não ser apresentada corretamente, fazendo-se necessário uma inversão da região iluminada com a não iluminada, conforme discutido a seguir.

\section{Invertendo a Região Tonalizada do Volume}

Em um volume de dados pode-se ter os escalares menores no interior de um material e os maiores no exterior. Em outros volumes de dados os escalares podem estar dispostos da maneira inversa (os escalares maiores no interior). Os gradientes calculados por diferenças centrais [Lev88] para os voxels do volume de dados sempre apontam em direção aos maiores escalares. Uma vez que esse gradiente aproxima o vetor normal à superfície, seu sentido é importante no cálculo da tonalização porque informa o hemisfério da superfície que sofrerá influência da luz. Para que a tonalização seja calculada corretamente, é interessante que os gradientes sempre apontem para o exterior da superfície. Como isso nem sempre acontece, a tonalização pode acontecer no hemisfério errado, ou seja, aquele que está voltado para o lado oposto ao da luz. A figura 4.12 apresenta o esquema de um objeto esférico tonalizado corretamente e outro incorretamente. As tonalizações em hemisférios "invertidos" podem ser corrigidas, pelo usuário, através da utilização do método InvertShadingHemisphereOn do $v$ tkVolumeTexture. Esse método simplesmente inverte o sentido dos vetores direção de visão e direção das luzes na cena. O método InvertShadingHemisphereOff defaz essa inversão.

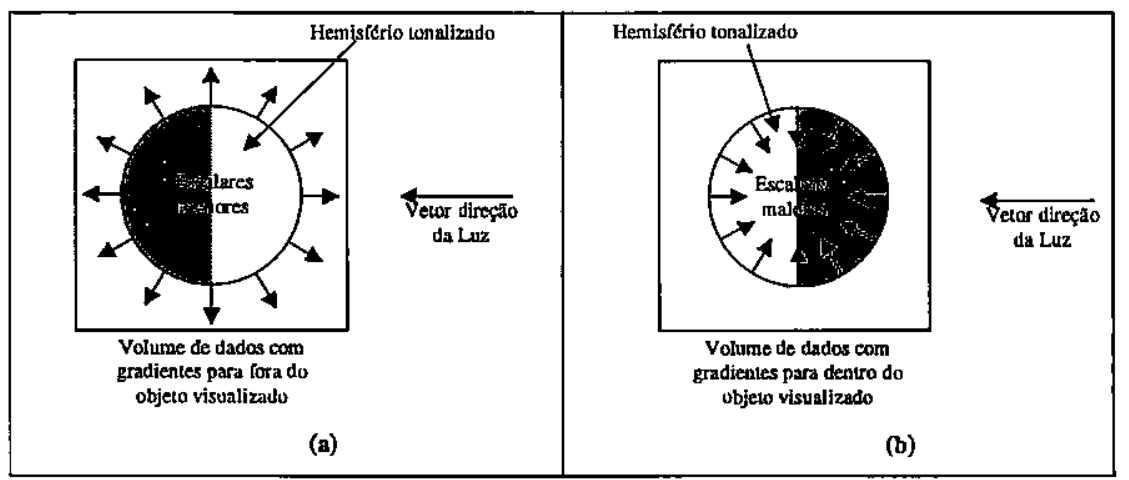

Figura 4.12 - Esquematização da visualização tonalizada de dois voiumes de dados. Em (a) o voiume de dados possul os escaiares menores no interior do objeto produzindo gradientes que apontam para fora do objeto acarretando em uma tonalização correta. Em (b) o voiume de dados possui escaiares maiores no interior do objeto o que produz a tonalizaçăo no hemisfério oposto.

O principal método da classe vtkVolumeTexture é o MakeVolumeTexture. Ele é responsável pela criação do mapa de textura de acordo com as escolhas do usuário, isto é, tonalizar ou não o volume de textura usando ou não a Tabela de Reflexão. A figura 4.13 apresenta a lógica desse método. 
Antes de dar início ao processo de criação do mapa de textura é necessário verificar as especificaçōes fornecidas pelo usuário. É possível criar três mapas de textura deferentes:

caso 1 - mapa de textura sem tonalização,

caso 2 - mapa de textura com tonalização usando tabela de reflexão e

caso 3 - mapa de textura com tonalização não usando tabela de reflexão.

Se o caso 2 ou 3 for solicitado, os gradientes do volume de dados devem ser gerados, caso ainda não tenham sido, e os vetores de direção das luzes e de visão devem ser convertidos do sistema de coordenadas do mundo para as do volume de dados. Se for o caso 2, os gradientes do volume de dados devem ser indexados com o Índice de Gradientes e a Tabela de Reflexão deve ser criada.

Como o processo de construção do mapa de textura com tonalização é computacionalmente caro, é interessante que o usuário faça uso desse recurso somente nos casos em que possa ajudar na interpretação dos dados em estudo. $\mathrm{O}$ vtkVolumeTexture tem como padrão a construção convencional do volume de textura, sem tonalização, e fornece os métodos SetShadeOn e SetShadeOff para habilitar ou desabilitar a visuàlização incorporando luz direcional. Caso o usuário precise de uma imagem de melhor qualidade ele pode habilitar ou desabilitar a utilização de tabelas (Índice de Gradientes e Tabela de Reflexão) pelos métodos SetUseOfReflectionTableOn e SetUseOfReflectionTableOff no vtkVolumeTexture. Os் métodos da classe $v t k$ VolumeTexture podem ser vistos com maiores detalhes no Apêndice A1. 


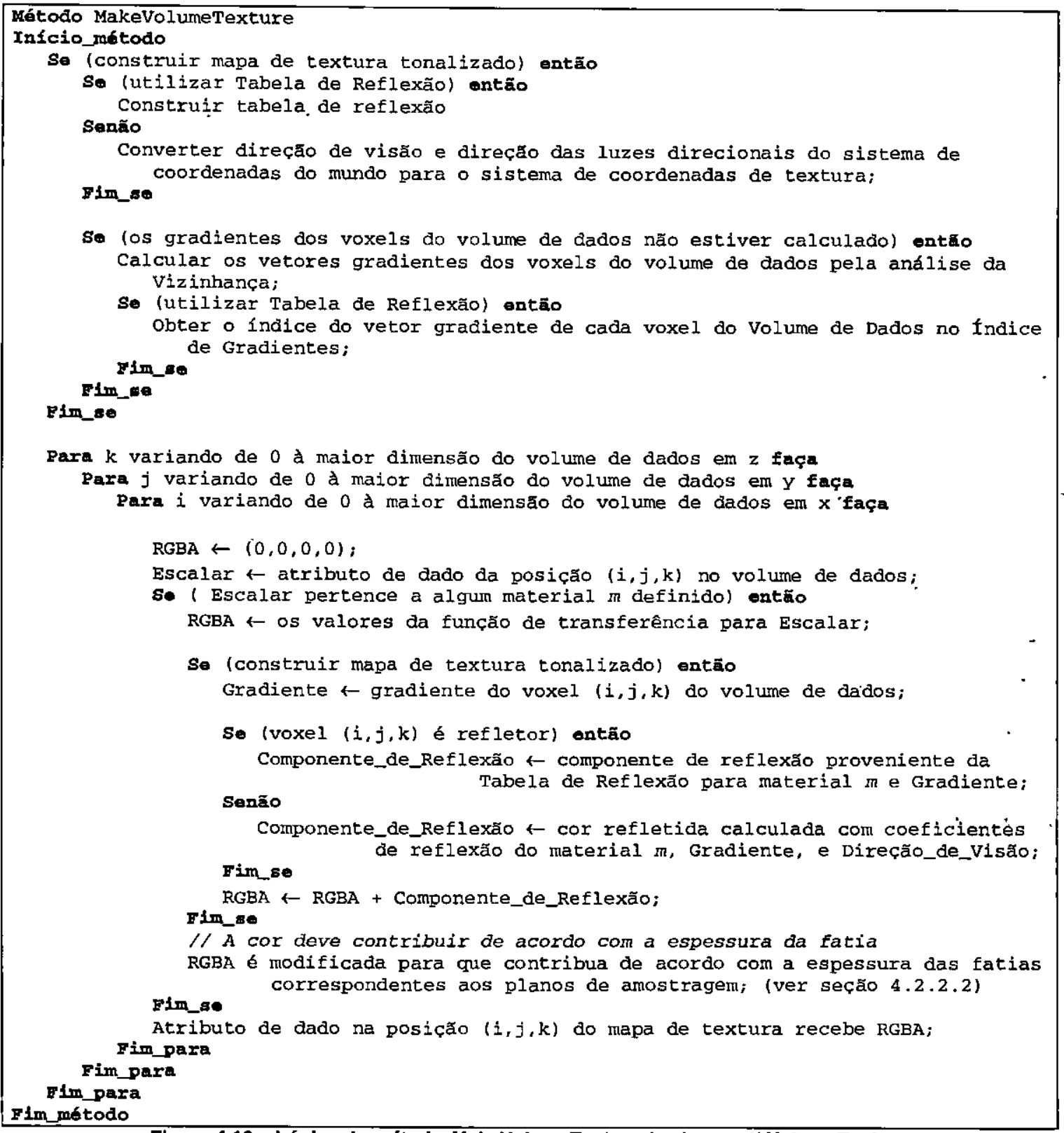

Figura 4.13 - Lógica do método MakeVolumeTexture da classe vikVolumeTexture.

A classe vtkVolumeTexture deve ser associada a uma outra classe para que a etapa de amostragem e rendering do volume de textura possa ser efetuada. Essa outra classe, chamada vtkVolumeTextureMapper, é descrita na próxima seção.

\subsubsection{A classe vtkVolumeTextureMapper}

A implementação do rendering por ray casting no VTK fica localizada na classe vtkVolumeRayCastMapper. A maneira como o método responsável pelo ray casting é invocado a partir do vtkRenderWindow foi analisada. Através dessa análise, chegou-se à conclusão que para 
implementar a abordagem de visualização DVRT no VTK seria necessário criar uma nova classe a partir da classe abstrata vtkVolumeMapper, o que levou à criação da classe vtkVolumeTextureMapper.

Para que uma cena seja renderizada no VTK, o usuário deve invocar o método Render presente no $v t k R e n d e r W i n d o w$. A partir do vtkRenderWindow é desencadeada uma sequiência de invocações de métodos para que finalmente seja executado o método Render presente no vtkVolumeTextureMapper. Esse é o método responsável pela execução do algoritmo de rendering volumétrico por mapeamento de textura.

A Figura 4.14 apresenta um esquema das chamadas de métodos até que o Render do vtkVolumeTextureMapper seja invocado. No vtkRenderWindow, o método Render chama uma seqüência de métodos dessa mesma classe chegando em um ponto que é invocado o método Render pertencente à classe vtkRendererCollection. Todos os objetos do tipo vtkRenderer adicionados ao $v t k R e n d e r W i n d o w$ inicial estão presentes nesse vtkRendererCollection, que por sua vez invoca 0 método Render de cada um de seus objetos vtkRenderer. No vtkRenderer o método Render invoca uma sequiência de métodos (inclusive visitando a classe vtkOpenGLRenderer) que chega a invocar o método Render presente no vtkRayCaster, esse objeto concentra os volumes sendo visualizados. Nesse ponto, todos os vtkVolumes adicionados ao vtkRenderer em questão são obtidos e processados. Cada vtkVolume invoca o método Render presente em alguma classe derivada da vtkVolumeMapper à qual está associada. Finalmente, se alguma das classes derivadas do vtkVolumeMapper for a vtkVolumeTextureMapper, o seu método Render é invocado e então ocorre o DVRT.

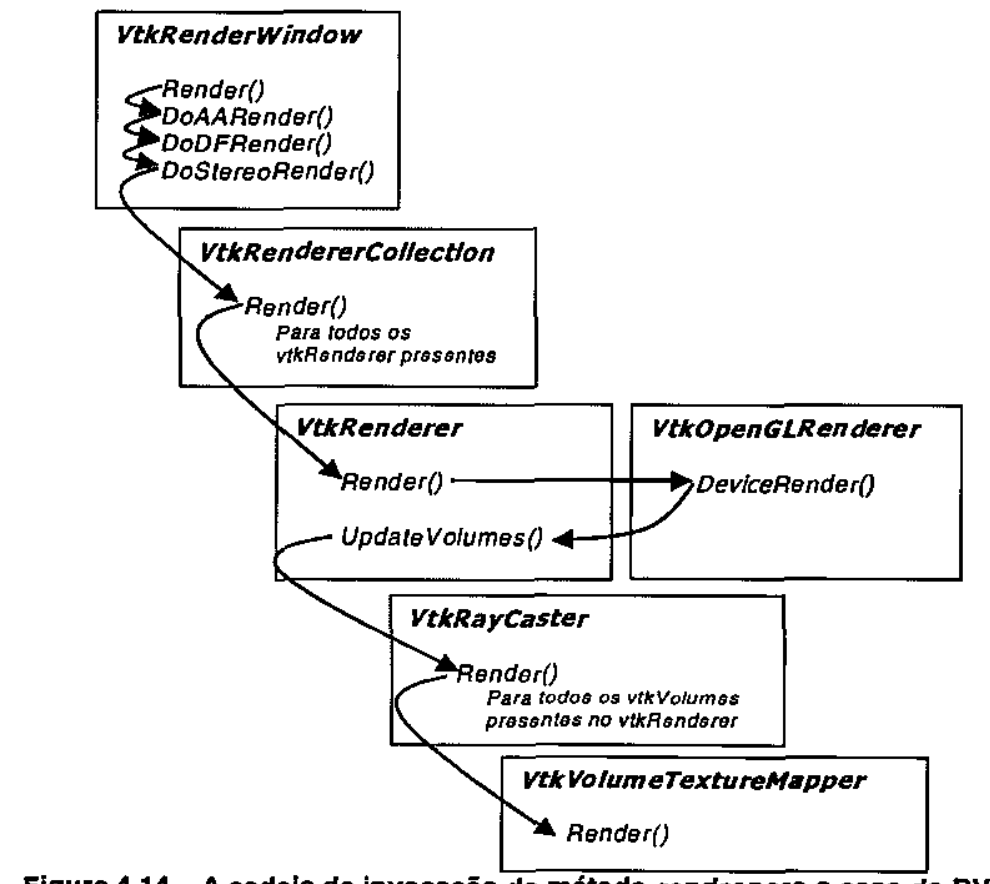

Figura 4.14 - A cadela de invocaçāo do método render para o caso do DVRT. 
A abordagem de visualização DVRT implementada é própria para rendering através de projeção paralela. Para que o método seja executado é necessário que a câmera ativa do vtkRenderer esteja ajustada para esse tipo de projeção e que uma escala adequada seja fornecida. Para isso, as seguintes linhas de código devem ser inseridas no programa:

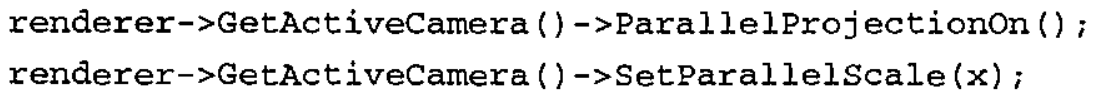

onde renderer é a instância da classe vtkRenderer. $\mathrm{O}$ valor da escala serve para aumentar ou diminuir o tamanho do volume na cena. Sem ajustar esse parâmetro, o volume pode se apresentar tão grande ou tão pequeno que impossibilita sua identificação.

A função básica do vtkVolumeTextureMapper é preencher dois vetores (arrays) de números reais: o RGBAlmage e o Zimage. Esses vetores contém informações sobre cada pixel da imagem relativa à viewport na qual o volume será visualizado. $O$ primeiro vetor contém informações de intensidades de cor (RGB) e opacidade (A), onde cada componente varia entre 0.0 e 1.0. As informações desse vetor estão dispostas na seqüência RGBARGBA ... RGBA. O segundo vetor, Zimage, contém informações de profundidade ( $Z$-buffer ), ao longo da normal ao plano de visão, e é utilizado para indicação da seqüência de obstrução dos objetos. Os dois vetores devem ser preenchidos sempre que o método Render for invocado, ou seja, sempre que acontecer alguma alteração na cena ou alguma mudança na câmera. As informações da imagem do volume renderizado estão presentes nesses dois vetơres.

Para que os vetores acima sejam preenchidos é necessário que todo o processo de DVRT seja executado. Nas próximas subseções são apresentadas como a classe vtkVolumeTextureMapper implementa a etapa, descrita na seção 3.3.2, de amostragem e rendering do mapa de textura.

\subsubsection{1 $O$ bounding Cube}

Para se definir os planos de amostragem no rendering, deve-se primeiro gerar um bounding cube tal que ele possa conter inteiramente o mapa de textura em qualquer rotação. Com isso, o comprimento do lado do bounding cube deve ser igual à diagonal do mapa de textura.

Para se obter os 8 pontos que definem o bounding cube é necessário conseguir, a partir da câmera ativa, 3 vetores: a direção de visão (dada pela posição da câmera e seu ponto focal); o vetor ViewUp (ver figura 4.3), e um terceiro vetor $(v l)$ obtido pelo produto vetorial dos dois primeiros. $O$ ponto central do volume de textura serve como início para a obtenção dos oito pontos através de somas consecutivas dos três vetores mencionados a esse ponto. A figura 4.15 apresenta a sequiência de obtenção dos pontos. Um ponto somado com um vetor de magnitude igual a $\mathrm{d}$ ou $\mathrm{d} / 2$ ( $\mathrm{d}$ é a dimensão do bounding cube) gera o próximo ponto da sequiência. 

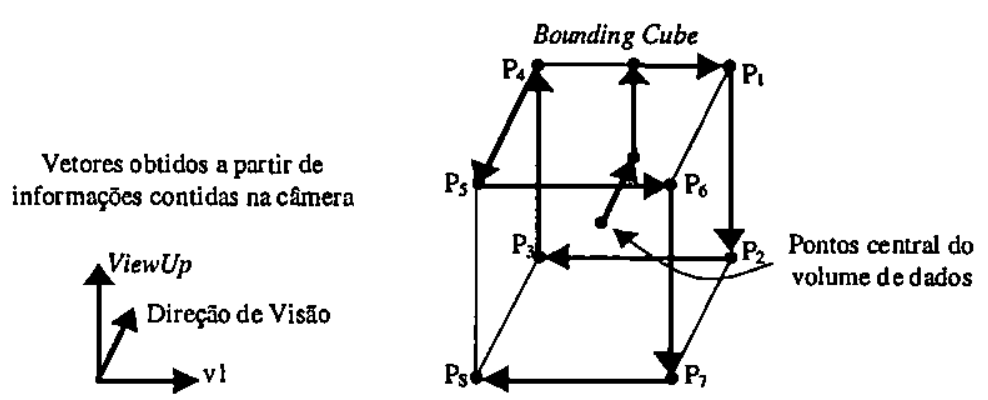

Flgura 4.15 - Seqũência de obtenção dos pontos que definem o bounding cube. A seqũeancia de obtenção dos pontos $6 P_{1}$ a $P_{8}$ ordenadamente.

\subsubsection{Os Planos de Amostragem}

É no bounding cube que os planos de amostragem são posicionados, como apresentado na seção 3.2. É necessário que o usuário entre com a distância $(\Delta)$ que deve separar os planos. $\mathrm{O}$ primeiro plano de amostragem é posicionado à distância de $\Delta / 2$ da face frontal do Bounding Cube. A quantidade de planos de amostragem (PA) é calculada levando-se em consideração o comprimento lateral do Bounding Cube (d) e $\Delta$, da seguinte forma:

$$
\mathrm{PA}=(\text { parte_inteira }(\mathrm{d}-\Delta / 2) / \Delta)+1
$$

onde a função parte_inteira retorna apenas a parte inteira do ponto flutuante de entrada. Os pontos que definem cada plano de amostragem são conseguidos a partir dos 4 pontos frontais do bounding cube. Os quatro pontos que limitam o plano de amostragem mais próximo do plano de projeção são conseguidos pela seguinte equação:

$$
\text { Ponto }_{(0, i)}=\text { Ponto da face frontal do Bounding Cube } \operatorname{Cu}_{(i)}+(\Delta / 2) * \text { direção de visão normalizada }
$$

Onde Ponto(k,i) significa ponto limitante $i$ do plano de amostragem $k$ e $0 \leq i \leq 3$ (os quatro pontos do plano frontal do bounding cube).

Os pontos que definem os próximos planos de amostragem são obtidos como se segue:

$$
\text { Ponto }_{(j, i)}=\text { Ponto }_{(j-1, i)}+\text { direção de visão normalizada } * \Delta
$$

onde $1 \leq j \leq \mathrm{PA} \mathrm{e} 0 \leq i \leq 3$.

A figura 4.16 apresenta um esquema da disposição dos planos de amostragem dentro do Bounding Cube para uma dada distância $\Delta$ entre planos. 


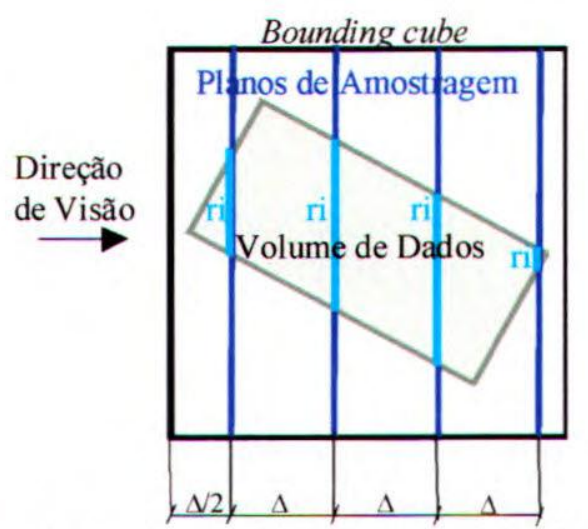

Figura 4.16 - Disposição dos Planos de Amostragem no Bounding Cube.

Nos planos de amostragem existe uma região denominada polígono de textura que é justamente a região de interesse do plano (representado por ri no esquema da figura 4.16). Os polígonos de textura são o assunto da seção seguinte.

\subsubsection{Os Poligonos de Textura}

Os polígonos de textura, apresentados anteriormente (ver figura 3.23), correspondem à região de interesse nos planos de amostragem, pois eles delimitam as áreas dos planos que estão inseridas no mapa de textura. A utilização desses polígonos no processo de amostragem acelera o rendering de um volume pois evita que os pontos dos planos de amostragem que não incidem no mapa de textura sejam processados. O polígono delimita exatamente a área do plano de amostragem que tem probabilidade de colher cores visíveis no mapa de textura (ver Figura 4.17).

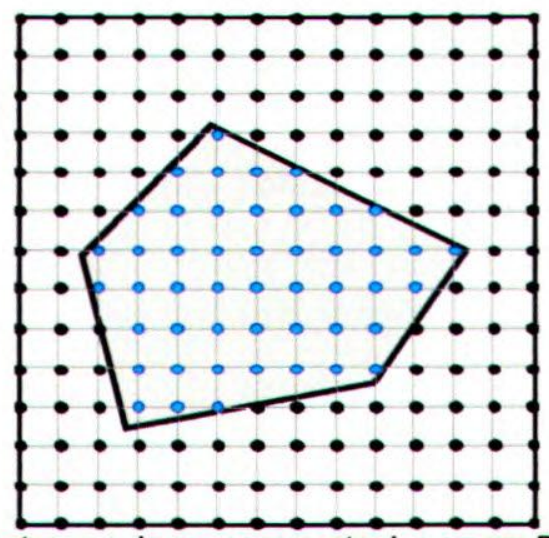

Figura 4.17 - Destaque em azul dos pontos que devem ser amostrados em um Plano de Amostragem com Polígono de Textura.

O algoritmo trivial para obtenção dos polígonos de textura consiste em calcular a interseção de cada plano de amostragem com cada aresta do volume de dados. Uma vez que o número de planos de amostragem é elevado e os métodos de rendering volumétrico direto são computacionalmente caros, foi criado um algoritmo mais elaborado para calcular os polígonos de textura. Esse algoritmo consiste em calcular vetores de acréscimo para cada aresta do volume de dados a fim de obter novos pontos por 
apenas soma de vetores a pontos. Para isso os vértices que delimitam o volume de dados são numerados de acordo com a figura 4.18. Também é definida uma relação de adjacência entre eles.

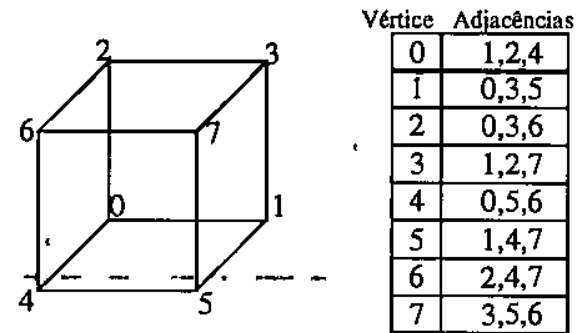

Figura 4.18 - A numeração dos vértlces do volume de dados e suas adjacências.

Cada vértice do volume de dados possui um indicador informando se ele já foi processado. Cada aresta possui uma estrutura contendo as seguintes informações:

- Pontolnicial e PontoFinal: são os dois pontos pertencentes ao volume de dados que definem a aresta. O ponto inicial é o que se encontra mais próximo ao observador.

- PrimeiroPonto: informa se a aresta já sofreu interseção com um plano

- EstadoDeProcessamento: informa se a aresta está em processamento, não processada ou se já foi processada

- EstadoVetorDeAcréscimo: informa se o vetor de acréscimo já foi criado

- VetorDeAcréscimo: vetor obtido subtraindo-se o primeiro ponto de interseção da aresta com um plano de amostragem do segundo ponto de.interseção (com o plano imediatamente consecutivo)

- ÚltimoPontoDeInterseção: coordenadas d́o ponto de interseção da aresta com o último plano de amostragem processádo. O ponto de interseção com o próximo plano é conseguido através da soma do vetor de acréscimo com o último ponto obtido.

Os planos de amostragem são submetidos aos cálculos dos polígonos de textura seguindo a ordem do plano mais próximo ao observador para o mais distante. Nem sempre todos os planos cortam o volume de textura, por isso, é necessário indicar em qual plano deve-se iniciar a obtenção dos polígonos para economizar processamento.

A lógica de implementação para obtenção do polígono de textura é apresentada na figura 4.19. -Inicialmente, os vértices do volume de dados são ordenados de acordo com as proximidades com o ponto de visão. Três arestas são inicializadas com o primeiro ponto detectado $\left(p_{0}\right)$ e seus três pontos adjacentes $\left(p_{1}, p_{2}\right.$ e $\left.p_{3}\right)$. Os três pontos adjacentes $\left(p_{1}, p_{2}\right.$ e $\left.p_{3}\right)$ também são ordenados pela proximidade com o ponto de visão e então as arestas $\left(a_{0}, a_{I}\right.$ e $\left.a_{2}\right)$ são criadas seguindo a mesma ordem. O ponto $p_{0}$ 
passa para o estado de já processado. As três arestas $a_{0}, a_{l}$ e $a_{2}$ são colocadas em estado de processamento. A figura 4.19 apresenta um exemplo para esses valores.

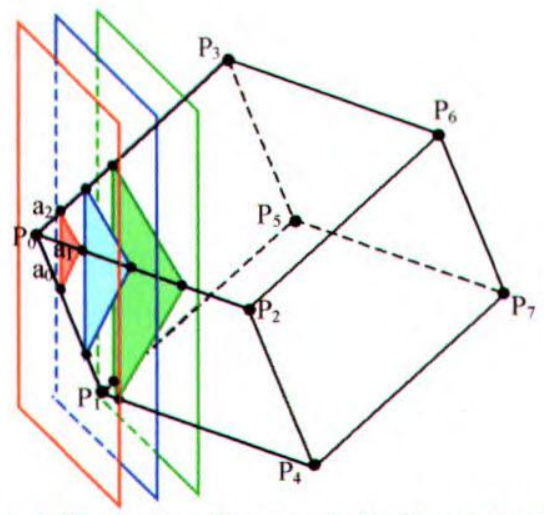

Figura 4.19 - Obtenção dos pontos que definem os polígonos de textura para os três primeiros planos de amostragem que interceptam o volume de dados.

O procedimento responsável pela obtenção do polígono de textura de um plano de amostragem começa detectando o conjunto de arestas que estão em processamento. Cada aresta desse conjunto é avaliada para se obter seu ponto de interseção com o plano de amostragem em questão. Esse ponto pode ser obtido em três casos diferentes:

Caso 1: a aresta ainda não sofreu interseção com algum plano de amostragem.

Caso 2: a aresta sofreu interseção com apenas um plano de amostragem.

Caso 3: a aresta já sofreu no mínimo 2 interseções com planos de amostragem.

Nos dois primeiros casos é necessário fazer o cálculo de interseção de uma reta com um plano. Porém, no terceiro caso, que tende a ocorrer com mais freqüência, o ponto de interseção é conseguido através de uma soma de um vetor com um ponto.

O ponto de interseção obtido pode pertencer ao segmento de reta definido pela aresta em questão ou pode estar atrás da aresta (é bom lembrar que os planos de amostragem são processados do mais próximo para o mais distante do observador). Se o ponto pertencer à aresta, ele é adicionado ao conjunto de pontos que definem o polígono de textura. Se o ponto não pertencer à aresta, a aresta em questão deixa de estar no estado de "em processamento" e passa a ser "já processada" e suas arestas adjacentes são formadas e submetidas à aquisição de pontos de interseção.

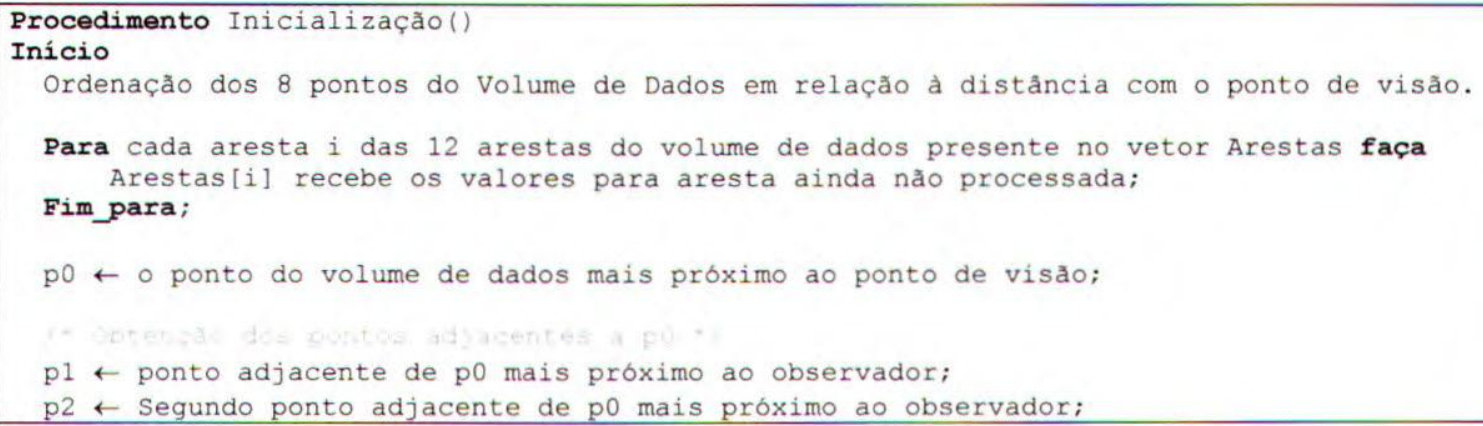




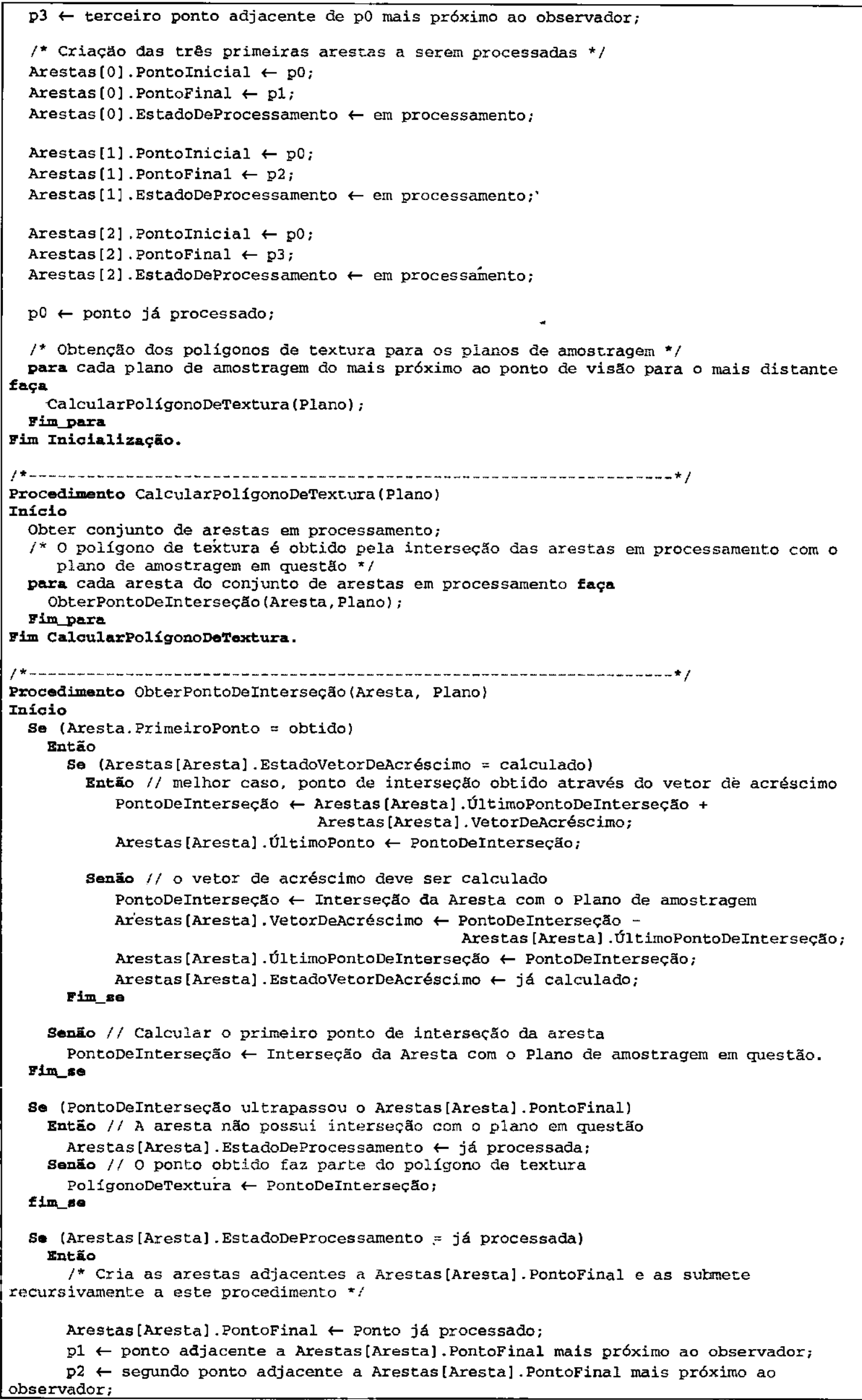




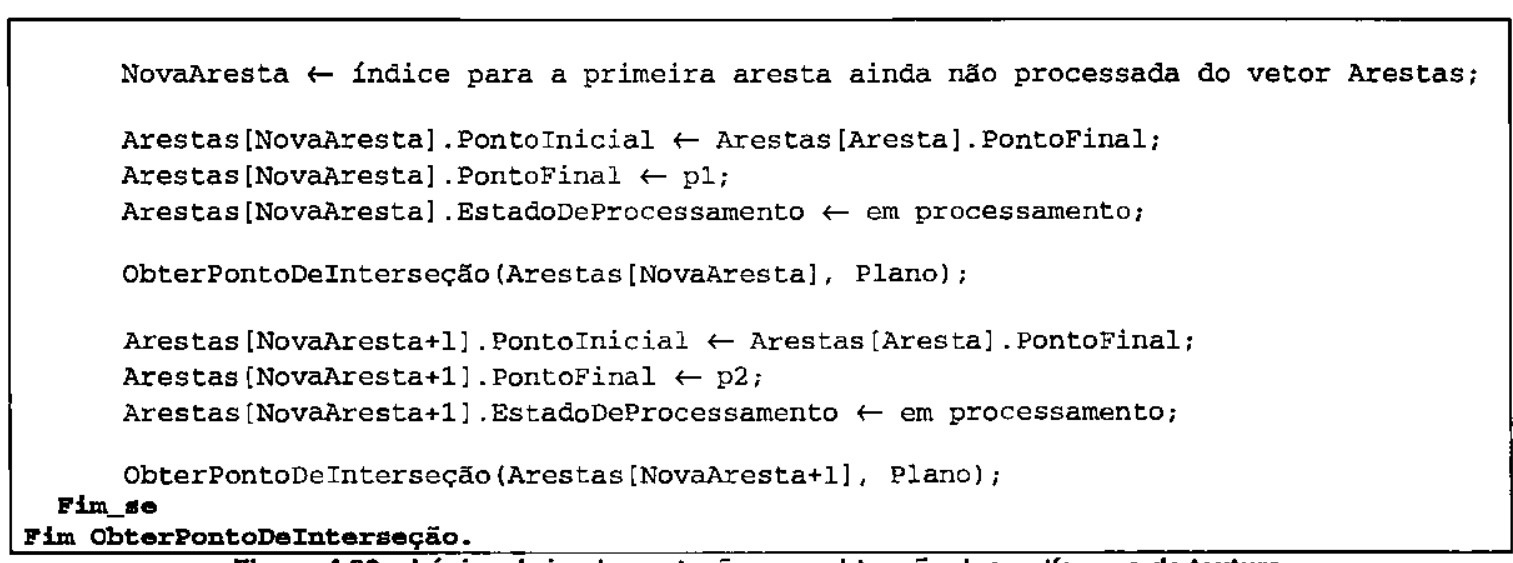

Figura 4.20 - Lógica de implementação para obtenção dos polfgonos de textura.

Quando os pontos do polígono de textura para um plano de amostragem são obtidos pelo processo descrito, eles não possuem uma orientação coerente e, por isso, devem ser orientados. Antes de se fazer a orientação propriamente dita, os pontos do polígono são projetados em um dos planos coordenados $(\mathrm{xxy}, \mathrm{yxz}, \mathrm{xxz})$ onde eles possam ser ordenados. A orientação de um polígono com $n$ pontos se dá da seguinte forma:

- Os pontos são ordenados crescentemente por uma das coordenadas $\left(p_{0}, p_{1}, \ldots, p_{n}\right)$.

- Um vetor base $(v)$ é criado do ponto mais à esquerda $\left(p_{0}\right)$ para o segundo ponto mais à esquerda $\left(p_{l}\right)$.

- Para cada ponto $p_{i} \operatorname{com}(2 \leq i \leq n)$ é calculado o coseno do ângulo entre o vetor base $(v)$ e o vetor formado entre o ponto $p_{o}$ e o ponto $p_{i}$.

- Os pontos $p_{i} \operatorname{com}(2 \leq i \leq n)$ são ordenados em ordem decrescente pelos cosenos calculados.

- O polígono orientado segue a ordem: $p_{0,} p_{1}$ e os outros pontos seguindo a ordem do passo anterior.

Quando todos os planos de amostragem possuírem polígonos de textura orientados, seus polígonos devem ser discretizados para que aconteça o processo de amostragem. Esse é o assunto da próxima seção.

\subsubsection{Preparação dos Polígonos de Textura para Amostragem}

De acordo com o descrito na seção 3.3.2, existe uma correspondência entre os planos de amostragem e os pixels da tela. Como apresentado, os polígonos de textura cobrem os pixels que têm probabilidade de receber contribuição de cor do mapa de textura. Como os polígonos de textura estão definidos no sistema de coordenadas do mundo, eles precisam ser convertidos para o sistema de coordenadas da 
tela para definir a região de pixels de interesse. A intenção é obter para cada $y$ do polígono de textura, um intervalo em $x$ que deve ser amostrado (em coordenadas da tela).

A preparação de um polígono de textura para a amostragem inicia-se com a conversão de suas coordenadas do mundo para as da tela. Dois inteiros limite_inferior e limite_superior são utilizados para delimitar as linhas de pixels que compreendem o polígono de textura. Dois vetores (arrays) de números inteiros são utilizados para delimitar a região de pixels de interesse: limite_à_esquerda $\mathrm{e}$ limite_à_direita. Esses vetores possuem um inteiro para cada linha de pixels entre limite_inferior e limite_superior (região em destaque na figura 4.21). O vetor limite_à_esquerda possui as referências para os pixels mais à esquerda cobertos pelo polígono e o vetor limite_à_direita os pixels mais à direita, para cada linha do polígono discretizado (ver figura 4.21).

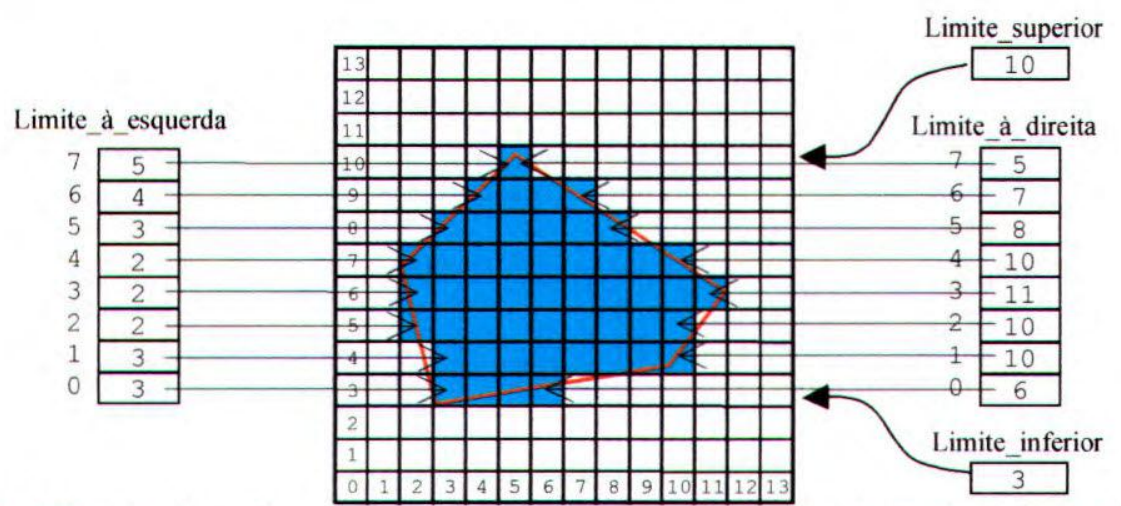

Figura 4.21 - Utilização dos vetores limite à esquerda e limite à direita e dos indicadores limite inferior e limite_superior para delimitar a região de pixels coberta pelo polígono de textura. A grade (14x14), no caso, delimita a região da tela coberta pelo plano de amostragem.

Inicialmente o vetor limite_à_esquerda é preenchido com o maior valor à direita (13 no caso da figura 4.21). O vetor limite_à_direita é preenchido com 0's. À medida que cada aresta do polígono de textura é discretizada, através do algoritmo de Bresenham [Hea97], os dois vetores limite vão sendo atualizados. Sempre que o algoritmo de Bresenham retorna um ponto $(x, y)$, ocorre os seguintes passos:

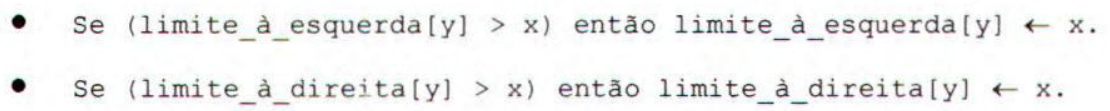

Quando todas as arestas do polígono tiverem sido discretizadas, as variáveis de limite possuirão as informações necessárias para indicar os pixels onde deve ocorrer amostragem. Feito isso, dá-se início ao processo de amostragem dos planos, como apresentado na próxima seção.

\subsubsection{O processo de amostragem}

O processo de amostragem consiste em coletar informações no mapa de textura para os planos de amostragem. Como visto na seção 3.2, três dos pontos que definem um plano de amostragem devem ter suas coordenadas transformadas do sistema de coordenadas do mundo para as da tela (display). Feita a conversão de coordenadas, o processo se dá como apresentado na figura 3.19. 
A amostragem se dá apenas nos pontos que incidem nos polígonos de textura.

A Figura 4.22 apresenta uma janela do VTK com um volume renderizado por DVRT utilizando 3 planos de amostragem. Nessa figura são destacadas as regiões da janela. A região em branco corresponde à viewport onde o volume está definido. A área delimitada por um retângulo em azul corresponde à região coberta pelos planos de amostragem. $\mathrm{O}$ cubo com arestas em preto corresponde ao volume sendo visualizado e é onde os polígonos de textura (em vermelho) estão inseridos.

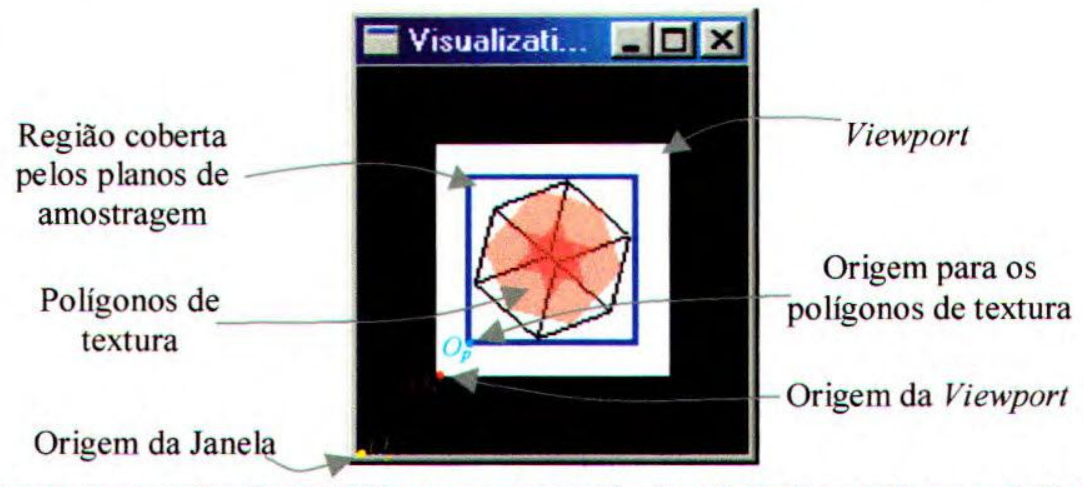

Figura 4.22 - Uma janela de visualização do VTK com apresentação das direfentes regiões envolvidas na amostragem com suas respectivas origens de coordenadas.

O processo de amostragem é intercalado com o de blending, uma vez que cada plano deve ser combinado com os anteriores para produzir a imagem final. Como apresentado no início da seção 4.2.2, a função do vtkVolumeTextureMapper consiste basicamente em preencher dois vetores (arrays): o RGBAImage e o Zimage. O primeiro deve conter informações de cor e opacidade para cada pixel e o segundo contém as informações de profundidade. Essas informações são relativas a todos os pixels presentes na viewport onde o volume está inserido. Portanto, o processo de amostragem tem como objetivo final atualizar os dois vetores com as informações do volume sendo visualizado.

Inicialmente, os vetores RGBAImagem e Zimage são preenchidos com intensidades de cor e opacidade nulas, e valores $z$ iguais a 1.0 (o limite ao fundo), respectivamente. Os vetores $\Delta \mathrm{x}$ e $\Delta \mathrm{y}$ para deslocamento entre os pontos de amostragens nos planos de amostragem são calculados.

Como visto na seção 3.3.2, a ordem de processamento dos planos de amostragem é feita de trás para frente, ou seja, o primeiro plano a ser amostrado é o que está mais distante do observador. À medida que os planos de amostragem vão sendo processados, os vetores RGBAImage e o Zimage devem ser atualizados com blending. A lógica do algoritmo utilizado para processar um plano de amostragem é apresentada na figura 4.23 . 


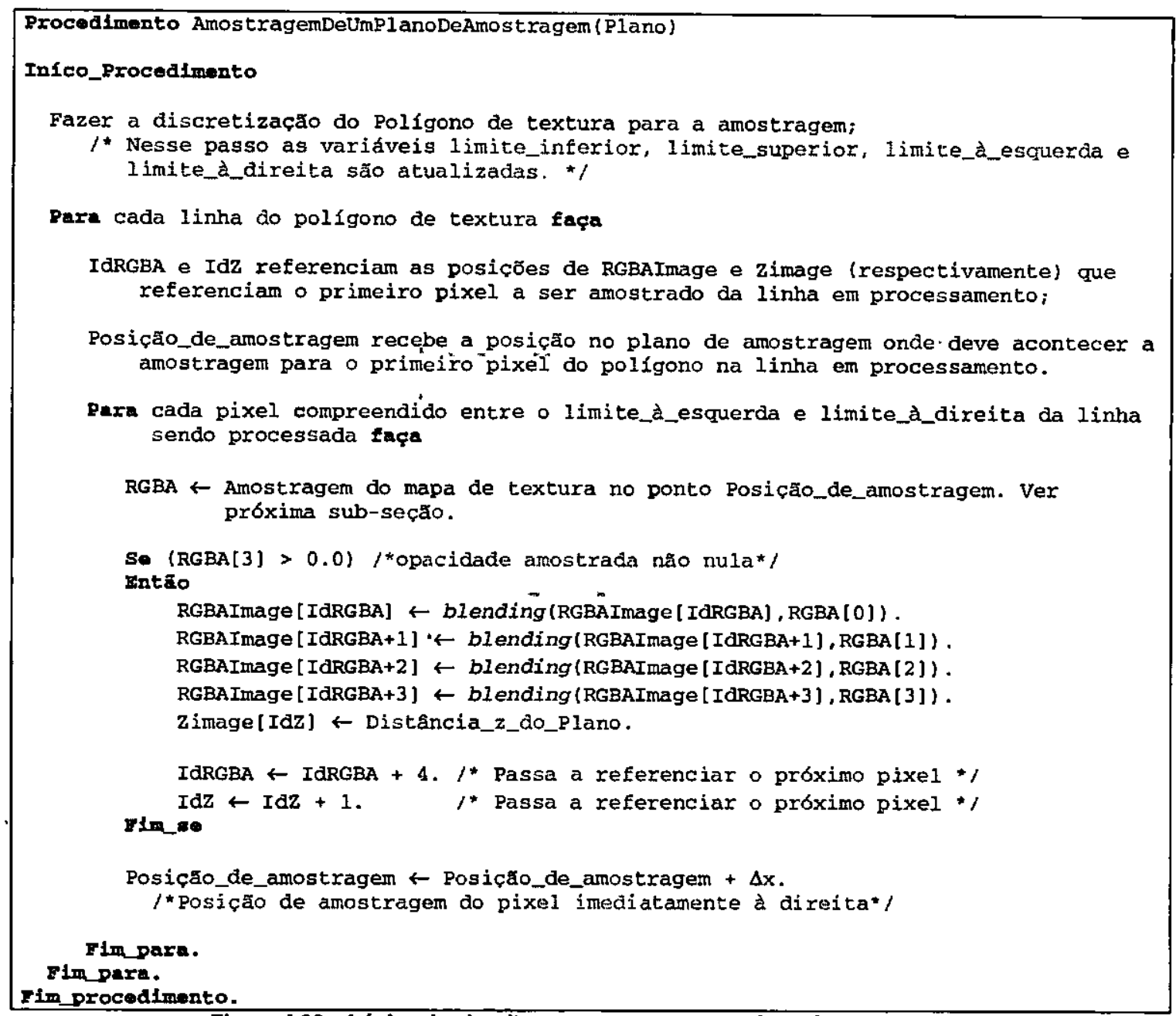

Figura 4.23 - Lógica do algoritmo para amostrar um plano de amostragem.

A área de amostragem de cada plano é delimitada pelas variáveis limite_inferior, limite_superior, limite_à_esquerda e limite_ḋ_direita, atualizadas no passo de preparação do polígono de textura para a amostragem, seção 4.2.2.4. Os pontos são amostrados seguindo a ordem da esquerda para direita e de baixo para cima. A figura 4.24 apresenta esquematicamente o processo de amostragem destacando o relacionamento das variáveis envolvidas. 
Sistema de Coordenadas da Tela

Região da Viewport

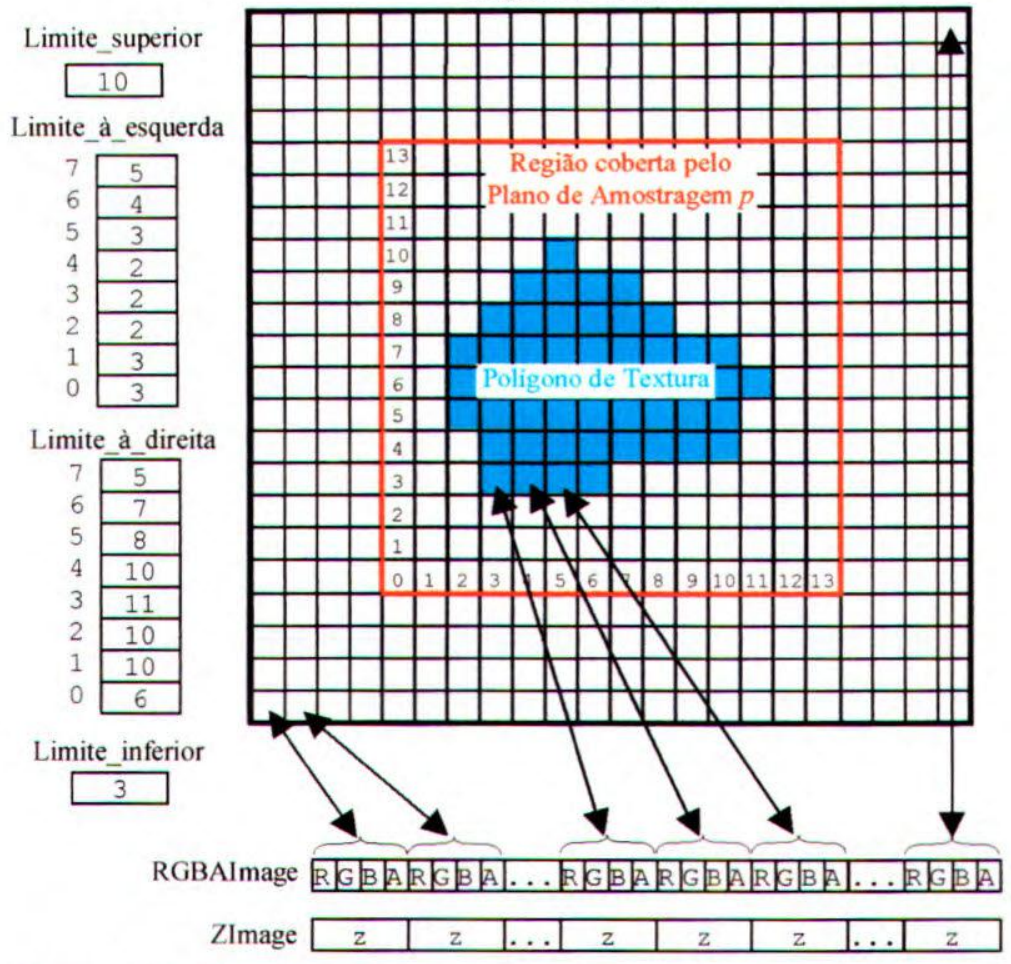

Sistema de Coordenadas do Mundo

Plano de Amostragem $p$

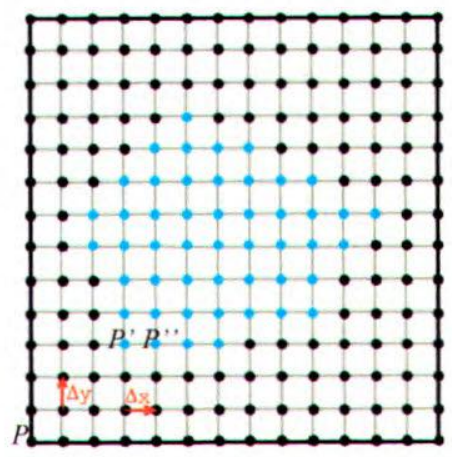

Onde:

$\boldsymbol{P}$ : Ponto de referência para os pontos de amostragem

P': Local da primeira amostragem $P^{\prime}=P+$ limite inferior ${ }^{*} \Delta y+$ limite à esquerda [0] ${ }^{*} \Delta x$ p": Local da segunda amostragem $P^{\prime \prime}=P^{\prime}+\Delta x$

$\Delta x$ e $\Delta y$ : Vetores para deslocamento entre pontos de amostragem

Figura 4.24 - $O$ processo de amostragem, destacando: o relacionamento dos vetores (arrays) RGBAlmage e Zimage com os pixels da Viewport na tela; a utilizaçăo dos limites do polígono de textura e os vetores de deslocamento ( $\Delta x \mathbf{e}$ $\Delta y)$ para alterar a posição do ponto de amostragem no plano de textura.

\subsubsection{A Coleta da Amostra}

O mapa de textura pode ser amostrado de duas maneiras diferentes. Como o mapa de textura é um volume de dados, suas unidades (os texels) podem conter os valores RGBA dispostos seguindo um modelo voxel ou célula, como discutido no capítulo 2 (ver figura 4.25). A vantagem de se usar a abordagem "texel-voxel" é que não é necessário fazer interpolação em cada amostragem, o que acelera o processo. Por outro lado, se for usado o "texel-célula" a imagem resultante é de melhor qualidade. O vtkVolumeTextureMapper possibilita a escolha de qual abordagem usar através dos métodos SetTexelAsVoxel() e SetTexelAsCell(0. A abordagem padrão é a "texel-voxel".

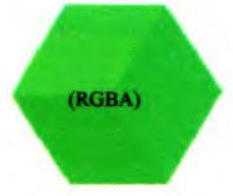

Texel como Voxel Mesmo (RGBA) para todo o texel

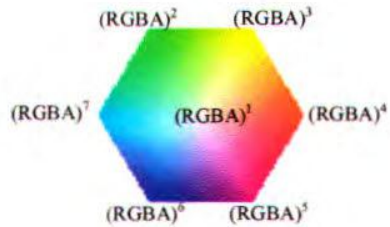

Texel como Célula

Diferentes (RGBA) nos vértices do texel

Figura 4.25 - Um texel do Mapa de Textura como os valores RGBA dispostos como voxel (esquerda) e célula (direita). 
Uma amostra retorna os valores RGBA contidos no mapa de textura para uma posição de amostragem. Para saber se os vetores RGBAImage e Zimage devem ser alterados, a opacidade coletada é verificada. Se ela for uma opacidade válida (maior que zero) os valores RGBA do RGBAImage são alterados pelo blending com os -valores amostrados e o Zimage recebe o valor de profundidade do plano. Caso contrário, não ocorre alteração alguma.

É importante observar que existem três origens distintas na tela (ver figura 4.22). A primeira é origem dos pixels da janela (ponto $O_{j}$ da figura 4.22). É segundo essa origem que os pontos são convertidos do sistema de coordenada do mundo para as da tela. As variáveis de limite do polígono de textura (limite_inferior, limite_superior, limite_à_esquerda e limire_à_direita) possuem suas entradas de acordo com úma origem colocada no pixel inferior esquerdo da região correspondente ao plano de amostragem (ponto $O_{p}$ da figura 4.22). Isso é necessário porque a função dessas variáveis é justamente servir como unidades de deslocamento da posição de amostragem (em $\Delta x$ ou em $\Delta y$ ) no plano (coordenadas do mundo). Os vetores RGBAImage e Zimage seguem uma origem posicionada no canto inferior esquerdo da região da viewport (ponto $\bar{O}_{v}$ da figura 4.22). Para que existä correspondência esses sistemas de coordenadas, a origem $O_{p}$ e $O_{v}$ também possuem suas coordenadas em relação à origem $O_{j}$.

Depois que todos os planos de amostragem tenham sido processados, os vetores RGBAImage e o Zimage possuem as informações da imagem referente ao volume. O próprio VTK se encarrega de apresentar a imagem (contida nos dois vetores) ao usuário.

É comum que o usuário que está fazendo uso de visualização para estudar um volume de dados faça ampliações das imagens geradas. Para que o DVRT possibilite a utilização dessas ampliaçōes, alguns cuidados tiveram que ser tomados. A próxima seção aborda esses cuidados.

\subsubsection{Possibilitando Ampliações da Imagem na Visualização por DVRT}

Como apresentado anteriormente, para que um plano de amostragem possa ser processado é necessário que exista uma correspondência entre os pontos de amostragem com os pixels da tela. Para isso, o ponto inferior esquerdo $\left(P_{\text {plano }}\right)$ do plano de amostragem (coordenadas do mundo) deve referenciar um pixel da tela (coordenadas da tela). Com isso, qualquer pixel $(x, y)$ que pertença ao polígono de textura tem seu ponto de amostragem obtido pela equação:

Ponto de amostragem para um pixel na posição $(\mathrm{x}, \mathrm{y})=\mathrm{P}_{\mathrm{Plano}}+\mathrm{x}^{*} \Delta \mathrm{x}+\mathrm{y}^{*} \Delta \mathrm{y}$

onde $\Delta x$ e $\Delta y$ são os vetores de deslocamento do ponto de amostragem no plano em coordenadas do mundo. 
O próprio VTK oferece funções para se fazer a transformação de pontos entre os sistemas de coordenadas. Essas funções são chamadas a partir do vtkRenderer. A função WorldToDisplay transforma um ponto definido no sistema de coordenadas do mundo para o sistema de coordenadas da tela. O problema com as ampliações ocorre porque essa função não funciona para pontos que caem fora da janela. Assim, se o ponto inferior esquerdo do plano é projetado fora da janela, a referência entre os pixels e as posições de amostragem é perdida.

Para resolver esse problema, os pixels nos quatro cantos da Viewport na janela de visualização são transformados para as coordenadas do mundo. Com isso, é definida uma região $\left(R_{\text {viewport }}\right)$ do espaço que possui coordenadas, que quando transformadas caem dentro da Viewport. Se os quatro pontos da face frontal do bounding cube estiverem dentro dessa região, então certamente todos os pontos do mapa de textura também estarão dentro da Viewport, e o processamento segue de maneira normal. Caso contrário, os seguintes passos são tomados:

- É calculada a região de interseção entre a face frontal do bounding cube e a região $R_{\text {viewport }}$. A região obtida ( $R_{\text {amostragem }}$ ) é onde as amostragens podem ser feitas.

- Os 4 pontos que definem $R_{\text {amostragem }}$ são transformados para as coordenadas da tela definindo a região $\left(R_{\text {amostragem-tela }}\right)$.

- Com os limites da região $R_{\text {amostragem-tela }}$ são calculados o número de pixels na vertical e horizontal. Esses números são utilizados para definir os vetores de deslocamento da posição de amostragem $(\Delta x$ e $\Delta y)$.

- Os polígonos de textura para os planos de amostragem são calculados normalmente como apresentado na seção 4.2.2.3. Para garantir que os polígonos possuam suas coordenadas dentro de $R_{\text {amostragem-tela }}$ é realizada a interseção dos polígonos e a região $R_{\text {amostragem. }}$ Os polígonos de textura passam a ser a região de interseção calculada (ver figura 4.26).

- Os novos polígonos de textura são discretizados e o processo segue normalmente.
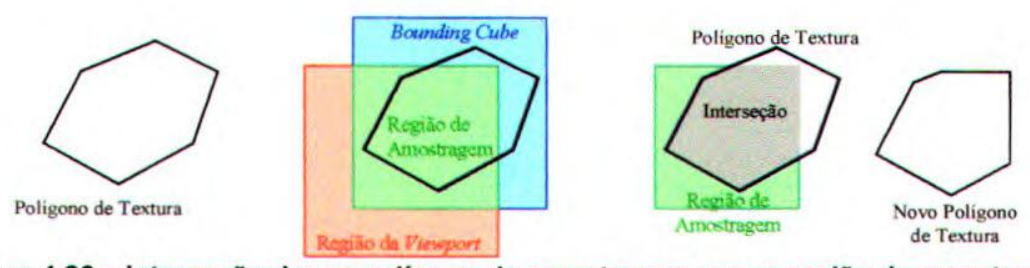

Figura 4.26 - Interseção de um polígono de amostragem com a região de amostragem.

A figura 4.27 apresenta o posicionamento da região de amostragem na tela e na cena(coordenadas do mundo) para um caso em que o bounding cube não está contido totalmente dentro da viewport. 


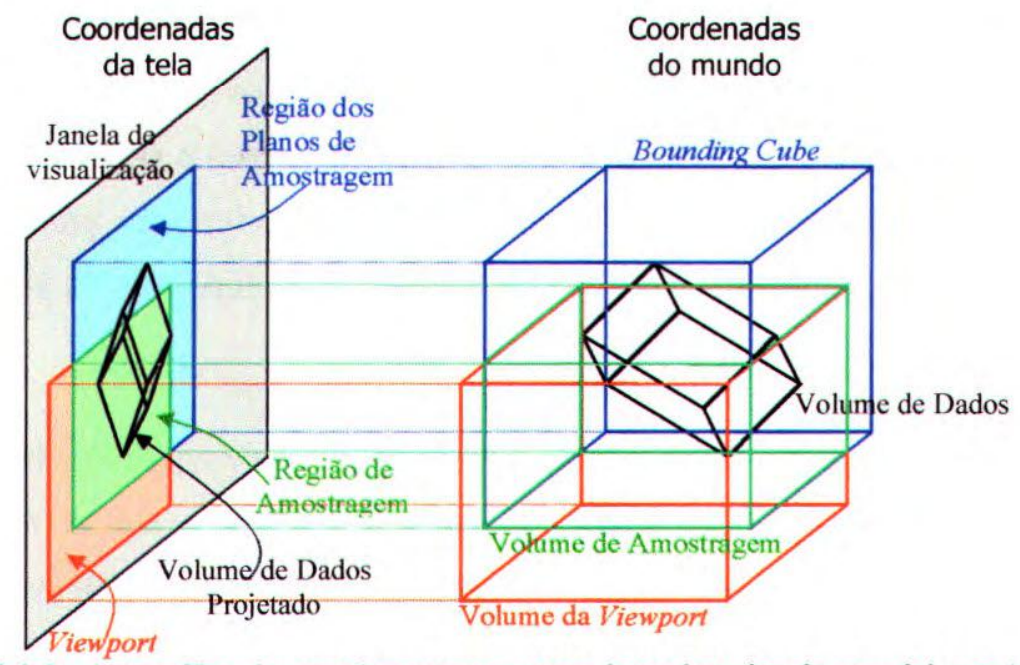

Figura 4.27 - A definição das regiões de amostragem no espaço (coordenadas do mundo) e na tela (coordenadas da tela)

Com esses cuidados, os pontos de amostragem dentro do polígono de textura sempre serão projetados dentro da região da viewport, evitando os erros de transformação de coordenadas.

Todo processo de rendering com mapeamento de textura volumétrica, incluindo os cuidados para ampliação, é administrado pelo método Render presente na classe vtkVolumeTexturaMapper. A organização lógica desse método é vista na seção seguinte.

\subsubsection{O Método Render}

O principal método do vtkVolumeTextureMapper é o Render. Como apresentado no início da seção, é através dele que o VTK chama a execução do DVRT. Portanto, é esse método que ordena os passos do DVRT vistos nesta seção 4.2.2, inclusive a criação do mapa de textura. A organização lógica método Render é apresentada na figura 4.28 .

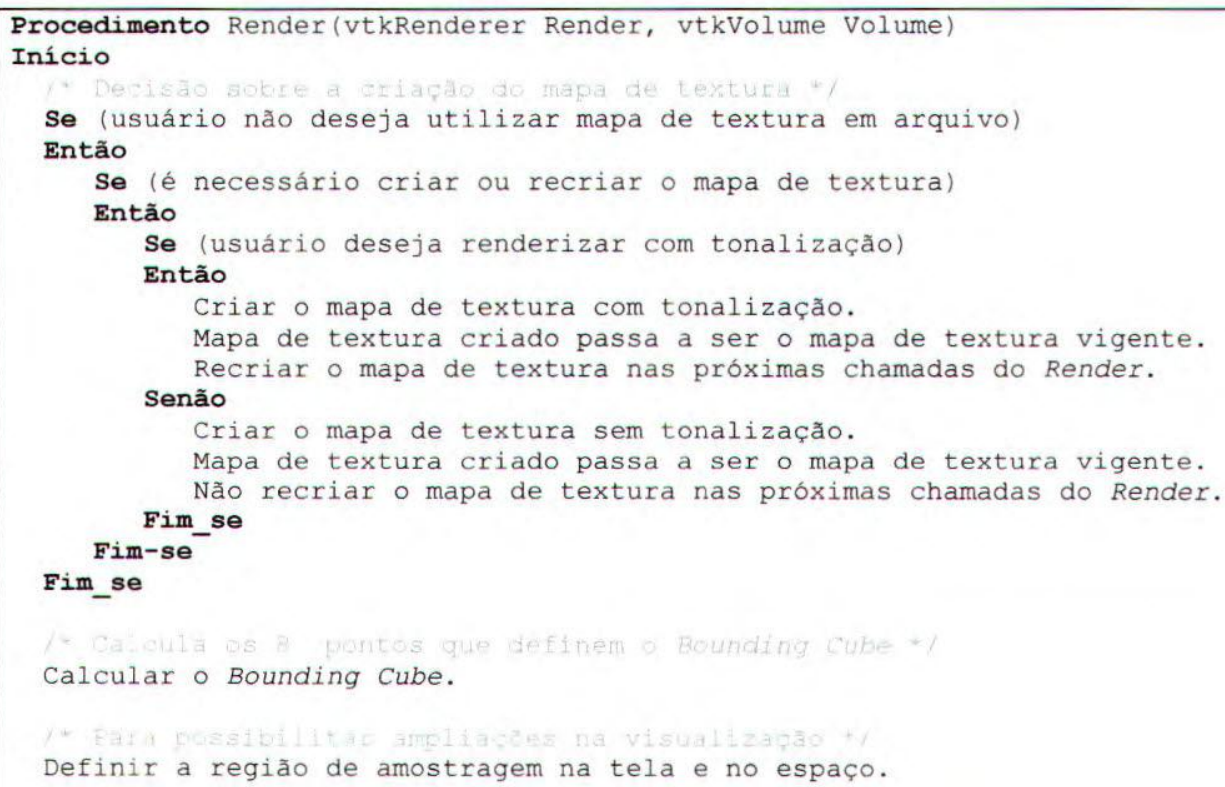




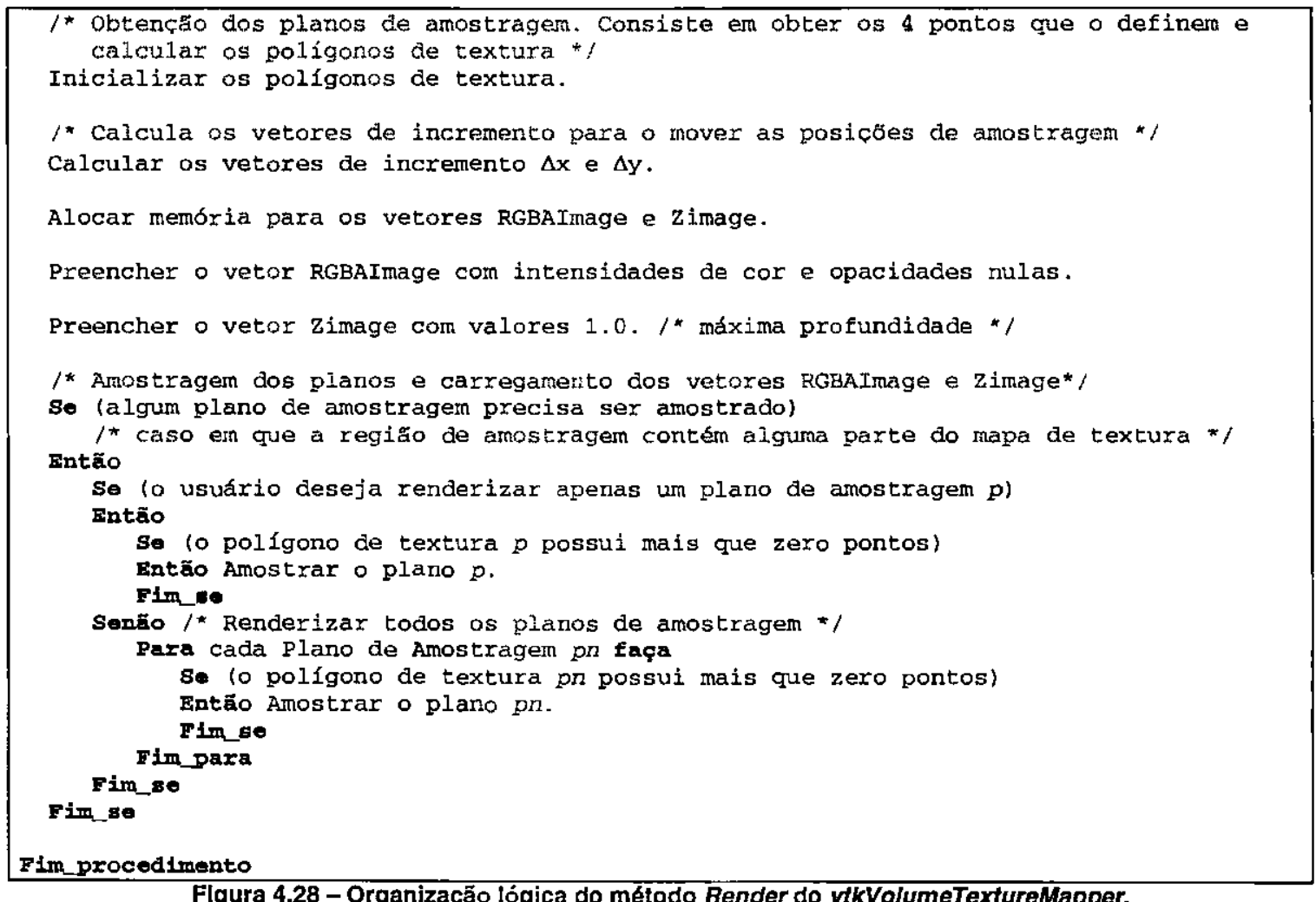

Uma descrição dos métodos públicos presentes na classe vtkVolumeTextureMapper, bem como das outras classes implementadas, pode ser vista no Apêndice A.

Classes implementadas para a realização do DVRT pertencem à hierarquia de classes do VTK, conforme apresentada na figura 4.29. No caso da figura, as classes vtkObject, vtkProcessObject, vtkVolumeMapper e vtkCollection estão presentes no VTK.

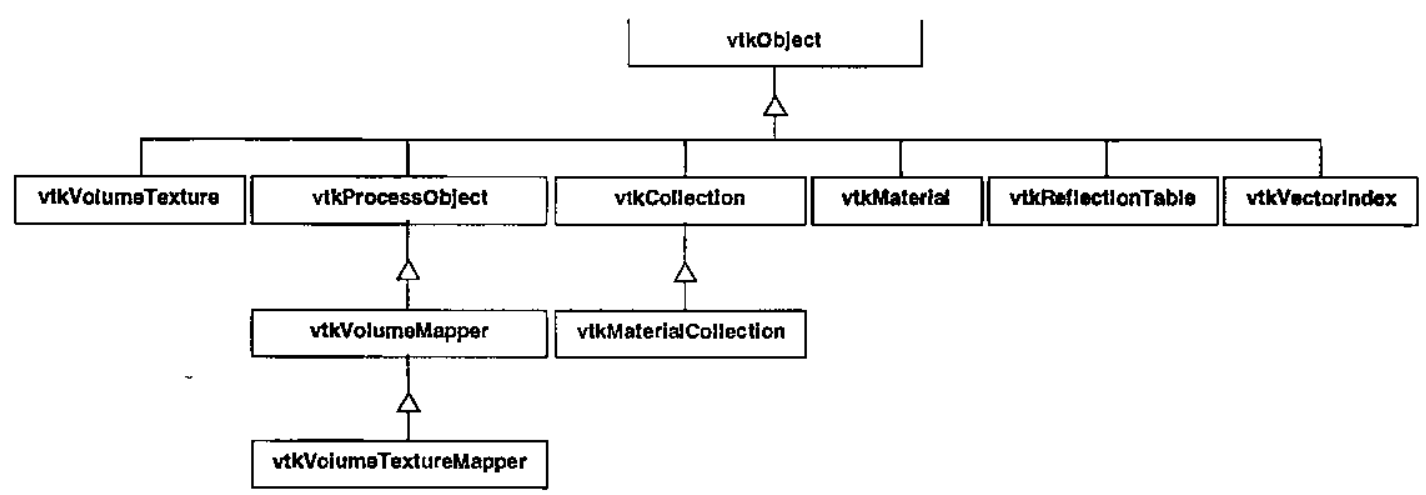

Figura 4.29 - Hierarquia de Classes apresentando as classes impiementadas para o DVRT.

O próximo capítulo apresenta os testes e os resultados obtidos na utilização do DVRT para geração de imagens de alguns volumes de dados. 


\section{Resultados}

Terminada a implementação do método de Rendering Volumétrico direto por mapeamento de textura (DVRT) no contexto do VTK, ele foi submetido a vários testes para verificar as características do algoritmo. Nos testes, foi levado em consideração principalmente o desempenho visual do método, ou seja, a qualidade das imagens geradas nas visualizações. A rapidez da renderização não foi muito enfatizada pelo fato do algoritmo ainda não estar contando com o apoio de hardware especializado para sua aceleração.

Durante os testes, a funcionalidade intema do método foi acompanhada, procurando verificar se as imagens resultantes correspondem às expectativas. Também foram efetuados testes do DVRT com dados dentários. E, finalmente, procurou-se avaliar seus resultados comparando-os com aqueles obtidos pelo Ray Casting, esse último presente na biblioteca VTK.

Os programas usados nos testes foram codificados na linguagem $\mathrm{C}++$, no ambiente de programação Microsoft Visual C++ 6.0, e foram executados num microcomputador com a seguinte configuração:

$\begin{array}{ll}\text { Processador: } & \text { Intel Pentium II } 450 \mathrm{MHz} \\ \text { Memória cache: } & 512 \mathrm{~KB} \\ \text { Memória RAM: } & 128 \mathrm{MB} \\ \text { Sistema Operacional: } & \text { Microsoft Windows NT 4.0 }\end{array}$

As classes desenvolvidas para o DVRT ficaram definidas numa biblioteca de ligação dinâmica (DLL Dinamic Linked Library), juntamente com uma biblioteca de referências externas, (.lib), correspondente à DLL. Essa biblioteca foi compilada separadamente das bibliotecas do VTK (vtkdll.dll e vtkdll.iib).

Neste capítulo são apresentados os testes realizados, bem como a avaliação dos resultados obtidos. Conclusões e sugestões para trabalhos futuros são apresentadas no próximo capítulo. 


\subsection{Testando o Comportamento do DVRT}

O volume de dados utilizado nesse primeiro teste, que verifica a funcionalidade interna do DVRT, foi gerado pela amostragem da equação de uma família de quádricas. Esse volume de dados é particularmente interessante para esse propósito porque o resultado visual produz elipsóides concêntricas, cuja curvatura típica facilitaria a observação de deformações, caso viessem a ocorrer. Outra vantagem desse volume de dados é que os vetores gradientes, calculados para cada voxel, possuem regularidade, o que auxilia a verificação do comportamento da tonalização pelo DVRT. Esse volume de dados possui as seguintes características:

Tamanho do arquivo de dados: 898 KBytes

Dimensões $(i, j, k)$ : $\quad 51,51,51$

Espaçamento entre os pontos: $\quad 0.02,0.02,0.02$

Um dos ajustes mais importantes no DVRT é o controle da distância entre os planos de amostragem, responsáveis por coletar informações no mapa de textura. A figura 5.1 apresenta o volume de dados renderizado com diferentes espaçamentos entre os planos. Na figura 5.1(a) e (b) os espaçamentos garantem que todos os texels, de espaçamento $(0.02,0.02,0.02)$, sejam amostrados. Na figura 5.1 (b) é possível verificar que acontecem artefatos que não acontece em (a) (veja a parte ampliada), os quais são bastante agravados em (c). No entanto, na figura 5.1 (a) foi utilizado o dobro de planos de amostragem que em (b), consumindo assim mais tempo de processamento. A vantagem de se usar imagens grosseiras como na figura 5.1 (c) e (d), é a possibilidade de ter uma noção do conteúdo do volume bem mais rapidamente, sendo interessante para a fase de classificação dos dados ou interação. Nessas imagens pode-se verificar também que o comportamento da função de blending, responsável pela composição da imagem, se comporta bem, produzindo cores bem próximas para diferentes espaçamentos.
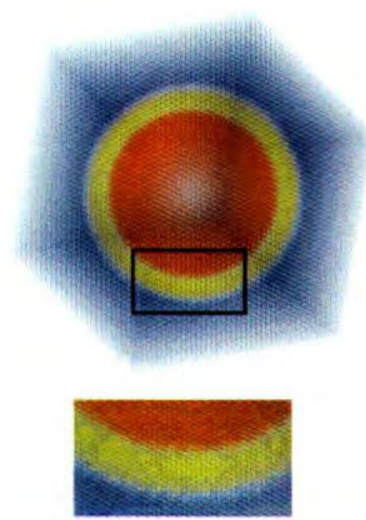

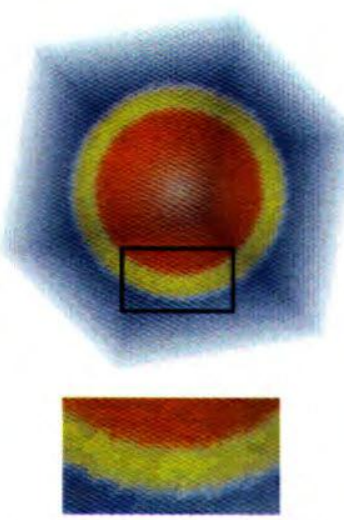

(b) Espaçamento $=0.02$
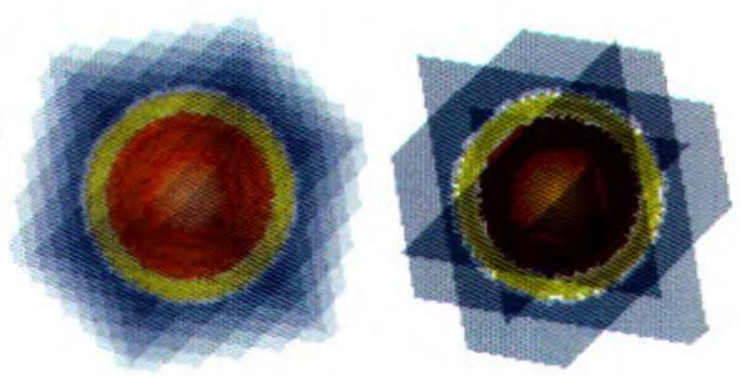

(c) Espaçamento $=0.1$

(d) Espaçamento $=0.3$

(a) Espaçamento $=0.01$

Figura 5.1 - DVRT utilizando diferentes espaçamento entre planos de amostragem. Em (a) e (b) são apresentadas as ampliações das regiões delimitadas. 
O volume de dados pode ser visualizado considerando os texels com a disposição das cores seguindo o conceito de voxel ou de célula. No primeiro, é utilizada uma cor uniforme no interior do texel. No segundo cores diferentes são associadas aos vértices do texel. A figura 5.2 apresenta as mesmas configurações de rendering para as duas possibilidades do texel (texel-voxel e texel-célula). Os dois modos apresentam vantagens e desvantagens. No caso do texel-voxel, o rendering é mais rápido (da ordem de 1/8 do tempo), uma vez que não é necessário fazer interpolação na posição de amostragem.No entanto, a imagem apresenta mais artefatos (figura 5.2(a)). No caso do voxel-célula, a imagem fica mais suavizada (figura 5.2(b)), porém possui rendering mais demorado e acontece um escurecimento na região de fronteira para opacidades altas (figura 5.2(d)). Esse escurecimento ocorre porque os texels que não pertencem a algum material definido (ou seja, possuem cor preta e transparência máxima) influenciam a interpolação nos pontos próximos à fronteira do material. No caso da figura 5.2(d) a noção tridimensional do objeto é causada pelo artefato de escurecimento dos voxels de fronteira.

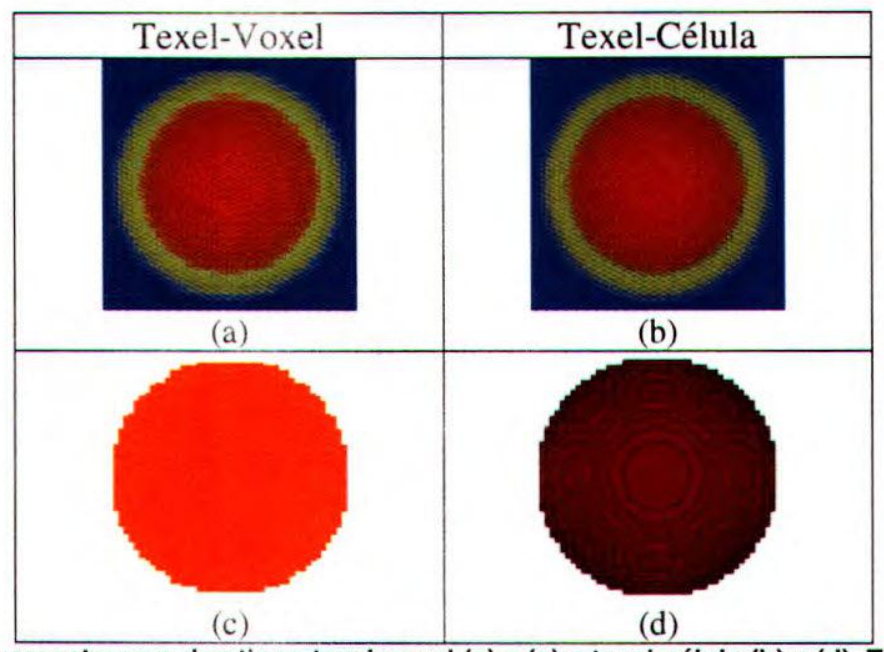

Figura 5.2 - DVRT com amostragem dos tipos texel-voxel (a) e (c) e texel-célula (b) e (d). Todas as imagens foram renderizadas sem tonalização. $\mathrm{Em}$ (c) e (d) o material é vermelho opaco (RGBA $=(1.0,0.0,0.0,1.0)$ ).

Durante a implementação foi levada em consideração a utilização de viewports na janela de apresentação do VTK, conforme abordado no capítulo 4. A figura 5.3 apresenta volumes renderizados em viewports diferentes. Também foi implementada a possibilidade de ampliar as visualizações, com o devido 'clipping', como pode ser visto na viewport da direita na figura 5.3.

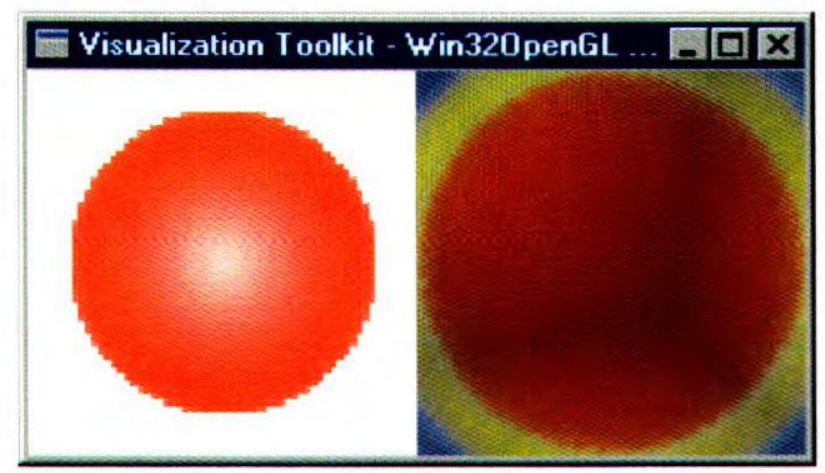


Figura 5.3 - Duas apresentações por DVRT, uma em cada viewport, na mesma janela de visualização do VTK. À direita, o volume é ampliado, com as extremidacles ultrapassando a fronteira da viewport.

As visualizações no DVRT podem ser tonalizadas, ou seja, interagir com as luzes direcionais presentes na cena. Pela definição de materiais, é possível que alguns deles sejam tonalizados e outros não. Na figura 5.1 apenas o material em vermelho foi apresentado com tonalização. A figura 5.4 apresenta visualizações tonalizadas para diferentes coeficientes, sendo que a luz tem a mesma direção da câmera e sua cor é branca. Na figura 5.4 é apresentada a variação do coeficiente de luz ambiente (5.4(a) a (e)), a variação do coeficiente de luz difusa $(5.4(\mathrm{f})$ a (j)), a variação do coeficiente de luz especular (5.4 (k) a (o)), e, finalmente, a variação do coeficiente de potência especular (5.4 (p) a (t)). Pela análise visual dessas imagens pode-se verificar que as tonalizações estão de acordo com os parâmetros especificados.

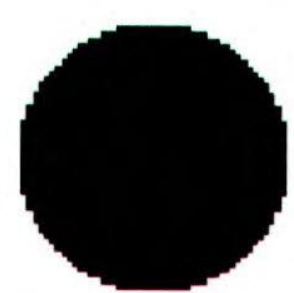

(a) $(0.0,0.0,0.0,0.0)$

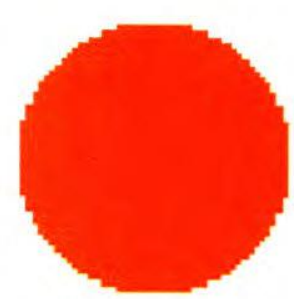

(f) $(1,0,0.0,0.0,0.0)$

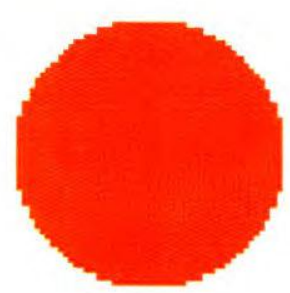

(k) $(1,0,0.0,0.0,10.0)$

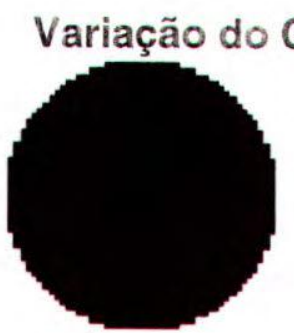

(b) $(0.25,0.0,0.0,0.0)$

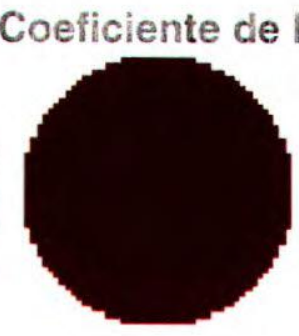

(c) $(0.5,0.0,0.0,0.0)$

(d) $(0.75,0.0,0.0,0.0)$

\section{Variação do Coeficiente de Luz Difusa}

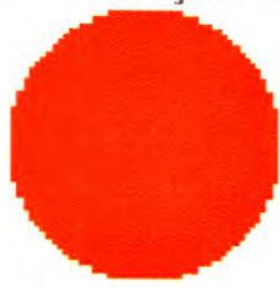

(g) $(1,0,0.25,0.0,0.0)$
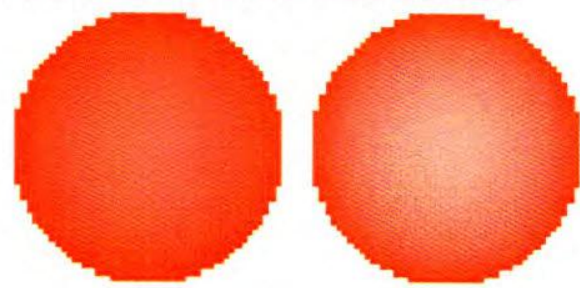

(h) $(1.0,0.5,0.0,0.0)$

(i) $(1.0,0.75,0.0,0.0)$

(j) $(1.0,1.0,0.0,0.0)$

\section{Variação do Coeficiente de Luz Especular}
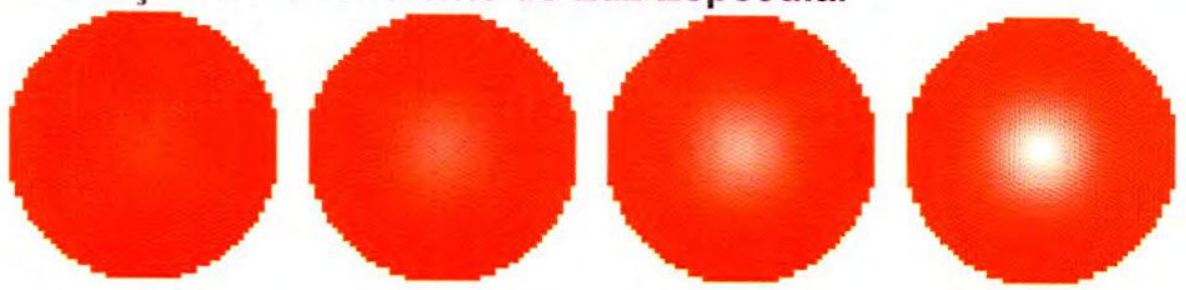

(1) $(1.0,0.0,0.25,10.0)$

(m) $(\mathrm{i} 0,0,0,0.5,100)$

(i) $(1.0,0.0,0.75,10.0)$

(o) $(1.0,0.0,1.0,100.0)$

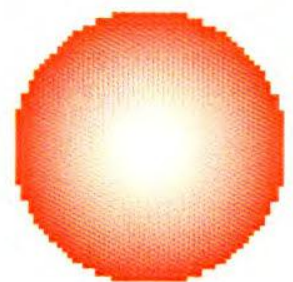

\section{Variação do Coeficiente de Potência Especular}

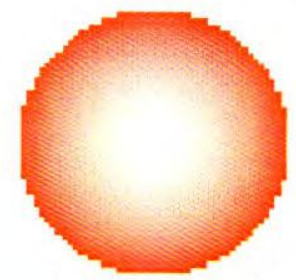

(p) $(1,0.0 .0,1.0,1.0)$

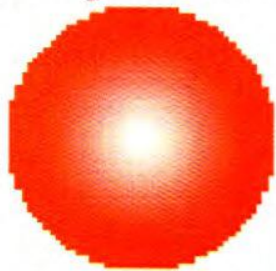

(q) $(1.0,0.0,1.0,5.0)$

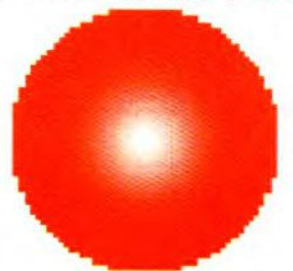

(1) $(1,0,0,0,1.0,10.0)$

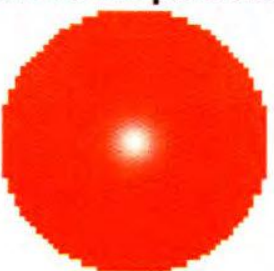

(s) $(1.0,0.0,1.0,50.0)$

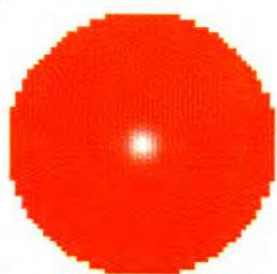

(t) $(1.0,0.0,1.0,100.0)$ 
Figura 5.4 - DVRT tonalizado para diferentes coeficientes. A esfera possui cor preta $(R G B=[0.0,0.0,0.0]$ ) e opacidade máxima (1.0). A tupla colocada abaixo de cada imagem indica os valores dos coeficientes de luz ambiente, de luz difusa, de luz especular e de potência especular respectivamente.

A figura 5.5 tem a finalidade de constatar que a tonalização está acontecendo apenas nas regiões do volume que estão voltadas para a luz. Na figura 5.5(a), o volume foi renderizado com a luz presente na mesma direção da câmera. Em seguida esse volume e a fonte de luz foram rotacionados à direita de 45 em 45 graus até completar $180^{\circ}$ (figura 5.5 (b) a (e)).

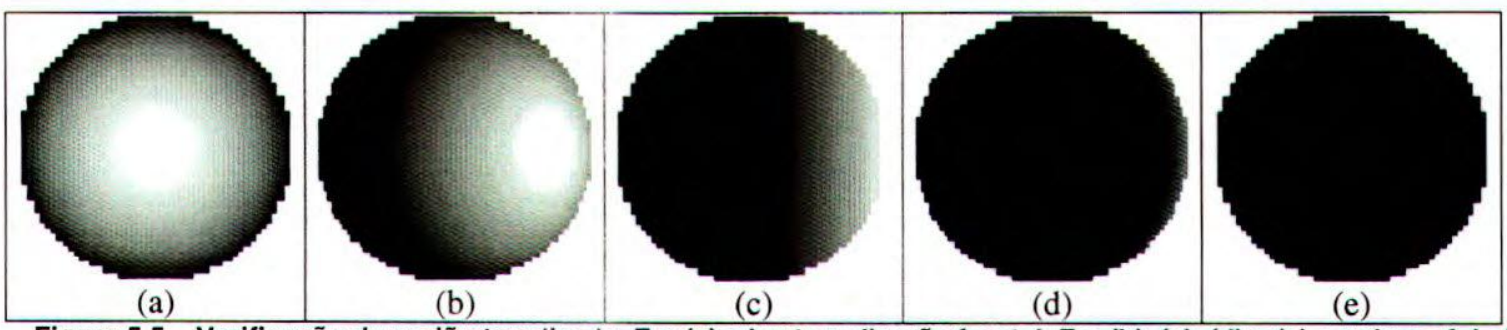

Figura 5.5 - Verificação da região tonalizada. Em (a) a luz tem direção frontal. Em (b), (c), (d) e (e) o volume foi girado $45^{\circ}, 90^{\circ}, 135^{\circ}$ e $180^{\circ}$ à direita.

As tonalizações podem levar em conta mais de uma luz direcional presente na cena. Além disso, suas cores não precisam ser necessariamente brancas, como pode ser visto na figura 5.6.

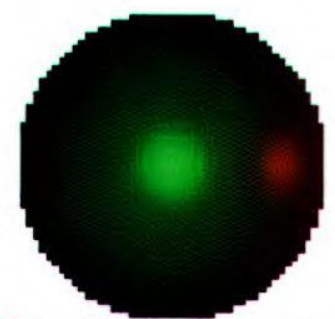

Figura 5.6 - Esfera preta apresentada por DVRT tonalizado com duas luzes presentes na cena. A luz verde se encontra na mesma direção da câmera e a vermelha tem sua direção da direita para a esquerda da cena.

O teste de inversão do hemisfério tonalizado através do método InvertShadingHemisfhereOn, descrito no capítulo 4, é apresentado na figura 5.7.

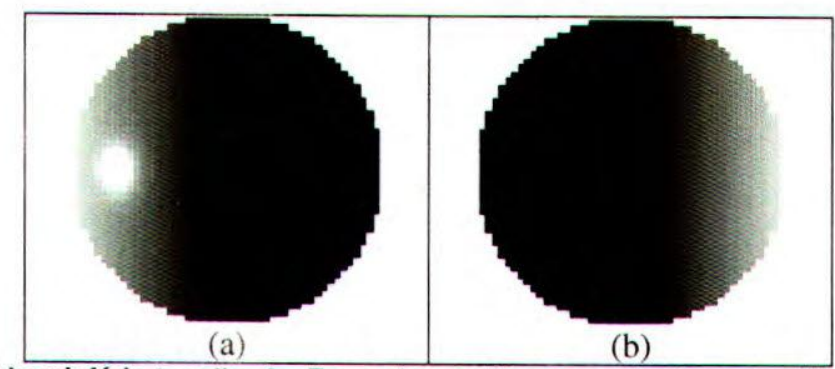

Figura 5.7 - Inversão do hemisfério tonalizado. Em ambas as imagens a luz tem sua direção da esquerda para a direita. Em (b) foi usado o método para inversẫo do hemisfério tonalizado.

Uma outra possibilidade que o DVRT apresenta é a utilização de tabelas para agilizar o rendering tonalizado. Quanto maior o número de entradas da tabela de reflexão, mais a imagem se aproxima da original (sem uso de tabelas), porém maior é o tempo para geração da tabela. A figura 5.8 apresenta as imagens obtidas com diferentes extensões da Tabela de Reflexão, que varia de acordo com o nível de refinamento do Índice de Gradientes (ng). A tabela de reflexão para ng igual a 2 produzem imagens 
com artefatos que prejudicam a análise do volume em estudo, portanto não é indicada. Em imagens para investigação rápida do volume pode-se utilizar ng igual a 3. A tonalização se comportou satisfatoriamente para ng maiores ou iguais a 4 .

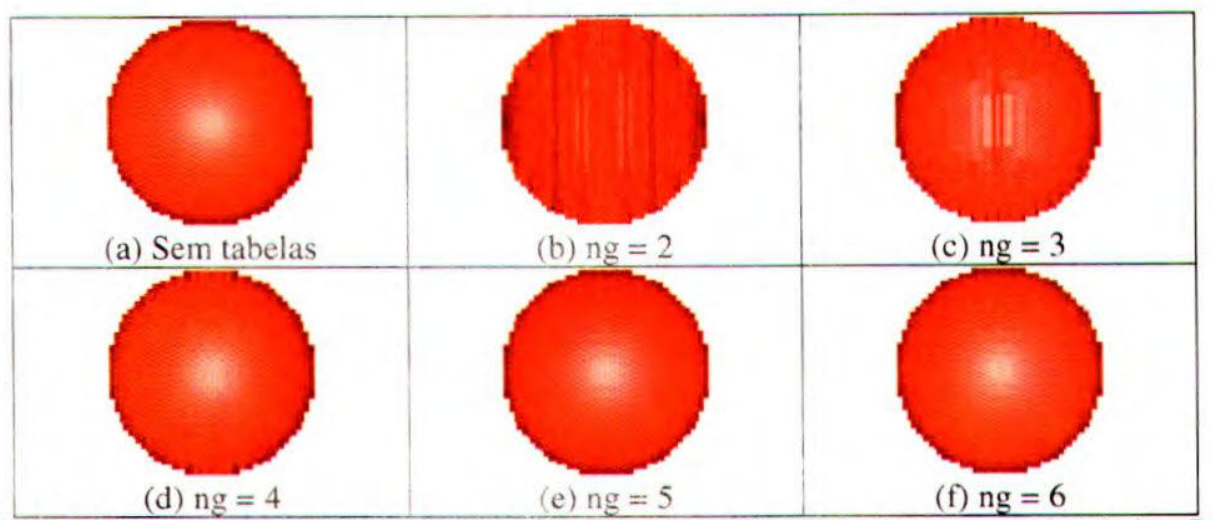

Figura 5.8 - DVRT utilizando tabela de reflexão. Em (a) o volume foi tonalizado sem uso de tabelas. De (b) a (f) foram utilizadas tabelas geradas para diferentes niveis de refinamento do índice de Gradientes (ng), como está indicado abaixo de cada imagem. As imagens foram renderizadas com: coeficientes de luz ambiente = 1.0, coeficientes de luz difusa $=0.5$, coeficiente de luz especular $=0.5$ e coeficiente de potência especular $=10$.

Os tempos necessários para a criação da Tabela de Reflexão podem ser vistos na tabela 5.1. A construção da Tabela de Reflexão compreende o tempo para a criação do Índice de Gradientes e do cálculo para o tabelamento da tonalização. O tempo cresce exponencialmente com o aumento de ng (número de gradientes), e pode-se perceber também que é a construção do Índice de Gradientes que consome mais tempo de processamento. O tempo para geração da tabela torna impraticável sua utilização para ng superior a 7, mas, como pode ser visto na figura 5.8, para ng igual a 5 a tonalização já é satisfatória. A vantagem de se utilizar tabelas pré-calculadas é obter uma considerável economia no tempo de processamento. De acordo com os resultados constatados, a implementação realizada para a Tabela de Reflexão apresentou resultados satisfatórios na relação qualidade da imagem por tempo de processamento.

\begin{tabular}{|c|c|c|c|c|c|c|c|c|}
\cline { 2 - 9 } \multicolumn{1}{c|}{} & $\mathrm{ng}=1$ & $\mathrm{ng}=2$ & $\mathrm{ng}=3$ & $\mathrm{ng}=4$ & $\mathrm{ng}=5$ & $\mathrm{ng}=6$ & $\mathrm{ng}=7$ & $\mathrm{ng}=8$ \\
\hline $\begin{array}{c}\text { Índice de } \\
\text { Gradientes }\end{array}$ & $0 \mathrm{~s}$ & $0 \mathrm{~s}$ & $0.01 \mathrm{~s}$ & $0.05 \mathrm{~s}$ & $0.42 \mathrm{~s}$ & $6.069 \mathrm{~s}$ & $92.06 \mathrm{~s}$ & $1638.42 \mathrm{~s}$ \\
\hline $\begin{array}{c}\text { Tabela de } \\
\text { Reflexão }\end{array}$ & $0 \mathrm{~s}$ & $0 \mathrm{~s}$ & $0.01 \mathrm{~s}$ & $0.0500001 \mathrm{~s}$ & $0.441 \mathrm{~s}$ & $6.159 \mathrm{~s}$ & $93.93 \mathrm{~s}$ & $1666.73 \mathrm{~s}$ \\
\hline $\begin{array}{c}\text { Número de } \\
\text { Gradientes }\end{array}$ & 72 & 216 & 744 & 2760 & 10632 & 41736 & 165384 & 658440 \\
\hline
\end{tabular}

Tabela 5.1 - Relação de tempo (aproximado em segundos) consumido na construção do índice de Gradientes e da Tabela de Reflexão, sendo que a construçäo da segunda engloba o tempo da primeira. A Tabela de Reflexão foi gerada para apenas dois materiais e uma fonte de luz. Na última linha é apresentada a quantidade de gradientes fornecidos pelo Índice cle Gradientes para cada ng.

Os resultados visuais do DVRT são bastante satisfatórios. Na próxima seção esse tema começa a ser discutido, através da aplicação do DVRT para o caso dentário. 


\subsection{Aplicando o DVRT aos dados dentários}

A principal motivação para usar Rendering Volumétrico Direto em dados odontológicos é que o volume de dados pode apresentar-se consideravelmente disforme. A figura 5.9 apresenta uma seqüência de fotografias de seções consecuticas de um dente. O volume de dados criado pela composição de diversas dessas fotos é bastante complicado de ser visualizado pela abordagem de extração de superfícies, ao passo que por DVR é mais direto. No entanto, ainda não foi obtida uma seqüência de fotografias que possibilitasse a construção de um volume de dados que correspondesse ao dente original. Isso porque o processo de fatiamento não é simples e fica difícil conseguir um espaçamento regular entre as fatias e também garantir um posicionamento relativo correto entre elas. Por isso, os dados dentários submetidos aos testes do DVRT são os obtidos através do método de reconstrução a partir de contornos (ver figura 5.10). Dados esses que são ideais para visualização por extração de superfícies, mas que também podem ser visualizados por DVRT, e são muito bons para testar a eficiência de expressão de forma, sem a criação das estruturas geométricas intermediárias geradas pelos métodos de extração de superfícies.
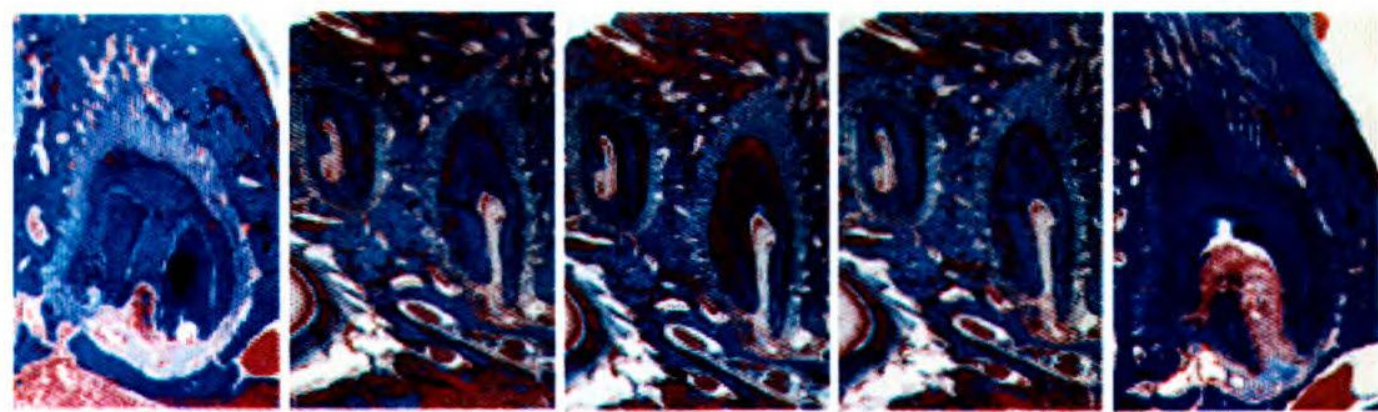

Figura 5.9 - Fotografias de seções seqüenciais de um dente descalcificado e tingido.

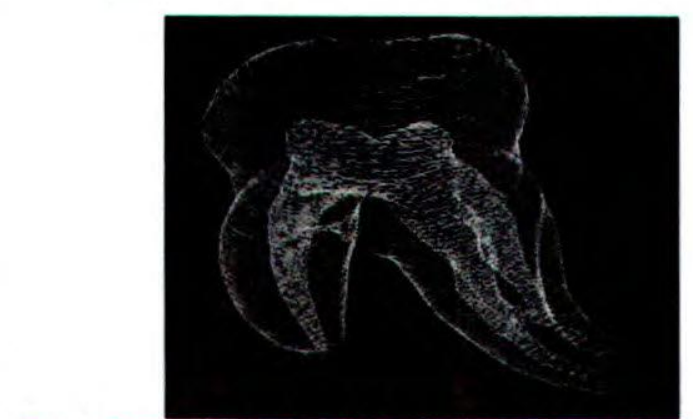

Figura 5.10 - Contornos do dente submetidos à reconstrução.

A partir de dados fornecidos pelos colaboradores da School of Information System da University of East Anglia na Inglaterra, os quais foram gerados a partir de um editor de contornos (ver [Goe 98]), foi feita uma adaptação desses conjuntos de dados para o formato aceito pelo filtro vtkSamplingFromContoursFilter, resultado de um trabalho de mestrado na área de reconstrução de superfícies em odontologia [Shi 98 a.b]. Foi necessário fazer algumas adaptações nesse filtro para que os volumes de dados gerados por ele fossem adaptados para o uso com o DVRT. Os dados se dividem em dois conjuntos: os contornos que definem a parte externa do dente e os que definem o canal do 
dente. Esses dois conjuntos foram submetidos ao filtro gerando dois volumes de dados, um com a informação da região externa do dente (ver figura 5.11 (a)) e outro com a informação interna, que inclui o canal (ver figura 5.11 (b)). Esses dois conjuntos foram mesclados gerando um terceiro volume de dados, no mesmo formato de malha regular (vtkStructuredPoints), contendo as duas informações (ver figura $5.11(\mathrm{c}))$.

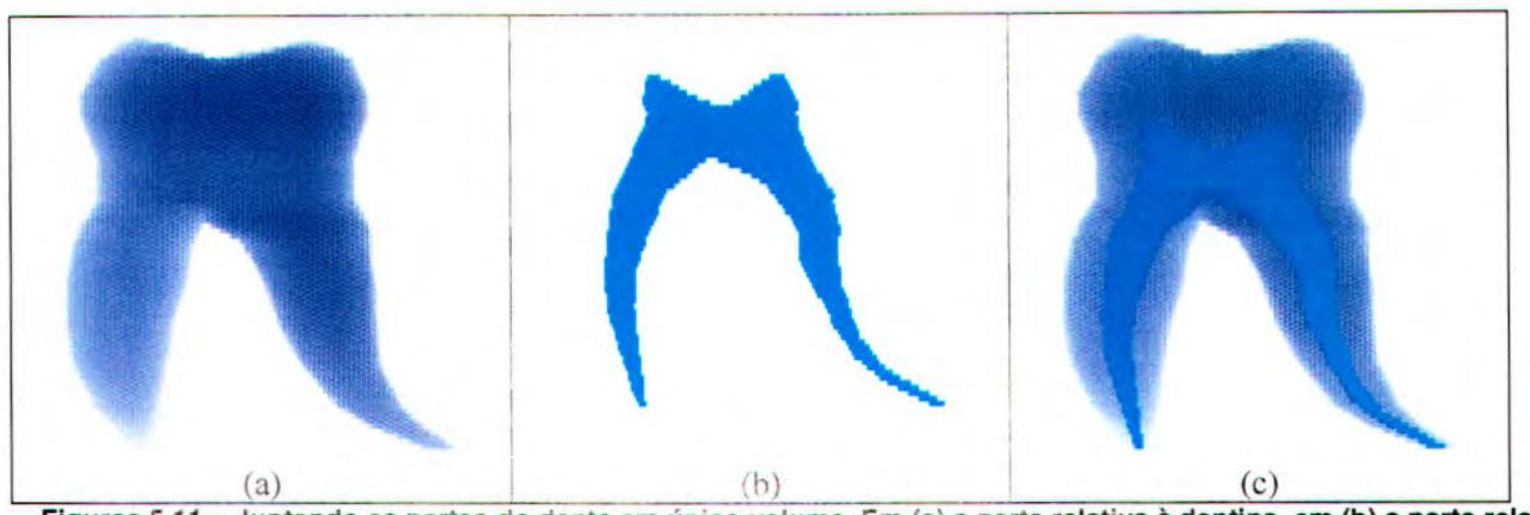

Figuras 5.11 - Juntando as partes do dente em único volume. Em (a) a parte relativa à dentina, em (b) a parte relativa ao canal e em (c) o dente formado pelas duas partes.

Além de fazer a junção dos dois volumes de dados do dente, foi necessário fazer uma alteração no filtro vtkSamplingFromContoursFilter para que a disposição dos escalares acarretasse em gradientes de comportamento mais regular, possibilitando assim, a tonalização. $\mathrm{O}$ filtro vtkSamplingFromContoursFilter gera uma grade sobre os contornos presentes em uma fatia e decide quais nós da grade estão fora (valor -1), dentro (valor 1) e sobre o contorno (valor 1). Quando acontece variação entre esses valores a menor distância de cada nó da grade ao contorno é calculada. Dessa maneira, a parte da malha que está fora do dente possui valores iguais a -1 , nos nós próximos à superfície (conjunto de contornos) as distâncias calculadas e dentro do dente valores 1. Com isso, os gradientes, calculados para os nós da grade, só possuíam magnitude maior que zero nos nós próximos à superfície, o que afeta a tonalização (ver figura 5.12 (a) e (c)). Decidiu-se então alterar o filtro para que ele calculasse também as distâncias para todos os pontos que estivessem dentro dos contornos, possibilitando gradientes válidos em todo o interior do dente, e melhorando sensivelmente a tonalização com um pouco de transparência (ver figura 5.12 (d)). A tonalização só se comporta bem com pouco de transparência porque torna possível a visão do interior do dente, onde os gradientes estão bem comportados. No entanto, quando a opacidade máxima é utilizada os artefatos continuam acontecendo como pode ser visto na figura 5.12 (b). 


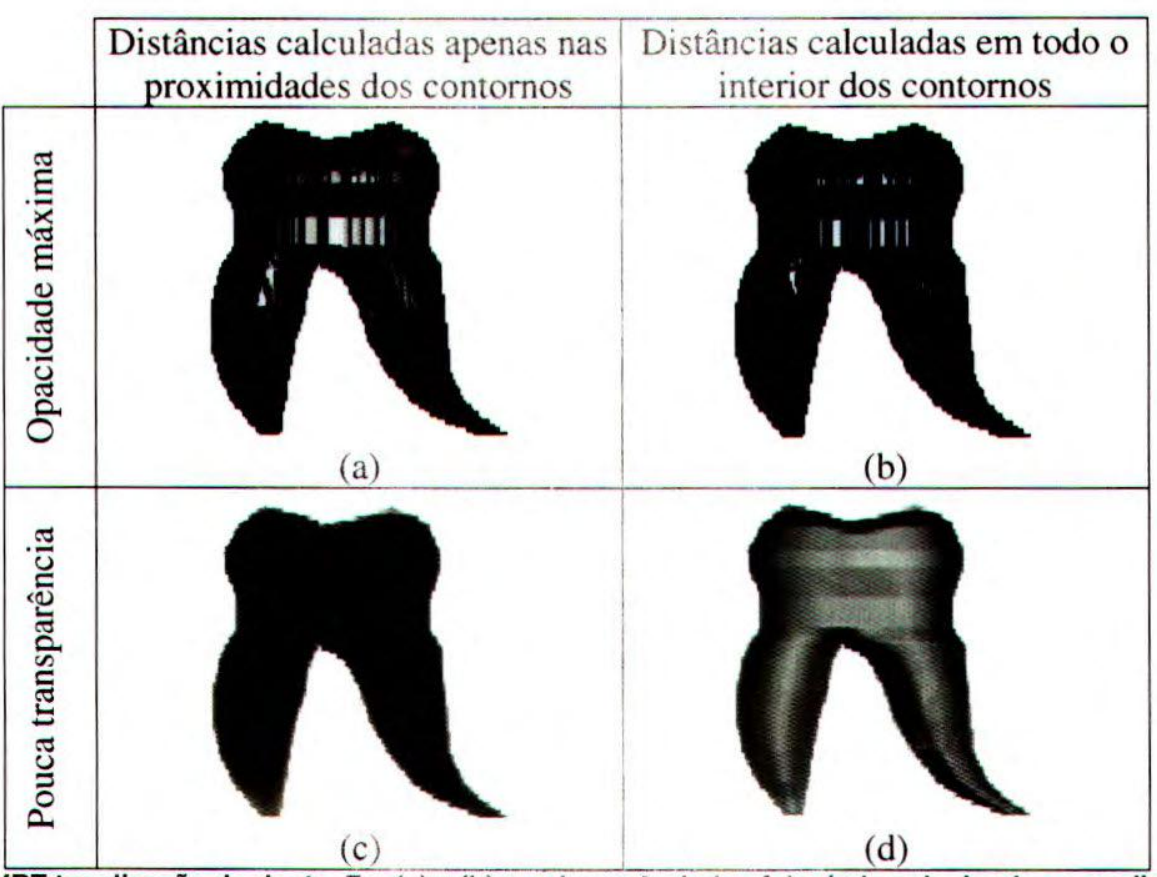

Figura 5.12 - DVRT tonalização do dente. Em (a) e (b) o volume de dados foi criado calculando-se as distâncias apenas na fronteira do contorno. Em (c) e (d) as distancias foram calculadas em todo o interior do dente. Em (a) e (d) os materiais apresentados têm opacidade máxima e em (b) e (c) estão com pouca transparência.

Mesmo com as alterações descritas acıma, a tonalização não está ideal. Como as distâncias são calculadas em planos $(x y)$ os gradiente se comportam muito bem para esse plano, ou seja, para as coordenadas $x$ e $y$ mas não para a $z$. Isso pode ser notado através da figura 5.13. Para que esse problema fosse resolvido seria necessário que as distâncias fossem calculadas não em relação aos contornos, mas em relação à superfície formada pelos contornos. Para isso, seria necessário alterar grande parte da estrutura do filtro, o que foge ao escopo desse trabalho. No entanto, se a tonalização não estiver sendo utilizada, o DVRT se comporta bem, como pode ser visto na figura 5.14 (c) e (d).

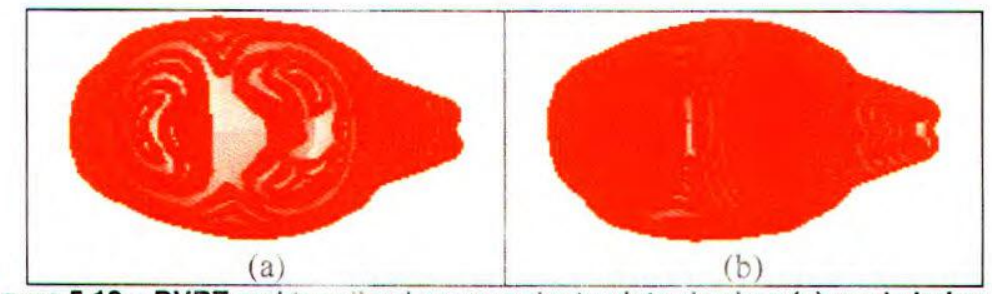

Figura 5.13 - DVRT mal to alizado para o dente visto de cima (a) ou de baixo (c).

Para esses testes, e também para os da seção seguinte, foram utilizados dois volumes de dados (vtkStructuredPoints) gerados para os mesmos conjuntos de contornos fornecidos pelos colaboradores da Inglaterra. A diferença entre eles está na resolução, ou seja, a taxa de amostragem dos contornos, que afeta a quantidade de células do conjunto de dados. Para os testes a seguir, as seguintes resoluções foram utilizadas: 
Dimensões:

Número de escalares:

Tamanho do arquivo:
Volume_1

$306 \times 174 \times 83$

4.419.252

21,933 MB
Volume 2

$158 \times 88 \times 83$

1.124 .816

5,636 MB

A contagem do tempo consumido na geração das imagens do Volume_1 pode ser vista na tabela 5.2. O uso da tonalização consome cerca de $25 \%$ do tempo da construção do mapa de textura sem o auxílio da Tabela de Reflexão. O tamanho da tabela influencia no tempo de processamento e na qualidade da imagem final e, nesse caso, foi de ?? entradas. No caso do uso do tabelamento, a geração da primeira imagem é mais demorada, pois necessita da criação do Índice de Gradientes e da Tabela de Reflexão, e no caso analisado consumiu 106.77 segundos, Durante as interaçōes, entretanto, a geração da imagem consumiu 22.55 segundos em média. Evidentemente, para o caso do não tabelamento, a geração da imagem toma sempre o mesmo tempo, com ou sem interação $(35,29 \mathrm{~s})$. A amostragem realizando interpolação ("texel-célula"), consome cerca de 8 vezes mais tempo de processamento que a amostragem sem uso desse recurso ("texel-voxel").

\begin{tabular}{|c|c|c|}
\hline \multicolumn{2}{|c|}{ Leitura do volume de dados } & $29,76 \mathrm{~s}$ \\
\hline \multicolumn{3}{|c|}{ Construção do Mapa de Textura } \\
\hline \multicolumn{2}{|l|}{ Sem tonalizaçāo } & $20,70 \mathrm{~s}$ \\
\hline \multirow[t]{3}{*}{ Com tonalização } & Sem tabelamento & $35,29 \mathrm{~s}$ \\
\hline & Com tabelamento 1 imagem & $109,78 \mathrm{~s}$ \\
\hline & 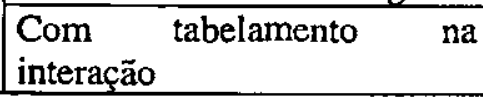 & $22,55 \mathrm{~s}$ \\
\hline \multicolumn{3}{|c|}{ Amostragem e blending } \\
\hline \multicolumn{2}{|c|}{ Texel-voxel } & $15,37 \mathrm{~s}$ \\
\hline \multicolumn{2}{|r|}{ Texel-célula } & $129,47 \mathrm{~s}$ \\
\hline
\end{tabular}

Tabela 5.2 - Contagem do tempo (em segundos) consumido nas várias etapas no DVRT. $O$ tabelamento para a tonalizaçāo fol feito para um nivei de refinamento igual a 5. O volume de dados utilizado fol o Volume_1.

A expectativa inicial para o tabelamento da tonalização implementado era que ele promovesse uma redução mais acentuada no tempo para criação do mapa de textura. Acredita-se que outras alternativas de tabelamento, como a apresentada em [Lei96], podem ser mais adequadas para o propósito do DVRT.

A utilização do rendering volumétrico, e em particular do DVRT, para o caso de odontologia, possui as mesmas motivações das demais imagens médicas. A combinação das técnicas de SF e DVR traz para a análise de dados as vantagens dos dois métodos. Uma discussão sobre o uso dessas duas 
abordagens pode ser visto em [Min00]. O SF permite fazer uma verificação de superfícies (como a identificação de forma) enquanto que o DVR permite explorar o conteúdo interno, e também evitar, para determinadas tarefas de visualização sobre dados irregulares, a necessidade de segmentação.

\subsection{Comparando o DVRT com o Ray Casting}

Nesta seção serão feitas algumas considerações a respeito do DVRT e do Ray Casting implementado no VTK. O principal argumento para o uso do DVRT ao invés do Ray Casting é a possibilidade de obter imagens de qualidades similares com uma rapidez maior devido ao uso de hardware gráfico. Embora o DVRT ainda não faça uso de hardware especializado, foram identificadas algumas diferenças entre os dois métodos como se segue.

Uma das exigências que o Ray Casting faz é que o volume de dados a ser submetido à visualização possua apenas escalares inteiros. Isso exige um pré processamento do volume de dados, caso ele contenha escalares em pontos flutuantes, como é o caso dos dados do dente sendo testados. A alternativa de se trabalhar apenas com números inteiros é interessante porque acelera o rendering, pois as operações com números inteiros são mais rápidas do que com pontos flutuantes. No caso do DVRT essa conversão não é realizada o que afeta um pouco seu desempenho.

A figura 5.14 apresenta visualizaçōes do mesmo volume de dados utilizado acima (Volume_1), em diferentes visões, sendo que as que estão à esquerda foram obtidas com DVRT e as da direita com Ray Casting, controlando os atributos visuais de ambas (cor, iluminação) para que possuam características físicas semelhantes. Observando as imagens podemos verificar que os dois métodos produzem imagens de qualidade parecida e também constatar que:

- A função de blending que faz a composição das amostragens no DVRT comporta-se mais coerentemente que no Ray Casting. Nas visōes laterais do dente, (figura 5.14 (b) e (d)), o Ray Casting obteve uma cor de azul mais intensa que em qualquer região das visões inferior e superior (figura 5.14 (f) e (h)). Isso não deveria acontecer, pois alguns raios que atravessam o dente nas visões (f) ou (h) são mais 'Iongos', e, portanto, colhem mais amostragens que nas visס̃es (b) ou (d). Isso deveria produzir uma intensidade maior de azul que em vários pontos da visão lateral, indicando sua profundidade. Já no DVRT, as regiōes mais profundas das figuras 5.14 (e) e (g), possuem cor mais intensa que na figura 5.14 (a) e (c), acusando a profundidade do dente sob aquelas direções de visualização. 
- O contorno do dente é mais suavizado no Ray Casting que no DVRT. Isso é decorrente do uso ou não de interpolação nos pontos de amostragem. As imagens do DVRT não fizeram uso desse recurso, mas como visto na seção anterior, é possível fazer uso dessa interpolação com o uso do texel-célula, como foi ilustrado na figura 5.2.

- Na figuras 5.14 (g) o DVRT promoveu a visualização da terminação do canal do dente (em vermelho) de maneira mais contínua que no Ray Casting (figura 5.14 (h)).

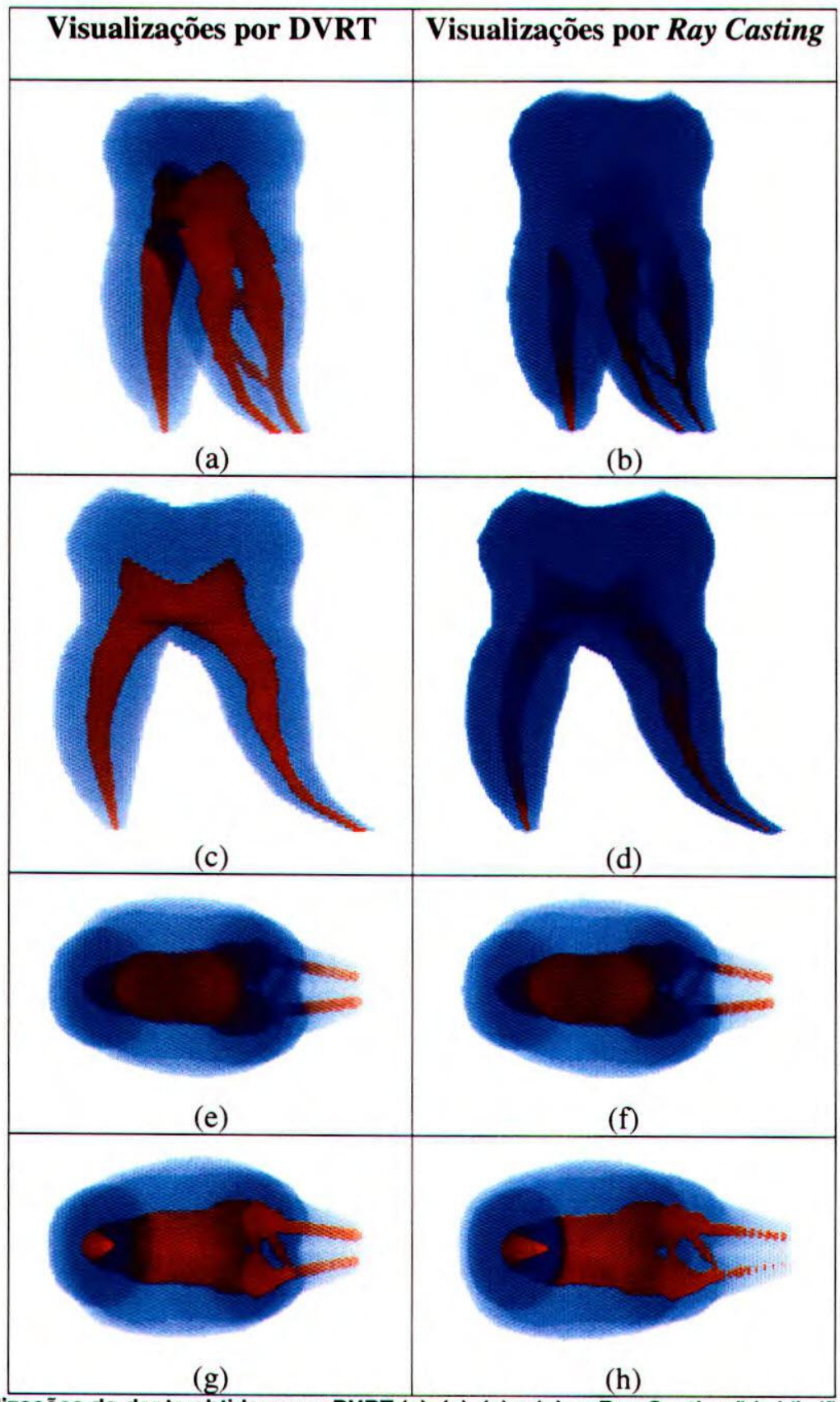

Figura 5.14 - Visualizações do dente obtidas com DVRT (a), (c), (e) e (g) e Ray Casting (b), (d), (f) e (h). Em (a) e (b), o dente é visto com uma rotação a partir da visão frontal (c) e (d). Em (d) e (e) o dente é visto de cima para baixo e em (g) e (h) de baixo para cima. 
A figura 5.15 apresenta as visualizações tonalizadas para as mesmas configurações da figura 5.14. Nas figuras $5.15,5.16$ e 5.17 pode-se observar que o comportamento da tonalização é diferente entre os dois métodos. Com relação ao resultado visual, pode-se constatar que:

- A tonalização no DVRT é mais suavizada que no Ray Casting, isso também pode ser visto na figura 5.17 .

- Uma vantagem do Ray Casting sobre o DVRT é que é possível obter efeitos completos de tonalização mesmo em volumes de dados onde os gradientes são irregulares, ao passo que, no DVRT, para obter esse mesmo efeito é necessário que a distribuição dos escalares no volume tenham um comportamento tal que os gradientes sejam bem direcionados. Para isso não devem existir quebras bruscas na direção dos gradientes (e, portanto, nos valores dos escalares numa vizinhança). Isso pode ser visto mais claramente na figura 5.16. Aqui, pelo fato do volume de dados possuir variações bruscas do gradiente na direção do eixo $z$, a tonalização (e, portanto, a noção de profundidade) fica prejudicada. Cumpre lembrar que isso é uma característica particular desse volume de dados, pelas razões do cálculo das distâncias discutidas acima, que não é uma situação típica na maioria dos volumes de dados.

- Um outro aspecto que diferencia o Ray Casting do DVRT é que em materiais com transparência acentuada, como a região azul da figura 5.15, a tonalização fica mais realçada para o Ray Casting. Isso aumenta a noção de profundidade do volume sendo, embora tenha o efeito de reduzir o nível de transparência escolhido. Para obter uma tonalização maior no DVRT, a transparência deve ser diminuída.

- Pelo fato do DVRT produzir uma suavização mais acentuada que o Ray Casting, o DVRT produz menos artefatos para figuras de parâmetros parecidos, ver figura 5.15 (e), (f), (g) e (h). No caso do Ray Casting esses artefatos destacam os contomos que deram origem ao volume de dados (figura 5.15 (f) e (h)). 
$\bullet$

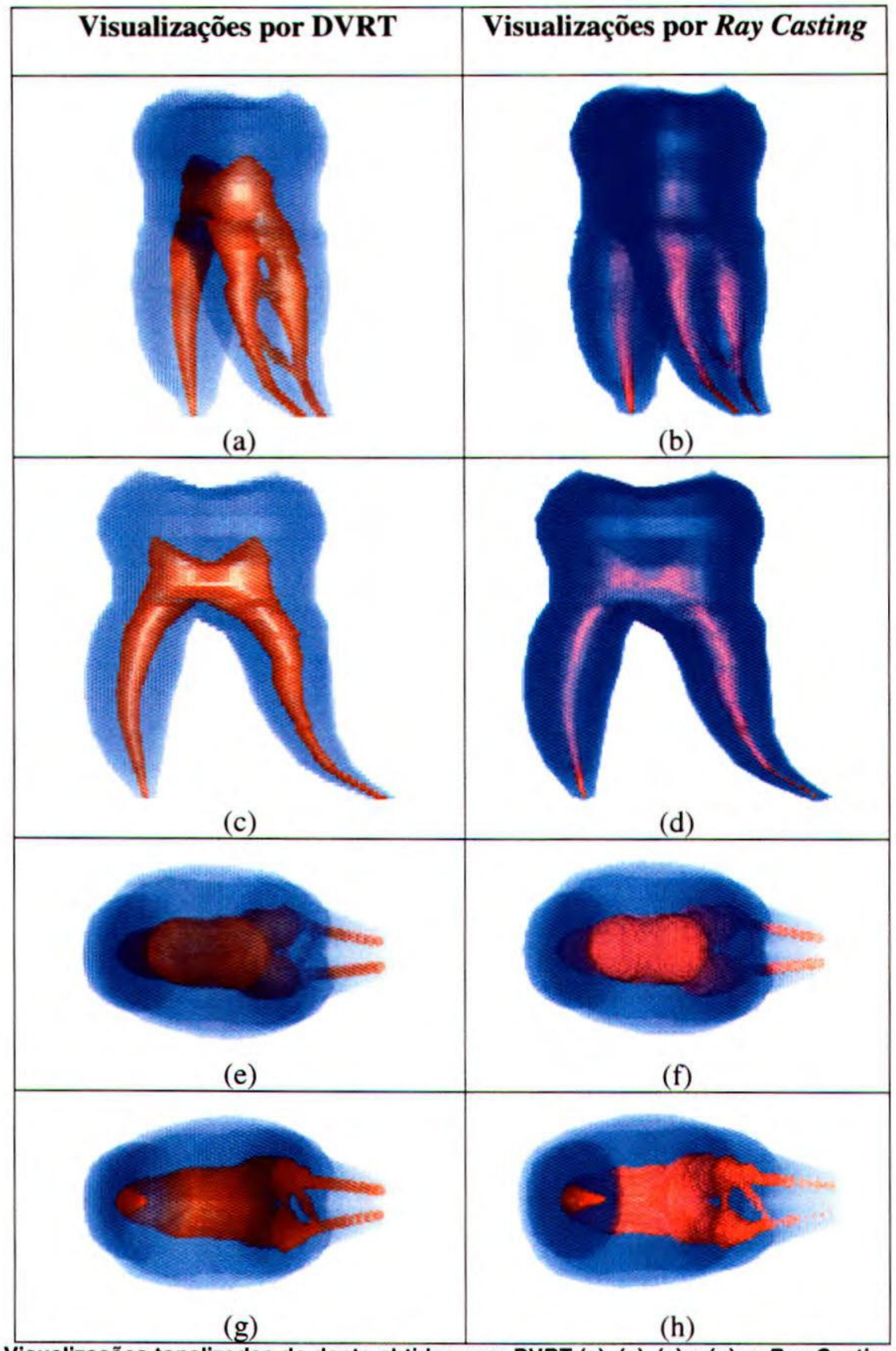

Figura 5.15 - Visualizações tonalizadas do dente obtidas com DVRT (a), (c), (e) e (g) e Ray Casting (b), (d), (f) e (h). Em (a) e (b), o dente é visto com uma rotação a partir da visão frontal (c) e (d). Em (d) e (e) o dente é visto de cima para baixo e em $(\mathrm{g})$ e $(\mathrm{h})$ de baixo para cima.

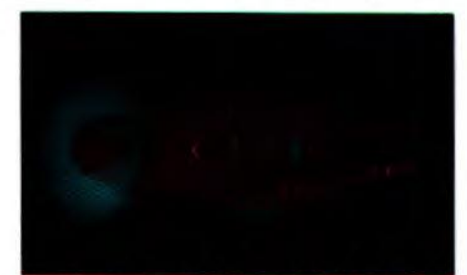

Visualização por DVRT

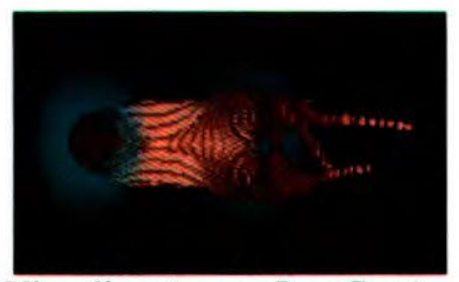

Visualização por Ray Casting

Figura 5.16 - Visualização tonalizada do dente onde a distribuição dos escalares não produzem um bom comportamento dos gradientes. 


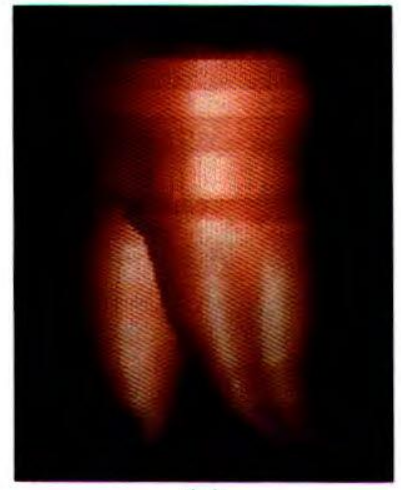

(a)

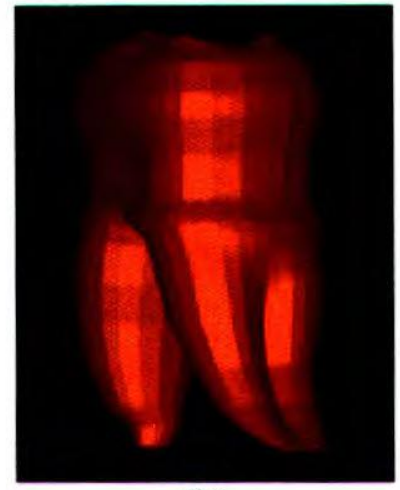

(b)

Figura 5.17 - Visualização tonalizada da parte externa do dente.

Neste capítulo foram apresentados alguns dos principais testes realizados com o método implementado. A implementação do DVRT foi testada de três maneiras diferentes. Primeiramente, foi observado o comportamento das imagens resultantes em relação às mudanças nos vários parâmetros. Isso pode ser chamado de "ajuste fino" da técnica, para alcançar um equilíbrio entre qualidade da imagem e custo computacional para uma aplicação particular. O método se comportou muito bem quanto à qualidade da imagem, sendo que ruídos e erros dificilmente acontecem.

Os demais testes foram destinados a verificar a eficiência do DVRT para visualização de dados dentários, e à comparação da imagem final com o método Ray Casting, também com dados dentários. Até o momento não foi possível testar o DVRT com os dados dentários apropriados para DVRT, isto é, dados que representem o volume completo do dente. Os dados utilizados foram gerados a partir de amostragem de contornos editados que, muito embora tivessem sido extraídos utilizando dados reais, ainda não representam o formato final a ser utilizado (fotografia ou tomografia). Entretanto, esses dados serviram como teste de muitas características mais importantes do método e para comparação com a saída visual das visualizações de superfícies, e os resultados foram bons.

Quanto à comparação entre DVRT e Ray Casting pode-se perceber que ambas as técnicas são muito similares. A principal diferença recai no tratamento da transparência para algumas visões, sendo que o DVRT se comportou mais adequadamente. O Ray Casting apresenta imagens mais brilhantes quando a tonalização é levada em consideração, ao passo que o DVRT promove uma reflexão mais suavizada, para o caso particular do volume de dados visualizado. O DVRT tonalizado é intimamente dependente do posicionamento dos gradientes enquanto que o Ray Casting tonaliza qualquer volume, mas destaca a discretização, característica indesejada para as técnicas de DVR.

No próximo capítulo são realizadas as conclusões gerais deste trabalho de mestrado. 


\section{Capítulo 6}

\section{Conclusões}

Neste trabalho de mestrado foram estudadas técnicas de visualização científica, sua aplicação em odontologia, e as diferenças entre as abordagens básicas para geração de visualizações de dados escalares. A parte inicial desta monografia apresenta esses temas. Além disso, foi estudado e implementado um método de rendering volumétrico direto que faz uso de texturas tridimensionais, o DVRT (Direct Volume Rendering with Texture). Esse método possibilita a geração de imagens tonalizadas, o que significa dizer que o volume de dados sofre influência das luzes direcionais presentes na cena.

O DVRT foi implementado no contexto do VTK (Visualization Toolkit) [Sch98]. O VTK é uma biblioteca de classes que possui a maioria das técnicas convencionais para visualização e computação gráfica. O seu código é aberto, está escrito em $\mathrm{C}++$, e foi projetado seguindo a filosofia de orientação a objetos, tendo como base a biblioteca gráfica OpenGL [Woo97]. Para que o DVRT fosse incorporado ao VTK foi necessário um estudo aprofundado do código fonte de algumas classes do VTK. Com isso chegou-se à conclusão que seria necessário incluir duas novas classes: a $v t k$ VolumeTexture e a vtkVolumeTextureMapper, que foram implementadas de modo a seguir os padrões contidos no VTK, e como especificações de outras classes já existentes.

O DVRT pode ser dividido em duas etapas principais: a construção do mapa de textura e o rendering. A primeira etapa está implementada na classe vtkVolumeTexture e a segunda na classe $v t k$ VolumeTextureMapper. Além dessas duas, também foram incluídas mais outras quatro classes para promover uma melhor modularização do código, a saber: vtkReflectionTable, vtkVectorIndex, $v t k M a t e r i a l$ e $v t k M a t e r i a l C o l l e c t i o n$. Elas auxiliam na criação do mapa de textura com tabelamento da tonalização (as duas primeiras) e classificação dos dados (as duas últimas).

Quanto ao período de implementação, foi encontrada algumas dificuldades principalmente pela falta de textos explicativos claros o suficiente para se ter um bom entendimento da abordagem de DVRT implementada. Alguns textos misturavam conceitos e apresentavam figuras que prejudicavam o entendimento da técnica. Isso, somado à forte tendência do leitor leigo a associar o DVR com mapeamento de textura com a técnica de mapeamento de texturas $2 \mathrm{D}$ em polígonos, tornou a elucidação das várias etapas do método mais trabalhosa do que se julgou originalmente. 
A incorporaçăo do DVRT no VTK foi facilitada por alguns aspectos e dificultadas por outros. Foi facilitada porque o VTK fomece vários itens já implementados comó a malha volumétrica, a apresentação da imagem na tela, a interface com o sistema operacional, uma forte estrutura orientada a objetos, e muitas outras. As dificuldades foram principalmente pelo VTK possuir uma estrutura complexa e portanto compreender a fundo o seu código não é uma tarefa fácil. Como o VTK está em constante atualização e o DVRT faz uso de recursos de implementação muito embutidos do VTK, sempre que uma nova versão do VTK é lançada, é necessário reestudar o seu código fonte e modificar o DVRT internamente, sendo que nem sempre essas alterações são triviais.

A implementação da fase de amostragem do mapa de textura no DVRT apresentou algumas dificuldades quanto à conversão de coordenadas. Nessa fase estão em evidência quatro sistemas de coordenadas (do mundo, de textura, da viewport e da tela) sendo que nas coordenadas da tela estão presentes 3 origens diferentes (a da janela, a da viewport da janela e da área correspondente aos planos de amostragens). Isso causou alguns contratempos na implementação do processo de amostragem, resultando em distorções na imagem resultante. Também problemas de aproximação causados pela transformação de coordenadas do mundo (números reais) para as da tela (números inteiros) foram observados, e causavam artefatos na imagem antes de serem corrigidos.

O DVRT implementado fomece muita flexibilidade ao usuário, possibilitando a sua configuração quanto aos aspectos visuais da imagem resultante e quanto ao desempenho do algoritmo. Como quase sempre acontece nas técnicas de DVR, uma imagem melhor exige maior quantidade de proçessamento, e no DVRT isso não é diferente.

Ó p̉rocéssó de amostragem pode ser feito cóm ou sem interpolação. A diferença visual reside no fato de que sèm interpolaçãó a imágem apresenta-se mais grosseira ao passo que com o uso desse recurso a imagem fica mais suave, porém com um custo computacional cerca de oito vezes maior.

$\dot{A}$ 'quantidade de amostragen's do mapa de textura pode ser ajustada pelo controle do espaçamento entre elas ao longo da direção de visão. Isso aumenta ou diminui o número de planos de amostragem que interceptam o mápa de textura. Quanto mais planos de amostragem, maior o custo computacional. Ássim, 'é possível e recomendável encontrar um espaçamento adequado para cada volume de dados.

O volume de dados pode ser visualizado de três formas diferentes: sem tonalização, com tonalização tabelada e com tonálização sem tabelamento. Dentro do DVRT, essa diferença se dá na criação do mapa de textura. Se o volume de dados for extenso, essas altemativas estão em ordem crescente de desempenho. Nos três casos, as imagens apresentadas possuíram uma boa qualidade.

O processo de tonalização é intimamente dependente dos gradientes calculados para os voxels. Quando a tonalizaçāo está habilitada e o volume de dados é adequado para tal recurso (produz 
gradientes 'bem comportad̄os'), a imagem apresenta-se bem suavizada; o que é uma característica desejável nas abordagens DVR. No entanto, quando o volume de dados possui um posicionamento mais aleatório de seus escalares, produzindo gradientes mal comportados, a tonalização fica prejudicada.

O tabelamento da tonalização apresentou resultados satisfatórios quanto à qualidade da imagem (com os devidos ajustes na tabela), pois consegue imagens bem próximas da "ideal" (sem tabelamento). No entanto, não promoveu uma economia de tempo considerada alta como era esperado inicialmente. Acreditamos que outras implementações de tabelamento da tonalização, como a proposta em [Lei96], podem acelerar mais o processo de criação do mapa de textura.

Como o Índice de Gradientes foi implementado em uma classe separada (vtkVectorIndex). É possível utilizar o mesmo índice para volumes diferentes submetidos simultaneamente ao DVRT. Isso ajuda a economizar tempo de processamento.

De uma maneira geral, o DVRT implementado apresentou resultados bastante satisfatórios, promovendo imagens fiéis aos volumes sendo visualizados, com um desempenho aceitável. No entanto, ele é limitado no sentido que foi implementado exclusivamente para malhas reguläres e que estāo no formato vtkStructuredPoints. Além disso, ele é próprio para projeção ortogonal, não funcionando para projeção perspectiva.

Um dos problemas do trabalho é não ter sido possível implementar a utilização de hardware para aceleração do DVRT. Com esse recurso seria possível ganhar muito tempo na geração das imagens, uma vez que uma das maiores vantagens do DVRT é justamente a utilização de hardware. No entanto, a implementação realizada foi guiada para que não seja necessário muito esforço em modificações uma vez que se deseje utilizar hardware próprio.

Como pode ser visto na figura 6.1, no VTK a imagem no momento da interação é bastante grosseira, mas permite ao usuário ter uma noção da orientação do volume sendo visualizado. Isso é muito importante para tarefas interativas com grandes volumes de dados. A degradação da imagem é fortemente compensada pelo ganho na velocidade de interação. O VTK implementa esse recurso para o Ray Casting e promove um grande conforto ao usuário na interação com o volume sendo visualizado. No caso do DVRT não é feito o uso das imagens rascunhadas, o que prejudica a interação. No entanto, acreditamos que nāo será difícil promover o uso de rascunhos no DVRT, necessitando

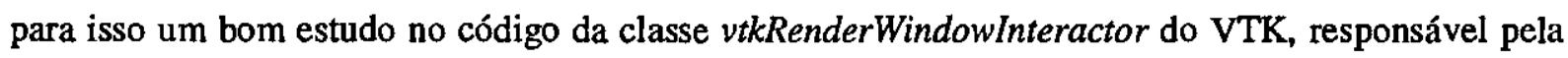
interação do usuário. 


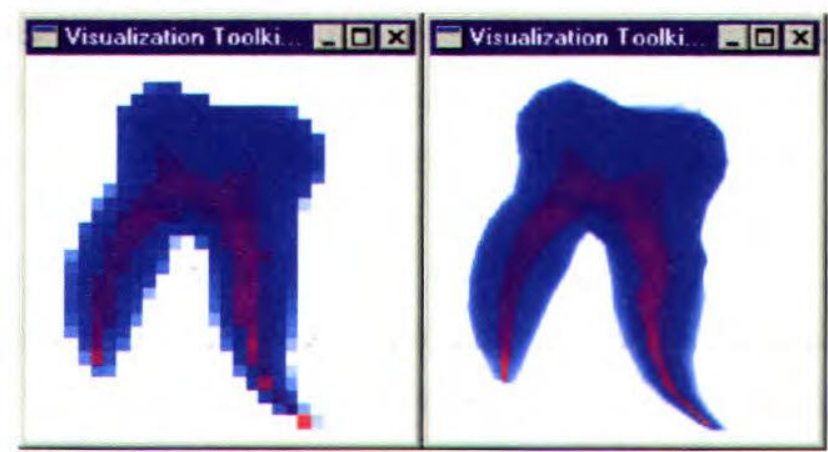

(a)

(b)

Figura 6.1 - Imagem rascunhada (a) de um volume no momento da interação e refinada (b) quando a interação é finalizada.

Apesar dos valores de profundidade de cada pixel da imagem na cena (Z-buffer) estarem sendo calculados, a imagem do DVRT aparece sempre se posicionando na frente dos demais objetos presentes na cena, como mostra a figura 6.2. Não se trata dos valores estarem sendo calculados erroneamente, e sim que o VTK não está fazendo uso dos valores de profundidade calculados. Necessitando também de um estudo apurado do código do VTK para resolver esse problema.

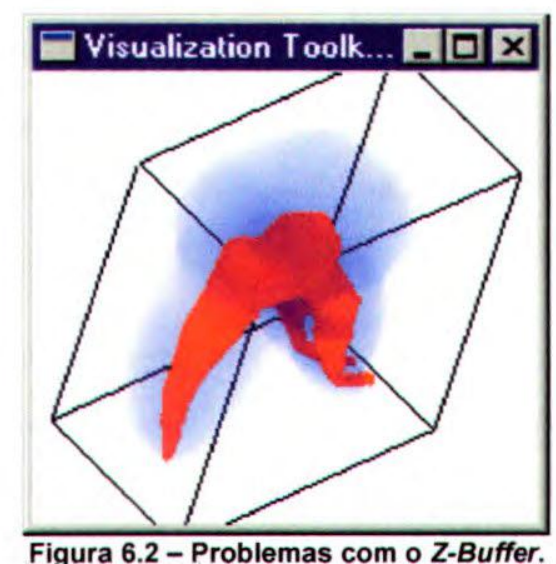

Os dados dentários submetidos ao DVRT foram obtidos usando um editor de contornos [Goe98], baseado em valores obtidos de um dente real. Eles correspondem a um conjunto de contornos extraídos de fatias para duas superficies do dente, uma interna e outra externa, ambas preservando o canal do dente. Esses contornos foram amostrados em uma malha regular usando uma técnica de amostragem baseada em distâncias [Shi98].

Por falta de dados dentários mais apropriados para o DVRT, devido principalmente à dificuldade de se conseguir material e recursos para sua obtenção, não foi possível perceber na prática todas as vantagens do DVRT ao caso dentário. Acreditamos que brevemente esses dados estarão à disposição do grupo de pesquisa do ICMC e será possível constatar essas vantagens. Acredita-se que a capacidade do DVR de mostrar o interior e as redondezas dos objetos pode vir a ser o grande benefício do método implementado no contexto do projeto do dente virtual, uma vez que é de interesse visualizar tecidos e outras estruturas embutidas no ambiente dos objetos sob manipulação pelo dentista em treinamento. 
Essa capacidade de fomecer visualização do interior de objetos pode ser observada nos testes realizados com o DVRT.

O processo de obtenção de dados por fatiamento do dente é bastante demorado, além de ser uma provável fonte de distorções. Atualmente, está disponivel a microtomografia, que permite obter os dados de uma forma mais rápida e precisa. Soma-se a essas vantagens o fato do processo ser não destrutivo [http://www.skyscan.com/CMTINF.HTM], permitindo que um único dente sirva para vários testes.

No geral, a área médica pode se beneficiar do DVRT, pois:

- Fomece uma visão do interior do volume, ao contrário dos métodos superficiais. Isso também é verdade para os demais métodos DVR.

- Fomece uma boa qualidade de imagem, com algumas vantagens sobre o Ray Casting, como visto no capítulo anterior.

- A geração da imagem pelo DVRT utilizando hardware tende a ser mais rápida que as outras técnicas de DVR.

Comparações entre o DVRT e o Ray Casting mostram que o primeiro, para a aplicação particular em estudo, não apresenta perdas de qualidade e em alguns casos produz um comportamento mais estável e consistente com as configurações fomecidas pelo usuário [Soa00]. Comentários sobre a comparação entre os dois métodos foram tecidos no capítulo 5.

No projeto de odontologia virtual, onde este trabalho de mestrado está inserido, tem-se procurado construir um sistema integrado de visualização e interação para auxiliar o treinamento de profissionais. Nesse caso, as informações volumétricas são muito importantes, e um dos objetivos é discutir estratégias para combinar apresentações por superfícies e DVR em um mesmo ambiente virtual. A própria existência de múltiplas técnicas de visualização já enriquece bastante uma aplicação desta e de áreas afins.

Muitas das informaçōes apresentadas por DVR são perdidas em apresentações puramente por superfícies. Acredita-se que o uso conjunto do DVRT com reconstrução de superfícies em um mesmo ambiente de interação e apresentação trará os benefícios das características de ambas as técnicas simultaneamente durante a manipulação de modelos do dente e da boca [Min00]. No caso do DVRT, a possibilidade de agilizar o processo por meio de hardware gráfico vislumbra a possibilidade de utilizar equipamentos não muito caros para promover visualização em tempo real. Uma dificuldade na execução dessa idéia é a falta de esquemas (estruturas de dados, manipuladores, abstraçōes) que 
integrem DVR com SF. Esse é um trabalho futuro que deverá ser realizado, em nível de doutorado, por membros do grupo de computação gráfica do LCAD/ICMC.

Em geral, o DVRT se comportou muito bem quanto às imagens resultantes, quanto à flexibilidade no controle dos parâmetros, e quanto à consistência. Existe uma possibilidde de 'afinação' do método com relação aos planos de amostragem, à definição de cores, à definição (ou não) de tabelas de indexação de gradientes, e à sua resolução. Essa 'afinação' pode adaptar o método a um ou outro tipo de dado, para auxiliar a visualização consecutiva de vários arquivos de mesma fonte, ou mesmo tipo. Um dos possíveis trabalhos futuros é uma investigação desse ajuste de parâmetros para, por exemplo, conjuntos de imagens tomográficas de um mesmo órgão.

O algoritmo DVRT pode ser melhorado de várias formas. Uma delas é fazer a implementação por hardware das etapas de amostragem e blending, conforme mencionado na seção 3.2.2.2. Para isso ser efetivo, uma boa placa gráfica com bastante memória de textura 3D é necessária. Do ponto de vista de implementação, o código já está preparado para que essa migração seja realizada. É necessário também considerar esquemas altemativos de tabelamento das características de luz direcional [Lei96].

Com a implementação no contexto do VTK do método de DVR com mapeamento de textura, e sua robustez de execução, é possível deixá-lo disponível para um número grande de usuários (todos aqueles que se utilizam do VTK), para que futuros testes possam ser executados e os resultados compilados.

O desenvolvimento do código também permitirá que futuras modificaçōes do método, planejadas pelo grupo, possam ser executados com maior facilidade. Também seu uso em contextos atuais de projetos do grupo, como visualização na intemet [Alv00], é imediato e já está em execução. 


\section{Referências Bibliográficas}

[Alg96] Algorri, M.; Schimitt, F. - Surface Reconstruction from Unstructured 3D Data, Computer Graphics Forum, vol. 15, no. 1, pp. 47-60, 1996.

[Alv00] Alves, A. D.; Oliveira, M. C. F.; Minghim, R.; Nonato, L. G. - Interactive Visualization over the WWW, artigo submetido ao Sibgrapi'2000.

[Bak95] Baker, M. P.; Wickens, C .D. - Human Factor in Virtual Environments for tue Visual Analysis of Scientific Data; Technical Report NCSA-TR032, NCSA, 26 pages. http://www.ncsa.vivc.edu/People/baker

[Ber89] Bergeron, R.G.; Grinstein, G.G. - A Reference Model of the Visualization of Multidimensional Data, Proc. Eurographics'89, Elsevier Science Publishers, 1989, pp.393-399.

[Bio98] http://biocomp/stanfort.edu/3dreconstruction/what is_reconstruction.htm sitè visitado em Out. de 1998.

[Blo98] Bloomenthal, J. - Introduction to Implicit Surfaces; Morgan Käufmann Publishers, 'Inc; 1998.

[Boi88] Boissonat J-D - Shape Reconstruction from Planar Cross Sections; Computer Vision, Graphics and Image Processing; 44; pp. 1-29; 1988

[Bro92] Brodlie, K.W.; Carpenter, L.A; Earnshaw, R A.; Gallop, J.R.; Hubbold, R.J.; Mumford, A. M.; Osland, C.D.; Quarendon, P. - Scientific Visualization Techniques' and Applications, Springer-Verlag, 1992.

[Bry94] Bryson, S.; Real-Time Exploratory Scientific Visualization and Virtual Reality; artigo presente no livro L. Rosenblum at al.; Scientific Visualization - Advances and Challenges; Academic Press; 1994

[Cab94] Cabral, B.; Cam, N.; Foran, J. - Accelerated Volume Rendering and Tomographic Reconstruction Using Texture Mapping Hardware; Proceedings of 1994 Symposium on Volume Visualization; pp.91-98, Out. 1994.

[CG87] ACM SIGGRAPH Computer Graphics, Special Issue on Visualization in Scientific Computing, vol. 21, no.6, Nov. 1987.

[CG98] Apostilas do curso de Computação Gráfica do ICMC (Instituto de Ciências Matemáticas e de Computação) da USP - São Carlos. Disponível no endereço http://www.gbdi.icmc.sc.usp.br/documentacao/apostilas/cg/.

[Cos96] Costa, A. R. - Dissertação de Mestrado: As Implicações Teóricas e a Implementação de um Completo Sistema de Visualização de Imagens Médicas, ICMSC-USP, 1996. 
[Dar93] Darken, R. P.; Silbert, J. L: - A toolset for mavigation in virtual envirounments. In uist93; pp.157-165; 1993

[Ear94] Earnshaw, R. A.; Jern, M.; - Fundamental Approaches do Interactive Real_Time Visulization Systems, in Rosemblum, L.J.; Earnshaw, R. et al. - Data Visualization: Research Issues, Applications and Future Directions, Academic Press, 1994.

[Ebe98] Ebert, D. S.; Musgrave, F، K.; Peachie,D.; Perlin, K.; Worley, S:-Texturing \& Modeling - A Procedural Approach; $2^{\text {nd }}$ Edition; AP Professional; 1998.

[Eko91] Ekoule, A. B; Peyrin, F.C.; Odet, C.L. - A triangulation Algorithm from Arbitrary Shaped Multiple Planar Contours, ACM Transactions on Graphics, vol. 10, no. 2, pp.182-199, Abr. 1991.

[Elv92] Elvins, T. T.; A Survey of Algorithms for Volume Visualization, Computer Graphics, vol. 26 (3); pp. 194-201, 1992

[Fan96] 'Fang, S.; Huang, S.; Srinivasan, R.; Reghavan, R. - Deformable Volume rendering by 3D Texture Mapping and Octree Enconding; IEEE Proceedings Visualization' 96; Out. 27 - Nov. 1; 1996;

[Fer96] Ferreira, R. A. - Odontologia em Imagens, Revista da APCD, vol. 50, no. 3, Mai./Jun. 1996.

[Fri91] Friedhoff, R.M.; Benzon, W. - Visualization: The Second Computer Revolution, W.H. Freeman and Co., 1991.

[Ga194] Gallop, J. - Underlying Data Models and Structures for Visualization, in Rosemblum, L. et al. (ed.) Scientific Visualization Advances and Challenges, Academic Press, 1994.

[Ge196] Gelder, A. V.; Kim K. - Direct Volume Rendering with Shading via ThreeDimensional Textures; University of California, Santa Cruz, CA 95064 USA; Technical Report UCSC-CRL-96-16; Jul 19, 1996; também em Proceedings of ACM/IEEE Synposium on Volume Visualization, San Francisco, Out. 1996.

[Goe98] Goetz, M. R.; Day, A. M. - Surface Roconstruction for Teeth, Proceedings or EUROGRAPHICS UK, 16 ${ }^{\text {th }}$ Annual Conference, 25-27 Mar., Leeds, UK, 1998.

[Grz98] Grzeszczuk, R.; Henn, C.; Yagel, R.; Advanced Geometric Techniques for Ray Casting Volume; ACM SIGGRAPH' 98; Course Notes 4; Abr. 20, 1998.

[Haa97] Haase, H.; Daí, F.; Strassner, J.; Göbel, M. - Immersive Investugarion os Scientific Data; Nielson, G. M.; Hagen H.; Miiller, H. - Scientific Visualization OverviewsMethodologies-Techniques; IEEE Computer Society; pp35-58; 1997

[Hea97] Hearn D.; Baker, M.P. - Conputer Graphics - C Version; Ed. Prentice Hall, 1997

[Hib95] Hibbard, W.; Levkowitz, H.; Haswell, J.; Rheigans, P.; Schroeder, F. -Interaction in Perceptually-Based Visualization; artigo presente no livro Grinstein, G.; Levkowitz, H. - Perceptual Issues in Visualization; Springer 1995

[Jon94] Jones, M. W.; Chen, M. - A New Approach to the Construction of Surfaces from Contour Data, Proc. EUROGRAPHICS'94, 13(3), 1994, 75-84. 
[Kau93] Kaufman,-A.; Cohen, D.; Yagel, R. - Volume Graphics, IEEE Computer, vol. 27, no. 7, Jul. 1993, pp.51-64.

[Kel93] Keller, P.K.; Keller, M.M. - Visual Cues: Practical Data Visualization, IEEE CS Press and IEEE Press, 1993.

[Kur98] Kurzion, Y.; Yagel, R. - Interactive Space Deformation with Hardware Assisted Rendering; ACM SIGGRAPH'98; Course.Notes 04; Abr. 20, 1998

[Lei96] Ricardo B. V. Leitão, Reynaldo P. Fagundes, Fábio J. Ayres, Eduardo T. Santos e Marcelo K. Zuffo - Um algoritmo Rápido para Iluminação Volumétrica; IX SIBGRAPI, pp 9 - 14, 1996.

[Lev88] Levoy, M., Display of Surfaces from Volumetric Data; IEEE Computer Graphics \& Applications, 8(3), pp 29-37, May 1988.

[Lor87] Lorensen, W.E.; Cline, H.E. - Marching Cubes: A High Resolution 3D Ssurface Construction Algorithm, ACM SIGGRAPH Computer Graphics, vol. 21, pp.163-169, 1987

[Lor95] Lorensen, W.E. - Marching Through the Visible Man, Proc. IEEE Visualization'95, pp.368-373, 1995.

[Mar97] Martins, A. L.; Oliveira, M.C.F.; Minghim, R. - Visualização Científica em Mecânica dos Fluidos, Notas do ICMSC no. 34, ICMSC - USP - São Carlos; Mar.1997.

[Mat94] Matveyev, S.B. - Approximation of Isosurface in the Marching Cube: Ambibuity Problem, Proc. IEEE Visualization'94, pp. 288-292, 1994.

[McC87] McCormick, B. H.; DeFanti, T. A.; Brown, M. D. - Visualization in Scientific Computing; Report of the NSF Advisory Panel on Graphics, Image Processing and Workstations, 1987.

[McR98] McReynolds, T. - Advanced Graphics Programming Techniques Using OpenGL; ACM SIGGRAPH'98; Course Notes 4; Abr. 20, 1998

[Mey92] Meyers, D.; Skinner, S; Sloan, K. - Surface from Contours, ACM Transactions on Graphics, vol. 11, no. 3, pp. 228-258, Jul. 1992.

[Min97a] Minghim, R.; de Oliveira, M. C. F.; Uma Introdução à Visualização Computacional, Jomadas de Atualização em Informática (JAI-97); capítulo 3; XVII Congresso da SBC, Brasília, 2 a 8 de Ago. de 1997. 45p

[Min97b] Minghim, R.; de Oliveira, M. C. F. - PowerVis: Empowering the User with a MultiModal Visualization System, II IEEE Workshop on Cybemetic Vision, São Carlos, Dez. 1996, publicado pela IEEE CS Press, 1997, pp. 106-I11.

[Min00] Minghim, R; Soares, I. P.; Oliveira, M. C. F.; Nonato, L. G. - Combination of Techniques to Enrich Visualization in Dentistry, Submetido ao Pacific Graphics'2000.

[Mon94] Montani, C; Scateni, R; Scopigno, R. - Discretized Marching Cubes, Proc. IEEE Visualization'95, pp.281-287, 1995.

[Non98] Nonato, L. G. - Reconstrução Volumétrica de Objetos Dados por Seções Bidimensionais, Tese de Doutorado, Departamento de Matemática, Pontifícia 
Universidade Católica do Rio de Janeiro; Rio de Janeiro, Jun. de 1998.

[Non00a] L. G. Nonato, R. Minghim, M. H. Shimabukuro, : "Qualitative Analysis of Reconstruction Techniques for Dentistry", accepted for publication in the Journal of Electronic Imaging (2000).

[Non00b] L.G. Nonato, R. Minghim; M.C.F. Oliveira, "Discussing Different Approaches for Delaunay 3D Reconstruction in the-Light of Applications in Dentistry", submitted to Pacific Graphics'2000.

[Oli98] Oliveira, M.; Minghim, R.; Tutiba, S.; Salvador, V. - Towards Perception Driven Visualization; Proceedings SIBGRAPI'98; pp. 127-134; Out. 20-23, 1998; IMPA, Rio de Janeiro, 1998

[Own96] Owen, G. S. - HyperVis - Teaching Scientific Visualization Using Hypermedia; ACM SIGGRAPH Education Committee; Site http://www.cs.gsu.edu/classes/hypervis.htm; modificado em Jul. 29, 1996

[Pau93] Pausch, R.; Shackelford, M. A.; Proffitt, D. - A user study comparing head-mounted and estatinary displays. In IEEE Symposium on reserch Frontiers in Virtual Reality, pp $41-45,1993$

[Pau95] Pausch, R., Bumette, T.; Brockway, D.; Weiblen, M. E. - Navigation and Locomotion in Virtual Worlds via Flight Into \{Hand-Held\} Miniatures. In SIGGRAPH 1995 in Los Angeles, CA , edited by Robert Cook, Addison Wesley, 399-400, 1995.

[Rhe95] - Rheigans P.; Landreth, C. - Perceptual Principals for Effective Visualizations; artigo presente no livro G. Grinstein and H. Levkowitz; Perceptual Issues in Visualization; Springer, 1995

[Ros94] Rosemblum, L.J.; Earnshaw, R.A.-- Data Visualization: Research Issues, Applications and Future Directions, Academic Press, 1994.

[Rou94] Roux, C; Coatrieux, J.L. - Panel: Vizualization in Medicine: Virtual Reality or Actual Reality?, Proc. IEEE Visualization'94, pp.396-399.

[Sch98] Schröeder, W.J.; Martin, K.; Lorensen, B. - The Visualization Toolkit - Na Object-Oriented Approach to 3D Graphics, $2^{\text {nd }}$ Edition; Prentice-Hall, 1998.

[Sha96] Shahidi, R. - Panel: Surface versus Volume Rendering in Medical Imaging: Techniques and Applications; Organàzer: Ramin Shahidi, Stanford University Medical Center; IEEE Proceedings Visualization'96; San Francisco CA; Out. 27 - Nov. 1, 1996.

[Shi98a] Shimabukuro, M.H. - Dissertação de mestrado: Dentes Virtuais: Visualização para Apoio a Atividades Odontológicas, ICMC-USP, São Carlos, SP, 1998.

[Shi98b] Shimabukuro, M.H.; Minghim, R.; Licciardi, P.R.D.B. - Visualisation and Reconstruction in Dentistry, Proc. Int. Conf. On Information Visualisation IV'98, London, UK, Jul. 1998, IEEE CS Press, pp.25-31

[Shi98c] Shimabukuro, M.H., Minghim, R., Licciardi, P.R.D.B. - "Implementing Visualization Procedures in Dental Applications", Proc. SCI'98: World Multiconference on Systemics Cybemetics and Informatics and the Intemational Conference on Information Systems Analysis and Synthesis, Orlando, E.U.A, vol. II, pp.481-488, Jul. 1998. 
[Soa99] Soares, I.P.- Visualização Volumétrica em Odontologia, Mini-dissertação apresentada ao ICMC-USP como parte dos requisitos para obtenção de título de Mestre na área de Ciências de Computação e Matemática Computacional, abr. 99.

[Soa00] Soares, I.P; Minghim R.; Oliveira, M.C.F.; Nonato, L.G. - Implementing and Applying Direct Volume Rendering with Textures; artigo submetido ao SIBGRAPI 2000

[Sto95] Stoakley, R.; Conway, M. J.; Pausch, R. - Virtual Reality on WIM: Interactive Worlds in Miniature; In Proceedings of Sigchi 1995.

[Tes95] Teschner, M.; Henn, C. - Texture Mapping in Technical, Scientific and Engineering Visualization; SGI, Ago. 4, 1995; também em ACM SIGGRAPH'98; Course Notes 17; Abr. 20, 1998

[Tre96] Treinish, L; Silver, D. - "Visualizing the Visible Human", IEEE Computer Graphics and Applications, vol. 16, no. 1, Jan. 1996, pp.7-9.

[Udu91] Udupa, J. K.; Herman, G. T. - 3D Imaging in Medicine, CRC Press, 1991.

[Wat8I] Watson, D.F.; Computing the n-dimensional Delaunay tessellation with application to Voronoi polytopos; The Computer Joumal; vol. 24; no. 2; pp. 167-172; 1981

[Wat89] Watt, A. - Fundamentals of Three-Dimensional Computer Graphics, Addison-Wesley, 1989.

[Wil91a] Wilhelms, J.; "Decisions in Volume Rendering"; State of Art in Volume Visualization; ACM SIGGRAPH' 91; Course notes, Course Number 8, ACM Press, Ago. 1991; pp I.1I.11

[Wil91b] Wilhelms, J. and Van Gelder, A. - A Coherent Projecion Approach for Direct Volume Rendering; Computer Graphics, vol 25; no 4; Ago. 1991; pp. 275-284

[Wol93] Wolf, R. S.; Yaeger, L. - Visualization of Natural Phenomena - Springer-Verlag, 1993.

[Wo097] Mason Woo; Jackie Neider; Tom Davis - OpenGL Programming Guide, Second Edition; Addison Wesley Developers Press, 1997.

[Vie98] Viega, J.; Conway, M. J.; Williams, G.; Pausch; R. - 3D Magic Lenses; http://www.cs.cmu.edu/ stage3/; site visitado em Fev. de 1999.

[Vin98] Vince, J.; Essential Virtual Reality Fast; Ed. Springer; 1998

[Yed96] Yedidyah L.; Augenstein, M.J.; Tenenbaun, A.M., Data Structures using C and C++, Second Edition, Prentice Hall, 1996 


\section{Apêndice $A$}

\section{Manual para as classes do DVRT}

Nesse apêndice são apresentados os manuais das classes implementadas para o DVRT. Os manuais seguem o modelo HTML oferecido pelo VTK.

\section{A Classe vtkMaterial}

VtkMaterial - armazena uma classificaçāo de voxels

Super Classe: vtkObject

Descrif̧ão: Armazena as informações referentes à classificação de voxels. $O$ material armazena o intervalo de escalares e os coeficientes de reflexão (Kd - coeficiente de reflexão difusa, Ks - coeficiente de reflexão especular e $\mathbf{n}$ - potência de reflexão especular).

Métodos:

- void SetScalarRange (float range[2]);

- void SetScalarRange (float range0, float range1);

- void GetScalarRange (float range[2]);

- void GetLowScalarRange (float LowScalar);

- float GetLowScalarRange ();

- void GetHighScalarRange (float HighScalar);

- float GeHighScalarRange ();

- void SetDiffuseCoefficient (float Kd);

- float GetDiffuseCoefficient ();

- void SetSpecularCoefficient (float Ks);

- float GetSpecularCoefficient 0;

- void SetSpecularPower (float $n$ );

- float GetSpecularPower 0; 


\section{Descrição dos Métodos:}

- void SetScalarRange (float range[2])

- void SetScalarRange (float range0, float range1)

- void GetScalarRange (float range[2]);

Obtém/retorna o intervalo de escalares do material.

- void GetLowScalarRange (float LowScalar);

- float GetLowScalarRange ();

- void GetHighScalarRange (float HighScalar);

- float GeHighScalarRange ();

Retorna o limite inferior/superior do intervalo de escalares.

- void SetDiffuseCoefficient (float $\mathrm{Kd}$ );

- float GetDiffuseCoefficient 0;

- void SetSpecularCoefficient (float Ks);

- float GetSpecularCoefficient (;

Obtém/retorna o coeficiente de reflexão difusa/especular.

- void SetSpecularPower (float $\mathrm{n}$ );

- float GetSpecularPower 0;

Obtém/retorna a potência de reflexão especular. 


\section{A Classe vtkMaterialCollection}

VtkMaterialCollection - manipula uma coleção de materiais

Super Classe: vtkCollection

Descrição: Manipula uma lista de materiais (vtkMaterial)

Métodos:

- void AddItem(vtkMaterial *a);

- void RemoveItem(vtkMaterial *a);

- int IsItemPresent(vtkMaterial *a);

- vtkMaterial *GetNextItem();

- vtkMaterial *GetItem(int m);

- int GetNumberOfMaterials0;

Descrição dos Métodos:

- void AddItem(vtkMaterial *a)

Adiciona um material na lista

- void RemoveItem(vtkMaterial *a)

Remove um material da lista

- int IsItemPresent(vtkMaterial *a)

Verifica se um material específico está presente. Retorna a posição desse material na lista.

- $\quad$ vtkMaterial *GetNextItem()

Retorna o próximo material na lista. NULL é retornado se a lista estiver esgotada.

- $\quad$ vtkMaterial *GetItem(int m)

Retorna o material na posição m na lista.

- int GetNumberOfMaterials 0

Retorna o número de materiais na lista. 


\section{A Classe vtkVectorlndex}

vtkVectorIndex - gera um índice de gradientes a partir do refinamento de uma esfera.

Super Classe: vtkObject

Descrição: O Índice de Vetores é uma discretização de vetores no espaço. É capaz de retornar um vetor unitário tabelado que melhor se aproxima de um dado vetor de entrada. A tabela contendo os vetores discretizados é obtida através de uma esfera de raio unitário e centrada na origem. O número de vetores do índice aumenta conforme o refinamento da esfera inicial (icosaedro).

\section{Métodos:}

- SetLevelOfRefinament(int d)

- int GetLevelOfRefinament();

- int GetVectorIndex(float $G[3])$;

- void GetVector(int i, float G[3]);

- int GetNumberOfVector();

- void BuildVectorIndex 0 ;

\section{Descrição dos Métodos:}

- SetLevelOfRefinament(int d)

- int GetLevelOfRefinament()

Definir/obtém o nível de refinamento da esfera geradora de vetores. Quanto maior o nível de refinamento, mais vetores possuirá o Índice.

- int GetVectorIndex(float V[3])

Retorna o índice de um vetor unitário tabelado que mais se aproxima de um dado vetor $(V)$.

- $\quad$ void GetVector(int i, float G[3])

Dado um índice de vetor $(i)$ o gradiente da tabela é retornado pela função ou através do parâmetro $G[3]$.

- int GetNumberOfVectors()

Retorna o número de vetores presentes no Índice de Vetores.

- void BuildVectorIndex (

Constrói a tabela de vetores. 


\section{A Classe vtkReflectiveTable}

vtkReflectiveTable - constrói e manipula uma tabela com componentes de reflexão para um modelo de iluminação.

Super Classe: vtkObject

Descrição: Uma tabela contendo os cálculos resultantes da componente de reflexão do modelo de iluminação é preenchida. Os vetores normais à superfície envolvidos nos cálculos são os presentes em um Índice de Vetores (vtkVectorIndex). $O$ número de entradas na tabela é igual ao número de materiais definidos multiplicado pelo número de vetores fornecidos pelo Índice de Vetores.

\section{Métodos:}

- void GetColorFromReflectiveTable(float g[3], int material, float color[3);

- void SetGradientIndex(vtkGradientIndex *Gn);

- vtkVectorIndex *GetVectorIndex $($;

- void InvertShadingHemisphereOnO;

- void InvertShadingHemisphereOff();

- void BuildReflectiveTable(vtkStructuredPoints *dataset, vtkLightCollection *lights, vtkMaterialCollection *materials, float view_direction[3]);

\section{Descrição dos Métodos:}

- void GetColorFromReflectiveTable(float v[3], int material, float color[3])

Dados um vetor $(v)$ e uma definição de material $(m)$ a função retorna uma cor (color) que representa a componente de luz refletida para $v$ e $m$.

- void SetVectorIndex (vtkVectorIndex *V)

- vtkVectorIndex *GetVectorIndex()

Obtém/retorna o Índice de Vetores da tabela de reflexãp. Possibilita a utilização de um Índice de Vetores externo. 
- void InvertShadingHemisphereOnO

- void InvertShadingHemisphereOff()

Liga/desliga a inversão da região onde acontece a tonalização. Em método é necessário porque os escalares em um volume de dados podem estar dispostos digerentemente. Hora o interior de um material possui escalares menores, hora maiores. A disposição dos escalares influencia diretamente na orientação dos gradientes que são necessários no cálculo da tonalização

- void BuildReflective'Table(vtkStructuredPoints *dataset, vtkLightCollection *lights, vtkMaterialCollection *materials, float view_direction[3])

Constrói a Tabela de Reflexāo para um determinado volume de dados (dataset) levando em consideração a direção de visão (view_direction) e a coleção de luzes direcionais (lights) e de materiais (materials). 


\section{A classe vtkVolumeTexture}

vtkVolumeTexture - gera o mapa de textura para um dado volume de dados.

Super Classe: vtkObject

Descrição: O mapa de textura é construído a partir de um volume de dados. Cada escalár presente no volume de dados possui um texel (unidade do mapa de textura) correspondente, contendo as intensidades de cor e opacidade (RGBA) adquiridos de acordo com as funções de transferência para o escalar. Sendo assim, o mapa de textura é o volume de dados classificado. Tanto o mapa de textura quanto o volume de dados devem ser do tipo vtkStructuredPoints.

Métodos:

- vtkVolumeTexture();

- vtkVolumeTexture0;

- static vtkVolumeTexture *New0;

- const char *GetClassName0;

- void SetDataset (vtkStructuredPoints *SP);

- void SetColor (vtkColorTransferFunction *colortransferfunction);

- void SetOpacity (vtkPiecewiseFunction *piecewisefunction);

- void SetShadingOn0;

- void SetShadingOff();

- unsigned char GetShadingOnOrOff();

- void SetUseOfTablesOn();

- void SetUseOfTablesOffo;

- unsigned char GetUseOfTablesOnOrOff();

- void SetLevelOfRefinament (unsigned char level);

- void SetGradients (vtkGradientIndex *g);

- vtkGradientIndex *GetGradientIndex();

- void SetLowScale(float value);

- void SetHighScale(float value);

- float GetLowScale();

- float GetHighScale0;

- $\quad$ void AddMaterial(vtkMaterial *Mat); 
- void AddMaterial(float min, float $\max$, float $\mathrm{Ka}$, float $\mathrm{Kd}$, float $\mathrm{Ks}$, float $\mathrm{SP}$ );

- void SetMaterials (vtkMaterialCollection *m);

- vtkMaterialCollection *GetMaterials ();

- int GetMaterialIndex(float data);

- void InvertShadingHemisphereOn0;

- void InvertShadingHemisphereOff();

- void MakeVolumeTexture(vtkRenderer *ren, float sample_distance);

- vtkStructuredPoints * GetVolumeTexture();

- vtkScalars *GetVolumeTextureScalars 0;

\section{Descrição dos métodos:}

- void SetDataset (vtkStructuredPoints *SP)

Possibilita a associação com o volume de dados a partir do qual será construído o mapa de textura.

- void SetColor (vtkColorTransferFunction *colortransferfunction)

- void SetOpacity (vtkPiecewiseFunction * piecewisefunction)

Para fazer a associação com as funções de transferência utilizadas para colher as intensidades de cor e opacidades para preencher o mapa de textura.

- void SetShadingOn0

- void SetShadingOffo

Liga e desliga a construção do mapa de textura tonalizado, ou seja, levando em consideração as luzes posicionadas na cena.

- unsigned char GetShadingOnOrOff()

Retorna se o mapa de textura será construído tonalizado (1) ou não (0).

- void SetUseOfReflectiveTableOnO

- void SetUseOfReflectiveTableOff()

Liga e desliga a utilização de tabela de reflexão na construção do mapa de textura tonalizado. As imagens resultantes do rendering sem a utilização de tabela de reflexão são de melhor qualidade.

- unsigned char GetUseOfTablesOnOrOff()

retorna se está condicionado para construir o mapa de textura usando (1) ou não (0) a tabela de reflexão. 
- void SetLevelOfRefinament(unsigned char level)

Define o nível de refinamento para a Índice, de Gradientes. Quanto menor o nível de refinamento, menos gradientes fazem parte do índice e menos aprimorada fica a imagem tonalizada. Recomenda-se a utilização do nível de refinamentọ igual a 5.

- void SetGradientIndex (vtkGradientIndex *g)

- vtkGradientIndex * GetGradientIndex()

Atribui/retorna um f́ndice de Gradientes criado, possibilitando o uso de um f́ndice de Gradientes externo.

- void SetLowScale(float value)

- float GetLowScale()

- void SetHighScale(float value)

- float GetHighScale()

Defini/retorna o fator de escala inferior/superior para se fazer um ajuste fino dos voxels classificados em refletores ou ambientes. Um voxel é classificado como refletor quando ele está na fronteira de um material sendo visualizado e é classificado como ambiente caso contrário. $O$ fator de escala inferior tem o valor default de 0.5 e o superior de 1.5 . Valores de escala inferiores mais próximos de zero fazem com que mais voxels no interior do material sejam selecionados como de fronteira. Para valores de escala superiores menores que 1.5 , voxels que não fazem parte do material sendo visualizado podem ser selecionados como de fronteira.

- $\quad$ void AddMaterial(vtkMaterial *m)

- void AddMaterial(float min, float max, float ka, float $\mathrm{Kd}$, float $\mathrm{Ks}$, float $\mathrm{SP}$ )

Adiciona uma definição de material contendo o intervalo de escalares e os coeficientes de iluminação (luz ambiente, luz difusa. Luz especular e potência especular).

- void SetMaterials (vtkMaterialCollection *m)

- vtkMaterialCollection *GetMaterials ()

Recebe/retorna uma coleção de definições de materiais.

- int GetMaterialindex(float data)

Retorna um índice informando qual dos materiais definidos possui o intervalo de escalares contendo o valor escalar data. 
- void InvertShadingHemisphereOnO

- void InvertShadingHemisphereOffo

Liga/desliga a inversão da região onde acontece a tonalização. Em método é necessário porque os escalares em um volume de dados podem estar dispostos digerentemente. Hora o interior de um material possui escalares menores, hora maiores. A disposição dos escalares influencia diretamente na orientação dos gradientes que são necessários no cálculo da tonalização.

- void MakeVolumeTexture(vtkRenderer *ren, float sample_distance)

Constrói o mapa de textura.

- vtkStructuredPoints *GetVolumeTexture()

Retorna o mapa de textura construído.

- vtkScalars *GetVolumeTextureScalars 0

Retorna os escalares que constituem os atributos de dados do mapa de textura. 


\section{A Classe vtkVolumeTextureMapper}

VtkVolumeTextureMapper - Classe mapeadora para rendering volumétrico direto com mapeamento de textura

Super Classe: vtkVolumeMapper

Descrição:

Realiza o rendering volumétrico direto por mapeamento de textura de um volume de dados.

Métodos:

- void SetVolumeTexture(vtkVolumeTexture *VolTex);

- void SetVolumeTextureDataset(vtkStructuredPoints *VolTexDt);

- vtkStructuredPoints *GetVolumeTextureDataset();

- void SetSampleDistance (float SampleDist);

- float GetSampleDistance ();

- void SetSampleInterpolationOn();

- void SetSampleInterpolarionOff0;

- void UpdateVolumeTextureOnce();

- void UpdateVolume'TextureAlways();

- void SetRenderToAllPlanes();

- void SetRender'ToOnePlane(int plane);

- float *GetRGBAPixelData( void);

- float *GetZBufferData( void );

Descrif̧ão dos Métodos:

- void SetVolumeTexture(vtkVolumeTexture *VolTex)

Para fazer a conexão com uma instância da classe responsável por construir o mapa de textura (vtkVolumeTexture).

- $\quad$ void SetVolumeTextureDataset(vtkStructuredPoints *VolTexDt)

Possibilita a utilização de um mapa de textura armazenado em um vtkStructuredPoints.

Método geralmente utilizado quando o mapa de textura está gravado em arquivo.

- vtkStructuredPoints *GetVolumeTextureDataset() 
Retorna o mapa de textura em processamento na forma de um vtkStructuredPoints.

- void SetSampleDistance (float SampleDist)

- flaot GetSampleDistance ()

Define/retorna a distância que separam os planos de amostragem.

- void SetSampleInterpolationOn()

Os texels do Mapa de textura são amostrados como se fossem células. Ou seja, a cor amostrada é interpolada de acordo com as cores presentes nos vértices do texel.

- void SetSampleInterpolationOff()

Os texels do Mapa de textura são amostrados como se fossem voxels. Ou seja, uma cor uniforme no interior de cada texel.

- void UpdateVolumeTextureOnce();

- void UpdateVolumeTextureAlways();

Faz com que o Volume de Textura seja atualizado apenas uma vez ou sempre que houver uma interação. Esses métodos só funcionam para o caso do rendering ser tonalizado.

- void SetRenderToAllPlanes0

Fazer a amostragem em todos os planos de amostragem definidos.

- void SetRender'ToOnePlane(int plane)

Fazer a amostragem apenas no plane-ésimo plano do conjunto de planos de amostragem.

Sendo que o plano de número zero é o que está mais próximo do observadòr.

- float *GetRGBAPixelData( void)

Retorna um vetor contendo todas as cores (RGBA) dos pixels correspondentes à viewport onde o volume de dados foi definido. $O$ vetor é preenchido seguindo a seqüência RGBARGBA ... RGBA, seguindo do ponto esquerdo/inferior para o direito/superior.

- float *GetZBufferData( void )

Retorna um vetor contendo todas as profundidades dos pixels correspondentes à viewport onde o volume de dados foi definido. $O$ vetor é preenchido seguindo do ponto esquerdo/inferior para o direito/superior. 
materials->Additem (material_1);

voltex->SetMaterials (materiāls);

// Acrescentando um vtkMaterial diretamente no vtkVolumeTexture material_2->SetMaterial $(0.031,0.2,1.0,0.5,0.5,10)$; voltex $\rightarrow$ ĀddMaterial (material_2);

// Acrescentando um material diretamente no vtkvolumeTexture voltex->AddMaterial $(0.5,1.3,1.0,0.0,1.0,10)$;

// Ajustando o criador do Mapa de Textura

voltex->SetDataset (reader->Getoutput()); // conexăo com o volume de dados

voltex->SetColor(color);

// função de transferência com as cores

voltex->Setopacity (opacity);

voltex->SetShadingon();

// DVRT com tonalização

voltex->SetUseofTableson();

voltex->SetLevelofRefinament (3);//foram testados também os valores 4 e 5 (figura B2)

// Ajustando o mapeador

mapper->SetVolumeTexture(voltex); // Ligação com o Mapa de Textura

mapper->SetSampleDistance(0.25); // Espaçamento entre os planos de amostragem

mapper->SetInterpolationon(); // Utilização de interpolação na amostragem

// Ajustando a projeção paralela

ren->GetActiveCamera () ->Parallel Projectionon() ;

ren->GetActiveCamera()->SetParallelScale(15); // com 1.0 de escala é possivel

ren->SetBackground $(1.0,1.0,1.0)$;

// Coneção do DVRT com o pipeline de visualização do VTK

volume->SetVolumeMapper (mapper);

ren->AddVolume (volume);

renwin->AddRenderer (ren);

renwin->SetSize $(100,100)$;

iren->SetRenderwindow (renwin);

// Adicionando uma outline

out line->Set Input (reader->Getoutput ()) ;

out lineMap->Set Input (outline->Getoutput ()) ;

outlineAc->SetMapper (outlineMap);

ren->AddActor (outlineAc);

renwin->Render () ;

iren->Start ()

\}

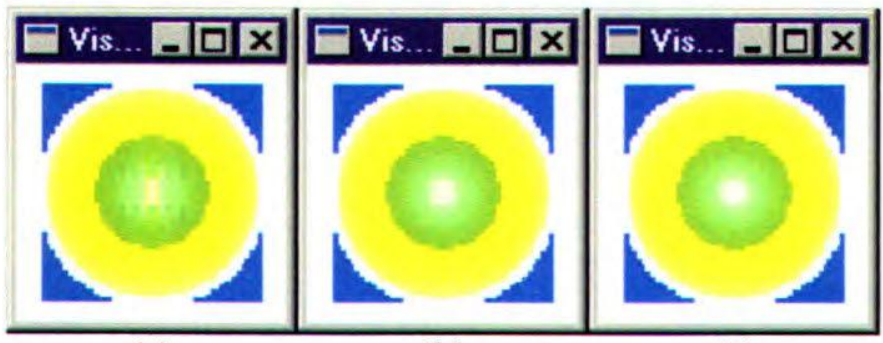

(a)

(b)

(c)

Figura B2 - Imagem obtida pelo programa DVRT_TONALIZADO. O nivel de refinamento foi ajustado para $3 \mathrm{em}$ (a), $4 \mathrm{em}$ (b) $\mathrm{e} 5 \mathrm{em}$ (c). 


\section{Exemplo 2 - Programa DVRT_TONALIZADO}

Este exemplo é uma evolução do exemplo anterior onde são acrescentados os seguintes recursos do DVRT:

- Tonalização com uso da tabela de Reflexão

- Uso de mais de um material com manipulação direta das classes vtkMaterial e vtkMaterialCollection

- Fazer uso de interpolação na amostragem do mapa de textura

A figura B2 apresenta imagens obtidas pelo programa DVRT_TONALIZADO, para uma variação do nível de refinamento de 3 a 5 .

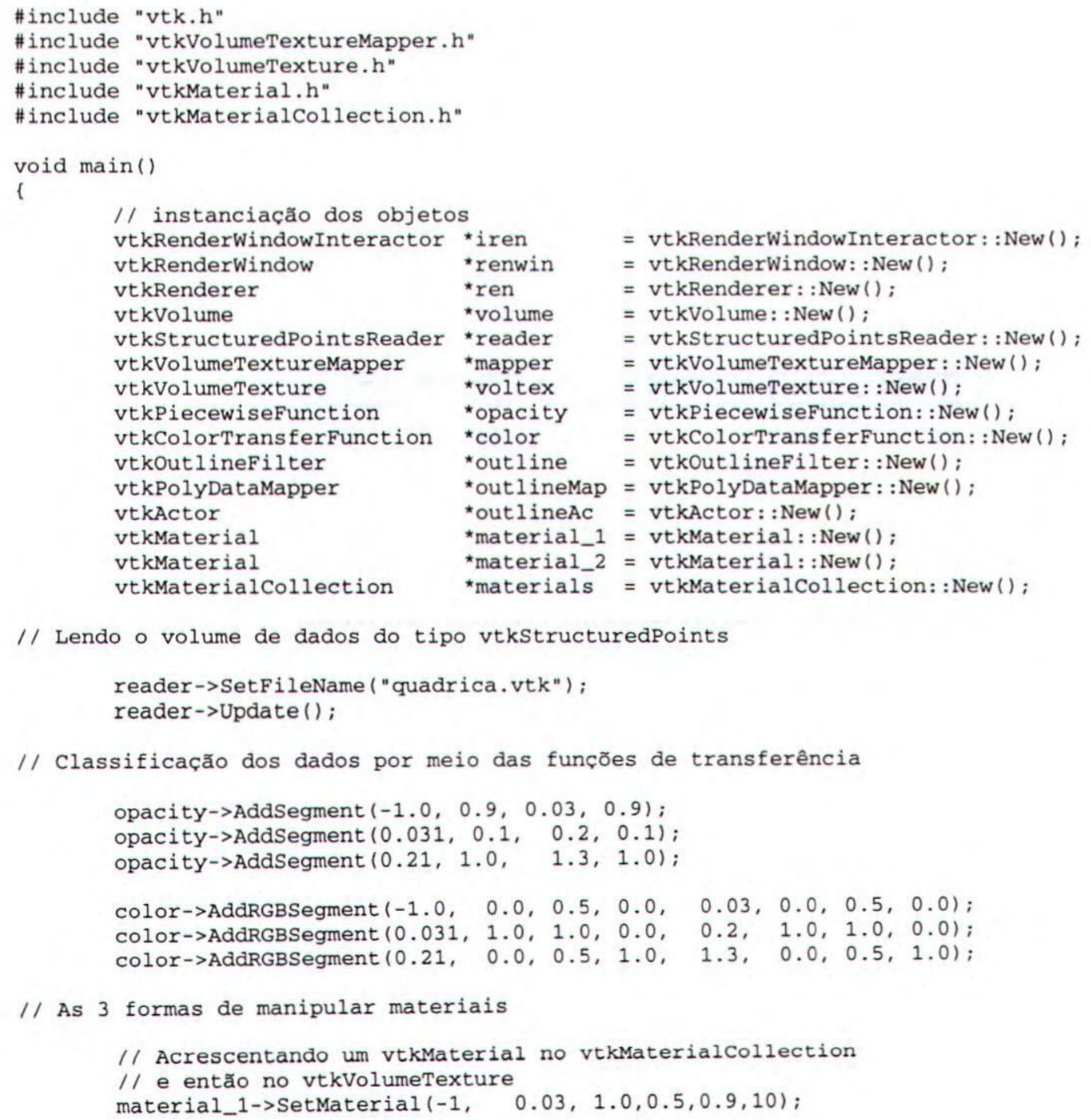


// Coneção do DVRT com o pipeline de visualização do VTK volume->SetVolumeMapper (mapper);

ren->AddVolume (volume);

renwin->AddRenderer(ren)

renwin->SetSize $(100,100)$;

iren->SetRenderWindow (renwin):

// Adicionando uma outline

outline->Set Input (reader->GetOutput ()) ;

outlineMap->SetInput (outline->Getoutput ());

outlineAc->SetMapper (outlineMap);

ren->AddActor (outlineAc);

renwin->Render ();

iren->Start ();

Com o programa acima obtem-se a imagem apresentada na figura B1.

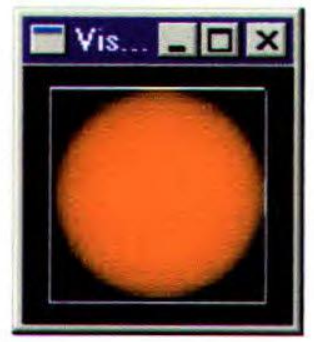

Figura B1 - Imagem obtida pelo programa DVRT_BÁsıCO. 


\section{Apềndice $B$}

\section{Exemplos de Programas com DVRT}

Este apêndice tem por finalidade fornecer alguns exemplos de programas em $\mathrm{C}++$ que fazem uso do DVRT. Nos próprios exemplos são encontrados cornentários explicativos sobre a funcionalidade do programa.

\section{Exemplo 1 - Progama DVRT_BÁsICO}

Este exemplo faz uso da configuração mínima necessária para se realizar o DVRT.

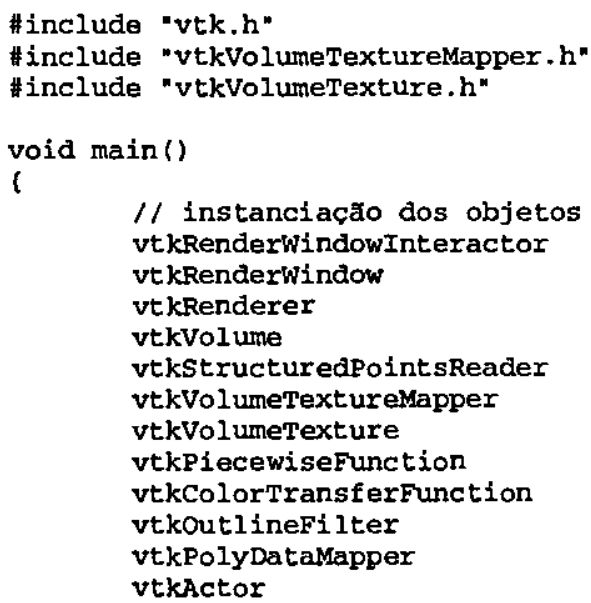

// Lendo o volume de dados do tipo vtkstructuredPoints reader->SetFileName ("quadrica.vtk");

reader-> Update ():

// Classificaçăo dos dados por meio das funçరes de transferência opacity->AddSegment $(-1.0,0.99,1.0,0.99)$; 